\title{
Pressure Fluctuations as a Diagnostic Tool for Fluidized Beds
}

\author{
Final Technical Report \\ DOE Award No.: DE-FG22-94PC94210--15
}

\author{
Principal Investigator: Robert C. Brown \\ Graduate Assistants: Ethan Brue, Joel R. Schroeder, and Ramon De La Cruz \\ Department of Mechanical Engineering \\ Iowa State University \\ Ames, IA 50011
}

May 30, 1998 


\section{Disclaimer}

This report was prepared as an account of work sponsored by an agency of the United States Government. Neither the United States Government nor any agency thereof, nor any of their employees, makes any warranty, express or implied, or assumes any legal liability or responsibility for the accuracy, completeness, or usefulness of any information, apparatus, product, or process disclosed, or represents that its use would not infringe privately owned rights. Reference herein to any specific commercial product, process, or service by trade

name, trademark, manufacturer, or otherwise does not necessarily constitute or imply its endorsement, recommendation, or favoring by the United States Government or any agency thereof. The views and opinions of authors expressed herein do not necessarily state or reflect those of the United States Government or any agency thereof. 


\section{Table of Contents}

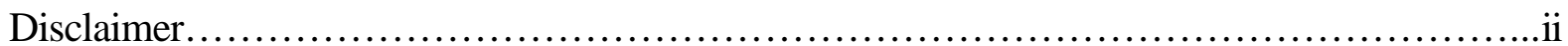

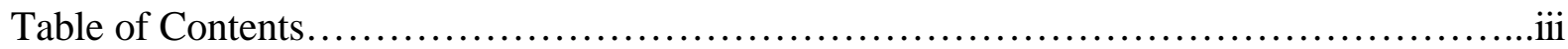

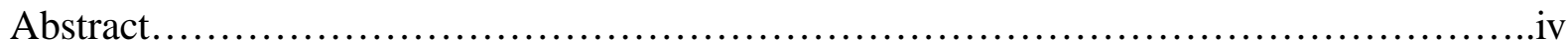

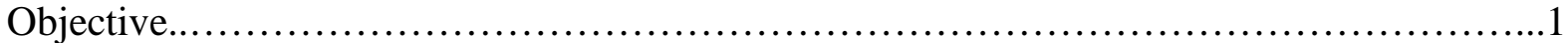

Motivation for Similitude Study................................................. 1

Motivation for Studies in Bubbling Fluidized Beds....................................2

Experimental Apparatus and Procedures: Bubbling Fluidized Beds

Bubbling Bed...................................................................

\section{Results and Discussion: Bubbling Fluidized Beds}

Measurement of Pressure Fluctuations in BFB Systems............................ 7

The Nature of Bubbling Fluidized Bed Pressure Fluctuations.......................15

BFB Pressure Fluctuations as a Global Phenomena............................ 23

Evaluation of the Global Theories of Fluidized Bed Oscillations....................23

Derivation of a Modified-Hiby Model for Bubbling Fluidized Bed Dynamics.......... 38

Surface Waves in Fluidized Bed Systems...................................45

The Use of Pressure Fluctuations to Validate Similitude Parameters..................46

BFB Similitude........................................................... 46

Transition Regime Fluctuations.......................................... 49

Validation of BFB similitude parameters..................................... 51

BFB Combustor Similitude Verification..................................... 54

Bubbling Bed Sensitivity Study......................................... 61

Experimental Apparatus and Procedures: Circulating Fluidized Bed

Circulating Fluidized Bed................................................... 80

Solids Flux Measurement..................................................... 80

Results and Discussion: Circulating Fluidized Bed

Global Theory of Pressure Fluctuations...................................... 83

CFB Similitude Background.............................................. 86

Fast Fluidization Fluctuations - General characteristics......................... 87

Discussion of Voidage Wave Phenomenon in CFBs.............................. 87

Discussion of Surface Wave Frequency Phenomena in CFBs.........................94

Summary of CFB Pressure Fluctuations........................................ 94

Investigation of CFB Similitude Parameters..................................... 95

L-valve Flow Characteristics.................................................... 98

ISU Power Plant CFB Boilers.............................................. 110

Fluctuations in Lower Regions of CFB Boiler................................... 110

Fluctuations in Upper Region of CFB Boiler..................................116

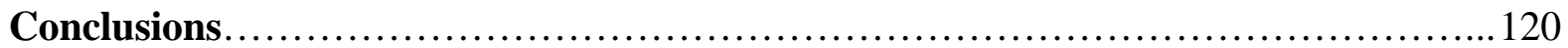


iv

\title{
Pressure Fluctuations as a Diagnostic Tool for Fluidized Beds
}

\author{
Final Technical Report \\ DOE Award No.: DE-FG22-94PC94210 \\ Principal Investigator: Robert C. Brown \\ Research Assistants: Ethan Brue and Joel R. Schroeder \\ Department of Mechanical Engineering \\ Iowa State University \\ Ames, IA 50011
}

\begin{abstract}
The purpose of this project was to investigate the origin of pressure fluctuations in fluidized bed systems. The study assessed the potential for using pressure fluctuations as an indicator of fluidized bed hydrodynamics in both laboratory scale cold-models and industrial scale boilers. Both bubbling fluidized beds and circulating fluidized beds were evaluated. Testing including both cold-flow models and laboratory and industrial-scale combustors operating at elevated temperatures.

The study yielded several conclusions on the relationship of pressure fluctuations and hydrodynamic behavior in fluidized beds. The study revealed the importance of collecting sufficiently long data sets to capture low frequency (on the order of $1 \mathrm{~Hz}$ ) pressure phenomena in fluidized beds. Past research has tended toward truncated data sets collected with high frequency response transducers, which miss much of the spectral structure of fluidized bed hydrodynamics. As a result, many previous studies have drawn conclusions concerning hydrodynamic similitude between model and prototype fluidized beds that is insupportable from the low resolution data presented.

Using appropriate data collection and analysis, this study was able to verify that a set of dimensionless parameters derived by other researchers can be used to achieve hydrodynamic similitude between cold -flow model and prototype bubbling fluidized beds. On the other hand, a related set of dimensionless parameters developed by other researchers for circulating fluidized beds were not able to accurately predict similitude between model and prototype. The present study was successful in slightly modifying this set of dimensionless parameters to correctly predict
\end{abstract}


V

similitude between cold-flow models. Similitude tests between a cold-flow bubbling fluidized bed model and a high temperature bubbling fluidized bed combustor were less successful. Although qualitative agreement in spectral plots of pressure fluctuations was obtained, the data was not sufficiently quantitative to permit its use in predicting the existence of similitude between cold model and hot prototype. Similitude tests between a cold-flow circulating fluidized bed and a hot-flow circulating fluidized bed combustor were also unsuccessful, but for different reasons. The circulating fluidized bed combustor, an industrial-scale boiler, presented unique data filtering problems that were never overcome. Modulated air dampers produced pressure fluctuations that propagated into the fluidized bed where they overwhelmed pressure fluctuations associated with the hydrodynamics of the particulate-gas mixture.

The study developed models of pressure fluctations in the circulating fluidized beds in an attempt to understand the nature of the fluctuations. As dynamical systems, circulating fluidized beds proved to be surprisingly complicated. Linear models were constructed from spectral plots of pressure fluctuations, but they proved of limited use in deriving physical insight into hydrodynamic behavior. A variety of acoustical and wave phenomena were used as the basis for explaining pressure fluctuations in the fluidized bed but with little success. 
Pressure Fluctuations as a Diagnostic Tool for Fluidized Beds

Robert C. Brown, Ethan Brue, and Joel R. Schroeder

\section{Objective}

The purpose of this project is to investigate the origin of pressure fluctuations in fluidized bed systems. The study will asses the potential for using pressure fluctuations as an indicator of fluidized bed hydrodynamics in both laboratory scale cold-models and industrial scale boilers.

\section{Motivation for Similitude Study}

Similitude theory has the potential to become an important tool for fluidized bed design and operation, since the complexity of fluidized bed hydrodynamics makes the development of general theoretical relations difficult. Using dimensional analysis and non-dimensional equations of motion, Glicksman and others derived similitude parameters for bubbling fluidized bed systems [1]. Glicksman extends his analysis to circulating fluidized beds by adding a dimensionless solids flux group to the required similitude parameters [2]. Numerous researchers have matched these parameters in geometrically similar cold-model fluidized beds or have tried to match model conditions in larger scale fluidized bed combustors. Researchers have used a number of techniques to verify that the matching of similitude parameters results in similar hydrodynamics. Typically for CFBs, axial voidage profiles are created from static pressure measurements along the riser. If these axial voidage profiles match, the local solids concentration at any location in the riser should be equal. Other studies have used the probability density function (PDF) of static pressure measurements in fluidized beds to match the distribution of pressure measurements obtained at various locations in the bed [3].

A number of similitude studies have compared the structure of pressure fluctuations in fluidized beds using Bode plots and power spectral density (PSD) functions to verify that hydrodynamic similitude has been achieved [4-6]. However, the validity of pressure fluctuation analysis for verifying similitude in fluidized bed models and industrial scale boilers cannot be assumed until a better understanding of the complex structure of pressure fluctuations is achieved. This study focuses on pressure fluctuation analysis as a method for similitude verification, 
outlining how pressure fluctuations should be analyzed and qualitatively describing the hydrodynamic information contained in these fluctuations.

\section{$\underline{\text { Motivation for Studies in Bubbling Fluidized Beds }}$}

The primary goal of this research is to study the nature of pressure fluctuations in circulating fluidized beds in order to asses how they can be used as a design tool (e.g. model scale-up) or diagnostic tool (e.g. boiler control) in industrial scale CFB combustors. In order to achieve this objective, it is necessary to have an adequate understanding of bubbling fluidized bed pressure fluctuations prior to studying similar fluctuations in CFBs for a number of reasons. First, the majority of previous research on this subject of fluidized bed fluctuations, has been conducted in bubbling fluidized beds. This existing data is useful in validating the experimental methods developed in the present study. Secondly, there are similarities in the structure of pressure fluctuations in bubbling fluidized beds and circulating fluidized beds. The fluctuations in the lower dense region of the CFB exhibit a similar frequency response profile as those observed in bubbling fluidized beds. Also, oscillatory second order system dynamics are observed in the fluctuation structure of all fluidization systems. Finally, fluidized bed similitude relations were first applied to bubbling beds and then extended to CFBs. Before the relations for CFB similitude can be validated using pressure fluctuations, the validity of using bubbling bed fluctuations to verify the achievement of BFB similitude must be addressed.

Despite the wealth of published research dealing with bubbling fluidized bed fluctuations there is still no consensus as to the phenomena that governs pressure fluctuations. This fundamental question is a difficult one for a number of reasons. First of all, experimental data suggests that multiple phenomena acting simultaneously may be responsible for fluctuations in fluidized bed systems. This being the case, the problem is not that previous studies have derived entirely incorrect theories for the appearance of periodic behavior in fluidized bed systems, but rather that they have composed an incomplete picture of a more complex system. Fluidized bed systems cannot always be characterized by a single frequency observed in the frequency spectrum. The characteristic frequency (or frequencies) of pressure fluctuations is not observed as a well defined single peak in the frequency response plots. Spectral analysis of fluidized bed fluctuations typically yields a broad distribution of frequencies centered around a dominant frequency. 
Therefore, any quantitative description of the fluctuation structure inherently contains a great deal of uncertainty. When multiple frequency phenomena are observed, this quantitative assessment becomes even more difficult. In addition to the complexity of the fluctuation signal, the configuration of the pressure measurement system plays a significant part in the information that can be obtained from pressure fluctuation measurements.

\section{Experimental Apparatus and Procedures: Bubbling Fluidized Beds}

\section{Bubbling Bed}

Experiments on bubbling fluidized beds was performed with three fluidized beds with diameters of $5.08 \mathrm{~cm}, 10.2 \mathrm{~cm}$, and $20.32 \mathrm{~cm}$. The column heights of the three beds in order of increasing diameter are $32 \mathrm{~cm}, 64 \mathrm{~cm}$, and $190 \mathrm{~cm}$. The smallest two beds were constructed of Plexiglas.

The largest bed, illustrated in Figure 1, is constructed of mild steel with a ceramic liner that allows high temperature combustion tests to be performed. In addition, a water jacket surrounds the ceramic wall to remove heat generated during combustion. Natural gas or coal can be burned in the combustor. An Accurate ${ }^{\circledR}$ mechanical auger is used to feed coal above the surface of the combustor. Fluidization air is provided from compressed air and controlled with a manually operated ball valve. Air flow rate in the combustor is measured with an orifice plate flow meter, while air flow rates in the cold models is measured with a calibrated rotameter. All BFBs are equipped with pressure taps for spectral analysis.

The $5.08 \mathrm{~cm}$ and $10.16 \mathrm{~cm}$ diameter fluidized beds are illustrated in Figure 2. Table 1 lists the distance above the distributor plate for each pressure tap. The $10.16 \mathrm{~cm}$ bed has pressure taps located on three sides of the bed as illustrated in Figure 2. Distributor plates were constructed to preserve geometric similitude among the various fluidized beds. In addition, several distributor plates were constructed to evaluate the effect of distributor plate design on hydrodynamic behavior of the beds. These designs are described in Table 2. All distributor plate are drilled in a square grid pattern. 


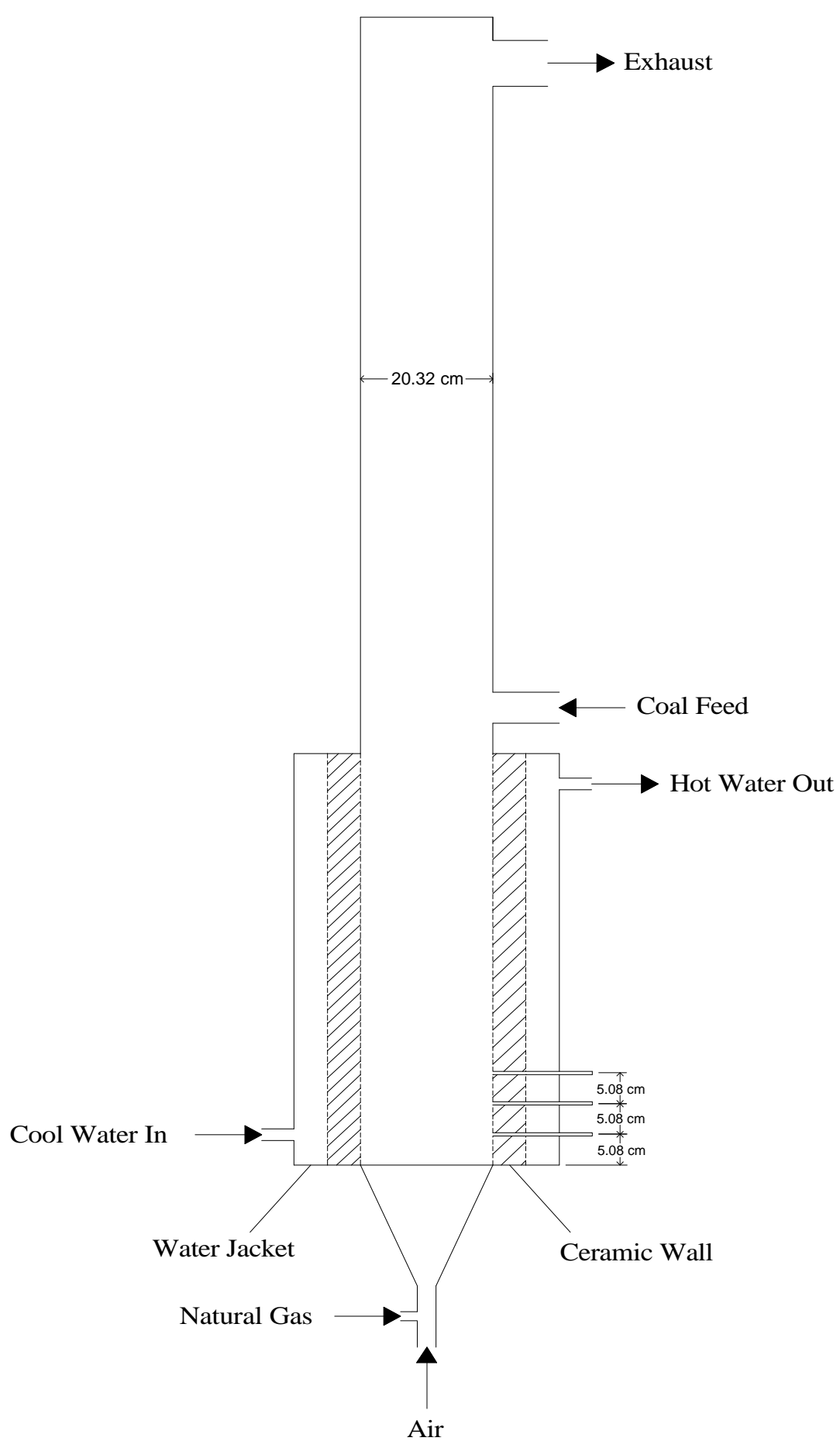

Figure 1: $20.32 \mathrm{~cm} \mathrm{BFB} \mathrm{combustor}$ 


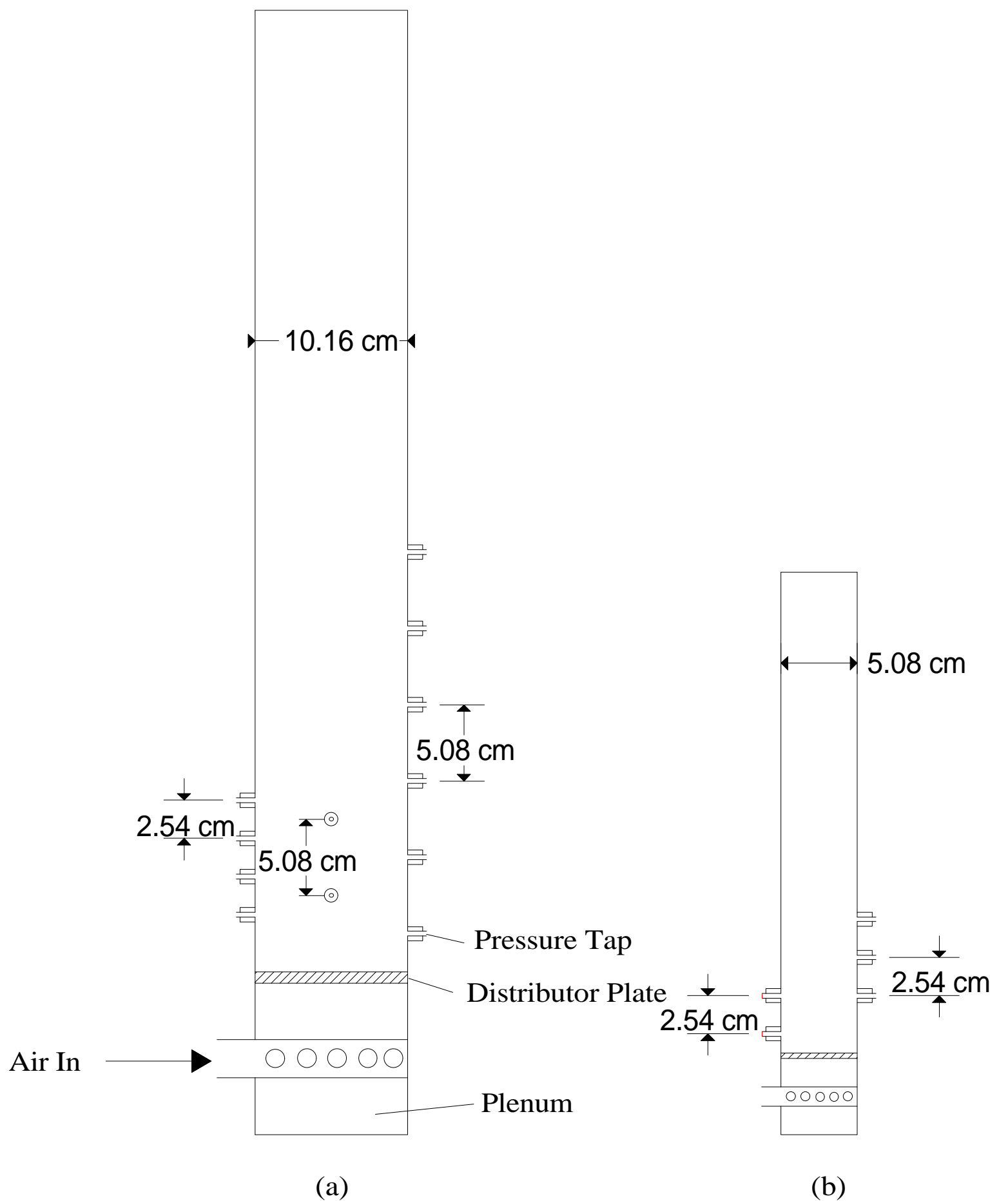

Figure 2: (a) $10.16 \mathrm{~cm} \mathrm{BFB,} \mathrm{(b)} 5.08 \mathrm{~cm} \mathrm{BFB}$ 
Table 1: Bed tap locations

\begin{tabular}{|c|c|c|c|c|}
\hline $20.32 \mathrm{~cm}$ combustor & \multicolumn{3}{|c|}{$10.16 \mathrm{~cm} \mathrm{BFB}$} & \multirow{2}{*}{$\frac{5.08 \mathrm{~cm} \mathrm{BFB}}{1.3}$} \\
\hline $5.1 \mathrm{~cm}$ & $3.8 \mathrm{~cm}$ & $5.08 \mathrm{~cm}$ & $2.5 \mathrm{~cm}$ & \\
\hline $10.2 \mathrm{~cm}$ & $6.4 \mathrm{~cm}$ & $10.16 \mathrm{~cm}$ & $7.6 \mathrm{~cm}$ & 3.8 \\
\hline \multirow[t]{3}{*}{$15.2 \mathrm{~cm}$} & $8.9 \mathrm{~cm}$ & & $12.7 \mathrm{~cm}$ & 6.4 \\
\hline & & & $17.8 \mathrm{~cm}$ & 8.9 \\
\hline & & & $22.9 \mathrm{~cm}$ & \\
\hline
\end{tabular}

Table 2: Distributor plate designs

\begin{tabular}{|c|c|c|c|}
\hline Plate Designation & Bed Size & Hole Diameter & $\underline{\text { Square Grid Size }}$ \\
\hline $\mathrm{A}$ & $5.08 \mathrm{~cm}$ & $0.6 \mathrm{~mm}$ & $3.5 \mathrm{~mm}$ \\
\hline B & $5.08 \mathrm{~cm}$ & $3.2 \mathrm{~mm}$ & $9.0 \mathrm{~mm}$ \\
\hline $\mathrm{C}$ & $10.16 \mathrm{~cm}$ & $1.2 \mathrm{~mm}$ & $7.0 \mathrm{~mm}$ \\
\hline $\mathrm{D}$ & $10.16 \mathrm{~cm}$ & $3.2 \mathrm{~mm}$ & $9.0 \mathrm{~mm}$ \\
\hline $\mathrm{E}$ & $10.16 \mathrm{~cm}$ & $2.4 \mathrm{~mm}$ & $14.0 \mathrm{~mm}$ \\
\hline $\mathrm{F}$ & $20.32 \mathrm{~cm}$ & $2.4 \mathrm{~mm}$ & $14.0 \mathrm{~mm}$ \\
\hline
\end{tabular}




\section{Results and Discussion: Bubbling Fluidized Beds}

\section{Measurement of Pressure Fluctuations in BFB Systems}

As shown by Davidson for bubbling beds [7] and by Brue for circulating beds [2], differential pressure measurements and absolute pressure measurements can yield distinctly different periodic structure. The differential measurement typically reveals a dominant frequency in the spectrum that is at a higher frequency than the dominant frequency measured by absolute pressure measurement. While the differential pressure is a function of the fluctuations in the voidage between two pressure taps, absolute pressure measurements record the pressure drop from the tap position to the upper bed surface. Consequently, absolute pressure measurement represents a change in the amount of material above the point of measurement. The absolute measurement could be considered a differential pressure measurement with the upper tap positioned at the bed surface (assuming a non-pressurized BFB). Consequently, the difference between the resulting absolute and differential signals is essentially a difference arising from an increased tap spacing, which will be discussed in more detail later.

As long as the measurement configuration remains the same (i.e. differential or absolute), the position of the observed frequency will not vary as the elevation of the pressure fluctuation measurement changes within the bed. This does not mean that the relative magnitude of each dominant frequency observed will not change. Figures 3 and 4 compare the frequency spectrum of pressure fluctuations measured simultaneously in a $20 \mathrm{~cm}$ deep bed at a bed elevations of 5.1 $\mathrm{cm}$ and $15.2 \mathrm{~cm}$ respectively. In the $5.1 \mathrm{~cm}$ measurement, both the $3.5 \mathrm{~Hz}$ frequency phenomena and the $2.2 \mathrm{~Hz}$ frequency behavior can be observed. While the $3.5 \mathrm{~Hz}$ frequency spike is not detected in the spectrum of the upper bed, the lower frequency phenomena is evident. This dominant lower frequency that appears at $2.2 \mathrm{~Hz}$ will be observed very near $2.2 \mathrm{~Hz}$ at all elevations. The Bode plots of fluctuations at all elevations are indicative of second order dynamics. Even above the bed a second order phenomena is observed in the gas fluctuations exiting the bed surface, although it is obvious that fluctuations are significantly damped out at this position (see Figure 5). This observation will be discussed further in connection with turbulent and fast fluidization. 
Not only does the elevation at which the pressure fluctuations are measured effect the appearance of the Bode plot profiles, but the spacing of pressure taps can also complicate the observed results. Figures 6 and 7 show the how the tap spacing can distort the observed results. In these figures simultaneous fluctuation measurements were recorded in a BFB at tap spacing of $2.5 \mathrm{~cm}$ and $5.1 \mathrm{~cm}$, respectively. These two Bode plots appear fundamentally different. In the case of the $2.5 \mathrm{~cm}$ spacing, a very dominant high frequency peak appears at around $5.5 \mathrm{~Hz}$ along with a highly damped $3.1 \mathrm{~Hz}$ phenomena that can be observed in the Bode plot. The dominant frequency virtually disappears in fluctuations from the $5.1 \mathrm{~cm}$ differential measurement, and a broad $2.2-3.1 \mathrm{~Hz}$ dominant frequency is observed.

A possible explanation for these apparent inconsistencies in the fluctuation spectrum is that the increased distance between the pressure taps introduces what could be considered spatial aliasing to the observed signal. An example using the simulated signals of Figures 7 and 8 best illustrates this concept. Figure 8 shows a possible distribution of local voidages across the height of a fluidized bed. This voidage distribution can be thought of as a series of bubble layers passing up through the fluidized bed. Differential pressure measurements record the average pressure or voidage between the taps. By averaging the local voidage measurements between the two tap configurations in Figure 8 (taps across $0-5 \%$ and $0-20 \%$ bed height), as the wave propagates upwards through the bed, the resulting voidage signal measured for both cases is shown in Figure 9. It is evident that the dominant frequency of the signal measured by the taps between $0-20 \%$ bed height is half of that observed in the taps that are closer. If such spatial aliasing was occurring in the bubbling bed system shown in Figure 7, the $5.5 \mathrm{~Hz}$ phenomena should be observed as a 2.2 $\mathrm{Hz}$ phenomena. Close inspection of Figure 7 confirms this. Locating the two pressure taps used in the differential measurement close together will decrease the chances of spatial aliasing effects. Although, if the taps are placed too close to one another the magnitude of the fluctuation will not be large enough to be accurately recorded by most transducers and noise may begin to mask the system dynamics. 


\begin{tabular}{|l|l|l|l|}
\hline \multicolumn{4}{|l|}{ Experimental operating conditions } \\
\hline Bed diameter & $10.16 \pm 0.01 \mathrm{~cm}$ & Bed height & $20.0 \pm 0.2 \mathrm{~cm}$ \\
\hline Particle diameter & $0.30 \pm 0.01 \mathrm{~mm}$ & Pressure measurement & differential \\
\hline Particle density & $2600 \pm 100 \mathrm{~kg} / \mathrm{m}^{3}$ & Pressure tap position & Lower $-2.5 \mathrm{~cm} / \mathrm{Upper}-7.6 \mathrm{~cm}$ \\
\hline Gas density (air) & $1.20 \pm 0.04 \mathrm{~kg} / \mathrm{m}^{3}$ & Avg. voidage bwt. taps & $0.48 \pm 0.06$ \\
\hline Superficial velocity & $12.7 \pm 0.6 \mathrm{~cm} / \mathrm{s}\left(\mathrm{U} / \mathrm{U}_{\mathrm{mf}}=1.4\right)$ & Experiment number & $6-21-1995-14.1$ \\
\hline
\end{tabular}
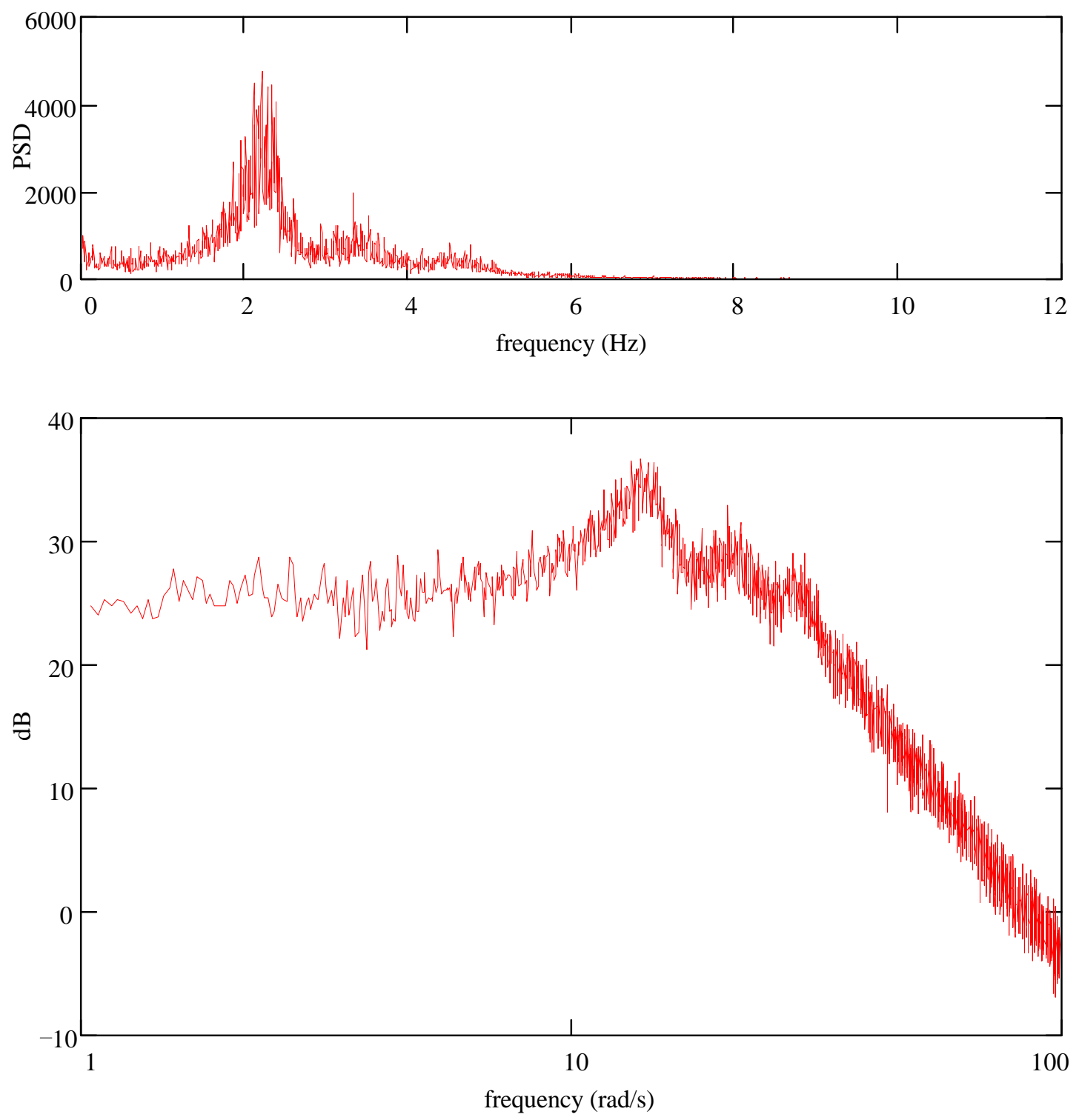

Figure 3: PSD and Bode plot of BFB fluctuations in the lower bed region 


\begin{tabular}{|l|l|l|l|}
\hline \multicolumn{4}{|l|}{ Experimental operating conditions } \\
\hline Bed diameter & $10.16 \pm 0.01 \mathrm{~cm}$ & Bed height & $20.0 \pm 0.2 \mathrm{~cm}$ \\
\hline Particle diameter & $0.30 \pm 0.01 \mathrm{~mm}$ & Pressure measurement & differential \\
\hline Particle density & $2600 \pm 100 \mathrm{~kg} / \mathrm{m}^{3}$ & Pressure tap position & Lower-12.7 cm/Upper- $17.8 \mathrm{~cm}$ \\
\hline Gas density (air) & $1.20 \pm 0.04 \mathrm{~kg} / \mathrm{m}^{3}$ & Avg. voidage bwt. taps & $0.47 \pm 0.06$ \\
\hline Superficial velocity & $12.7 \pm 0.6 \mathrm{~cm} / \mathrm{s}\left(\mathrm{U} / \mathrm{U}_{\mathrm{mf}}=1.4\right)$ & Experiment number & $6-21-1995-14.1$ \\
\hline
\end{tabular}
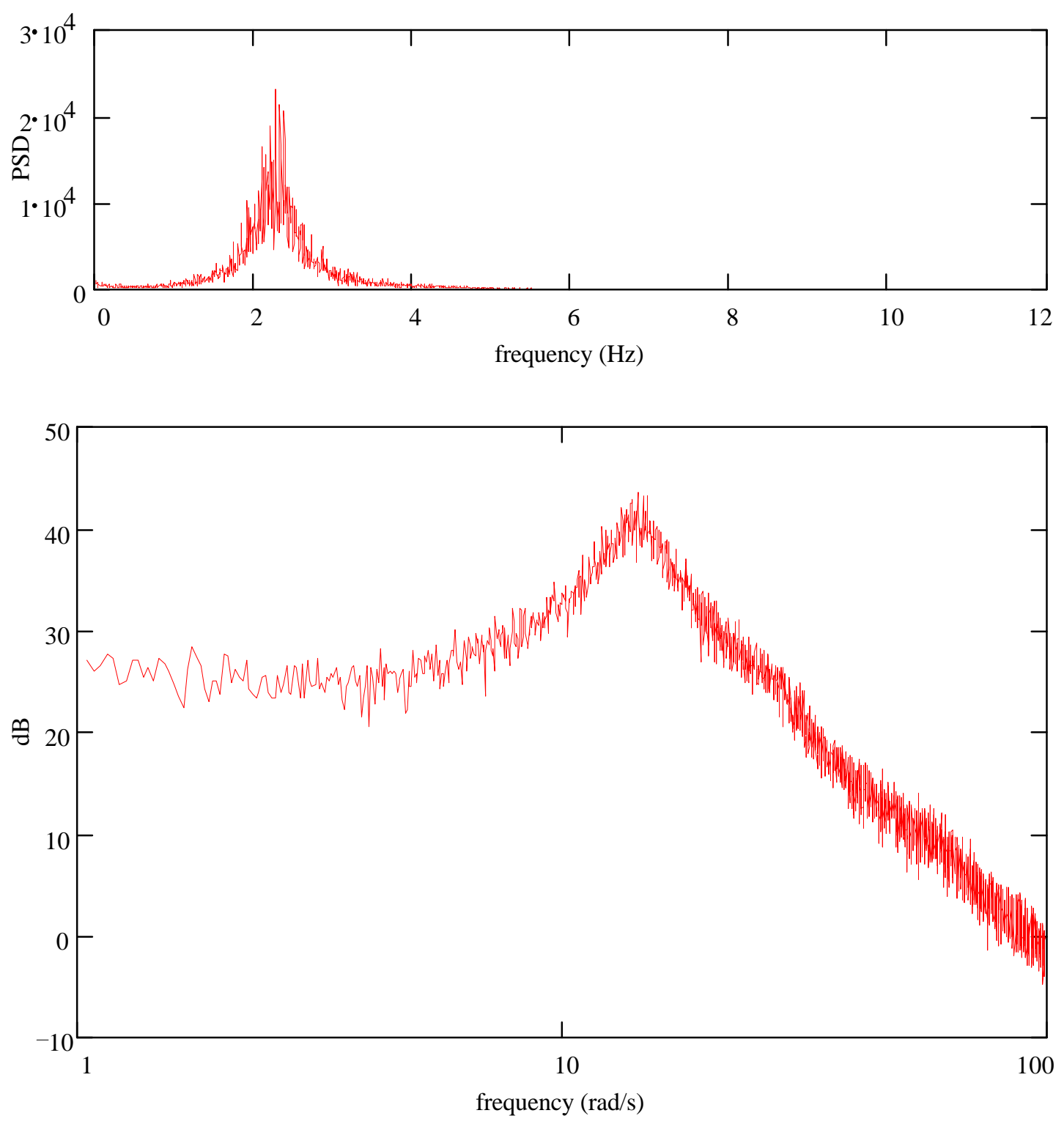

Figure 4: PSD and Bode plot of BFB fluctuations in the upper bed region 


\begin{tabular}{|l|l|l|l|}
\hline \multicolumn{5}{|l|}{ Experimental operating conditions } \\
\hline Bed diameter & $10.16 \pm 0.01 \mathrm{~cm}$ & Bed height & $20.0 \pm 0.2 \mathrm{~cm}$ \\
\hline Particle diameter & $0.30 \pm 0.01 \mathrm{~mm}$ & Pressure measurement & differential \\
\hline Particle density & $2600 \pm 100 \mathrm{~kg} / \mathrm{m}^{3}$ & Pressure tap position & Lower-22.9 cm/Upper-27.9 cm \\
\hline Gas density (air) & $1.20 \pm 0.04 \mathrm{~kg} / \mathrm{m}^{3}$ & Avg. voidage bwt. taps & No particles bwt. taps \\
\hline Superficial velocity & $12.7 \pm 0.6 \mathrm{~cm} / \mathrm{s}\left(\mathrm{U} / \mathrm{U}_{\mathrm{mf}}=1.4\right)$ & Experiment number & $6-21-1995-14.1$ \\
\hline
\end{tabular}
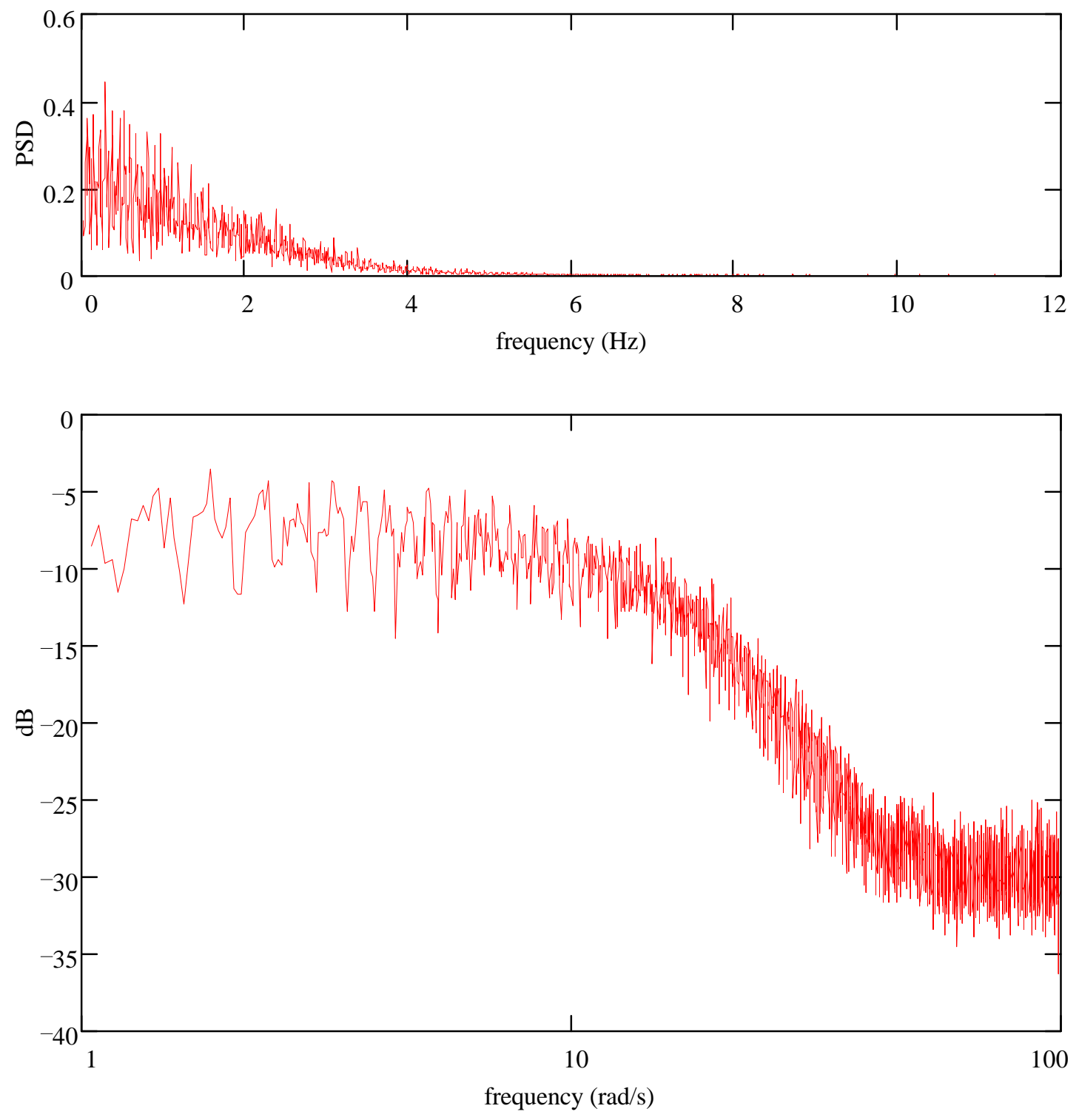

Figure 5: PSD and Bode plot of BFB fluctuations above the bed 


\begin{tabular}{|l|l|l|l|}
\hline \multicolumn{5}{|l|}{ Experimental operating conditions } \\
\hline Bed diameter & $5.08 \pm 0.01 \mathrm{~cm}$ & Bed height & $12.0 \pm 0.2 \mathrm{~cm}$ \\
\hline Particle diameter & $0.20 \pm 0.01 \mathrm{~mm}$ & Pressure measurement & differential \\
\hline Particle density & $2600 \pm 100 \mathrm{~kg} / \mathrm{m}^{3}$ & Pressure tap position & Lower $-3.8 \mathrm{~cm} / \mathrm{Upper}-6.4 \mathrm{~cm}$ \\
\hline Gas density (air) & $1.20 \pm 0.04 \mathrm{~kg} / \mathrm{m}^{3}$ & Avg. voidage bwt. taps & $0.48 \pm 0.06$ \\
\hline Superficial velocity & $5.6 \pm 0.6 \mathrm{~cm} / \mathrm{s}\left(\mathrm{U} / \mathrm{U}_{\mathrm{mf}}=1.4\right)$ & Experiment number & $11-21-1995-11.8$ \\
\hline
\end{tabular}
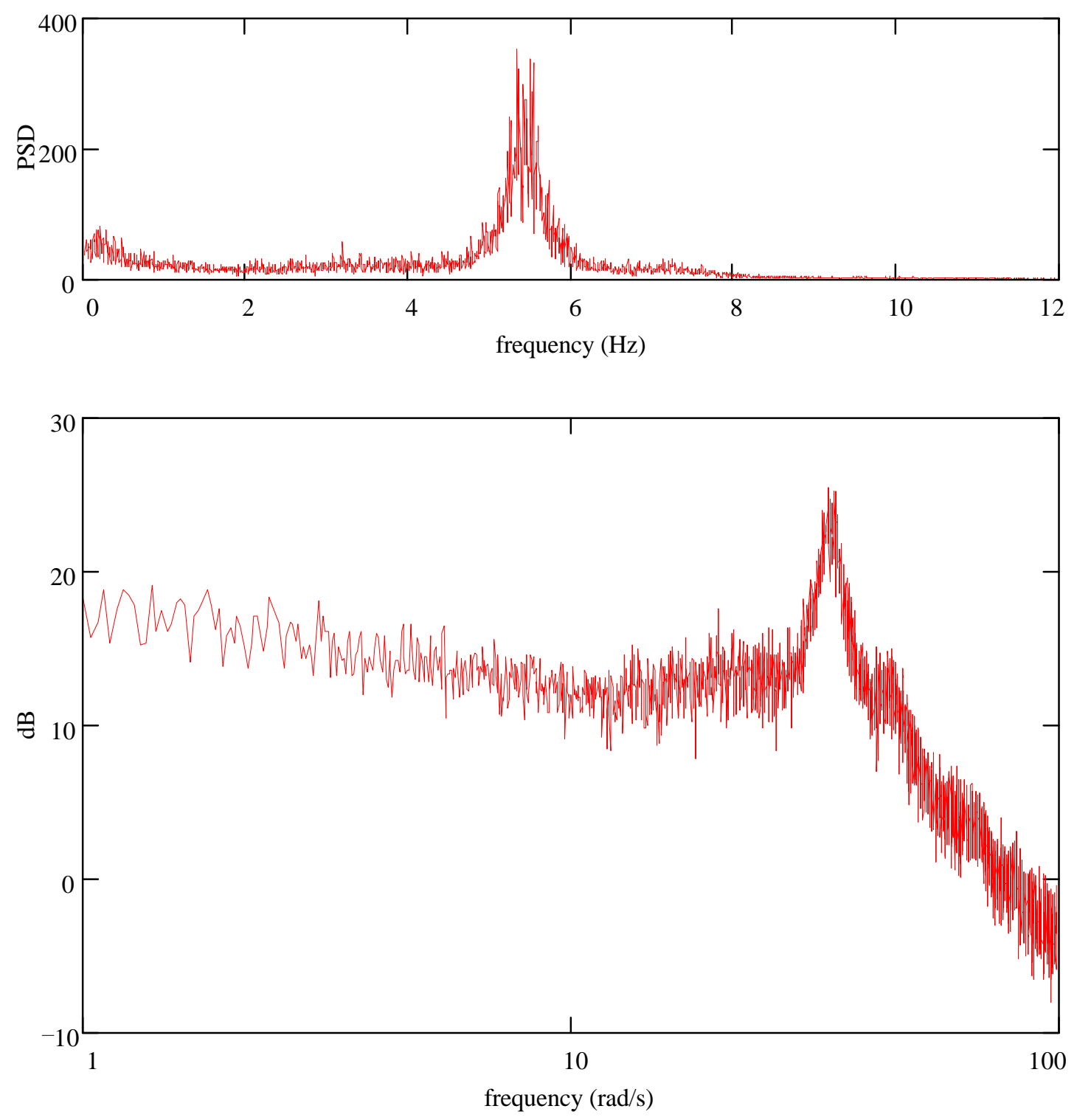

Figure 6: PSD and Bode plot BFB fluctuations with 1.0" $(2.5 \mathrm{~cm})$ tap spacing 


\begin{tabular}{|l|l|l|l|}
\hline \multicolumn{5}{|l|}{ Experimental operating conditions } \\
\hline Bed diameter & $5.08 \pm 0.01 \mathrm{~cm}$ & Bed height & $12.0 \pm 0.2 \mathrm{~cm}$ \\
\hline Particle diameter & $0.20 \pm 0.01 \mathrm{~mm}$ & Pressure measurement & differential \\
\hline Particle density & $2600 \pm 100 \mathrm{~kg} / \mathrm{m}^{3}$ & Pressure tap position & Lower $-3.8 \mathrm{~cm} / \mathrm{Upper}-8.9 \mathrm{~cm}$ \\
\hline Gas density (air) & $1.20 \pm 0.04 \mathrm{~kg} / \mathrm{m}^{3}$ & Avg. voidage bwt. taps & $0.46 \pm 0.09$ \\
\hline Superficial velocity & $5.6 \pm 0.6 \mathrm{~cm} / \mathrm{s}\left(\mathrm{U} / \mathrm{U}_{\mathrm{mf}}=1.4\right)$ & Experiment number & $11-21-1995-11.8$ \\
\hline
\end{tabular}
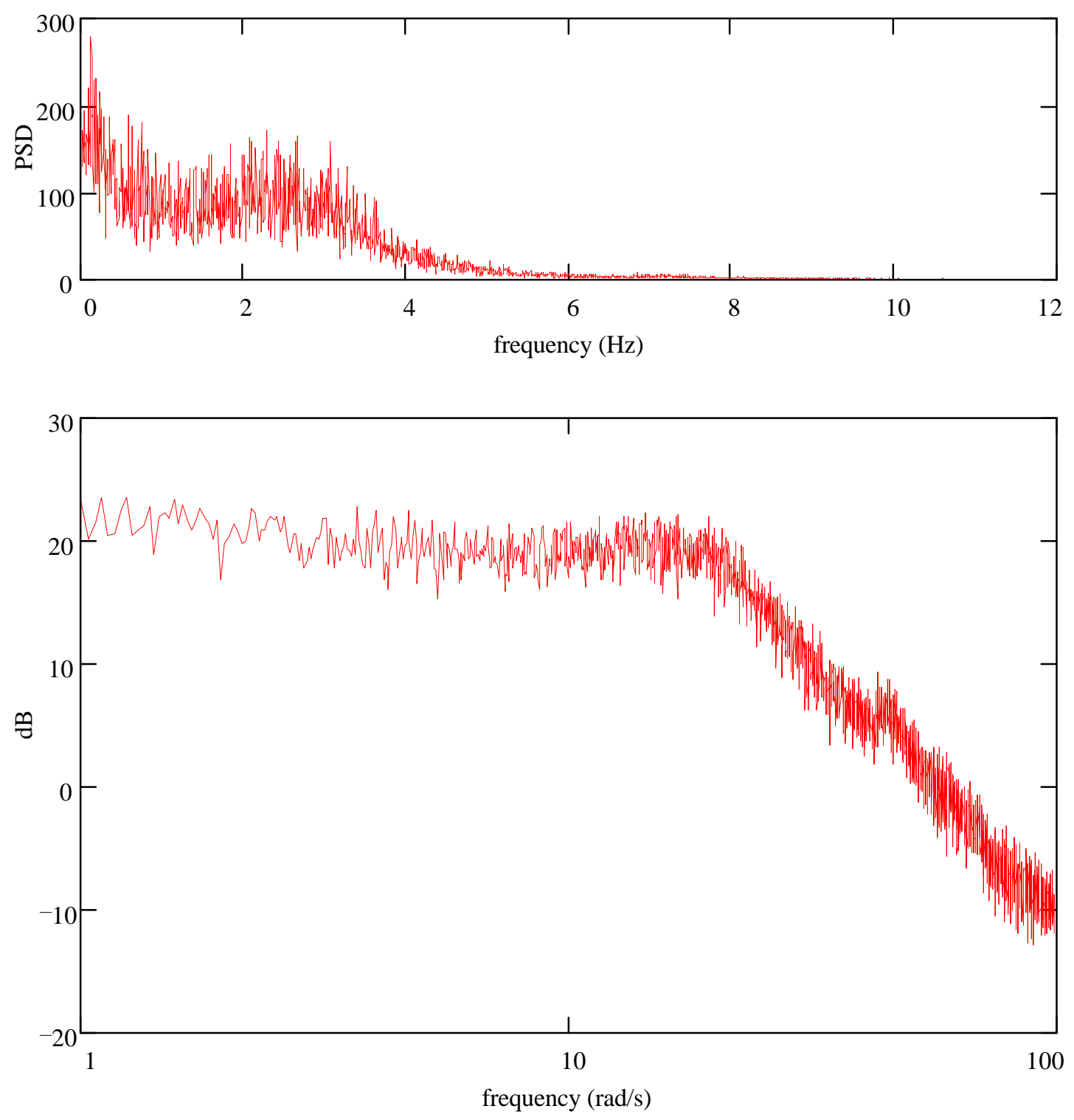

Figure 7: PSD and Bode plot BFB fluctuations with 2.0”(5.1 cm) tap spacing 


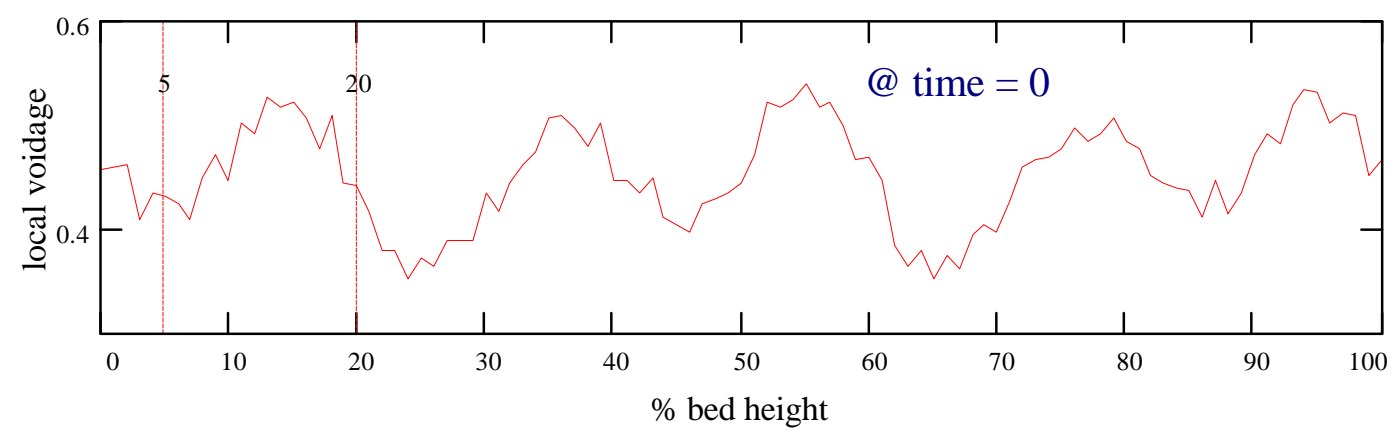

Figure 8: Example of voidage variations across fluidized bed at given time

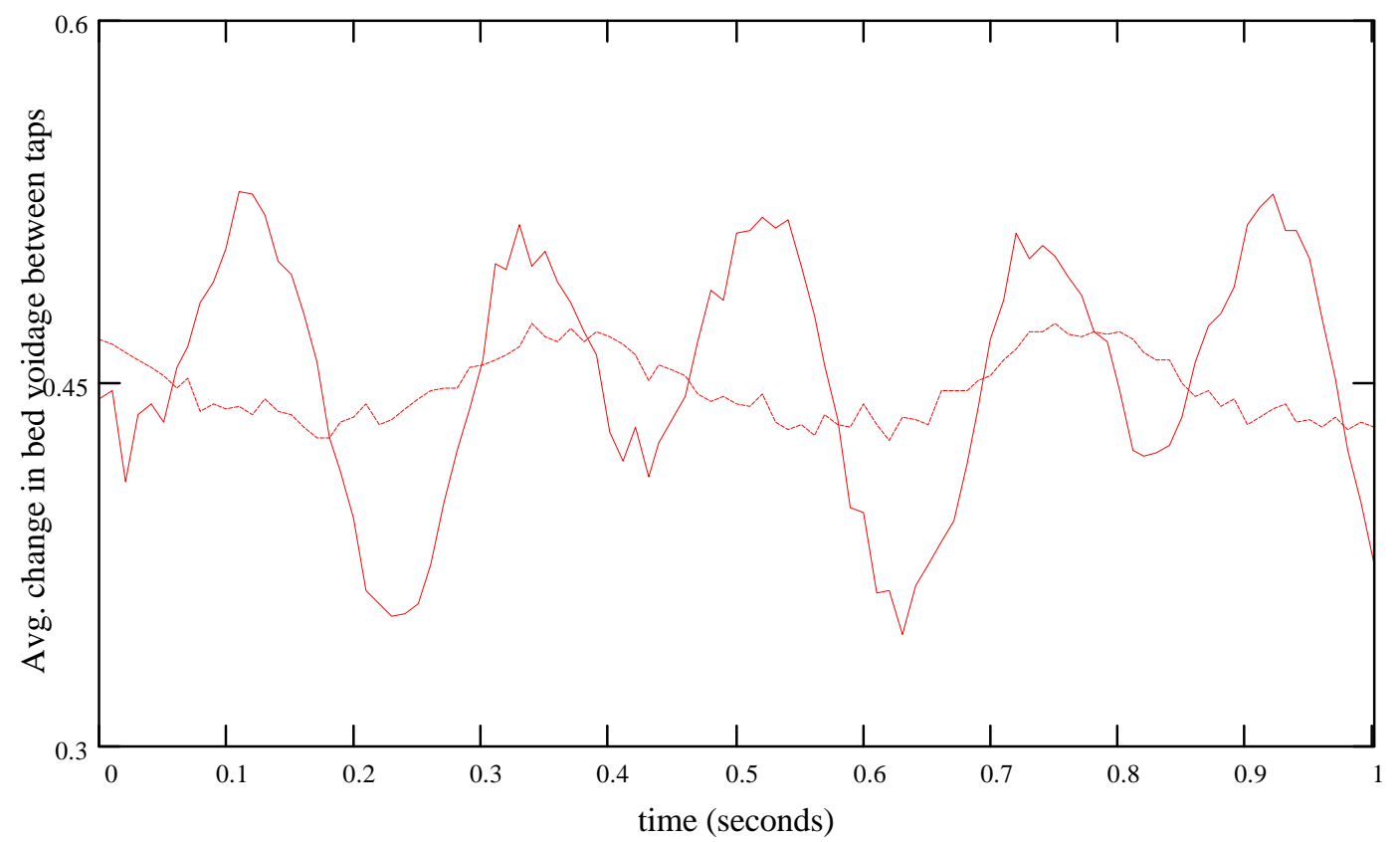

- Voidage measured between $0 \%$ and $5 \%$ bed height

- Voidage measured between $0 \%$ and $20 \%$ bed height

Figure 9: Example - measured average voidage at two different tap spacings 
Considering that both the method of pressure fluctuation measurement and the method of pressure fluctuation analysis make a significant difference in the observed results, it is not surprising that there is still no consensus as to the phenomena governing pressure fluctuations.

The Nature of Bubbling Fluidized Bed Pressure Fluctuations

A number of general characteristics of bubbling fluidized bed pressure fluctuations have been observed by previous researchers and in the present study as well. Under conditions of low to moderate velocity bubbling fluidization, the particle size does not have a significant effect on the overall dynamic character of the fluctuations. Figures 10 - 12 show three Bode plots of fluctuations taken from similar beds of $0.2 \mathrm{~mm}, 0.3 \mathrm{~mm}$, and $0.4 \mathrm{~mm}$ glass beads fluidized at $\mathrm{U} / \mathrm{U}_{\mathrm{mf}}=1.4$. The profiles for each particle size are identical. Any slight variations in the dominant frequency as the particle diameter is changed, are likely due to variations in bubble properties or bed voidage. For further verification that particle diameter does not strongly influence the frequency of the system see Figures 12-15 and Figure 18.

Bed diameter has a significant effect on the Bode plot profiles, although it is important to emphasize that bed diameter does not effect the position at which dominant system frequencies observed until the bubbling regime approaches slugging or turbulent conditions. Figures 16 and 17 show the Bode plots of the 10.2 and $5.1 \mathrm{~cm}$ diameter beds respectively. In both beds the particle size, bed height, tap height \& spacing, and superficial velocity are identical. It is evident that changes is the diameter can significantly effect the frequency response, changing the degree of damping of the observed frequency. Despite the increased damping, the natural frequencies at which the bed operates under do not change. In both figures, dominant frequencies appear at 3.1 and $5.5 \mathrm{~Hz}$, although the higher $(5.5 \mathrm{~Hz})$ frequency dominates as the bed diameter decreases.

As shown in Figures $12-15$, for $\mathrm{U} / \mathrm{U}_{\mathrm{mf}}>1.2$, changes in the superficial velocity does not effect the dominant frequency in the bubbling fluidization regime. At the onset of fluidization, the dominant frequency increases only slightly and then levels off as the superficial velocity is increased above $\mathrm{U} / \mathrm{U}_{\mathrm{mf}}>1.2$. It should again be emphasized that the superficial velocity will not change the characteristic period of oscillation of the system, but it may dictate the damping of the observed frequencies in the spectrum. 


\begin{tabular}{|l|l|l|l|}
\hline \multicolumn{4}{|l|}{ Experimental operating conditions } \\
\hline Bed diameter & $10.16 \pm 0.01 \mathrm{~cm}$ & Bed height & $10.0 \pm 0.2 \mathrm{~cm}$ \\
\hline Particle diameter & $0.20 \pm 0.01 \mathrm{~mm}$ & Pressure measurement & differential \\
\hline Particle density & $2600 \pm 100 \mathrm{~kg} / \mathrm{m}^{3}$ & Pressure tap position & Lower $-2.5 \mathrm{~cm} / \mathrm{Upper}-7.6 \mathrm{~cm}$ \\
\hline Gas density (air) & $1.20 \pm 0.04 \mathrm{~kg} / \mathrm{m}^{3}$ & Avg. voidage bwt. taps & $0.49 \pm 0.06$ \\
\hline Superficial velocity & $5.7 \pm 0.6 \mathrm{~cm} / \mathrm{s}\left(\mathrm{U} / \mathrm{U}_{\mathrm{mf}}=1.4\right)$ & Experiment number & $6-30-1995-11.1$ \\
\hline
\end{tabular}
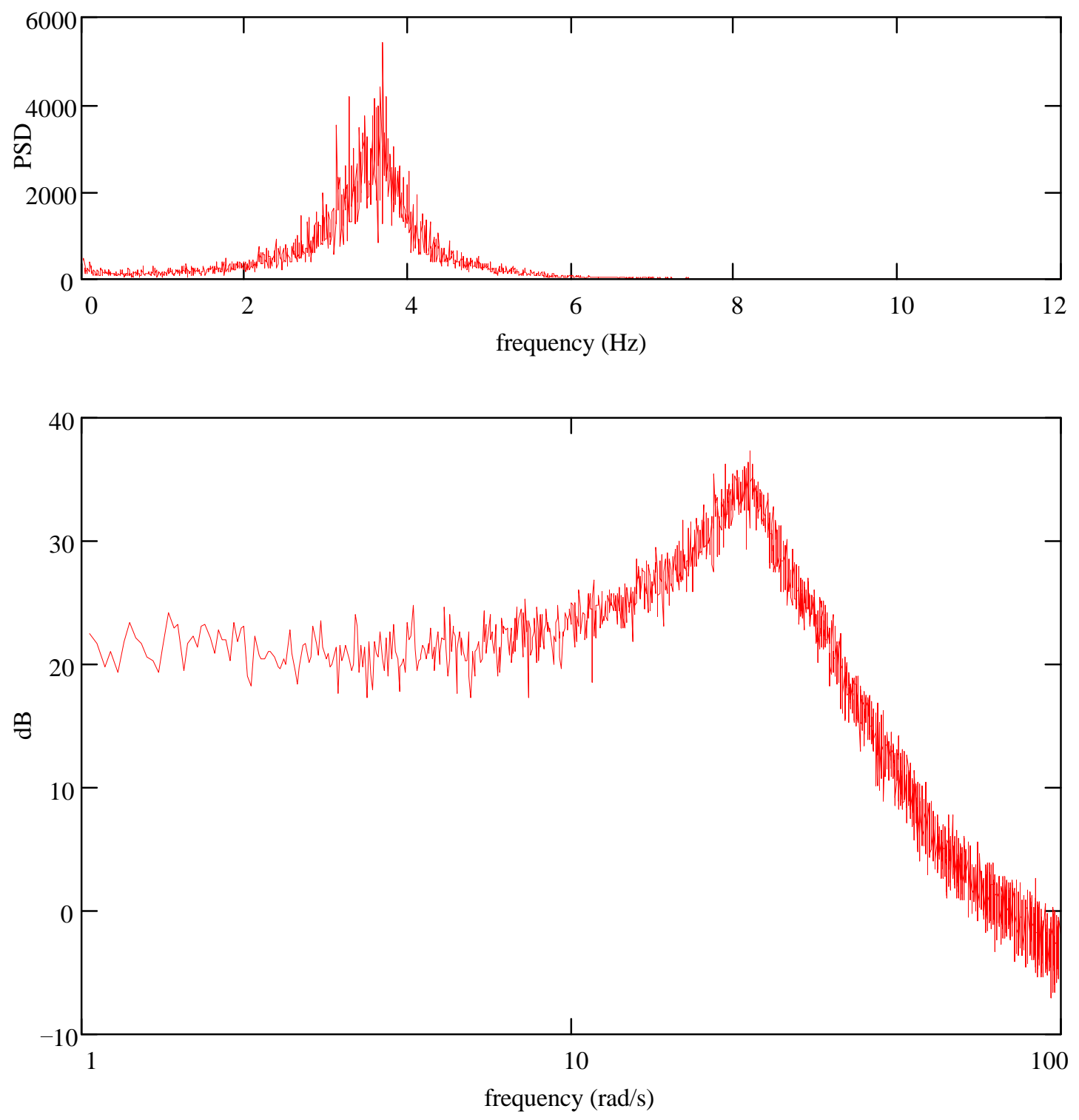

Figure 10: PSD and Bode plot of $0.2 \mathrm{~mm}$ glass bead BFB fluctuations 


\begin{tabular}{|l|l|l|l|}
\hline \multicolumn{5}{|l|}{ Experimental operating conditions } \\
\hline Bed diameter & $10.16 \pm 0.01 \mathrm{~cm}$ & Bed height & $10.0 \pm 0.2 \mathrm{~cm}$ \\
\hline Particle diameter & $0.30 \pm 0.01 \mathrm{~mm}$ & Pressure measurement & differential \\
\hline Particle density & $2600 \pm 100 \mathrm{~kg} / \mathrm{m}^{3}$ & Pressure tap position & Lower $-2.5 \mathrm{~cm} / \mathrm{Upper}-7.6 \mathrm{~cm}$ \\
\hline Gas density (air) & $1.20 \pm 0.04 \mathrm{~kg} / \mathrm{m}^{3}$ & Avg. voidage bwt. taps & $0.49 \pm 0.06$ \\
\hline Superficial velocity & $12.7 \pm 0.6 \mathrm{~cm} / \mathrm{s}\left(\mathrm{U} / \mathrm{U}_{\mathrm{mf}}=1.4\right)$ & Experiment number & $6-22-1995-16.4$ \\
\hline
\end{tabular}
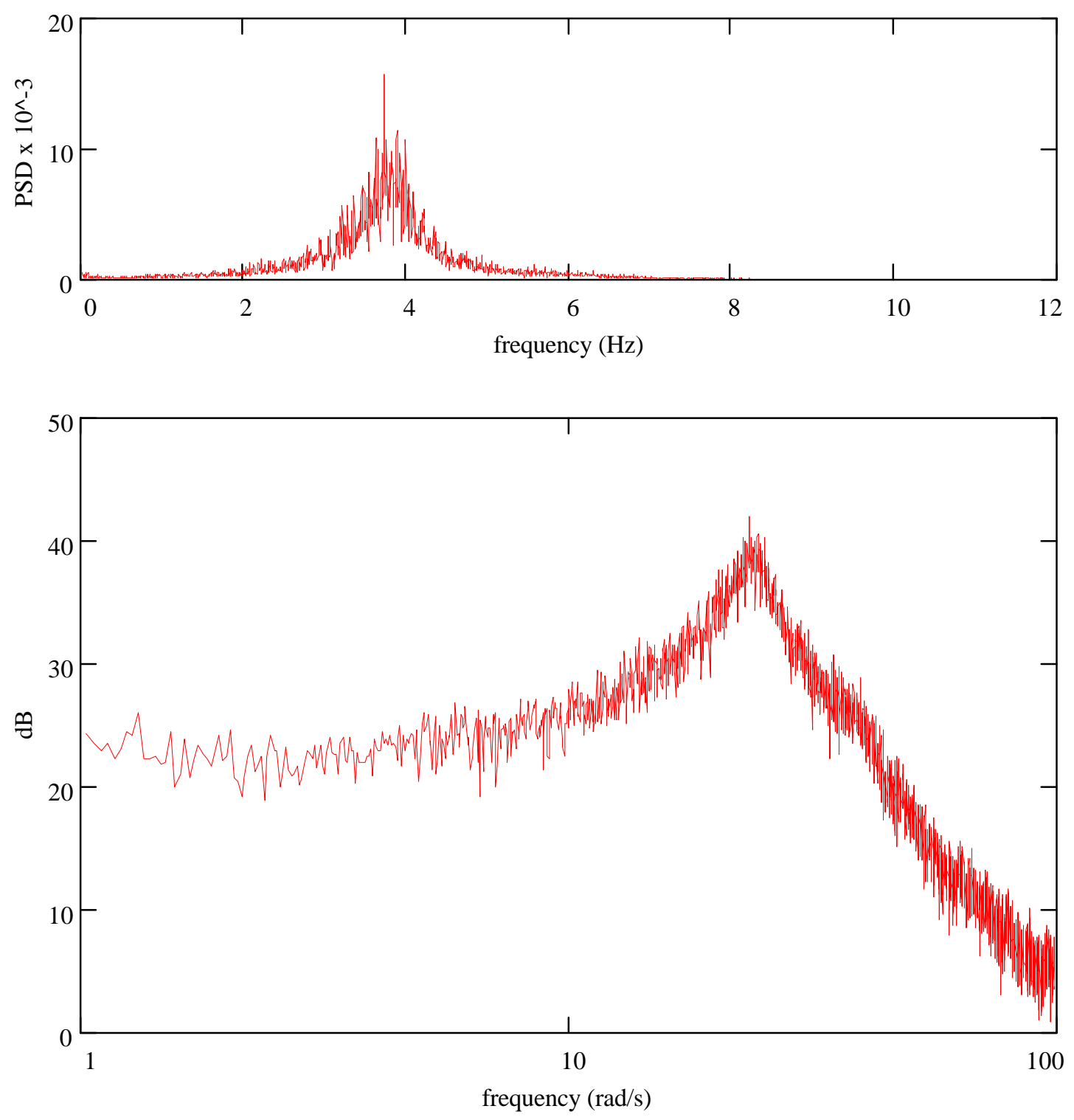

Figure 11: PSD and Bode plot of $0.3 \mathrm{~mm}$ glass bead BFB fluctuations 


\begin{tabular}{|l|l|l|l|}
\hline \multicolumn{5}{|l|}{ Experimental operating conditions } \\
\hline Bed diameter & $10.16 \pm 0.01 \mathrm{~cm}$ & Bed height & $10.0 \pm 0.2 \mathrm{~cm}$ \\
\hline Particle diameter & $0.40 \pm 0.01 \mathrm{~mm}$ & Pressure measurement & differential \\
\hline Particle density & $2600 \pm 100 \mathrm{~kg} / \mathrm{m}^{3}$ & Pressure tap position & Lower $-2.5 \mathrm{~cm} / \mathrm{Upper}-7.6 \mathrm{~cm}$ \\
\hline Gas density (air) & $1.20 \pm 0.04 \mathrm{~kg} / \mathrm{m}^{3}$ & Avg. voidage bwt. taps & $0.50 \pm 0.06$ \\
\hline Superficial velocity & $19.6 \pm 0.6 \mathrm{~cm} / \mathrm{s}\left(\mathrm{U} / \mathrm{U}_{\mathrm{mf}}=1.4\right)$ & Experiment number & $7-3-1995-8.4$ \\
\hline
\end{tabular}
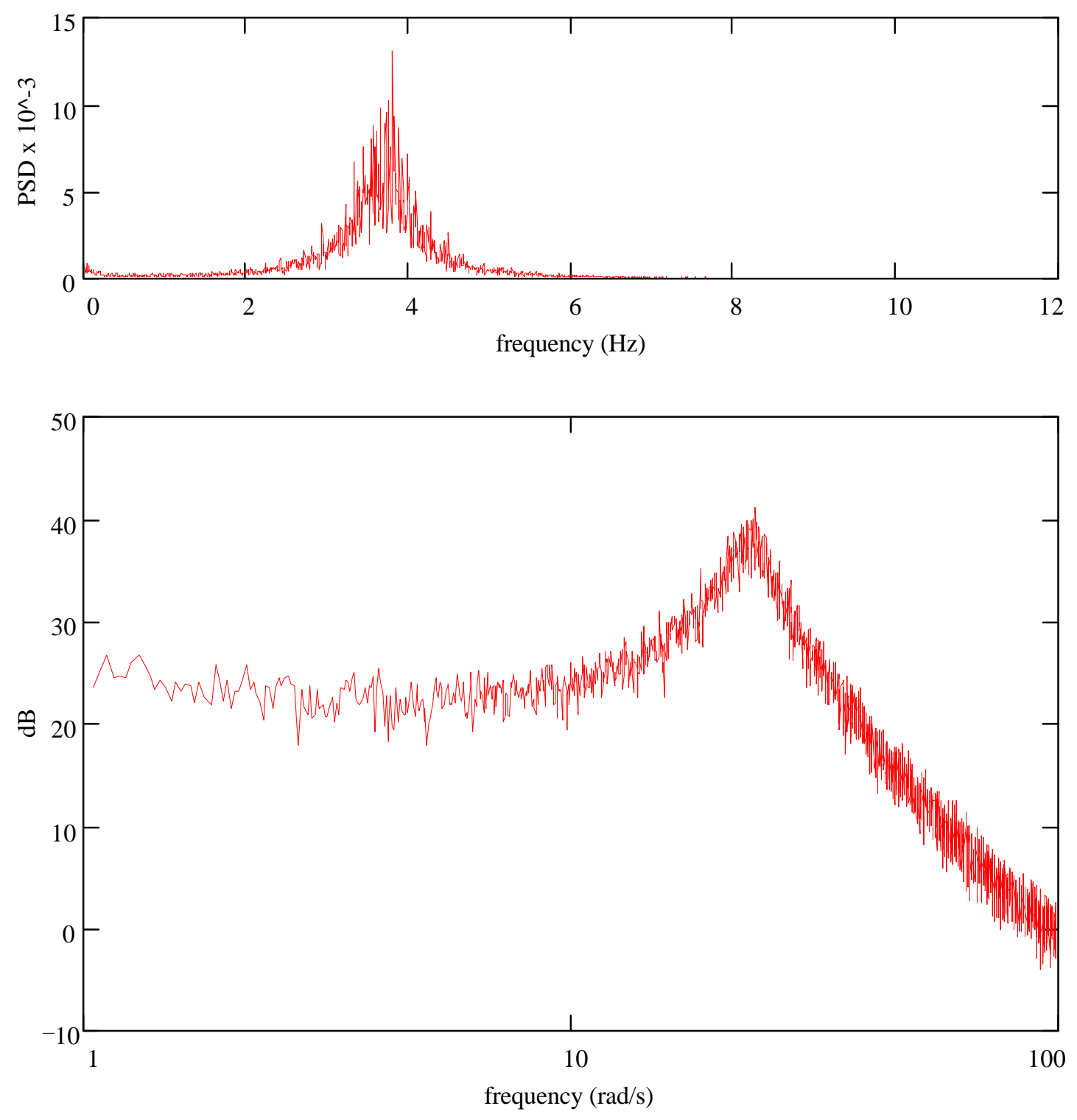

Figure 12: PSD and Bode plot of $0.4 \mathrm{~mm}$ glass bead BFB fluctuation 


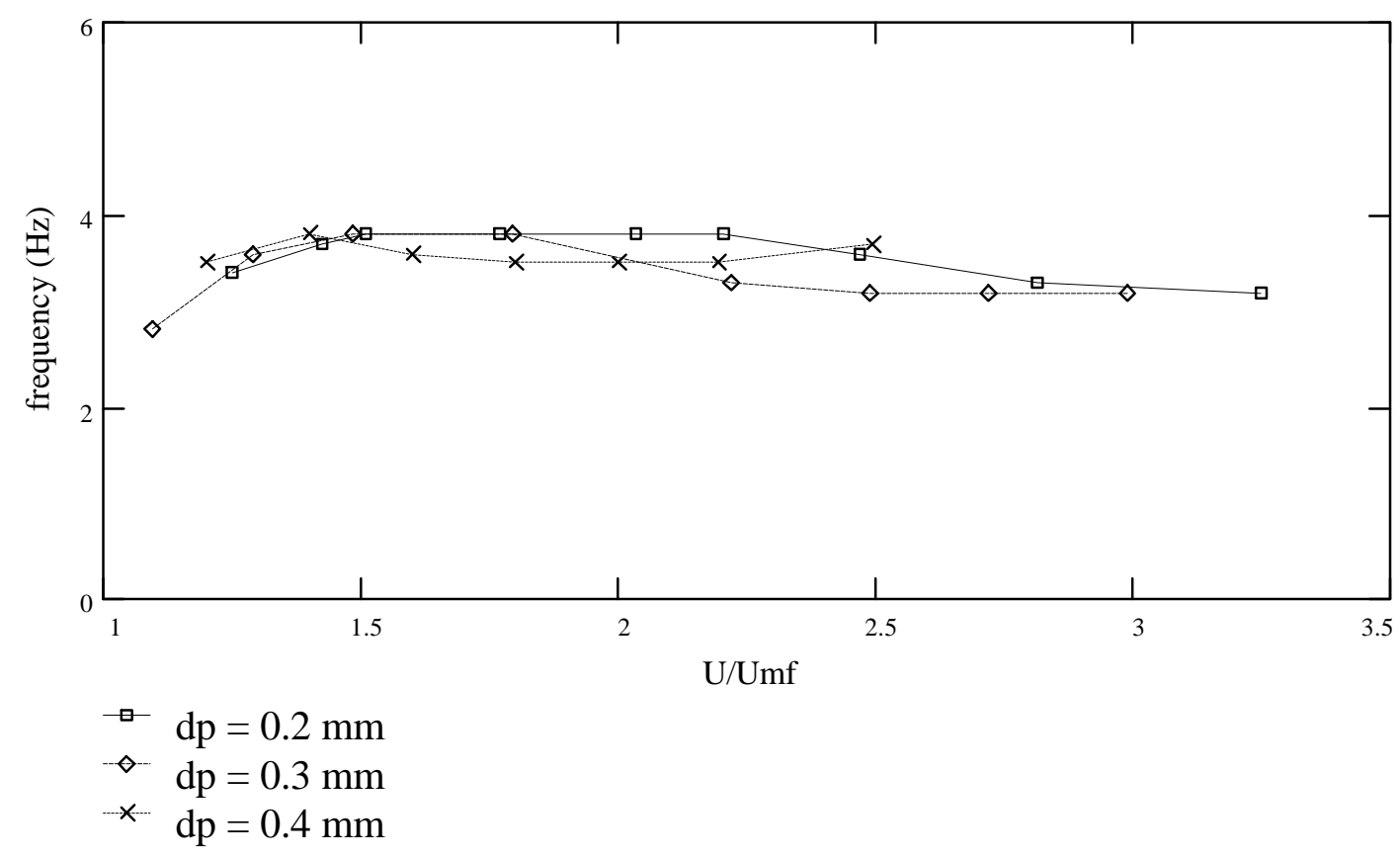

Figure 13: Fluctuation frequency versus U/Umf for $10.0 \mathrm{~cm}$ bed height

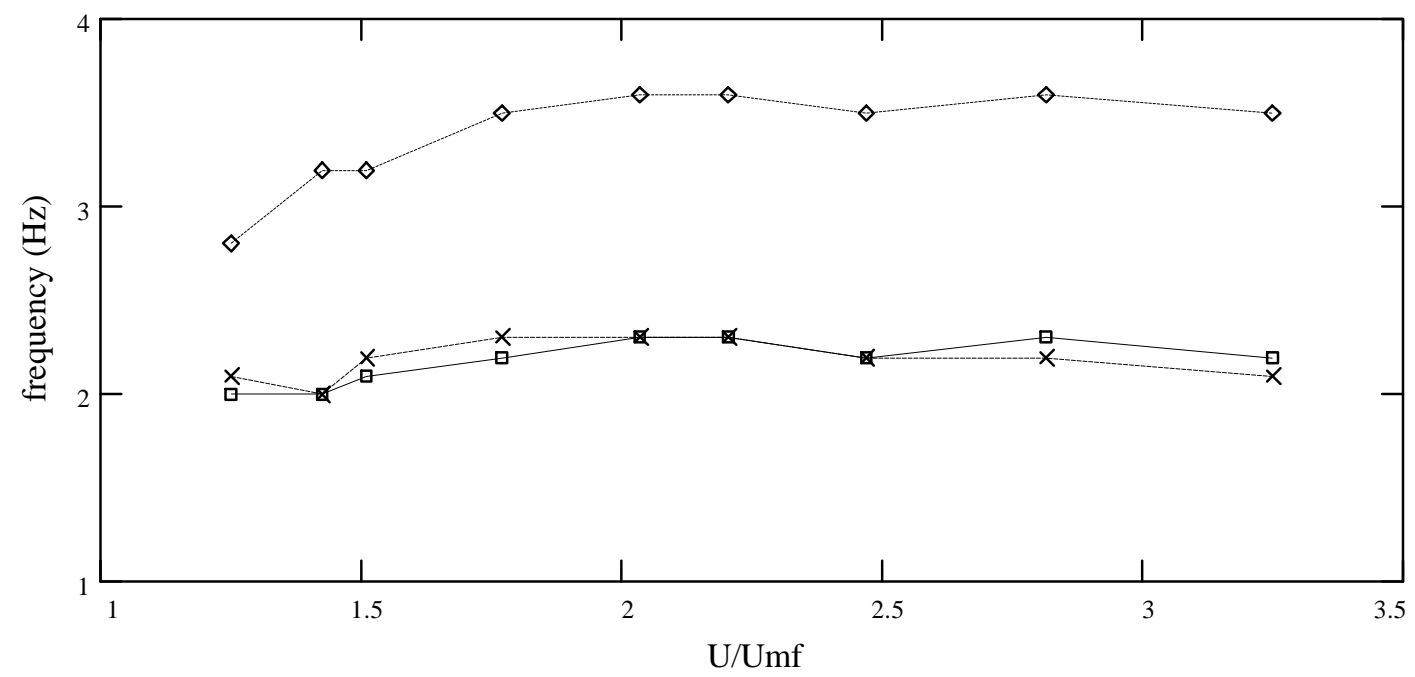

- Taps@1" \& 3 " - first peak

$\diamond$ Taps@1" \& 3" - second peak

* Taps@ 5" \& 7"

Figure 14: Fluctuation frequency versus $\mathrm{U} / \mathrm{Umf}$ for $20 \mathrm{~cm}$ bed height and $\mathrm{dp}=0.2 \mathrm{~mm}$ 


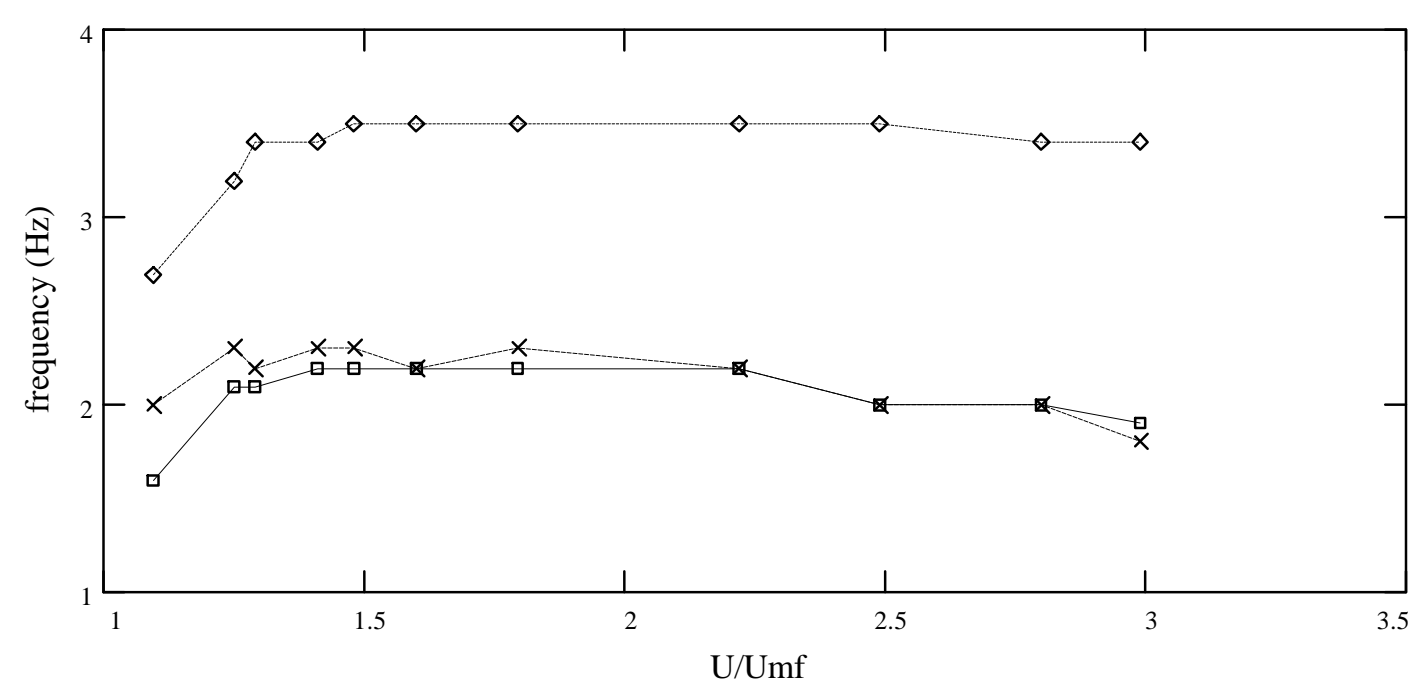

- Taps @ 1" \& 3 " - first peak

$\diamond$ Taps@1" \& 3" - second peak

* Taps@ $5^{\prime} \& 7 "$

Figure 15: Fluctuation frequency versus $\mathrm{U} / \mathrm{Umf}$ for $20 \mathrm{~cm}$ bed height and $\mathrm{dp}=0.3 \mathrm{~mm}$

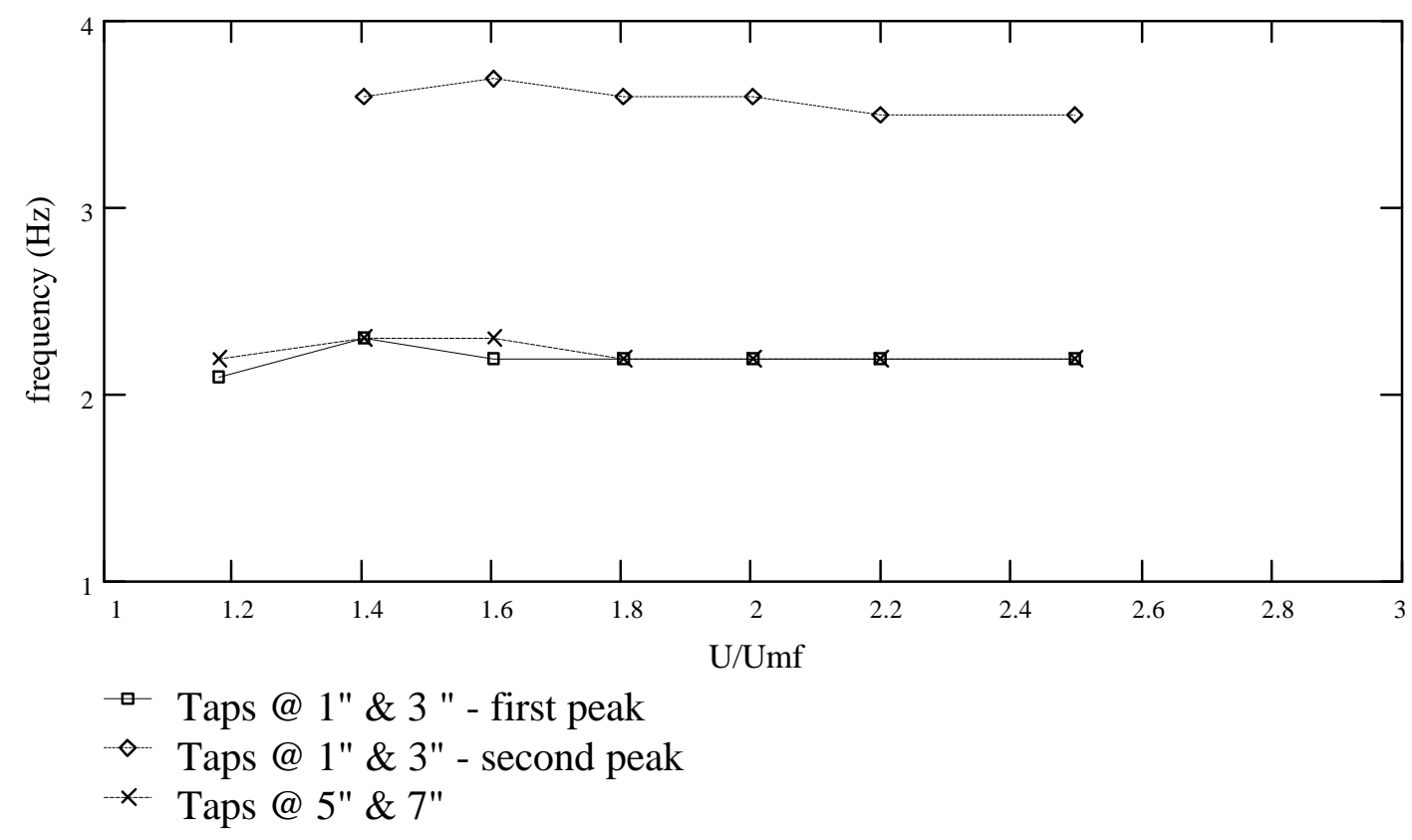

Figure 16: Fluctuation frequency versus U/Umf for $20 \mathrm{~cm}$ bed height and $\mathrm{dp}=0.4 \mathrm{~mm}$ 


\begin{tabular}{|l|l|l|l|}
\hline \multicolumn{5}{|l|}{ Experimental operating conditions } \\
\hline Bed diameter & $5.08 \pm 0.01 \mathrm{~cm}$ & Bed height & $12.0 \pm 0.2 \mathrm{~cm}$ \\
\hline Particle diameter & $0.20 \pm 0.01 \mathrm{~mm}$ & Pressure measurement & differential \\
\hline Particle density & $2600 \pm 100 \mathrm{~kg} / \mathrm{m}^{3}$ & Pressure tap position & Lower $-3.8 \mathrm{~cm} / \mathrm{Upper}-6.4 \mathrm{~cm}$ \\
\hline Gas density (air) & $1.20 \pm 0.04 \mathrm{~kg} / \mathrm{m}^{3}$ & Avg. voidage bwt. taps & $0.48 \pm 0.06$ \\
\hline Superficial velocity & $5.6 \pm 0.6 \mathrm{~cm} / \mathrm{s}\left(\mathrm{U} / \mathrm{U}_{\mathrm{mf}}=1.4\right)$ & Experiment number & $11-21-1995-11.8$ \\
\hline
\end{tabular}
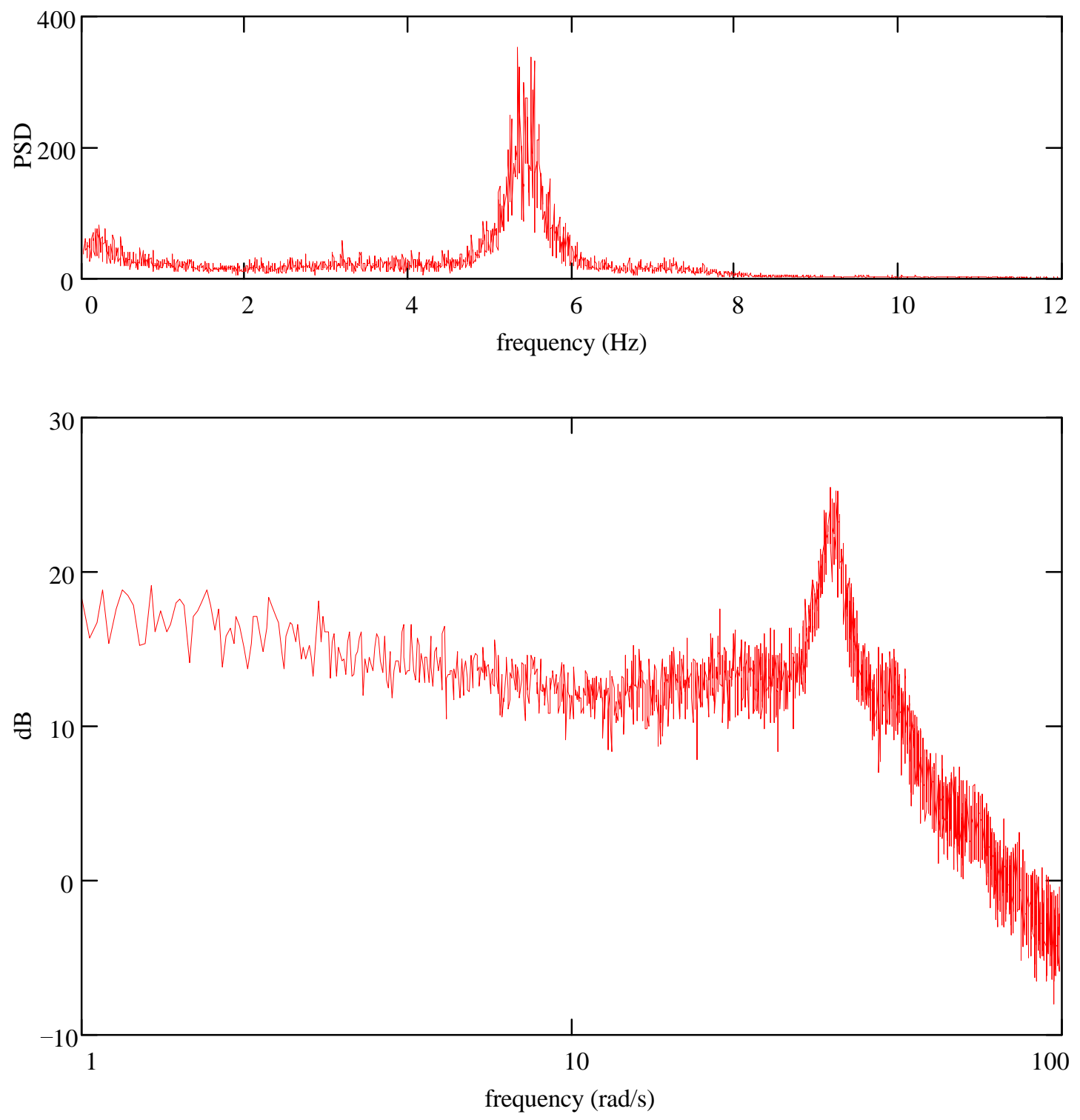

Figure 17: PSD and Bode plot of BFB fluctuations in $5.1 \mathrm{~cm}$ diameter bed 


\begin{tabular}{|l|l|l|l|}
\hline \multicolumn{4}{|l|}{ Experimental operating conditions } \\
\hline Bed diameter & $10.16 \pm 0.01 \mathrm{~cm}$ & Bed height & $12.0 \pm 0.2 \mathrm{~cm}$ \\
\hline Particle diameter & $0.20 \pm 0.01 \mathrm{~mm}$ & Pressure measurement & differential \\
\hline Particle density & $2600 \pm 100 \mathrm{~kg} / \mathrm{m}^{3}$ & Pressure tap position & Lower $-3.8 \mathrm{~cm} / \mathrm{Upper}-6.4 \mathrm{~cm}$ \\
\hline Gas density (air) & $1.20 \pm 0.04 \mathrm{~kg} / \mathrm{m}^{3}$ & Avg. voidage bwt. taps & $0.48 \pm 0.06$ \\
\hline Superficial velocity & $5.6 \pm 0.6 \mathrm{~cm} / \mathrm{s}\left(\mathrm{U} / \mathrm{U}_{\mathrm{mf}}=1.4\right)$ & Experiment number & $11-21-1995-11.8$ \\
\hline
\end{tabular}
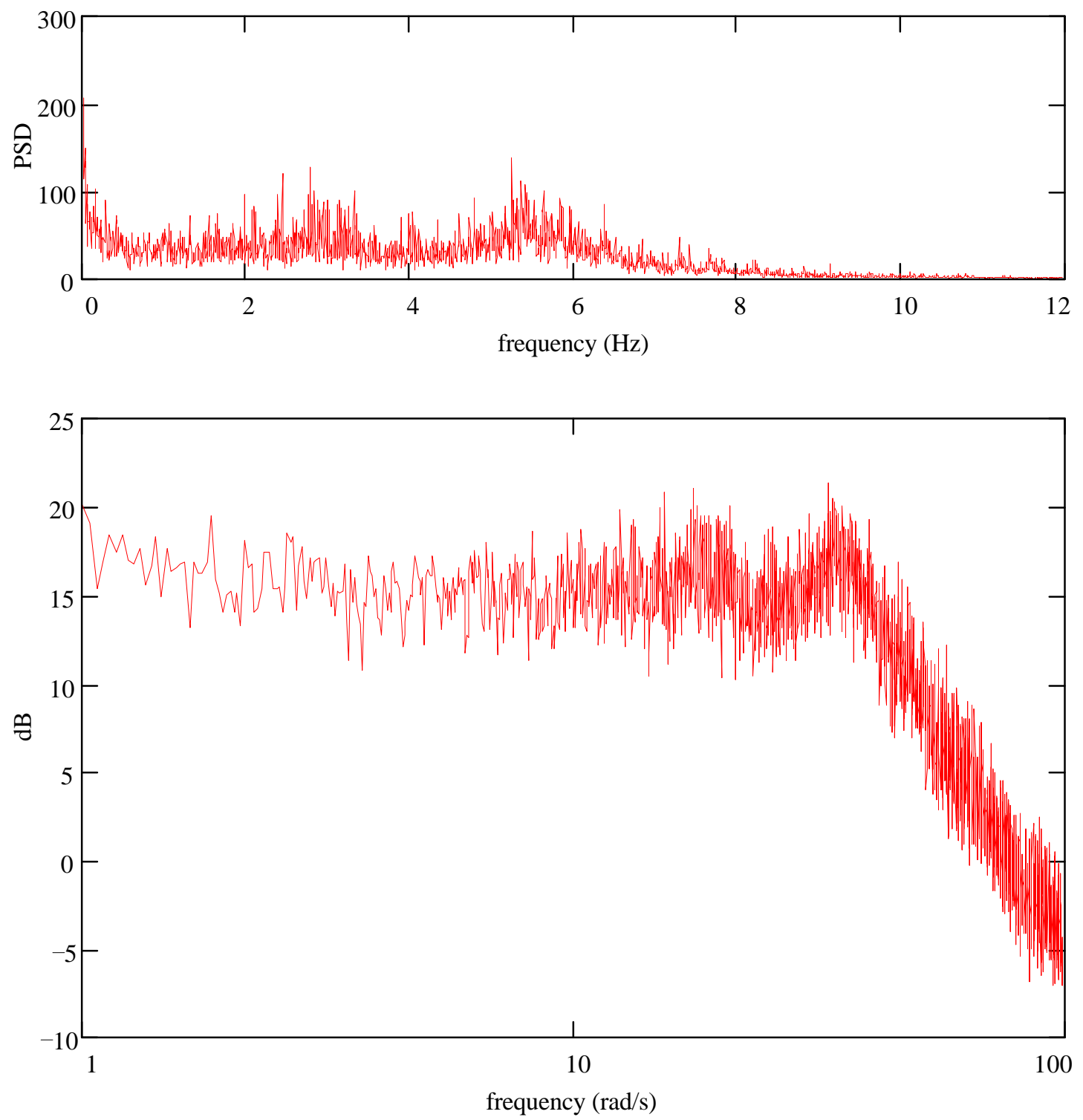

Figure 18: PSD and Bode plot of BFB fluctuations in $10.2 \mathrm{~cm}$ diameter bed 


\section{BFB Pressure Fluctuations as a Global Phenomena}

Our work suggests that two different types of global phenomena are responsible for pressure fluctuations in bubbling fluidized beds. Our research has led us to dismiss the possibility of random local phenomena (such as bubbles) being the explanation of pressure fluctuations in bubbling beds for two reasons. Static pressure measurements in a BFB were simultaneously recorded from the center of the bed and at the bed wall. The Bode plot profiles of the fluctuations at these two locations were identical. If the passage of local bubbles were solely responsible for pressure fluctuations, the hydrodynamics at the center of the bed would produce a different fluctuation structure, since the majority of bubbles rise to the surface through the center of the bed. Further evidence of the global nature of pressure fluctuations was obtained from an experiment in which two different drilled hole distributor plates were tested under identical operating conditions. The two distributor plates had the same total hole-area, but one had 72 holes while the other had only 36 holes. Since bubbles form at the distributor plate holes, the 72 hole plate would produce more bubbles than the 36 hole plate. As is shown in Figures 19 - 20, the Bode plots of the pressure fluctuations from the two different distributor plate cases are identical, suggesting that random bubble passage in the vicinity of the region of pressure measurement is not a sufficient explanation for the fluctuations. This argument does not lead to the conclusion that bubbles are not responsible for pressure fluctuation phenomena, but rather that the global phenomena that dictates fluidized bed hydrodynamics may also govern the periodic production of bubbles.

\section{Evaluation of the Global Theories of Fluidized Bed Oscillations}

Three different categories of global phenomena are highlighted by Roy and Davidson [8]: a natural frequency of oscillation of the entire bed; a surface phenomena that propagates pressure fluctuations down through the bed; and a plenum compression wave phenomena exhibited in fluidized beds with low resistance distributor plates. This third phenomena is not of interest in this study. To eliminate the effect of this phenomena, high resistance distributor plates are used. It is hypothesized that two global fluidization phenomena are responsible for the structure of fluctuations. These two phenomena will be generally referred to as the natural frequency and the surface frequency. 


\begin{tabular}{|l|l|l|l|}
\hline \multicolumn{5}{|l|}{ Experimental operating conditions } \\
\hline Bed diameter & $10.16 \pm 0.01 \mathrm{~cm}$ & Bed height & $10.0 \pm 0.2 \mathrm{~cm}$ \\
\hline Particle diameter & $0.40 \pm 0.01 \mathrm{~mm}$ & Pressure measurement & differential \\
\hline Particle density & $2600 \pm 100 \mathrm{~kg} / \mathrm{m}^{3}$ & Pressure tap position & Lower $-2.5 \mathrm{~cm} / \mathrm{Upper}-7.6 \mathrm{~cm}$ \\
\hline Gas density (air) & $1.20 \pm 0.04 \mathrm{~kg} / \mathrm{m}^{3}$ & Avg. voidage bwt. taps & $0.50 \pm 0.06$ \\
\hline Superficial velocity & $19.6 \pm 0.6 \mathrm{~cm} / \mathrm{s}\left(\mathrm{U} / \mathrm{U}_{\mathrm{mf}}=1.4\right)$ & Experiment number & $7-7-1995-11.6$ \\
\hline
\end{tabular}
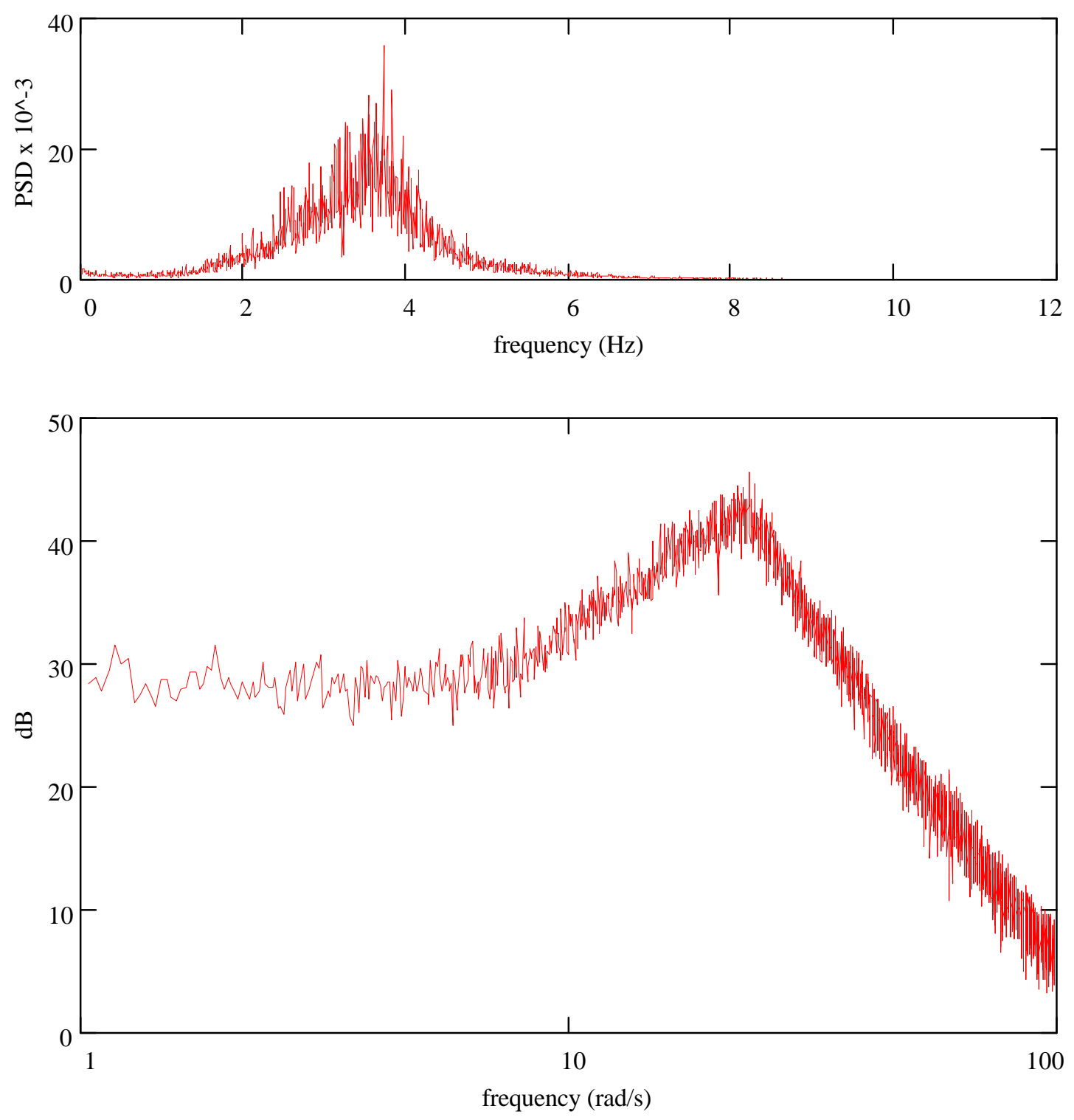

Figure 19: PSD and Bode plot of BFB fluctuations with 36 hole distributor 


\begin{tabular}{|l|l|l|l|}
\hline \multicolumn{5}{|l|}{ Experimental operating conditions } \\
\hline Bed diameter & $10.16 \pm 0.01 \mathrm{~cm}$ & Bed height & $10.0 \pm 0.2 \mathrm{~cm}$ \\
\hline Particle diameter & $0.40 \pm 0.01 \mathrm{~mm}$ & Pressure measurement & differential \\
\hline Particle density & $2600 \pm 100 \mathrm{~kg} / \mathrm{m}^{3}$ & Pressure tap position & Lower $-2.5 \mathrm{~cm} / \mathrm{Upper}-7.6 \mathrm{~cm}$ \\
\hline Gas density (air) & $1.20 \pm 0.04 \mathrm{~kg} / \mathrm{m}^{3}$ & Avg. voidage bwt. taps & $0.50 \pm 0.06$ \\
\hline Superficial velocity & $19.6 \pm 0.6 \mathrm{~cm} / \mathrm{s}\left(\mathrm{U} / \mathrm{U}_{\mathrm{mf}}=1.4\right)$ & Experiment number & $7-3-1995-8.4$ \\
\hline
\end{tabular}
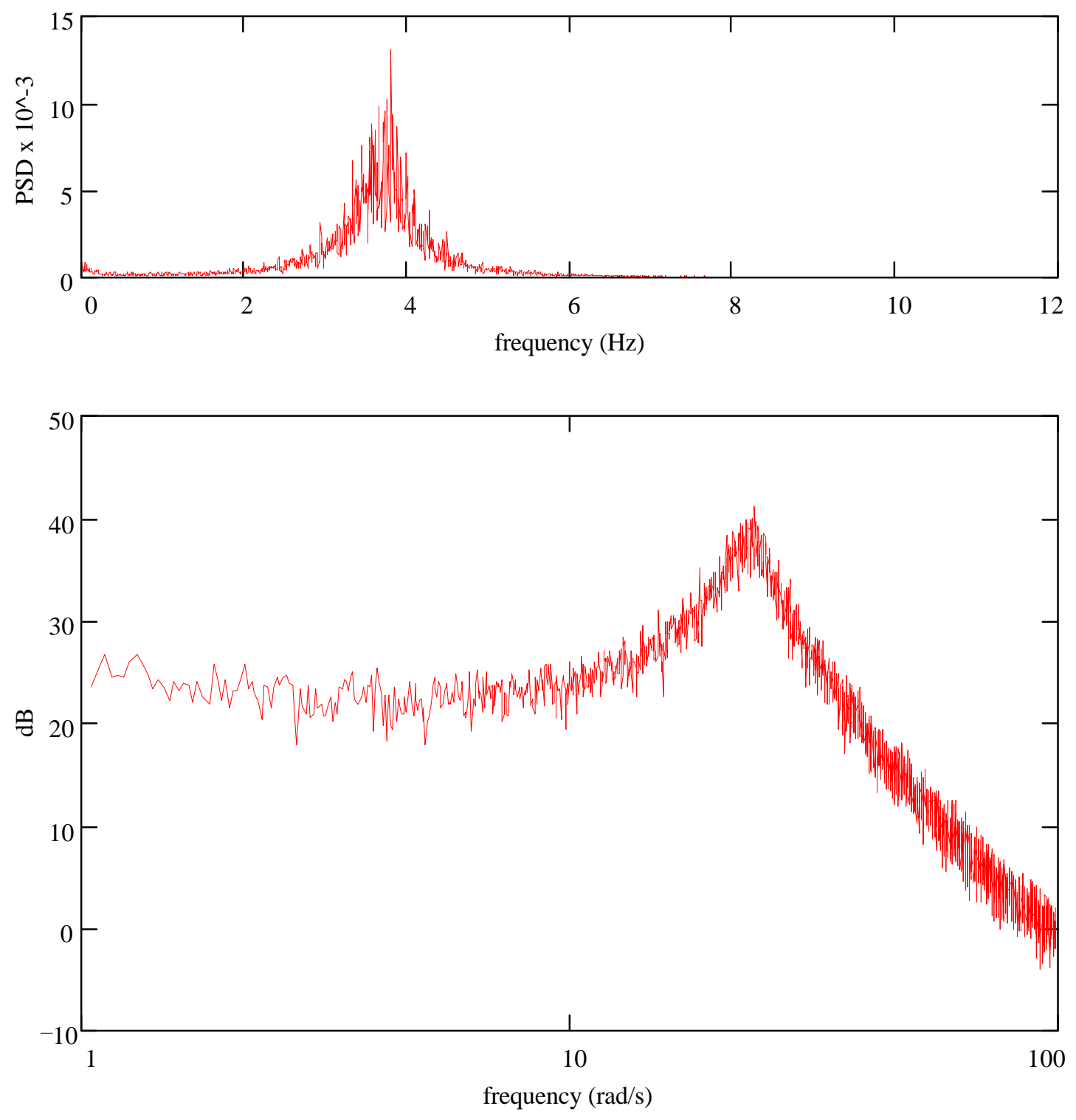

Figure 20: PSD and Bode plot of BFB fluctuations with 72 hole distributor plate 
When evaluating potential theories for the origin of fluctuations in bubbling beds, two requirements must be considered. The first requirement is that the theory must be able to account for the second order system behavior observed in fluidized bed systems. The Bode plots of all fluidized bed systems exhibit a final asymptotic slope of $-40 \mathrm{~dB} / \mathrm{decade}$. Figures 21 and 22 show examples of simple second order systems. In many cases, a single second order system is not sufficient to describe fluidization hydrodynamics. Experiments suggest that the dynamics of fluidization can be described by a model that assumes multiple second order systems acting concurrently within the fluidized bed system. Second order systems acting in parallel will also yield $-40 \mathrm{~dB} / \mathrm{decade}$ final Bode plot roll off (as shown by example in Figure 23). Secondly, the theory must be able to predict the observed dominant frequencies accurately and explain why at low bed heights they appear to be inversely proportional to the square root of bed height.

There are three researchers who have proposed mechanisms that meet these two requirements. The first two researchers to present mechanisms for fluctuations were Hiby [9] and Verloop [10]. Fundamentally the mechanism proposed by both these researchers is the same,although the derivations differ slightly. While Verloop maintains that the entire incipiently fluidized bed oscillates in phase, Hiby proposes a system of oscillating layers being "pulled into tune." The changes in bed voidage as the bed lifts and returns to its initial position result in the fluctuations of static pressure drop across the bed. While Verloop focuses on shallow incipiently fluidized beds, Hiby extends this phenomena to explain layers of bubble production which coincide with the natural oscillations of the bed.

Baskakov [11] takes a different approach to fluidized bed dynamics. He proposes a direct analogy between fluidized bed dynamics and a hydraulic pendulum (e.g. U-tube manometer). For Baskakov the changes in voidage (or pressure) are due to changes in the height of the surface caused by the rise of a large single bubble. As the bubble rises through the bed it entrain solids to the top of the bed, causing the bed surface to rise. The solids return downward along the sides of the bed to restore the bed to its equilibrium condition. This cyclic movement of solids up the center of the bed via bubbles and back down the sides via annular flow constitutes Baskakov's oscillatory pendulum. The primary weakness of Baskakov's theory lies in the validity of the hydraulic pendulum analogy. The simplifying assumptions that go into this analogy are not convincing. Baskakov's derivation is based on the U-tube manometer not a fluidized bed system. 


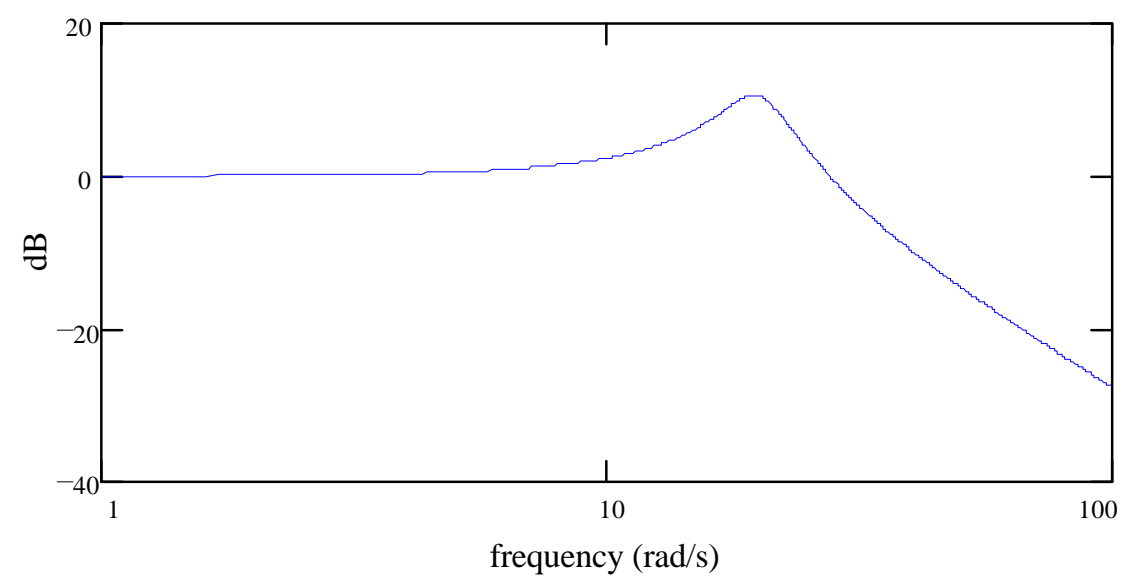

Figure 21: Example - simple 2nd order underdamped system Bode plot $\left(\omega_{n}=20 \mathrm{~s}^{-1}, \varsigma=0.3\right)$

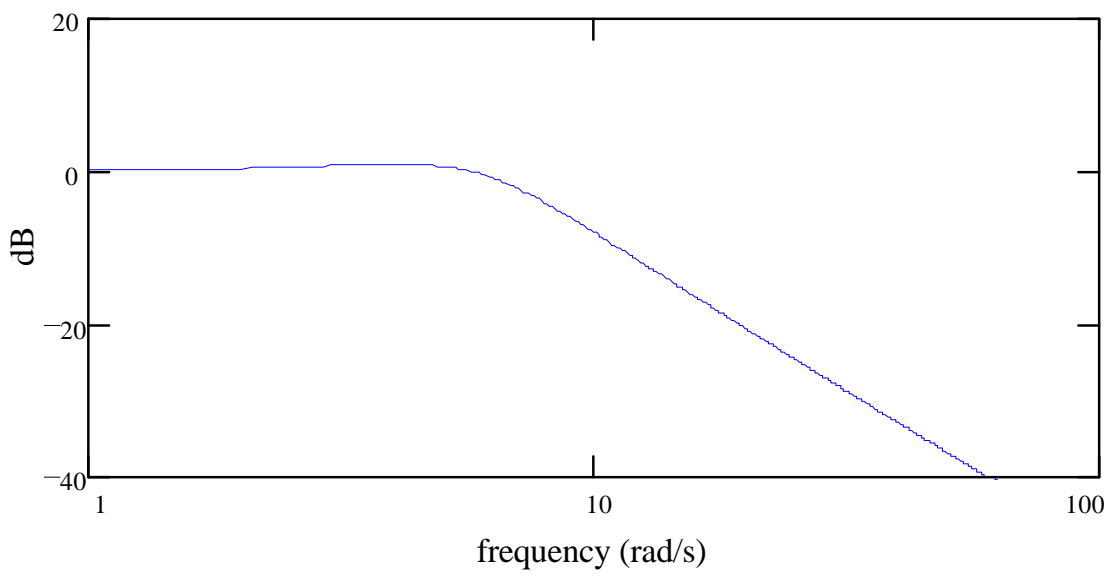

Figure 22: Example - simple 2nd order overdamped system Bode plot $\left(\omega_{n}=6 \mathrm{~s}^{-1}, \varsigma=1.1\right)$

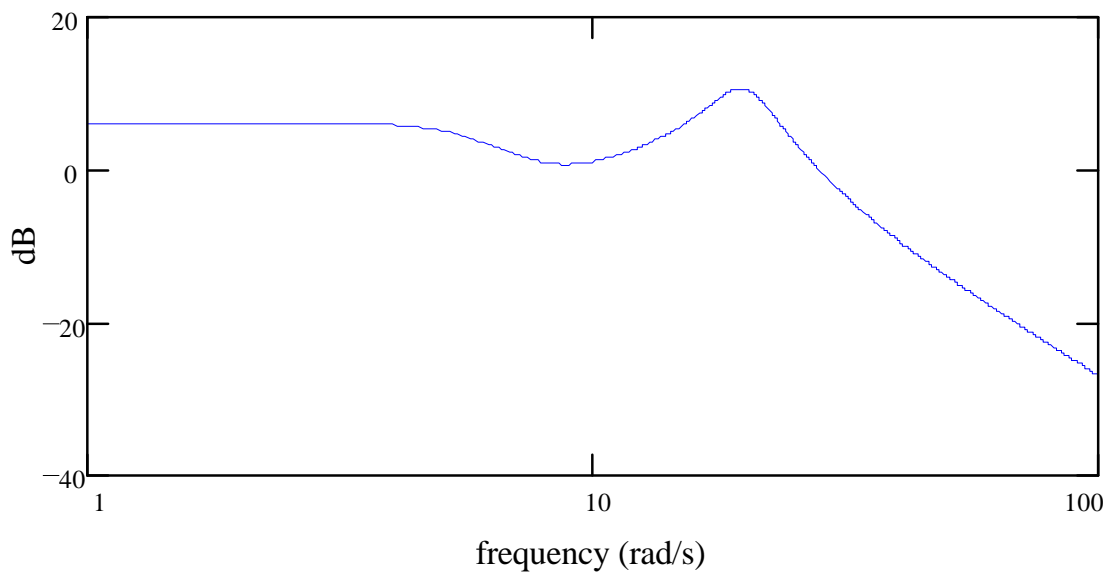

Figure 23: Example - Bode plot of the above second order systems acting in parallel 
He simply assumes a direct analogy can be made to the fluidized bed. Secondly, Baskakov's model is dependent on bubbles as a forcing mechanism; he does not explain the possibility or origin of the necessary periodic bubble formations.

In all three theories, the experimental data that Hiby publishes for incipiently fluidized beds fits relatively well with the predicted frequency, although Hiby's own relation provides the best fit. The relations derived for the natural frequency of the bed proposed by the authors above is summarized below:

Hiby (1967)

$$
\omega=\sqrt{\frac{g \cdot(1-\varepsilon)}{\left(0.75 \cdot \pi^{2}\right) \cdot H \cdot \varepsilon}}
$$

Verloop (1974)

$$
\omega=\frac{1}{2 \cdot \pi} \sqrt{\frac{g \cdot(2-\varepsilon)}{H \cdot \varepsilon}}
$$

Baskakov (1986)

$$
\omega=\frac{1}{\pi} \sqrt{\frac{g}{H}}
$$

The reason for preferring Hiby's relation over Verloop's similar derivation is because it better predicts the observed frequency. The experimental evidence from this study of bubbling bed fluctuations supports Hiby's hypothesis that the natural bed frequency may dictate the bubble production frequency. Figures 24 through 31 show how experimental data gathered from this studies bubbling bed systems compare with the models above (using $\varepsilon=0.49$ ). Clearly, Hiby's model comes the closest to predicting the observed dominant frequency even in bubbling fluidized beds. The relations of Hiby and Verloop differ from Baskakov's relation in two significant ways. First, the assumptions involved in the derivation of Hiby and Verloop's relations are based on fluidized bed hydrodynamics, rather than simply the dynamics of a U-tube pendulum. Secondly, as seen by comparing equations 1 - 3, Baskakov's relation proposes that the fundamental frequency is not a function of the bed voidage, as it is in the Verloop and Hiby relations. While Baskakov asserts that experiments show that the frequency is independent of voidage, no conclusive experimental data has ever been published that definitively supports this claim. Our experimental data was not taken in such a manner to confirm either hypothesis. In order to support such a claim, an accurate means of measuring the overall bed voidage must be used. Also, typically the range of fluidization voidages is very small (e.g. 0.46-0.49) making a systematic study of the effect of voidage difficult. For these reasons, Hiby's relation seems to be 
the most plausible theory to explain the oscillatory behavior in bubbling fluidized bed systems, but as will be shown in the following section, this theory has a fundamental error in its assumptions. By correcting this assumption, a modified Hiby formulation is derived that better predicts the observed frequency.

Since only Hiby's data for incipient fluidization was used for comparison to these theories, it was not observed that as the bed height increases to heights greater than $10 \mathrm{~cm}$, multiple peaks begin appearing in the spectrum, complicating the overall system (see Figures 25 and 26). As the bed height increases the frequency tends to be at a lower frequency than predicted by theories for natural bed oscillations. Increasing the height increases bubble coalescence, resulting in the upper surface lifting or erupting from its equilibrium position. Throughout the bed, this subsequent oscillation of the surface can be detected concurrently with natural bed oscillations. In very deep beds significant coalescence occurs and the surface fluctuations will occur at a slightly lower frequency than the natural bed frequency. This surface effect will begin to interfere with the natural oscillation of the bed such that the observed frequency is less than the predicted value inversely proportional to the square root of the bed height. This effect produced by excessive bubble coalescence was not observed by other researchers since previous experimental data was recorded in beds that were operated at incipient fluidization conditions only. The decrease in the fluctuation frequency due to this surface phenomena is most pronounced as the particle size decreases. For large particle sizes, the slope observed on the log-log plot of frequency versus bed height is close to the -0.5 predicted by theory (see Figure 30 ). For smaller particle sizes the slope becomes steeper and seems to approach a slope closer to -1.0 as the bed height increases (see Figures 28 and 29). Smaller particles will tend to produce smaller bubbles. These smaller bubbles will rise faster, increasing the rate of bubble coalescence. As coalescence increases, the surface eruption frequency decreases due to the fewer (but larger) bubbles at the bed surface. Figure 31 shows how the observed frequencies are complicated in small diameter beds, or more specifically, beds with a high H/D ratio. Again, this is due to bubble coalescence, which will increase as the height is increased, and to slugging behavior which increases as the diameter is reduced. 


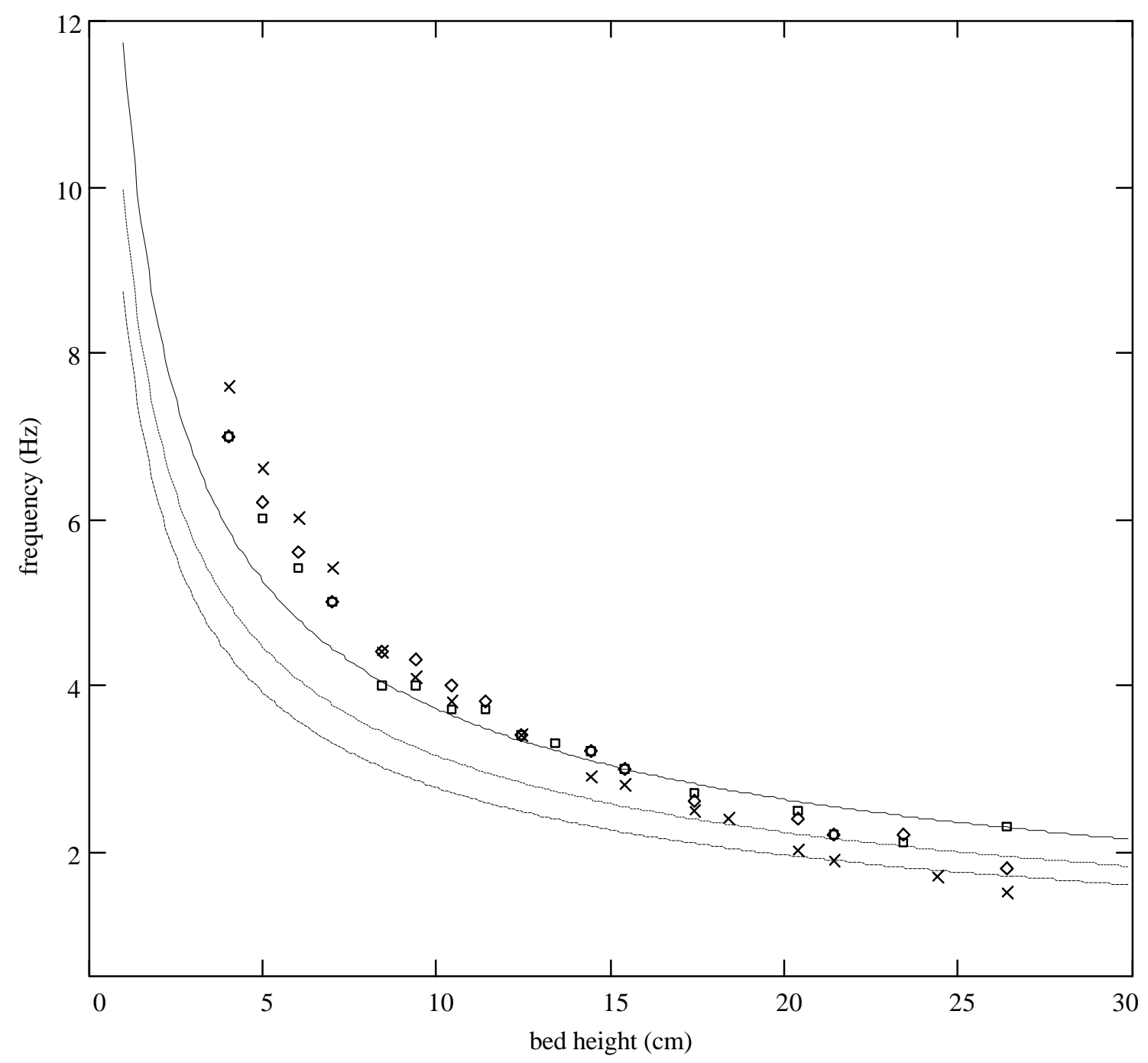

- Hiby (1967) - fluidization approximation

- Verloop \& Heertjes (1974)

- Baskakov (1986)

$\times \quad 0.2 \mathrm{~mm}$ glass beads

$\diamond 0.3 \mathrm{~mm}$ glass beads

- $\quad 0.4 \mathrm{~mm}$ glass beads

Figure 24: $\quad$ Comparison of proposed models to experimental data ( $\mathrm{D}=4.0$ ") Frequency vs. only the lowest dominant BFB frequency observed 


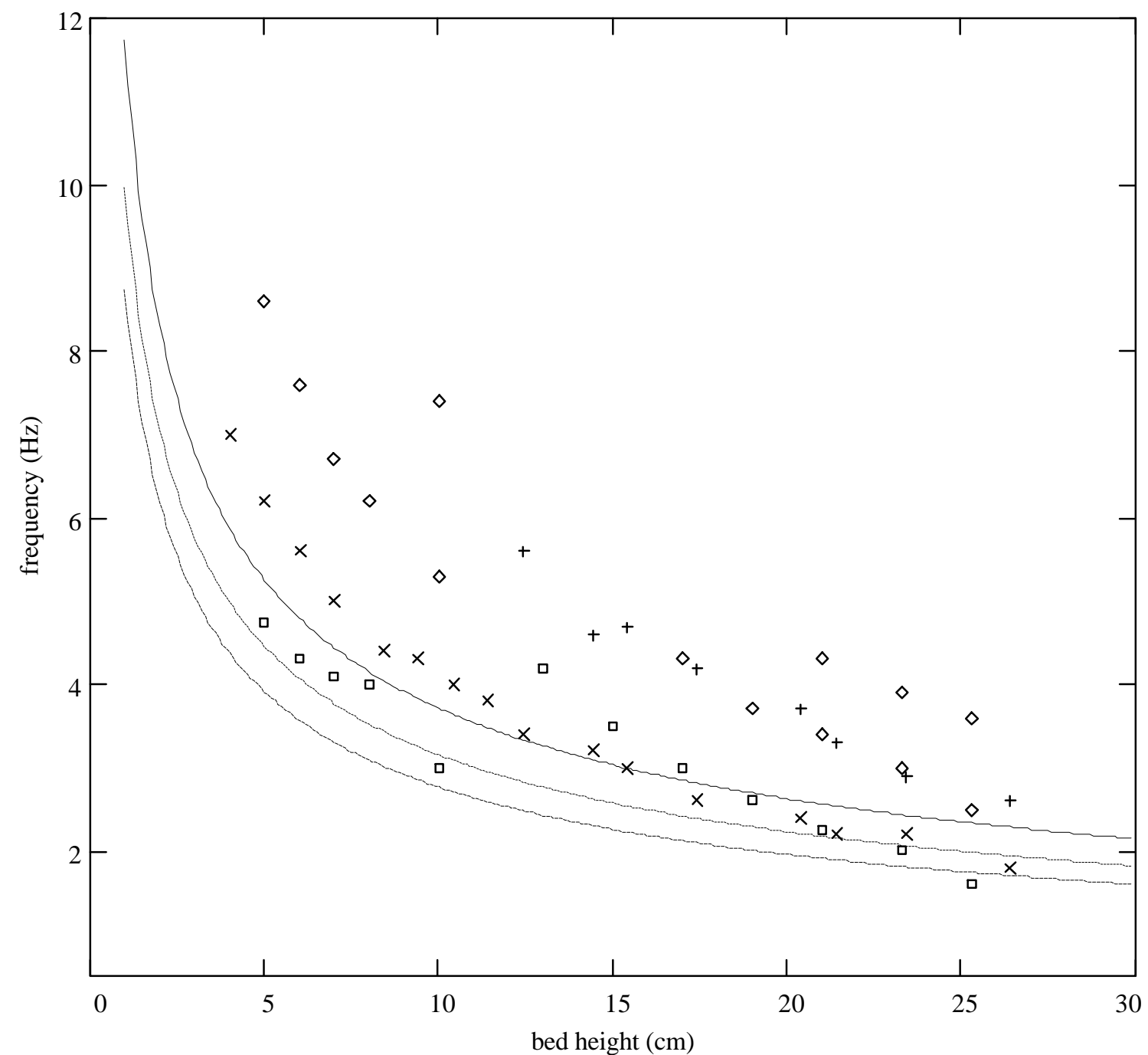

- Hiby (1967) - fluidization approximation

- Verloop \& Heertjes (1974)

- Baskakov (1986)

$\times \mathrm{D}=4.0^{\prime \prime}$ - first peak

$+\mathrm{D}=4.0^{\prime \prime}$ - second peak

- $\mathrm{D}=2.0^{\prime \prime}$ - first peak

$\diamond \mathrm{D}=2.0^{\prime \prime}$ - second peak

$\diamond \mathrm{D}=2.0^{\prime \prime}$ - third peak

Figure 25: Comparison of proposed models to experimental data for $0.3 \mathrm{~mm}$ glass beads Frequency vs. all dominant BFB frequencies 


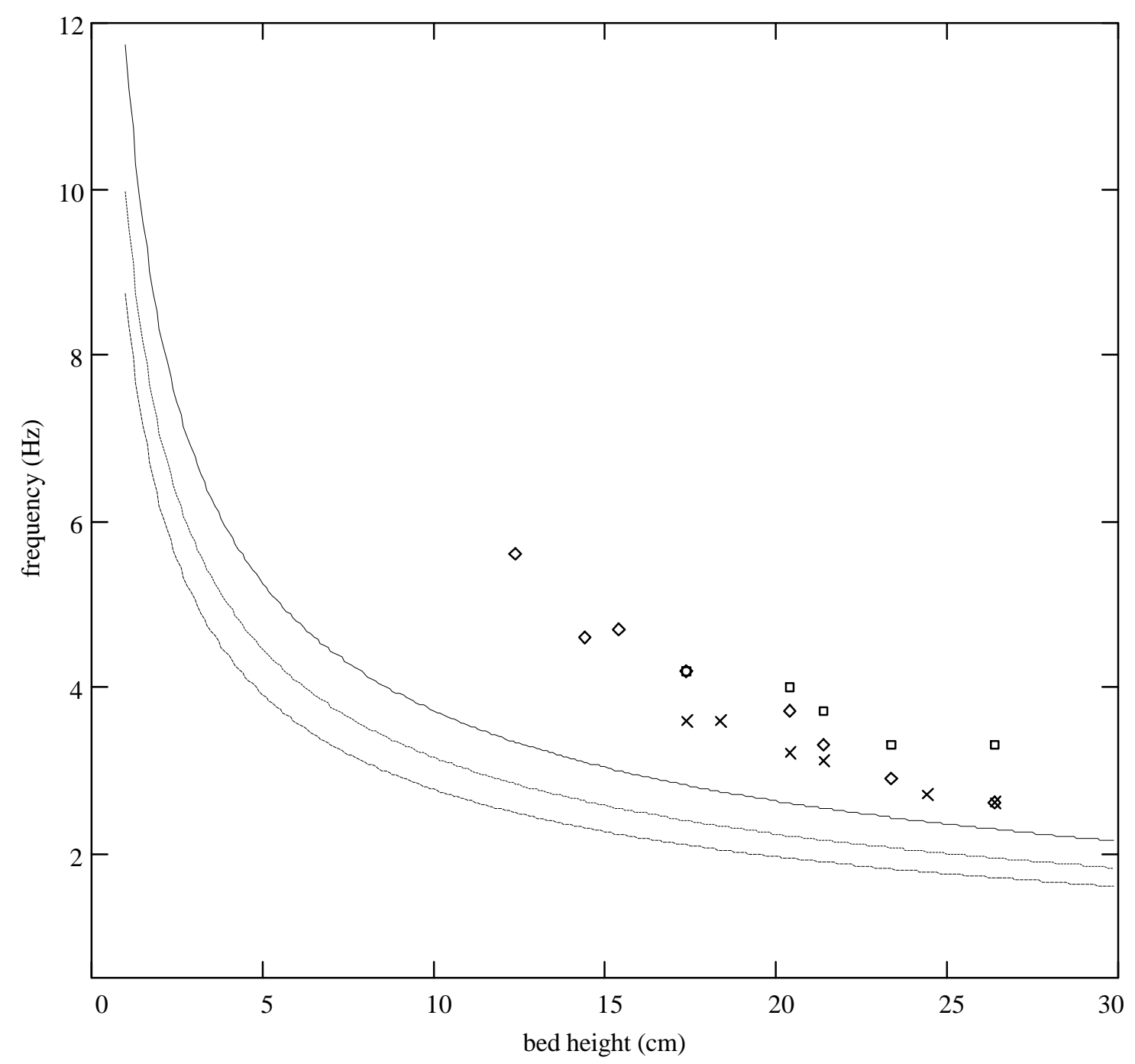

- Hiby (1967) - fluidization approximation

- Verloop \& Heertjes (1974)

- Baskakov (1986)

$\times \quad 0.2 \mathrm{~mm}$ glass beads

$\diamond 0.3 \mathrm{~mm}$ glass beads

- $0.4 \mathrm{~mm}$ glass beads

Figure 26: Comparison of proposed models to experimental data ( $\mathrm{D}=4.0$ ") Frequency vs. only the higher dominant BFB frequency observed 


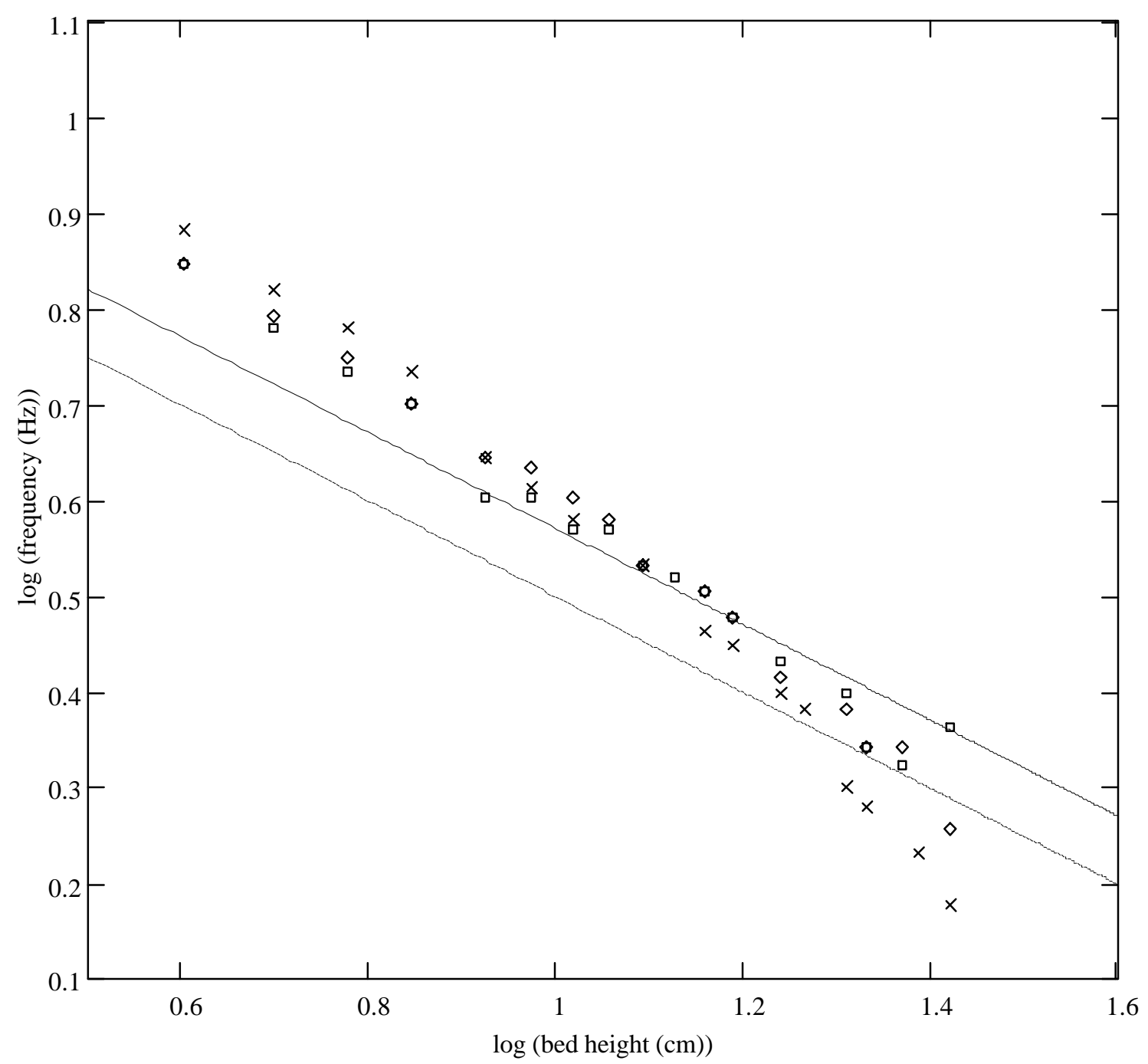

- Hiby

- Baskakov

$\times \quad 0.2 \mathrm{~mm}$ glass beads

$\diamond 0.3 \mathrm{~mm}$ glass beads

- $0.4 \mathrm{~mm}$ glass beads

Figure 27: $\quad \log -\log$ comparison of proposed models to experimental data $(\mathrm{D}=4.0$ ") $\log$ (frequency) vs. $\log$ (only the lowest dominant BFB frequency observed) 


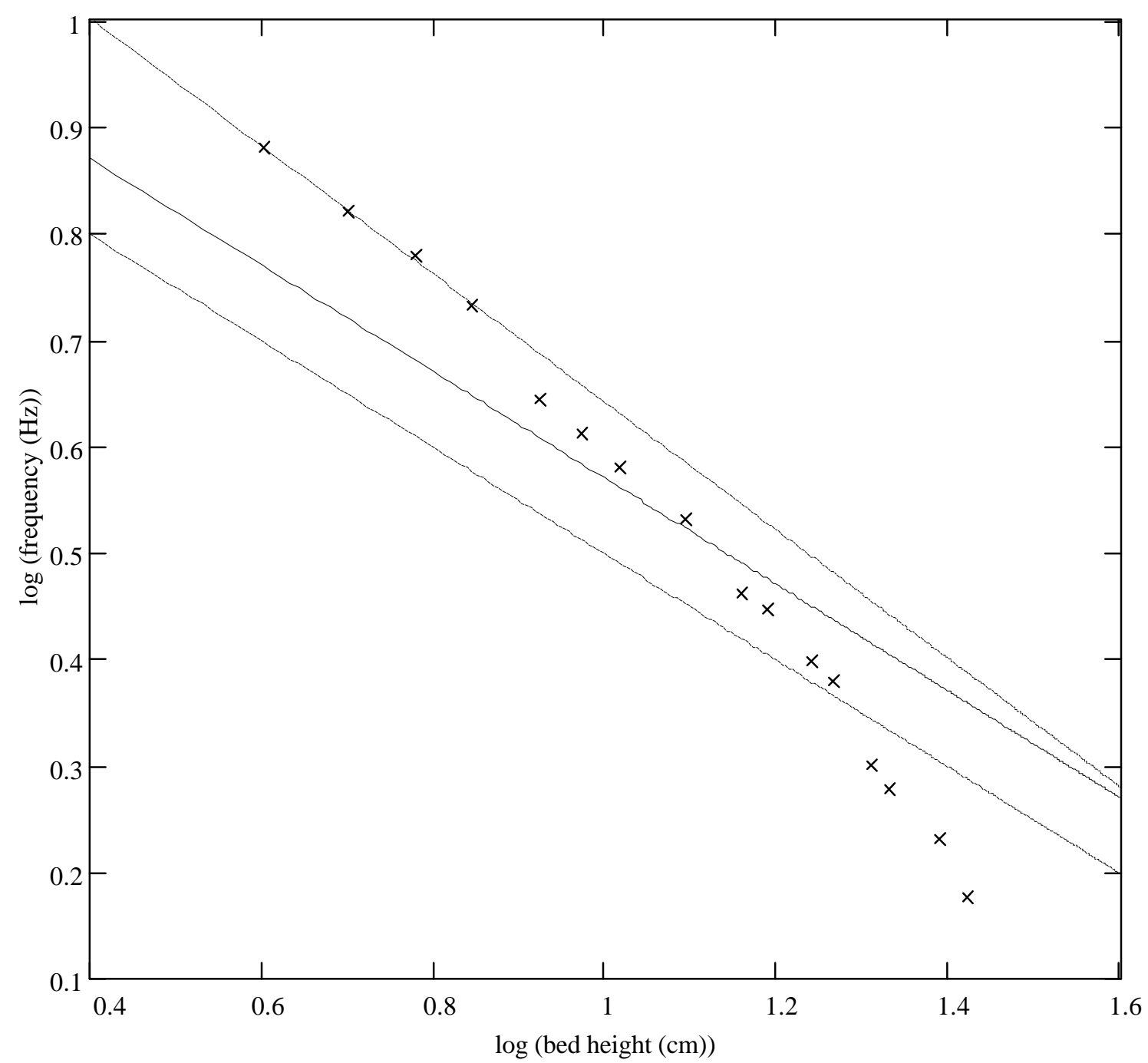

- Hiby

- Baskakov

$\times \quad 0.2 \mathrm{~mm}$ glass beads

- linear regression (first 4 points - slope $=-0.60$ )

Figure 28: $\quad \log -\log$ comparison of proposed models to experimental data $(\mathrm{D}=4.0$ ") $\log$ (frequency) vs. $\log$ (only the lowest dominant BFB frequency observed) with linear regression of the first four data points of $\mathrm{dp}=0.2 \mathrm{~mm}$ 


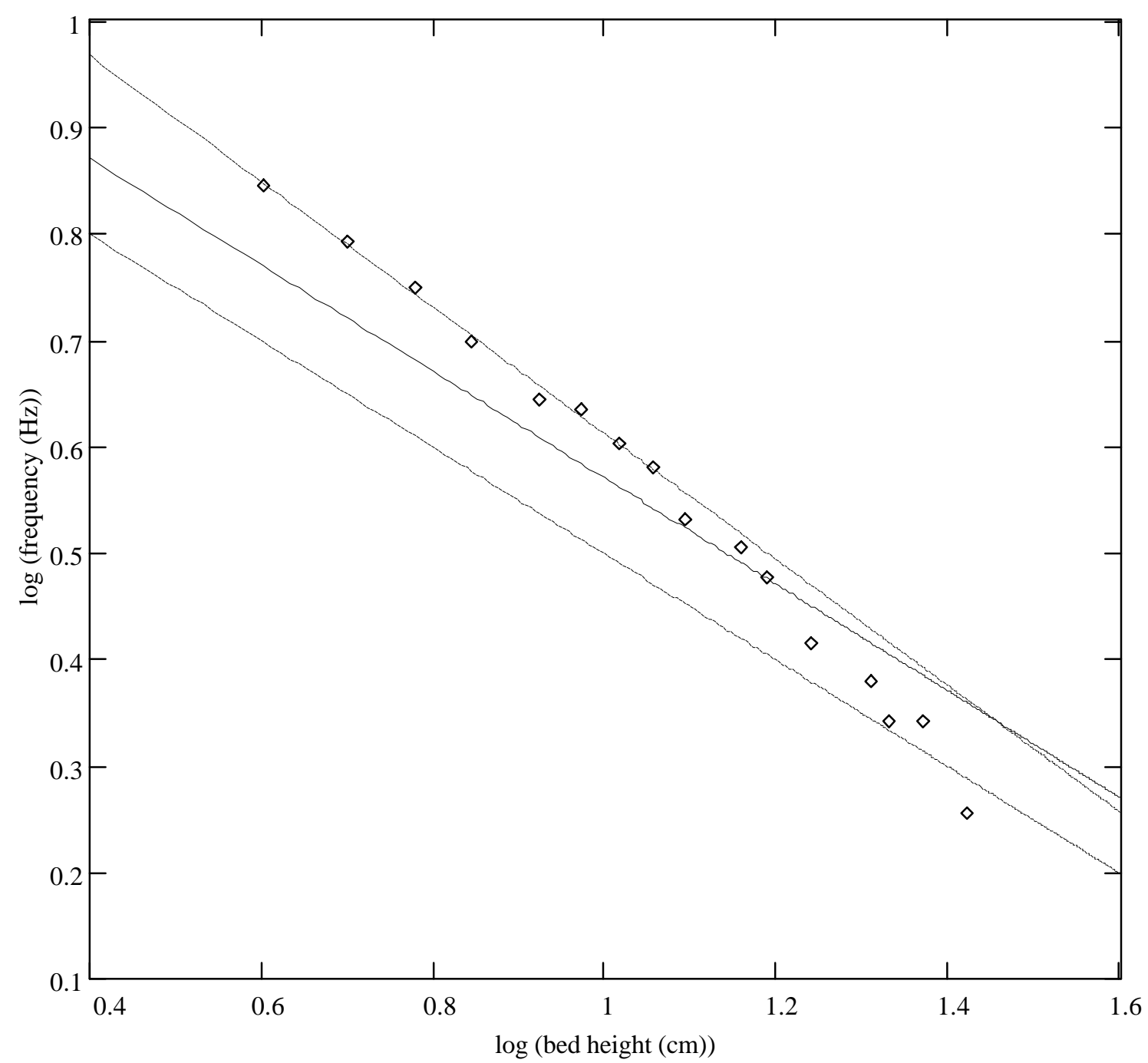

- Hiby

- Baskakov

$\diamond 0.3 \mathrm{~mm}$ glass beads

- linear regression (first 8 points - slope $=-0.59$ )

Figure 29: $\quad \log -\log$ comparison of proposed models to experimental data $(\mathrm{D}=4.0 ")$ $\log$ (frequency) vs. $\log$ (only the lowest dominant BFB frequency observed) with linear regression of the first eight data points of $\mathrm{dp}=0.3 \mathrm{~mm}$ 


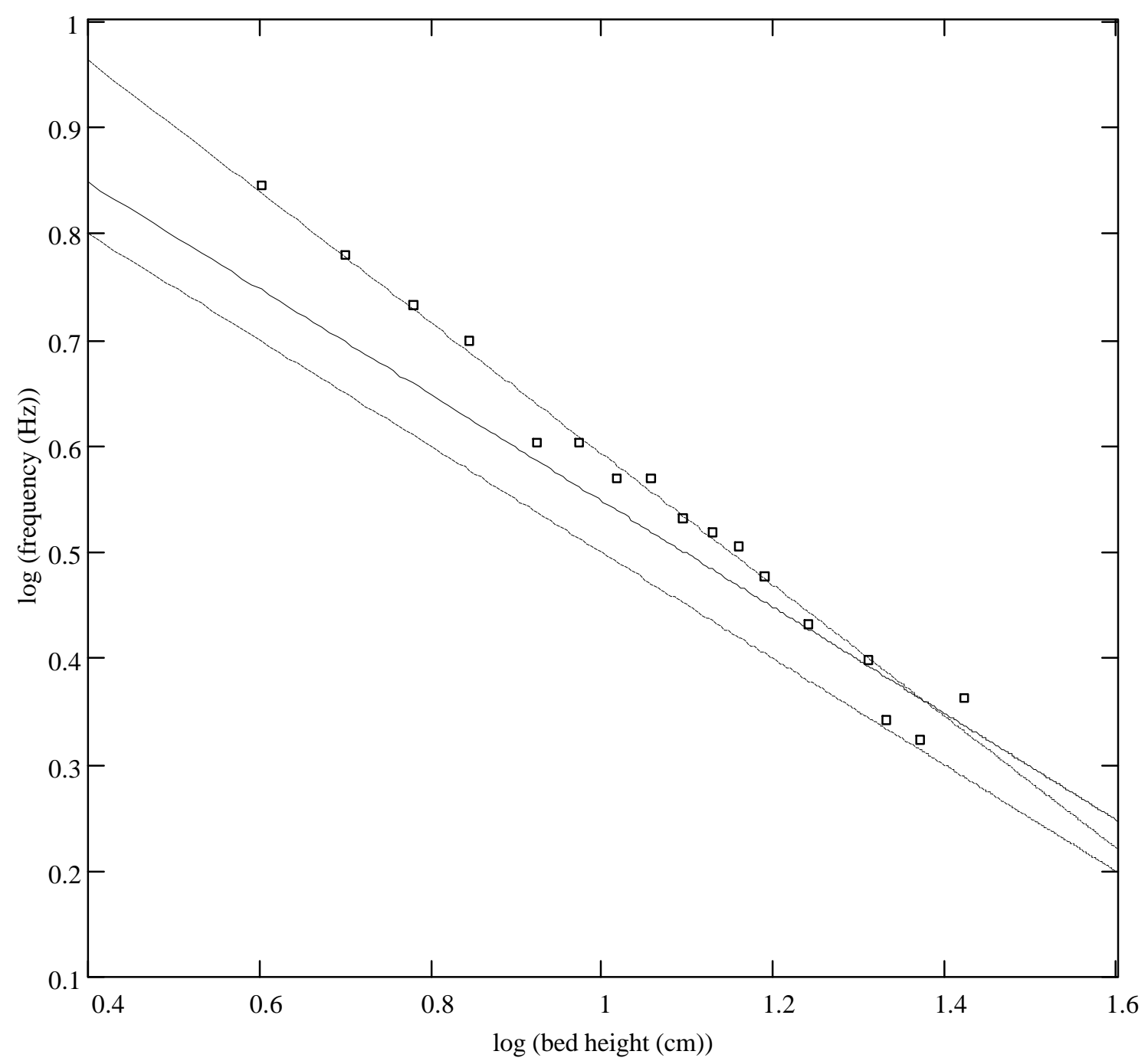

- Hiby

- Baskakov

- $0.4 \mathrm{~mm}$ glass beads

- linear regression (first 12 points - slope $=-0.62$ )

Figure 30: $\quad \log -\log$ comparison of proposed models to experimental data $(\mathrm{D}=4.0$ ") $\log$ (frequency) vs. $\log$ (only the lowest dominant BFB frequency observed) with linear regression of the first twelve data points of $\mathrm{dp}=0.4 \mathrm{~mm}$ 


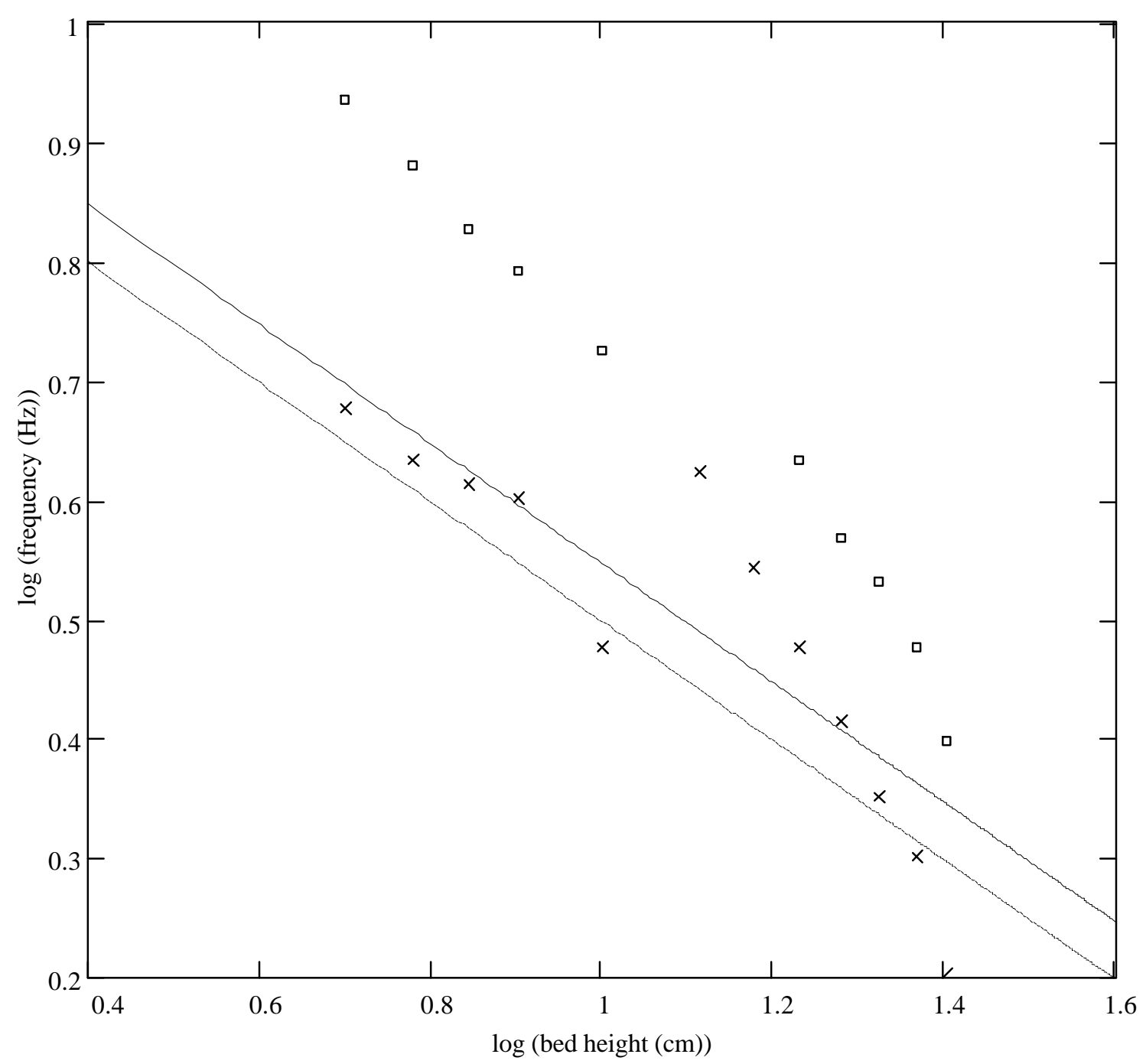

Hiby

Baskakov

- $\quad \mathrm{D}=2.0 \% / \mathrm{dp}=0.3 /$ second peak

$\times \mathrm{D}=2.0 " / \mathrm{dp}=0.3 /$ first peak

Figure 31: $\quad \log$-log comparison of proposed models to experimental data $(\mathrm{D}=2.0$ ") $\log$ (frequency) vs. $\log$ (all dominant BFB frequencies observed) 


\section{Derivation of a Modified-Hiby Model for Bubbling Fluidized Bed Dynamics}

While Hiby's research provides the most plausible theory and rigorous derivation to date, he makes a fundamental error in the assumptions used in his theoretical derivation. By correcting this error, a more accurate relation can be developed to both predict the natural frequency and explain the second order dynamics observed in the BFB pressure fluctuations. Hiby begins his derivation by considering a single particle suspended in a fluidized bed [9]. If this particle is displaced from its equilibrium position (either upwards or downwards), the forces on the particle are altered in such a way to bring it back to its equilibrium position. The number of particles in a fluidized bed can be defined as:

$$
N=\frac{V_{s}}{V_{p}}=\frac{V \cdot(1-\varepsilon)}{\left(\frac{\pi}{6}\right) \cdot d_{p}^{3}}
$$

The force acting on a single particle is the sum of its weight and the drag force exerted by the gas flow (neglecting buoyancy forces which are typically very small in gas fluidization systems). The average drag force on an individual particle can be estimated by dividing the total lifting force acting on the bed $(\Delta \mathrm{p} \cdot \mathrm{A})$ by the total number of particles.

$$
F=-m g+\frac{\pi \cdot \Delta p \cdot A \cdot d_{p}{ }^{3}}{6 \cdot V \cdot(1-\varepsilon)}
$$

Substituting $\mathrm{A} / \mathrm{V}=1 / \mathrm{H}$ :

$$
F=-m g+\left(\frac{\pi \cdot d_{p}^{3}}{6 \cdot(1-\varepsilon)}\right) \cdot\left(\frac{\Delta p}{H}\right)
$$

Under fluidization conditions the pressure drop can be estimated using the Ergun equation at minimum fluidization velocity $\left(\mathrm{U}_{\mathrm{mf}}\right)$. This is where Hiby makes an error in his derivation. He uses the variable $\mathrm{U}$ rather than the constant $\mathrm{U}_{\mathrm{mf}}$ to estimate the pressure drop in an incipiently fluidized bed. While at incipient conditions these will be equal by definition, his use of $U$ rather than $U_{m f}$ leads him to some faulty conclusions, as will be shown later. From the Ergun equation:

$$
\frac{\Delta p}{H}=150 \cdot \frac{U_{m f} \cdot \mu}{d_{p}{ }^{2}} \cdot \frac{(1-\varepsilon)^{2}}{\varepsilon^{3}}+1.75 \cdot \frac{\rho_{g} \cdot U_{m f}{ }^{2}}{d_{p}} \cdot \frac{(1-\varepsilon)}{\varepsilon^{3}}
$$


Therefore:

$$
F=-m g+\left(\frac{\pi \cdot d_{p}^{3}}{6}\right) \cdot\left(150 \cdot \frac{U_{m f} \cdot \mu}{d_{p}{ }^{2}} \cdot \frac{(1-\varepsilon)}{\varepsilon^{3}}+1.75 \cdot \frac{\rho_{g} \cdot U_{m f}{ }^{2}}{d_{p}} \cdot \frac{1}{\varepsilon^{3}}\right)
$$

The assumption is made that all individual particles oscillate such that at every moment all particles show the same relative vertical displacement from their equilibrium position. The oscillation in voidage is only a function of time, and is independent of the height in the bed. Under most normal fluidization conditions the average voidage measured throughout the bed is relatively constant, making this a valid assumption. The amplitude of an individual particle $\mathrm{i}$ is then proportional to its height $h_{i}\left(a_{i} \sim h_{i}\right)$, and,

$$
\frac{d h_{i}}{h_{i}}=\frac{d H}{H}
$$

relating $\varepsilon$ to the bed height,

$$
\varepsilon=\frac{V-V_{s}}{V}=1-\frac{V_{s}}{A \cdot H}
$$

solving for $\mathrm{H}$,

$$
H=\frac{V_{s}}{A \cdot(1-\varepsilon)}
$$

Using Newton's second law we can calculate the natural frequency of an oscillating particle.

Given that: $\quad a_{i}(t)=-\omega^{2} \cdot h_{i}(t)$

$$
F=m_{i} a_{i}=-\left(m_{i} \cdot \omega_{i}^{2}\right) \cdot h_{i}
$$

it follows that,

$$
\frac{d F}{d h_{i}}=-\left(m_{i} \cdot \omega_{i}^{2}\right)
$$

Solving for $\omega_{i}$,

$$
\omega_{i}^{2}=-\frac{1}{m} \cdot \frac{d F}{d h_{i}}=-\frac{6}{\pi \cdot d_{p}^{3} \cdot \rho_{s}} \cdot \frac{d F}{d \varepsilon} \cdot \frac{d \varepsilon}{d h_{i}}
$$

From equation (9),

$$
\frac{d H}{d h_{i}}=\frac{H}{h_{i}}
$$

Differentiating equation (11), 


$$
\frac{d \varepsilon}{d H}=\frac{V_{s}}{A \cdot H^{2}}
$$

From equations (16), (15), and (11),

$$
\frac{d \varepsilon}{d h_{i}}=\frac{d \varepsilon}{d H} \cdot \frac{d H}{d h_{i}}=\frac{V_{s}}{A \cdot H \cdot h_{i}}=\frac{1-\varepsilon}{h_{i}}
$$

Differentiating equation (8),

$$
\frac{d F}{d \varepsilon}=-\left(\frac{\pi \cdot d_{p}^{3}}{6}\right) \cdot\left(150 \cdot \frac{U_{m f} \cdot \mu}{d_{p}{ }^{2}} \cdot \frac{3-2 \cdot \varepsilon}{\varepsilon^{4}}+1.75 \cdot \frac{\rho_{g} \cdot U_{m f}{ }^{2}}{d_{p}} \cdot \frac{3}{\varepsilon^{4}}\right)
$$

Substituting (17) and (18) into equation (14),

$$
\omega_{i}{ }^{2}=\frac{3}{\rho_{s} \cdot h_{i}} \cdot\left(150 \cdot \frac{U_{m f} \cdot \mu}{d_{p}{ }^{2}} \cdot \frac{(1-\varepsilon) \cdot(3-2 \cdot \varepsilon)}{3 \cdot \varepsilon^{4}}+1.75 \cdot \frac{\rho_{g} \cdot U_{m f}{ }^{2}}{d_{p}} \cdot \frac{1-\varepsilon}{\varepsilon^{4}}\right)
$$

Therefore:

$$
\omega_{i}=C_{1} \cdot h_{i}^{-0.5}
$$

where

$$
C_{1}=\sqrt{\frac{3}{\rho_{s}}\left(150 \cdot \frac{U_{m f} \cdot \mu}{d_{p}{ }^{2}} \cdot \frac{(1-\varepsilon) \cdot(3-2 \cdot \varepsilon)}{3 \cdot \varepsilon^{4}}+1.75 \cdot \frac{\rho_{g} \cdot U_{m f}{ }^{2}}{d_{p}} \cdot \frac{1-\varepsilon}{\varepsilon^{4}}\right)}
$$

This shows that the natural frequency of a particle depends on its height in the bed. It is obvious that the bed will tend to oscillate at an overall mean frequency as the bed is "pulled into tune". Hiby estimates this mean frequency by summing up a weighted average based on the amplitude of oscillation of each layer of particles.

$$
\omega_{m}=\frac{\int_{0}^{H} C_{1} \cdot h^{-0.5} d h}{\int_{0}^{H} h d h}=\frac{4}{3} \cdot C_{1} \cdot H^{-0.5}
$$

therefore,

$$
\omega_{m}=\frac{4}{3} \sqrt{\frac{3}{\rho_{s} \cdot H} \cdot\left(150 \cdot \frac{U_{m f} \cdot \mu}{d_{p}{ }^{2}} \cdot \frac{(1-\varepsilon) \cdot(3-2 \cdot \varepsilon)}{3 \cdot \varepsilon^{4}}+1.75 \cdot \frac{\rho_{g} \cdot U_{m f}{ }^{2}}{d_{p}} \cdot \frac{1-\varepsilon}{\varepsilon^{4}}\right)}
$$

and converting to cycles per second $(\mathrm{Hz})$,

$$
v_{m}=\frac{2}{3 \cdot \pi} \sqrt{\frac{3}{\rho_{s} \cdot H} \cdot\left(150 \cdot \frac{U_{m f} \cdot \mu}{d_{p}{ }^{2}} \cdot \frac{(1-\varepsilon) \cdot(3-2 \cdot \varepsilon)}{3 \cdot \varepsilon^{4}}+1.75 \cdot \frac{\rho_{g} \cdot U_{m f}{ }^{2}}{d_{p}} \cdot \frac{1-\varepsilon}{\varepsilon^{4}}\right)}
$$


Hiby develops an equation identical to equation 24 except that $v_{\mathrm{m}}$ is a function of $U$ rather than $\mathrm{U}_{\mathrm{mf}}$. Using some algebraic manipulation, and an approximation he arrives at a simplified equation of the form shown in equation 28 below. By initially using the better assumption of $U_{\mathrm{mf}}$ rather than $U$ in equation 7 the following relations can be used to simplify the equation 24 . For Rep < 20 the first term within the bracket dominates and $U_{\mathrm{mf}}$ can be estimated,

$$
U_{m f}=\frac{d_{p}{ }^{2} \cdot \rho_{s} \cdot g}{150 \cdot \mu} \frac{\varepsilon_{m f}{ }^{3}}{1-\varepsilon_{m f}}
$$

Assuming $\varepsilon_{\mathrm{mf}} \approx \varepsilon$, the natural frequency from (24) would reduce to:

$$
v_{m}=\frac{2}{3 \cdot \pi} \sqrt{\frac{g}{H} \cdot\left(\frac{(3-2 \cdot \varepsilon)}{\varepsilon}\right)}
$$

For $\operatorname{Rep}>20$ the second term within the bracket dominates and $\mathrm{U}_{\mathrm{mf}}$ can be estimated,

$$
U_{m f}=\sqrt{\frac{d_{p} \cdot \rho_{s} \cdot g \cdot \varepsilon_{m f}^{3}}{1.75 \cdot \rho_{g}}}
$$

Again, assuming $\varepsilon_{\mathrm{mf}} \approx \varepsilon$, the natural frequency from (24) would reduce to:

$$
v_{m}=\frac{2}{3 \cdot \pi} \sqrt{\frac{3 \cdot g}{H} \cdot\left(\frac{1-\varepsilon}{\varepsilon}\right)}
$$

For this study $\mathrm{Re}_{\mathrm{p}}$ is significantly less than twenty and Equation (26) should predict the frequency of oscillation for shallow fluidized beds. Figures 32 and 33 demonstrate that equation 26 more accurately predicts the observed natural frequency than any previously proposed model. The error in Hiby's derivation is made evident as he tries to address his relations dependence on $U$ and $d_{p}[9]$. According to his theory, the superficial velocity and the particle diameter would have a significant effect on the observed frequency. Using his relation, for laminar conditions of flow, $v_{\mathrm{m}}$ $\sim \mathrm{U}^{-0.31}$ and $\mathrm{v}_{\mathrm{m}} \sim \mathrm{d}_{\mathrm{p}}{ }^{-1}$. For turbulent conditions $\mathrm{v}_{\mathrm{m}} \sim \mathrm{U}^{-1}$ and $\mathrm{v}_{\mathrm{m}} \sim \mathrm{d}_{\mathrm{p}}{ }^{-0.5}$. These predictions are contrary to experimental observations which show frequency to be independent of $U$ and $d_{p}$. 


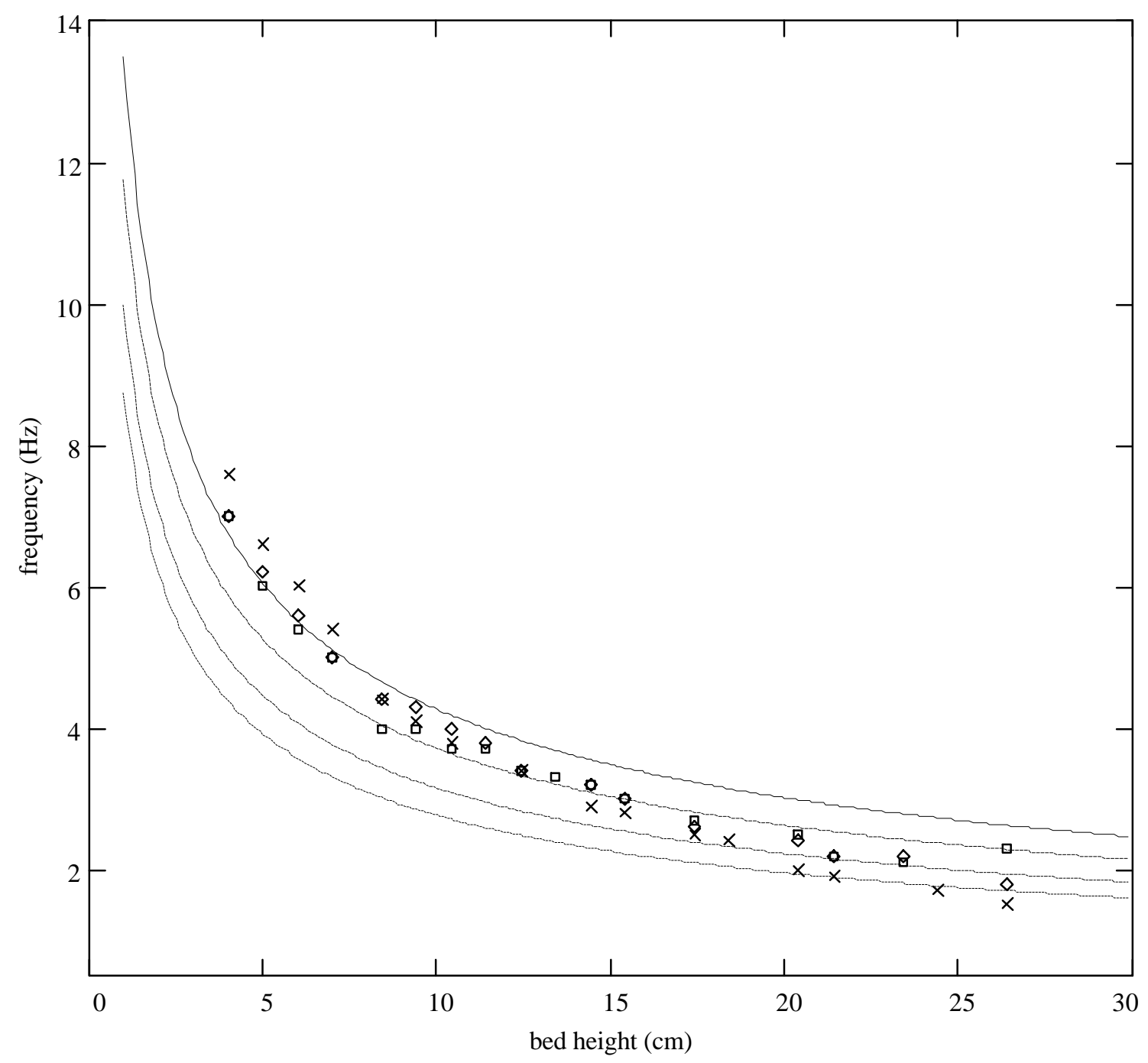

- Modified Hiby derivation for laminar conditions

- Hiby (1967) - fluidization approximation

- Verloop \& Heertjes (1974)

- Baskakov (1986)

$\times 0.2 \mathrm{~mm}$ glass beads

$\diamond 0.3 \mathrm{~mm}$ glass beads

- $0.4 \mathrm{~mm}$ glass beads

Figure 32: Comparison of modified Hiby model to experimental data ( $D=4.0$ ") Frequency vs. only the lowest dominant BFB frequency observed 


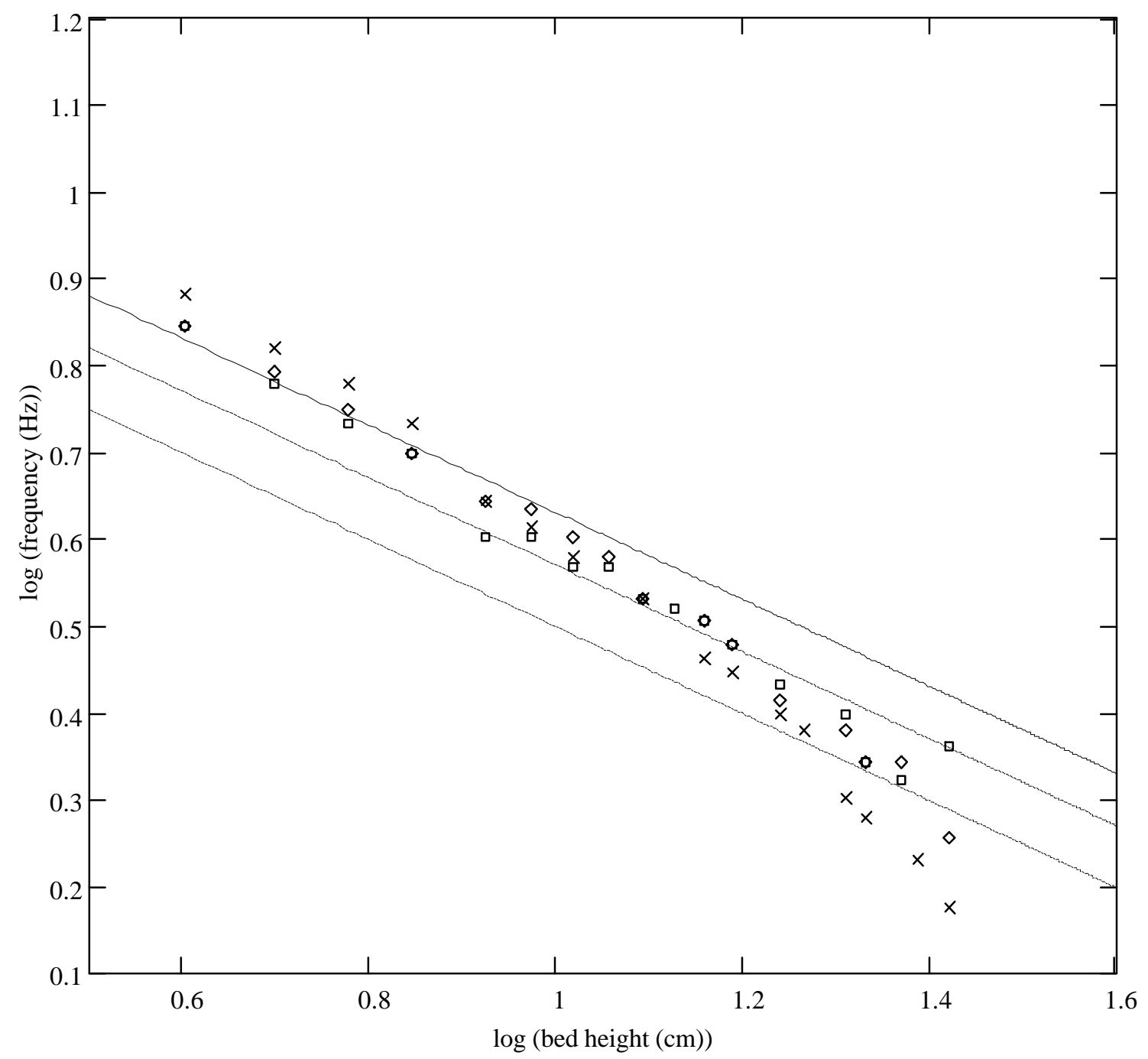

- Modified Hiby

- Hiby (1967)

- Baskakov (1986)

$\times 0.2 \mathrm{~mm}$ glass beads

$\diamond 0.3 \mathrm{~mm}$ glass beads

- $0.4 \mathrm{~mm}$ glass beads

Figure 33: $\quad \log -\log$ comparison of modified Hiby model to experimental data $(\mathrm{D}=4.0$ ") $\log$ (frequency) vs. $\log$ (only the lowest dominant BFB frequency observed) 
In addition to establishing that the modified Hiby relation better predicts the observed natural frequency of the bed, it is evident from the derivation of this dynamic model that pressure fluctuations will exhibit second order behavior. From Newton's second law on a single particle with $\mathrm{u}(\mathrm{t})$ as the white noise forcing function and neglecting damping mechanisms:

$$
\frac{d h^{2}(t)}{d t^{2}}+\omega^{2} h_{i}(t)=u(t)
$$

Knowing that the change in position is proportional to the change in voidage, and the change in voidage proportional to the change in pressure drop.

$$
\frac{d \Delta p^{2}(t)}{d t^{2}}+\omega^{2} \Delta p(t)=u(t)
$$

The modified Hiby relation satisfies the two important criteria for a global dynamic model of shallow fluidized bed systems. It not only predicts well the dominant frequency, but also provides an explanation for the second order pressure fluctuation response observed. The first peak observed in the frequency spectrum is the result of this natural bed frequency.

The second dominant peak that appears in the spectrum of deep beds represents the interference of the surface eruption frequency with the natural bed frequency. Due to the increased coalescence of bubbles, the surface dynamics become more pronounced and nearly equal in magnitude to the natural bed fluctuations. This surface phenomena will have two effects. First, as seen in Figures 3 and 4, this frequency of surface eruption is propagated down throughout the bed and can be observed simultaneously interfering with the pressure fluctuations of the lower bed region. The higher frequency spikes in the spectrum are the result of simultaneously measuring the natural and surface fluctuations which are not acting in phase. Secondly, as this surface phenomena becomes more pronounced, and as bubble coalescence produces surface eruptions at a frequency lower than the natural frequency, this effect begins to pull the natural frequency "out of tune with the bed height" to a lower frequency. This is why the experimental results begin to deviate from the proposed model in Figures 32 and 33 at heights of around $10 \mathrm{~cm}$. The observed frequency continues to deviate to a greater extent from its predicted value as the bed height and corresponding coalescence continues to increase. In the case of very tall and narrow beds, a third, even higher, frequency peak can be observed in the spectrum. This 
high frequency is always observed at twice the frequency of the natural bed frequency. It is possible that this is a harmonic overtone of this fundamental natural frequency.

\section{Surface Waves in Fluidized Bed Systems}

In addition to the voidage waves reported and discussed previously, another second order phenomenon that may be responsible for pressure fluctuations in fluidized beds is surface waves analogous to surface waves observed in water. As proposed by Sun et. al [12], since the hydrodynamics of fluidized bed systems exhibit many of the characteristics of liquid, surface waves are expected in a fluidized bed. Water waves are classified according to the ratio of water depth $(H)$ to wave length $(\lambda)[13]$. For $H / \lambda<1 / 20$, the waves are termed shallow waves and the frequency is dependent on both the water depth and wave length. For shallow waves, the governing wave equation (presented by Sun [12]) reduces to a simplified relation that can be used to estimate the wave frequency:

$$
\omega=\frac{\sqrt{g H}}{\lambda}
$$

For intermediate depth waves $1 / 20>\mathrm{H} / \lambda<1 / 2$, the wave equation cannot be reduced to a simple expression for wave frequency, and must be estimated as:

$$
\omega=\frac{1}{2 \cdot \pi} \sqrt{\left[\frac{g}{\lambda \cdot 2 \cdot \pi} \cdot \tanh \left(\frac{2 \cdot \pi}{\lambda} \cdot H\right)\right]}
$$

For deep waves $(H / \lambda>1 / 2)$, the wave equation can be again be simplified and the frequency is only dependent on the wavelength and can be estimated as:

$$
\omega=\sqrt{\frac{g}{2 \pi \lambda}}
$$

For surface waves in a cylindrical container the wavelength is determined by the container diameter:

$$
D=\frac{n}{2} \lambda
$$

where $\mathrm{n}$ is an integer greater than zero. The fundamental frequency is represented by $\mathrm{n}=1$, with overtones represented by higher integer values. Assuming that a half-wave is established in the bed $(\lambda / 2=\mathrm{D})$ the deep wave frequency in a fluidized bed could be estimated as: 


$$
\omega=\sqrt{\frac{g}{4 \pi D}}
$$

This surface wave phenomenon provides additional insight into the pressure dynamics of both turbulent (transition regime) and circulating beds.

\section{The Use of Pressure Fluctuations to Validate Similitude Parameters}

Glicksman $[14,15]$ has done the most extensive research on the subject of similitude in fluidized bed systems. Using both the Buckingham Pi theorem and derivations based on fundamental equations of motion, Glicksman proposes a set of similitude parameters that govern fluidization. Glicksman assumes that if the PSDs or PDFs of pressure fluctuations match between model and prototype, then the fluidized beds are in hydrodynamic similitude. However, he does not distinguish the important characteristics of the PSD that must match in order for two beds to be governed by similar dynamics. Particularly in CFBs, Glicksman's data does not show the important spectral characteristics in the PSD due to inadequate data sampling. Furthermore, Glicksman never questioned whether pressure fluctuations were correlated to the hydrodynamic state of a fluidized bed. In addition to relating Bode plot characteristics to physical phenomena in fluidized beds, a secondary goal of this study is to reassess whether pressure fluctuations can be used to validate proposed $\mathrm{BFB}$ and $\mathrm{CFB}$ similitude parameters.

\section{$\underline{\text { BFB Similitude }}$}

The Buckingham Pi theorem will be used to develop the important non-dimensional fluidized bed parameters. Using the frequency of pressure fluctuations as the dependent parameter, all independent variables important for bubbling fluidization can be defined:

$$
\omega=f\left(U, g, D, H, d_{p}, \rho_{s}, \rho_{g}, \mu, \phi\right)
$$

The dimensions are as follows:

$$
\begin{array}{llll}
{[\omega]=1 / \mathrm{T}} & {[\mathrm{U}]=\mathrm{L} / \mathrm{T}} & {[\mathrm{g}]=\mathrm{L} / \mathrm{T}^{2}} & {[\mathrm{D}]=\mathrm{L}} \\
{[\mathrm{H}]=\mathrm{L}} & {\left[\mathrm{d}_{\mathrm{p}}\right]=\mathrm{L}} & {\left[\rho_{\mathrm{s}}\right]=\mathrm{M} / \mathrm{L}^{3}} & {\left[\rho_{\mathrm{g}}\right]=\mathrm{M} / \mathrm{L}^{3}} \\
{[\mu]=\mathrm{M} / \mathrm{LT}} & {[\phi]=1} & &
\end{array}
$$

If we choose $\mathrm{U}, \mathrm{d}_{\mathrm{p}}$, and $\rho_{\mathrm{g}}$ as the dimensionally independent parameters the remaining variables can be non-dimensionalized based on these variables. 


$$
\begin{array}{lll}
g \rightarrow \frac{g \cdot d_{p}}{U^{2}} & H \rightarrow \frac{H}{d_{p}} & D \rightarrow \frac{D}{d_{p}} \\
\rho_{s} \rightarrow \frac{\rho_{s}}{\rho_{g}} & \mu \rightarrow \frac{\mu}{\rho_{g} \cdot U \cdot d_{p}} & \omega \rightarrow \omega \cdot \frac{d_{p}}{U}
\end{array}
$$

Recognizing the dimensionless $g$ and $\mu$ as the inverse of the Froude number and Reynolds number respectively the full set of dimensionless parameters as Glicksman defines them is:

$$
F r=\frac{U^{2}}{g \cdot d_{p}} \quad \frac{H}{d_{p}} \quad \frac{D}{d_{p}} \quad \frac{\rho_{g}}{\rho_{s}} \quad \operatorname{Re}_{p}=\frac{\rho_{g} \cdot U \cdot d_{p}}{\mu}
$$

Also, it is more convenient to modify the dependent frequency spectrum parameter by multiplying by other dimensionless groupings as shown below.

$$
\omega \cdot \frac{d_{p}}{U} \Rightarrow \omega \cdot \frac{d_{p}}{U} \times \sqrt{\frac{U^{2}}{g \cdot d_{p}}} \times \sqrt{\frac{H}{d_{p}}} \Rightarrow \omega \cdot \sqrt{\frac{H}{g}}
$$

By matching the dimensionless parameters in a $10.2 \mathrm{~cm} \mathrm{BFB}$ and a $5.1 \mathrm{~cm}$ pressurized $\mathrm{BFB}$, the corresponding non-dimensionalized Bode plots can be compared.

Another important dependent variable that should be compared in fluidized bed systems is the pressure drop per unit length. Non-dimensionalizing this dependent variable via the same Buckingham Pi approach used above yields:

$$
\frac{\Delta P}{L}=\rho_{s} \cdot(1-\varepsilon) \cdot g \Rightarrow \rho_{s} \cdot(1-\varepsilon) \cdot g \cdot \frac{D}{U^{2} \cdot \rho_{f}}=\frac{\rho_{s}}{\rho_{f}}(1-\varepsilon) \cdot F r \Rightarrow(1-\varepsilon)
$$

In addition to the Bode plot profiles of pressure fluctuations being similar, the local voidage measured in the fluidized bed should be equal.

Using the full set of dimensionless parameters should result in similitude; however, it becomes difficult to scale very large fluidized beds to the laboratory scale. Considering that solids in industrial fluidized beds are already very small, scaling with the $D / d_{p}$ parameter becomes very difficult.

Glicksman et al. [16] propose that since the Ergun equation approximately represents the drag forces and at low Reynolds number the Ergun equation reduces to its first set of terms, matching $\mathrm{U} / \mathrm{U}_{\mathrm{mf}}$, voidage, and Froude number guarantees that the drag is identical. With this assumption, the full set of dimensionless parameters reduces to: 


$$
F r=\frac{U^{2}}{g \cdot D}, \quad \frac{\rho_{s}}{\rho_{g}}, \quad \frac{U}{U_{m f}}, \frac{H}{D}, \quad \phi, \quad \text { PSD }
$$

Using this simplified set of parameters increases the flexibility in the design of a model to simulate a prototype reactor. With the full set of parameters, after the model fluidizing gas properties are chosen, there exists only one set of particle size and density, bed size, and gas velocity which can be used in the model. Using the simplified set, fixing the fluidizing gas properties only fixes the particle density in the model. The model size can be changed as long as the velocity is adjusted to keep the Froude number constant. A particle size is then picked to keep $\mathrm{U} / \mathrm{U}_{\mathrm{mf}}$ constant.

Scaling large industrial units to small laboratory scale units can still be difficult with Glicksman's reduced set. Large changes in bed diameter will require reductions in the superficial velocity to keep the Froude number constant. Velocity reductions require smaller particle sizes to keep $\mathrm{U} / \mathrm{U}_{\mathrm{mf}}$ constant. If the diameter change between prototype and model is great enough and the particle size in the prototype is small enough, it will become difficult to find particles which are small enough and which fluidize well.

Returning to the full set of similitude parameters (with hydraulic Reynolds number substituted for $\left.\mathrm{D} / \mathrm{d}_{\mathrm{p}}\right)$ :

$$
F r=\frac{U^{2}}{g \cdot d_{p}} \quad \frac{H}{D} \quad \operatorname{Re}_{H}=\frac{\rho_{g} \cdot U \cdot D}{\mu} \quad \frac{\rho_{g}}{\rho_{s}} \quad \operatorname{Re}_{p}=\frac{\rho_{g} \cdot U \cdot d_{p}}{\mu}
$$

Based on the knowledge that at high hydraulic Reynolds numbers inertial forces in the gas flow dominate frictional forces at the wall, an argument for dropping the hydraulic Reynolds number can be made. The friction factor in a pipe becomes essentially independent of hydraulic Reynolds number at sufficiently high values of hydraulic Reynolds number [17], thus changing the bed diameter at high values of hydraulic Reynolds number will not affect the overall fluidized bed hydrodynamics. With this simplification, the set of similitude parameters reduces to:

$$
F r=\frac{U^{2}}{g \cdot d_{p}} \quad \frac{H}{D} \quad \frac{\rho_{g}}{\rho_{s}} \quad \operatorname{Re}_{p}=\frac{\rho_{g} \cdot U \cdot d_{p}}{\mu}
$$

This simplified set relaxes the constraint on the ratio of particle diameter to bed diameter as long as the hydraulic Reynolds number is high in both the model and prototype bed. 
With this simplification, scaling the bed becomes a matter of matching the density ratios and choosing appropriate velocities and particle diameters based on the fluidizing gas viscosities. It can be shown based on the above similitude parameters, the following relations apply for similitude:

$$
\frac{\rho_{s 1}}{\rho_{s 2}}=\frac{\rho_{g 1}}{\rho_{g 2}} \quad \frac{U_{1}}{U_{2}}=\left(\frac{v_{1}}{v_{2}}\right)^{\frac{1}{3}} \quad \frac{d_{p 1}}{d_{p 2}}=\left(\frac{v_{1}}{v_{2}}\right)^{\frac{2}{3}}
$$

where $v$ is the kinematic viscosity of the fluidizing gas.

\section{Transition Regime Fluctuations}

Pressure fluctuations in the transition regime provide an important link between the nature of fluctuations in bubbling and circulating beds. Depending on the diameter of the bed, this regime can be described as a slugging or turbulent bed. The Bode plots throughout this regime continue to represent the output of multiple second order systems (i.e. a $-40 \mathrm{~dB} /$ decade asymptotic slope). As previously shown, the frequency of voidage waves in BFB pressure fluctuations stays relatively constant as the superficial velocity increases. This holds true in the transition regime even as the bed approaches the fast fluidization regime (U/Umf $>20.0$ for the prototype BFB). This is shown in Figure 34 which plots the observed frequencies versus $U / U_{m f}$ for the transition regime. The surface eruption frequency phenomena observed in bubbling fluidized beds is also observed in the transition regime. This surface eruption frequency approaches the voidage wave frequency as the superficial velocity increases. At high velocities near fast fluidization, these two frequencies become nearly impossible to differentiate.

An interesting result observed in Figure 34, is that an additional frequency peak, that is nearly non-existent in BFBs, begins to appear in the spectrum of transition regime beds at a frequency of $0.9 \mathrm{~Hz}$ in the prototype. This frequency (although significantly damped) is seen first in the pressure fluctuations recorded immediately above the bed surface as the bed moves from bubbling to fast fluidization. At $\mathrm{U} / \mathrm{Umf}>18$ this frequency is observed in the bed fluctuation 


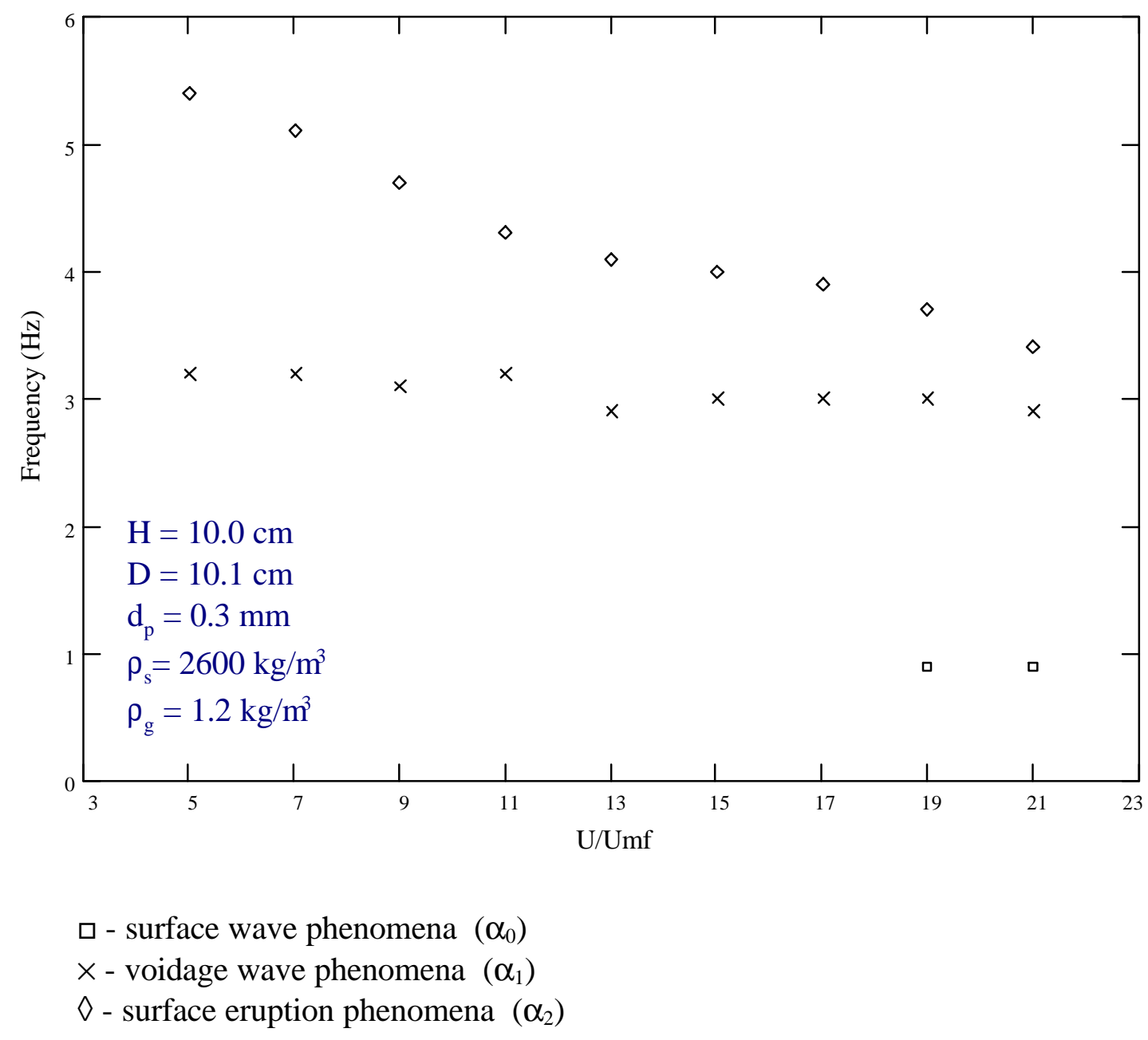

Figure 34: Dominant frequencies observed in turbulent bed pressure fluctuations (measured at $50 \%$ bed height) 
measurements as well. This suggests that this phenomenon is not solely a characteristic of fast fluidization. As the superficial velocity increases in the transition regime, a well defined bed surface is no longer observed. While some bubbles are still observed propagating through the system, the predominant motion of the bed is the sloshing motion at the surface. This sloshing motion increases in magnitude until, near the fast fluidization regime, some particles are projected 1-3 m above the original surface of the bed. Visually it is easy to relate such a motion to the wave behavior of a liquid.

According to surface wave theory, deep beds should exhibit a wave frequency inversely proportional to $\sqrt{D}$. For the prototype BFB, the predicted frequency for surface waves is 0.45 $\mathrm{Hz}$ for the fundamental, and $0.9 \mathrm{~Hz}$ for the first harmonic. For the model $\mathrm{BFB}$, the predicted frequency is $0.65 \mathrm{~Hz}$ for the fundamental, and $1.3 \mathrm{~Hz}$ for the first harmonic. These values correspond closely to the frequency measured in fluidized systems approaching the fast fluidization regime for both the model and the prototype.

In summary, the voidage fluctuation phenomena and the surface eruption frequency (seen previously in BFB Bode plots) are observed throughout the transition from turbulent to fast fluidization. A surface wave phenomenon with its corresponding harmonics can be observed near the onset of fast fluidization.

\section{Validation of BFB similitude parameters}

Table 3 summarizes the results from a similitude study on the prototype and model bubbling fluidized beds over a broad range of operating conditions. The table indicates which experiments resulted in similar Bode plot profiles in the prototype and model. For hydrodynamics to be considered similar, the voidage must be equal in the two beds. Also, the dimensionless frequency and damping of the observed peaks in the fluctuation spectrum must match. The damping coefficients and system frequencies were quantitatively estimated by fitting multiple second order systems (acting in parallel) to the BFB Bode plots, as was done in previous work [18]. Table 3 rates the degree of similarity between the important dependent parameters in the prototype and model BFB under similitude. The rating for each observed frequency includes both a comparison of the damping and a comparison of the dimensionless frequency. The table includes the complete set of independent dimensionless parameters used in each run. The percent 
Table 3. Summary of BFB similitude study

\begin{tabular}{|l|l|l|l|l|l|l|l|l|l|l|l|}
\hline Exp. \# & $\mathrm{U} / \mathrm{U}_{\mathrm{mf}}$ & $\mathrm{Re}_{\mathrm{p}}$ & $\mathrm{Fr}$ & $\rho_{\mathrm{s}} / \rho_{\mathrm{g}}$ & $\mathrm{H} / \mathrm{D}$ & $\mathrm{D} / \mathrm{d}_{\mathrm{p}}$ & $\% \mathrm{H}$ & $\varepsilon$ & $\alpha_{1}$ & $\alpha_{2}$ & $\alpha_{0}$ \\
\hline & & & & & & & & & & & \\
\hline 1 & 1.1 & 4.1 & 5.9 & 2.2 & 1.06 & 254 & 100 & N/A & $* *$ & $* *$ & - \\
\hline 2 & 1.1 & 4.0 & 5.9 & 2.2 & 1.06 & 254 & 100 & N/A & $* *$ & $* *$ & - \\
\hline 3 & 1.4 & 5.4 & 10 & 2.2 & 1.06 & 254 & 100 & N/A & $* *$ & $* *$ & - \\
\hline $4 \mathrm{a}$ & 1.1 & 4.2 & 5.9 & 2.2 & 1.48 & 254 & 68 & $* *$ & $* *$ & - & - \\
\hline $4 \mathrm{~b}$ & 1.1 & 4.2 & 5.9 & 2.2 & 1.48 & 254 & 100 & $* *$ & $*$ & $* *$ & - \\
\hline $5 \mathrm{a}$ & 1.4 & 5.3 & 10 & 2.2 & 1.48 & 254 & 68 & $*$ & $* *$ & $*$ & - \\
\hline $5 \mathrm{~b}$ & 1.4 & 5.3 & 10 & 2.2 & 1.48 & 254 & 100 & N/A & $*$ & $*$ & - \\
\hline $6 \mathrm{a}$ & 1.8 & 6.9 & 16 & 2.2 & 1.48 & 254 & 68 & $* *$ & $* *$ & - & - \\
\hline $6 \mathrm{~b}$ & 1.8 & 6.9 & 16 & 2.2 & 1.48 & 254 & 100 & N/A & $*$ & $* *$ & - \\
\hline $7 \mathrm{a}$ & 1.1 & 4.2 & 5.9 & 2.2 & 1.97 & 254 & 25 & $* *$ & $* *$ & $* *$ & - \\
\hline $7 \mathrm{~b}$ & 1.1 & 4.2 & 5.9 & 2.2 & 1.97 & 254 & 50 & $* *$ & $* *$ & $*$ & - \\
\hline $8 \mathrm{a}$ & 1.4 & 5.3 & 10 & 2.2 & 1.97 & 254 & 25 & $* *$ & $* *$ & $* *$ & - \\
\hline $8 \mathrm{~b}$ & 1.4 & 5.3 & 10 & 2.2 & 1.97 & 254 & 50 & $* *$ & $* *$ & - & - \\
\hline $9 \mathrm{a}$ & 1.8 & 6.9 & 16 & 2.2 & 1.97 & 254 & 25 & $* *$ & $* *$ & - & - \\
\hline $9 \mathrm{~b}$ & 1.8 & 6.9 & 16 & 2.2 & 1.97 & 254 & 50 & $* *$ & $* *$ & - & - \\
\hline 10 & 1.1 & 2.0 & 3.3 & 2.2 & 1.06 & 339 & 100 & N/A & $*$ & $* *$ & - \\
\hline 11 & 1.4 & 2.6 & 5.5 & 2.2 & 1.06 & 339 & 100 & N/A & $* *$ & $* *$ & - \\
\hline 12 & 1.8 & 3.3 & 9 & 2.2 & 1.06 & 339 & 100 & N/A & $*$ & $*$ & - \\
\hline 13 & 2.2 & 4.0 & 13 & 2.2 & 1.06 & 339 & 100 & N/A & $*$ & no & - \\
\hline $14 \mathrm{a}$ & 1.1 & 2.0 & 3.3 & 2.2 & 1.48 & 339 & 68 & $* *$ & $* *$ & $*$ & - \\
\hline $14 \mathrm{~b}$ & 1.1 & 2.0 & 3.3 & 2.2 & 1.48 & 339 & 100 & N/A & $*$ & $*$ & - \\
\hline $15 \mathrm{a}$ & 1.4 & 2.6 & 5.6 & 2.2 & 1.48 & 339 & 68 & $* *$ & $* *$ & $*$ & - \\
\hline $15 \mathrm{~b}$ & 1.4 & 2.6 & 5.6 & 2.2 & 1.48 & 339 & 100 & N/A & $*$ & $*$ & - \\
\hline $16 \mathrm{a}$ & 1.8 & 3.3 & 9 & 2.2 & 1.48 & 339 & 68 & $* *$ & $* *$ & $*$ & - \\
\hline $16 \mathrm{~b}$ & 1.8 & 3.3 & 9 & 2.2 & 1.48 & 339 & 100 & N/A & no & $*$ & no \\
\hline & & & & & & & & &
\end{tabular}

Rating system:

** Dependent parameter identical in prototype and model

* Dependent parameter is approximately the same in prototype and model

no Dependent parameter does not match in prototype and model

$\alpha_{0}$ - surface wave phenomenon

$\alpha_{1}$ - voidage wave phenomenon

$\alpha_{2}$ - surface eruption frequency 
(Table 3 continued)

\begin{tabular}{|l|l|l|l|l|l|l|l|l|l|l|l|}
\hline Exp. \# & $\mathrm{U} / \mathrm{U}_{\mathrm{mf}}$ & $\mathrm{Re}_{\mathrm{p}}$ & $\mathrm{Fr}$ & $\rho_{\mathrm{s}} / \rho_{\mathrm{g}}$ & $\mathrm{H} / \mathrm{D}$ & $\mathrm{D} / \mathrm{d}_{\mathrm{p}}$ & $\% \mathrm{H}$ & $\varepsilon$ & $\alpha_{1}$ & $\alpha_{2}$ & $\alpha_{0}$ \\
\hline & & & & & & & & & & & \\
\hline $17 \mathrm{a}$ & 2.2 & 4.0 & 13 & 2.2 & 1.48 & 339 & 68 & $* *$ & $*$ & $* *$ & $*$ \\
\hline $17 \mathrm{~b}$ & 2.2 & 4.0 & 13 & 2.2 & 1.48 & 339 & 100 & $\mathrm{~N} / \mathrm{A}$ & no & $*$ & no \\
\hline $18 \mathrm{a}$ & 1.1 & 2.0 & 3.3 & 2.2 & 1.97 & 339 & 25 & $*$ & $* *$ & $* *$ & - \\
\hline $18 \mathrm{~b}$ & 1.1 & 2.0 & 3.3 & 2.2 & 1.97 & 339 & 50 & $* *$ & $*$ & $* *$ & - \\
\hline $19 \mathrm{a}$ & 1.4 & 2.6 & 5.5 & 2.2 & 1.97 & 339 & 25 & $* *$ & $* *$ & $* *$ & - \\
\hline $19 \mathrm{~b}$ & 1.4 & 2.6 & 5.5 & 2.2 & 1.97 & 339 & 50 & $* *$ & $*$ & $* *$ & - \\
\hline $20 \mathrm{a}$ & 1.8 & 3.3 & 9 & 2.2 & 1.97 & 339 & 25 & $* *$ & $* *$ & $* *$ & - \\
\hline $20 \mathrm{~b}$ & 1.8 & 3.3 & 9 & 2.2 & 1.97 & 339 & 50 & $* *$ & $*$ & $* *$ & - \\
\hline $21 \mathrm{a}$ & 2.2 & 4.0 & 13 & 2.2 & 1.97 & 339 & 25 & $* *$ & $* *$ & no & no \\
\hline $21 \mathrm{~b}$ & 2.2 & 4.0 & 13 & 2.2 & 1.97 & 339 & 50 & $* *$ & $*$ & $*$ & no \\
\hline $22 \mathrm{a}$ & 1.1 & 0.6 & 1.0 & 2.2 & 1.48 & 508 & 68 & $* *$ & $*$ & no & - \\
\hline $22 \mathrm{~b}$ & 1.1 & 0.6 & 1.0 & 2.2 & 1.48 & 508 & 100 & N/A & no & $*$ & - \\
\hline $23 \mathrm{a}$ & 1.4 & 0.7 & 1.6 & 2.2 & 1.48 & 508 & 68 & $* *$ & $*$ & $*$ & - \\
\hline $23 \mathrm{~b}$ & 1.4 & 0.7 & 1.6 & 2.2 & 1.48 & 508 & 100 & N/A & $*$ & no & - \\
\hline $24 \mathrm{a}$ & 1.8 & 1.0 & 2.7 & 2.2 & 1.48 & 508 & 68 & $* *$ & $*$ & no & - \\
\hline $24 \mathrm{~b}$ & 1.8 & 1.0 & 2.7 & 2.2 & 1.48 & 508 & 100 & N/A & $*$ & no & - \\
\hline $25 \mathrm{a}$ & 1.1 & 0.6 & 1.0 & 2.2 & 1.97 & 508 & 25 & $* *$ & $* *$ & - & - \\
\hline $25 \mathrm{~b}$ & 1.1 & 0.6 & 1.0 & 2.2 & 1.97 & 508 & 50 & $* *$ & $* *$ & - & - \\
\hline $26 \mathrm{a}$ & 1.4 & 0.7 & 1.6 & 2.2 & 1.97 & 508 & 25 & $* *$ & $* *$ & $*$ & - \\
\hline $26 \mathrm{~b}$ & 1.4 & 0.7 & 1.6 & 2.2 & 1.97 & 508 & 50 & $* *$ & $* *$ & $*$ & - \\
\hline $27 \mathrm{a}$ & 1.8 & 0.6 & 2.7 & 2.2 & 1.97 & 508 & 25 & $*$ & $* *$ & $*$ & - \\
\hline $27 \mathrm{~b}$ & 1.8 & 0.6 & 2.7 & 2.2 & 1.97 & 508 & 50 & $* *$ & $* *$ & no & - \\
\hline & & & & & & & & & & \\
\hline
\end{tabular}


height at which the pressure measurement is taken is also given. In general, matching dimensionless parameters in two BFBs results in similar pressure dynamics. The average voidage matches well in both beds under all conditions.

The only exception is that under conditions of relatively high superficial velocity, when pressure fluctuations are measured in the upper regions of the bed, the peaks that result from surface phenomena do not always show similar damping or dimensionless frequency. Evidently, the nature of bubble coalescence in the model and prototype differ as the surface eruptions begins to dominate the spectrum. Observation of the bubbling bed surface confirms the differences. The surface of the small bed is noticeably lifted by large single bubble eruptions, while the prototype surface exhibits multiple bubble eruptions across a more stationary surface.

\section{$\underline{\text { BFB Combustor Similitude Verification }}$}

With a reliable set of scaling parameters, researchers can confidently design and build fluidized bed pilot plants which will scale to large industrial units. To have confidence in similitude, it is important to validate the previously given scaling parameters. Using a $20.32 \mathrm{~cm}$ diameter bubbling fluidized bed combustor, a $10.16 \mathrm{~cm}$ diameter cold $\mathrm{BFB}$, and a $5.08 \mathrm{~cm}$ cold $\mathrm{BFB}$, this study attempts to achieve similitude between a hot BFB combustor and cold BFB.

Only a few researchers have attempted to validate the scaling parameters between hot and cold beds. Fitzgerald et al[19] and Nicastro and Glicksman[4] have applied the scaling rules to small scale fluidized bed combustors. Fitzgerald et al [19], using a $2 \mathrm{~m}$ x 2 m BFB combustor prototype and a $0.46 \mathrm{~m} \times 0.46 \mathrm{~m}$ cold BFB model, concluded that agreement of the autocorrelation plots was insufficient to prove similitude. They suggested that additional unidentified parameters such as electrostatic forces, distributor plate scaling, and/or bed geometry must be important. Nicastro and Glicksman [4] using a $0.61 \mathrm{~m}$ x $0.61 \mathrm{~m} \mathrm{BFB}$ combustor as prototype and a $0.15 \mathrm{~m} \times 0.15 \mathrm{~m}$ cold model concluded that similitude was achieved when the full set of dimensionless parameters were matched. Both researchers use pressure fluctuations to confirm similitude. Fitzgerald used autocorrelation functions, whereas Nicastro and Glicksman used the power spectral density functions.

Nicastro and Glicksman only collect data for 40 to 120 seconds thus missing much of the low frequency phenomena that characterizes fluidized bed fluctuations. The PSD plots presented 
by Nicastro and Glicksman for the combustor (prototype) and cold fluidized bed (model) have neither the same power level nor exactly the same dimensionless frequency. As shown in the methods of analysis section, inadequate data sampling and averaging can lead to misleading results and conclusions. In addition, Nicastro and Glicksman did not specify what constituted a "good match" between model and prototype power spectral plots.

To evaluate similitude between hot and cold fluidized beds, the BFB combustor was fluidized with silica sand with a sphericity of 0.70 . Tests were run with both natural gas and Pittsburgh \#9 coal to test for possible differences in pressure fluctuations resulting from combustion. The conditions of the combustor and subsequent similitude trial are listed in Table 4 . As can be seen in Figures 35 and 36, there is no discernible difference in the structure of the Bode plot for the combustor when fueled with natural gas or coal. The only difference is the slightly larger fluctuations arising from the burning of natural gas.

After repeating the combustor run with different pressure transducers and computers while achieving similar results, similitude was attempted in a $5.08 \mathrm{~cm}$ diameter cold BFB using the full set of scaling parameters. Fluidizing parameters (see Table 4) were calculated to properly scale the $5.08 \mathrm{~cm}$ BFB from the conditions in the combustor using Glicksman's full set of similitude parameters previously listed. From this full set, it was found that copper particles provided a good density match when fluidized with air at ambient conditions. The resulting Bode and PSD plot for the $5.08 \mathrm{~cm}$ diameter BFB as shown in Figure 37

Examining the results for the full set similitude trial as shown in Figure 38 a distinct shift in peak frequency between the combustor and model is seen. On a nondimensional basis, multiplying the frequencies by the square root of bed height divided by g (gravitational constant), the peak frequency changes from 0.35 in the combustor to 0.27 in the model. In addition, a second, but much lower magnitude frequency peak occurs in the cold model at approximately 0.48 that is not seen in the combustor. This second frequency peak, may be the result of flow instabilities in this small bed.

This study's proposed scaling parameter simplification and Glicksman's simplified set of scaling parameters are used to test similitude using a $10.16 \mathrm{~cm}$ bed. The operating conditions are 
Table 4: Bed operating conditions

\begin{tabular}{|c|c|c|}
\hline Combustor - Coal & Combustor - $\mathrm{CH}_{4}$ & \\
\hline $\mathrm{d}_{\mathrm{p}}=0.725 \mathrm{~mm}$ & $\mathrm{~d}_{\mathrm{p}}=0.725 \mathrm{~mm}$ & \\
\hline $\mathrm{D}=20.32 \mathrm{~cm}$ & $\mathrm{D}=20.32 \mathrm{~cm}$ & \\
\hline $\mathrm{L}=18.0 \mathrm{~cm}$ & $\mathrm{~L}=18.0 \mathrm{~cm}$ & \\
\hline $\mathrm{U}=0.494 \mathrm{~m} / \mathrm{s}$ & $\mathrm{U}=0.618 \mathrm{~m} / \mathrm{s}$ & \\
\hline$\rho_{\mathrm{g}}=0.355 \mathrm{~kg} / \mathrm{m}^{3}$ & $\rho_{\mathrm{g}}=0.318 \mathrm{~kg} / \mathrm{m}^{3}$ & \\
\hline$\rho_{\mathrm{s}}=2600 \mathrm{~kg} / \mathrm{m}^{3}$ & $\rho_{\mathrm{s}}=2600 \mathrm{~kg} / \mathrm{m}^{3}$ & \\
\hline $\mathrm{T}=805 \operatorname{deg} \mathrm{C}$ & $\mathrm{T}=782 \operatorname{deg} \mathrm{C}$ & \\
\hline $\mathrm{U} / \mathrm{U}_{\mathrm{mf}}=1.91$ & $\mathrm{U} / \mathrm{U}_{\mathrm{mf}}=2.4$ & \\
\hline $\operatorname{Re}_{p}=2.9$ & $\operatorname{Re}_{p}=3.3$ & \\
\hline $\mathrm{Fr}=34.3$ & $\mathrm{Fr}=53.8$ & \\
\hline$\rho_{\mathrm{s}} / \rho_{\mathrm{g}}=7330$ & $\rho_{\mathrm{s}} / \rho_{\mathrm{g}}=8180$ & \\
\hline $\mathrm{L} / \mathrm{D}=0.89$ & $\mathrm{~L} / \mathrm{D}=0.89$ & \\
\hline $\mathrm{D} / \mathrm{d}_{\mathrm{p}}=280$ & $\mathrm{D} / \mathrm{d}_{\mathrm{p}}=280$ & \\
\hline full set & Glicksman's reduced & $D / d_{p}$ relaxation \\
\hline $5.08 \mathrm{~cm}$ cold $\mathrm{BFB}$ & $\underline{10.16 \mathrm{~cm} \text { cold } \mathrm{BFB}}$ & 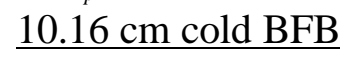 \\
\hline $\mathrm{d}_{\mathrm{p}}=0.200 \mathrm{~mm}$ & $\mathrm{~d}_{\mathrm{p}}=0.238 \mathrm{~mm}$ & $\mathrm{~d}_{\mathrm{p}}=0.200 \mathrm{~mm}$ \\
\hline $\mathrm{D}=5.08 \mathrm{~cm}$ & $\mathrm{D}=10.16 \mathrm{~cm}$ & $\mathrm{D}=10.16 \mathrm{~cm}$ \\
\hline $\mathrm{L}=4.5 \mathrm{~cm}$ & $\mathrm{~L}=8.6 \mathrm{~cm}^{*}$ & $\mathrm{~L}=9.0 \mathrm{~cm}$ \\
\hline $\mathrm{U}=0.247 \mathrm{~m} / \mathrm{s}$ & $\mathrm{U}=0.298 \mathrm{~m} / \mathrm{s}$ & $\mathrm{U}=0.247 \mathrm{~m} / \mathrm{s}$ \\
\hline$\rho_{\mathrm{g}}=1.20 \mathrm{~kg} / \mathrm{m}^{3}$ & $\rho_{\mathrm{g}}=1.20 \mathrm{~kg} / \mathrm{m}^{3}$ & $\rho_{\mathrm{g}}=1.20 \mathrm{~kg} / \mathrm{m}^{3}$ \\
\hline$\rho_{\mathrm{s}}=8930 \mathrm{~kg} / \mathrm{m}^{3}$ & $\rho_{\mathrm{s}}=8930 \mathrm{~kg} / \mathrm{m}^{3}$ & $\rho_{\mathrm{s}}=8930 \mathrm{~kg} / \mathrm{m}^{3}$ \\
\hline $\mathrm{T}=20 \operatorname{deg} \mathrm{C}$ & $\mathrm{T}=20 \operatorname{deg} \mathrm{C}$ & $\mathrm{T}=20 \operatorname{deg} \mathrm{C}$ \\
\hline $\mathrm{U} / \mathrm{U}_{\mathrm{mf}}=1.3$ & $\mathrm{U} / \mathrm{U}_{\mathrm{mf}}=1.9$ & $\mathrm{U} / \mathrm{U}_{\mathrm{mf}}=1.3$ \\
\hline $\operatorname{Re}_{p}=3.2$ & $\operatorname{Re}_{p}=4.7$ & $\operatorname{Re}_{p}=3.2$ \\
\hline $\mathrm{Fr}=31.7$ & $\mathrm{Fr}=38.0$ & $\mathrm{Fr}=31.7$ \\
\hline$\rho_{\mathrm{s}} / \rho_{\mathrm{g}}=7420$ & $\rho_{\mathrm{s}} / \rho_{\mathrm{g}}=7420$ & $\rho_{\mathrm{s}} / \rho_{\mathrm{g}}=7420$ \\
\hline $\mathrm{L} / \mathrm{D}=0.89$ & $\mathrm{~L} / \mathrm{D}=0.85$ & $\mathrm{~L} / \mathrm{D}=0.89$ \\
\hline $\mathrm{D} / \mathrm{d}_{\mathrm{p}}=260$ & $\mathrm{D} / \mathrm{d}_{\mathrm{p}}=426$ & $\mathrm{D} / \mathrm{d}_{\mathrm{p}}=508$ \\
\hline
\end{tabular}

*Bed height was only $8.6 \mathrm{~cm}$ instead of $9.0 \mathrm{~cm}$ due to lack of available material. 

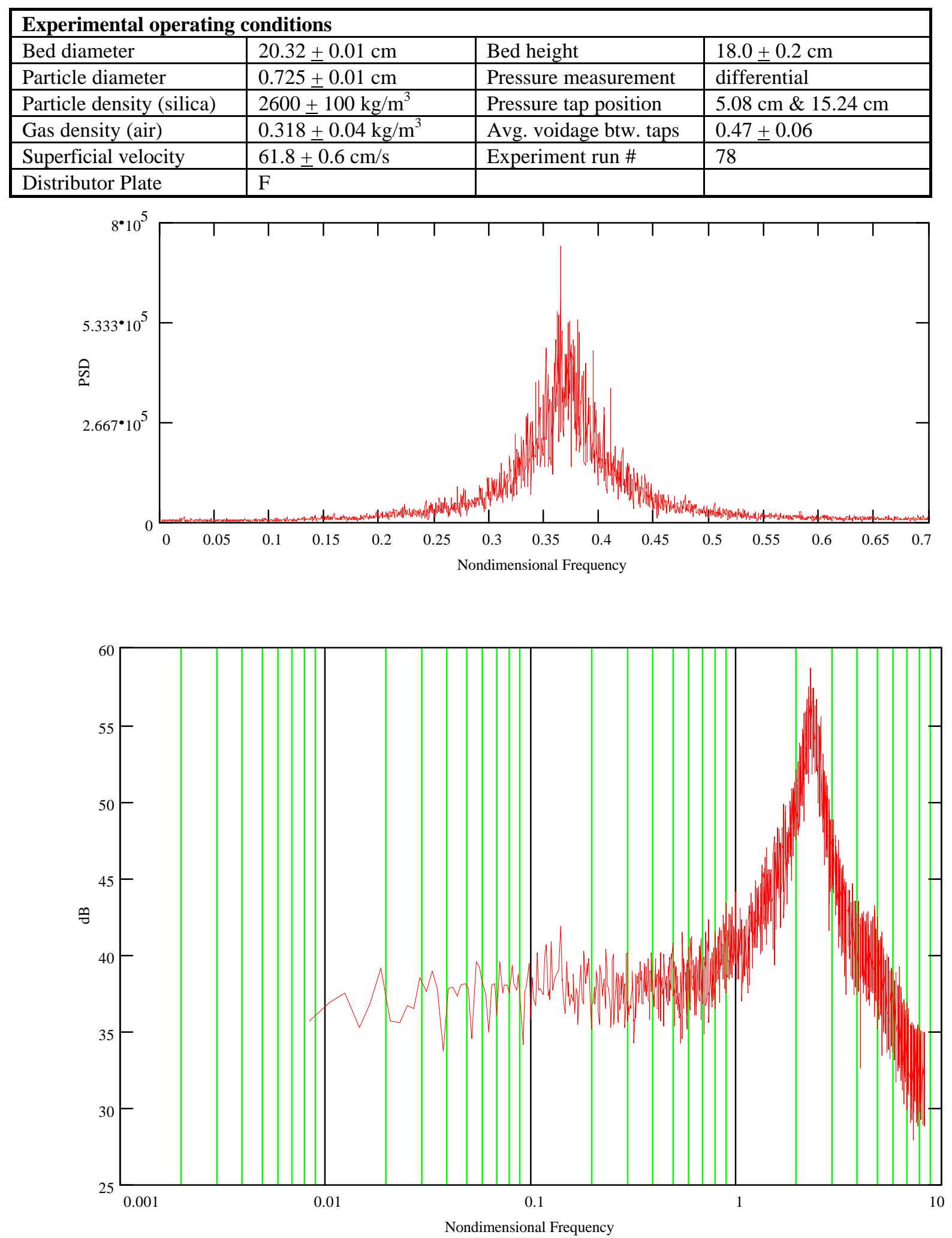

Figure 35: PSD and Bode plot of BFB pressure fluctuations in BFB Combustor $\left(\mathrm{CH}_{4}\right)$ 

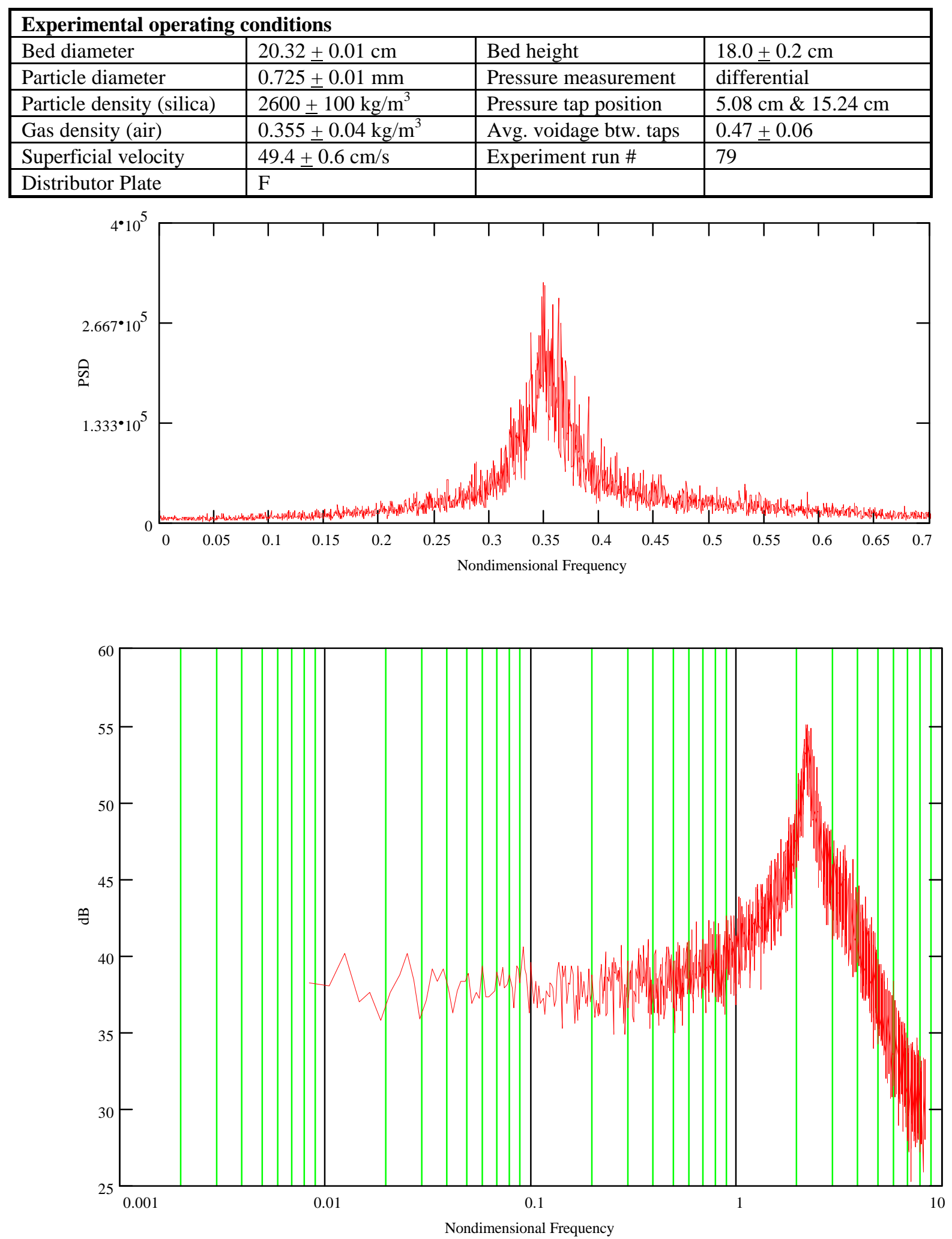

Figure 36: PSD and Bode plot of BFB pressure fluctuations in BFB combustor (coal) 
59
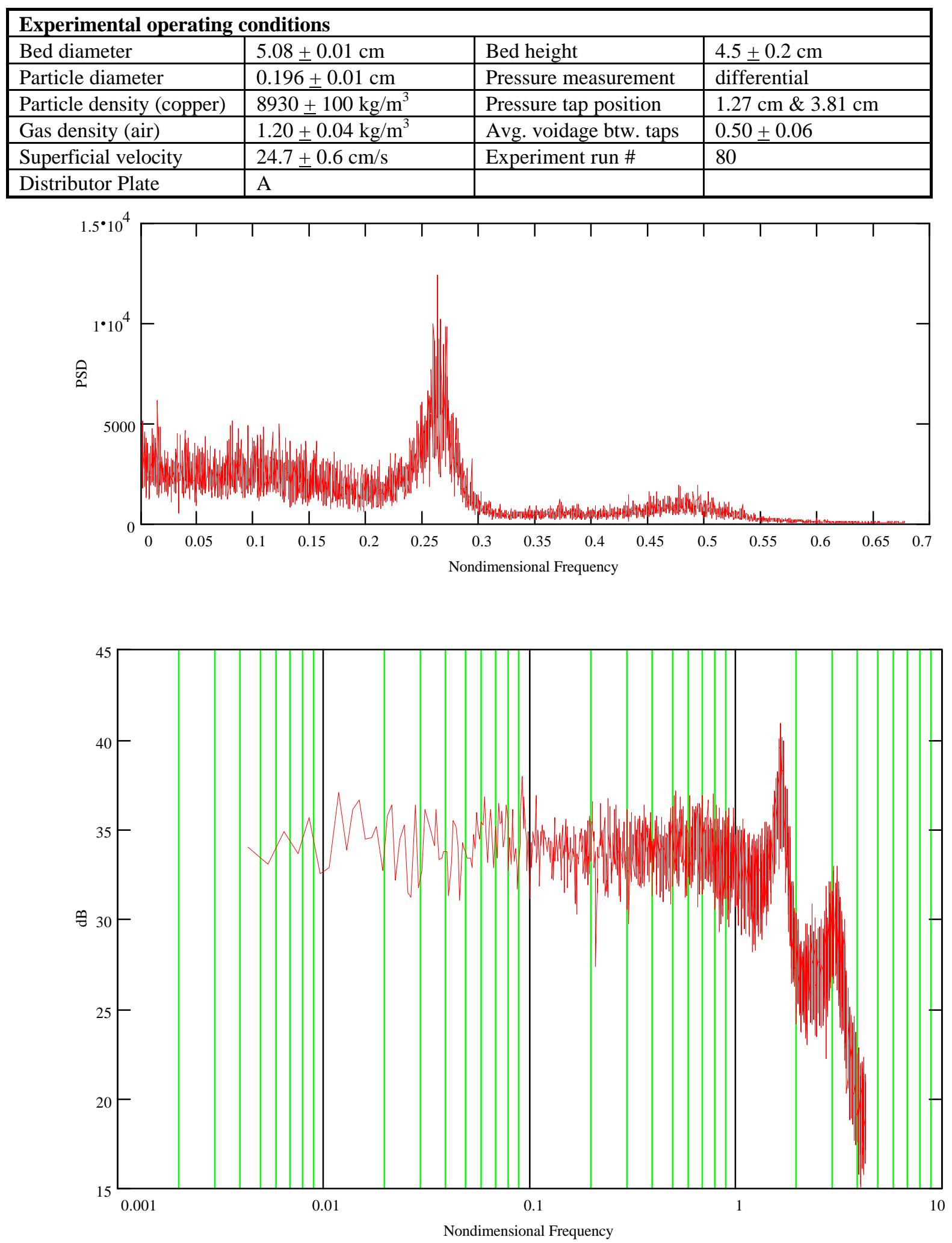

Figure 37: PSD and Bode plot of BFB pressure fluctuations in $5.08 \mathrm{~cm}$ diameter bed full set of similitude parameters 

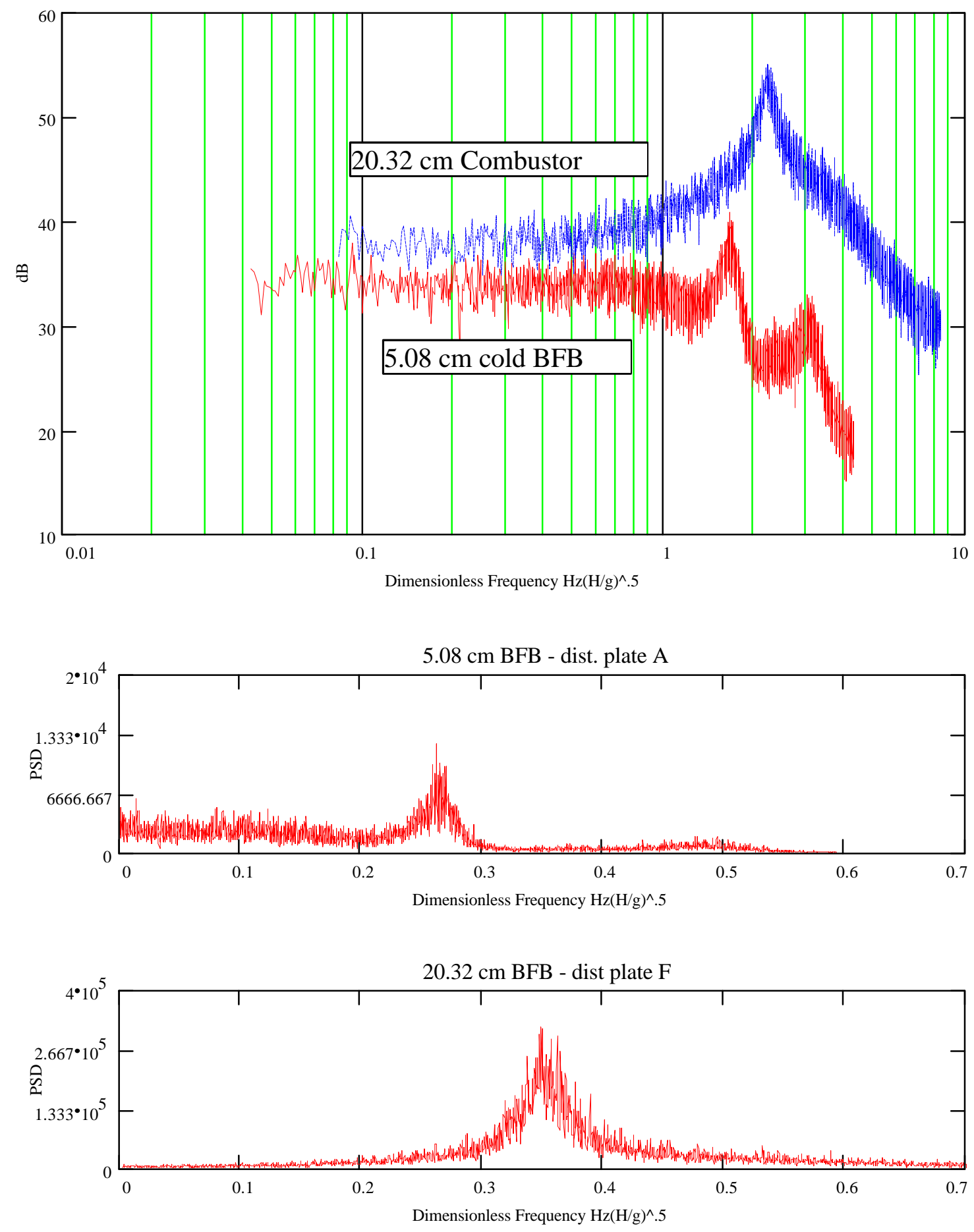

Figure 38: Hot bed similitude with $5.08 \mathrm{~cm}$ cold BFB method: full set scaling parameters comparison of Figure 36 and Figure 37 
listed in Table 4 for both methods of scaling. Using the proposed simplification, the same fluidization conditions exist in the $10.16 \mathrm{~cm}$ bed as exist in the $5.08 \mathrm{~cm}$ bed. This condition is expected as long as the hydraulic Reynolds number is high enough that wall effects can be ignored.

Using Glicksman's reduced set, the $10.16 \mathrm{~cm}$ bed with fluidization air at ambient conditions were selected. With these choices, an appropriate size of size of copper was selected using the Ergun equation to find a particle size with the correct minimum fluidization velocity to match the $\mathrm{U} / \mathrm{U}_{\mathrm{mf}}$ ratio of the combustor. Operating under the fluidization conditions listed in Table 4, the resulting Bode and PSD plot is shown as Figure 39. The comparison for this hot bed similitude is given in Figure 40. The peak frequency for the $10.16 \mathrm{~cm}$ BFB occurs at the nondimensional frequency of 0.27 as it did in the $5.08 \mathrm{~cm} \mathrm{BFB}$, however; a second lower magnitude frequency peak does not occur. Thus the second frequency appears to arise from some flow instability in the smaller bed. This result suggests that very small beds may not be able to achieve similitude even if the full set of dimensionless parameters is used. The magnitude of the fluctuations is much higher than the $5.08 \mathrm{~cm}$ bed which can be attributed to a higher superficial velocity in the bed.

Using this study's proposed relaxation of the $\mathrm{D} / \mathrm{d}_{\mathrm{p}}$ scaling parameter results in Bode plots with nearly the same peak frequency magnitude and fall off slope as the combustor run as shown in Figure 41 and in the similitude comparison shown in Figure 42. As with Glicksman's simplification, the second low magnitude, high frequency peak seen in the $5.08 \mathrm{~cm}$ bed is not present; however, a shift in peak frequency is seen. Assuming pressure fluctuations fully characterize the hydrodynamics of the fluidized beds, one of two things can be concluded. Either none of the cases are in similitude or the method for non-dimensionalizing is in error.

\section{Bubbling Bed Sensitivity Study}

In an attempt to better understand the phenomena seen in the scaling parameter validation study, a parametric study was conducted to look for general trends in the effect of individual parameters. In order to use spectral analysis of pressure fluctuations to confirm similitude, it is important to know the sensitivity of the spectral analysis to individual parameters. Describing the 
62

\begin{tabular}{|l|l|l|l|}
\hline Experimental operating conditions \\
\hline Bed diameter & $10.16 \pm 0.01 \mathrm{~cm}$ & Bed height & $8.6 \pm 0.2 \mathrm{~cm}$ \\
\hline Particle diameter & $0.238 \pm 0.01 \mathrm{~cm}$ & Pressure measurement & differential \\
\hline Particle density (copper) & $8933 \pm 100 \mathrm{~kg} / \mathrm{m}^{3}$ & Pressure tap position & $2.5 \mathrm{~cm} \mathrm{\&} 7.6 \mathrm{~cm}$ \\
\hline Gas density (air) & $1.20 \pm 0.04 \mathrm{~kg} / \mathrm{m}^{3}$ & Avg. voidage btw. taps & $0.49 \pm 0.06$ \\
\hline Superficial velocity & $29.8 \pm 0.6 \mathrm{~cm} / \mathrm{s}$ & Experiment run \# & 98 \\
\hline Distributor Plate & $\mathrm{C}$ & & \\
\hline
\end{tabular}
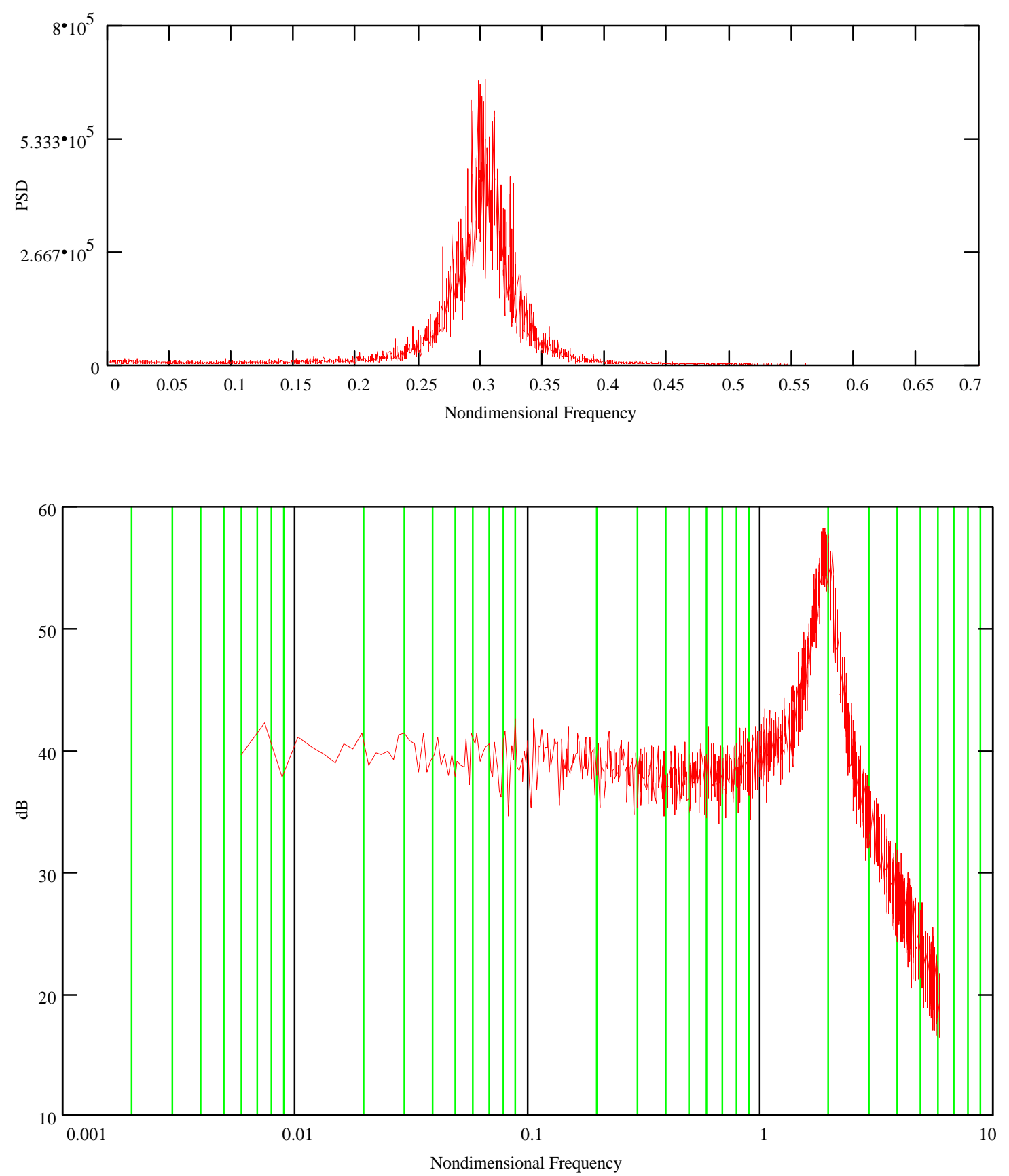

Figure 39: PSD and Bode plot of BFB pressure fluctuations in $10.16 \mathrm{~cm}$ diameter bed Glicksman's reduced set of similitude parameters 

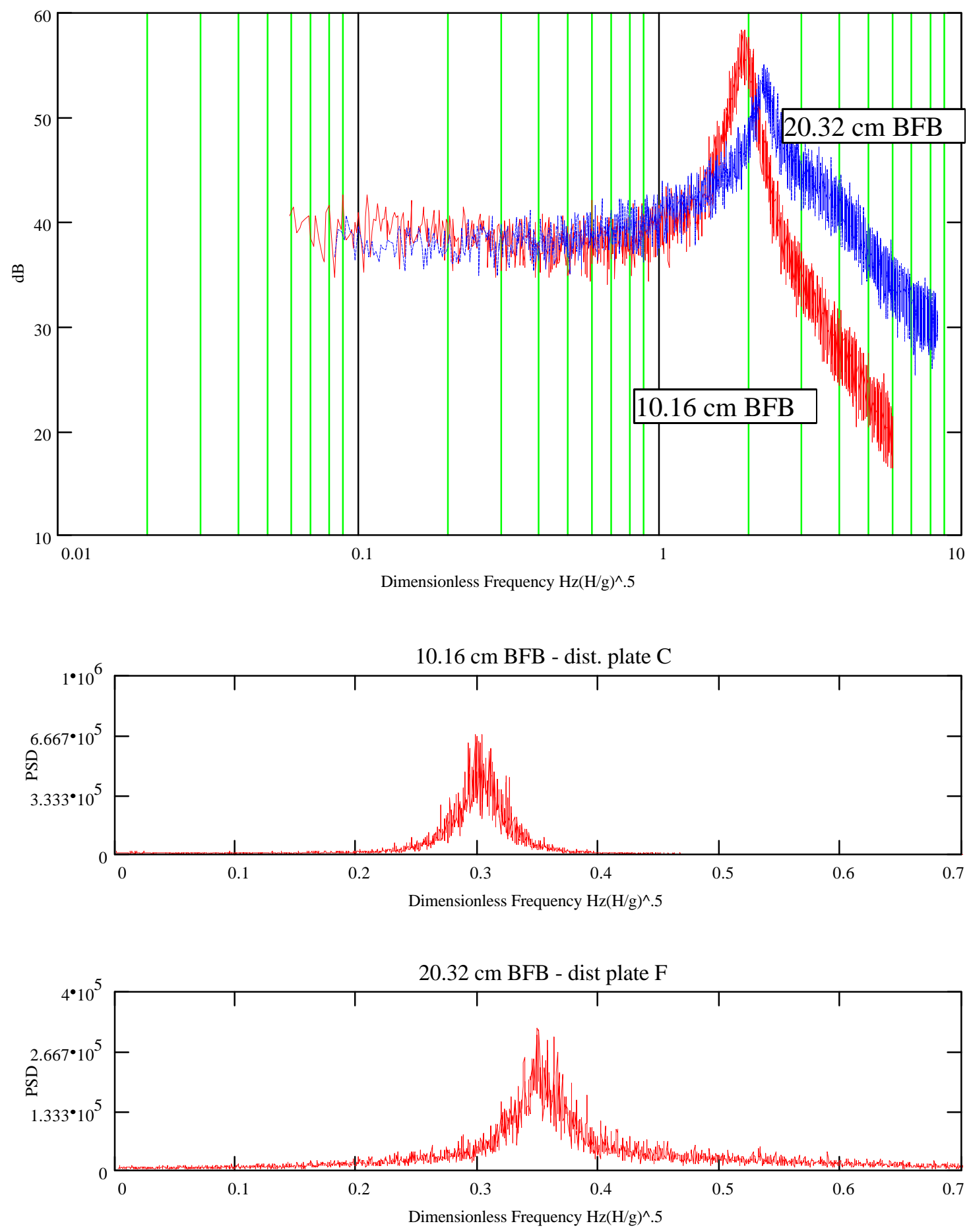

Figure 40: Hot bed similitude with $10.16 \mathrm{~cm}$ cold BFB method: Glicksman's reduced set comparison of Figure 36 and Figure 39 
64

\begin{tabular}{|l|l|l|l|}
\hline \multicolumn{4}{|l|}{ Experimental operating conditions } \\
\hline Bed diameter & $10.16 \pm 0.01 \mathrm{~cm}$ & Bed height & $9.0 \pm 0.2 \mathrm{~cm}$ \\
\hline Particle diameter & $0.18 \pm 0.01 \mathrm{~mm}$ & Pressure measurement & differential \\
\hline Particle density (copper) & $8930 \pm 100 \mathrm{~kg} / \mathrm{m}^{3}$ & Pressure tap position & $2.5 \mathrm{~cm} \& 7.6 \mathrm{~cm}$ \\
\hline Gas density (air) & $1.20 \pm 0.04 \mathrm{~kg} / \mathrm{m}^{3}$ & Avg. voidage btw. taps & $0.53 \pm 0.06$ \\
\hline Superficial velocity & $24.7 \pm 0.6 \mathrm{~cm} / \mathrm{s}$ & Experiment run \# & 100 \\
\hline Distributor Plate & D & & \\
\hline
\end{tabular}
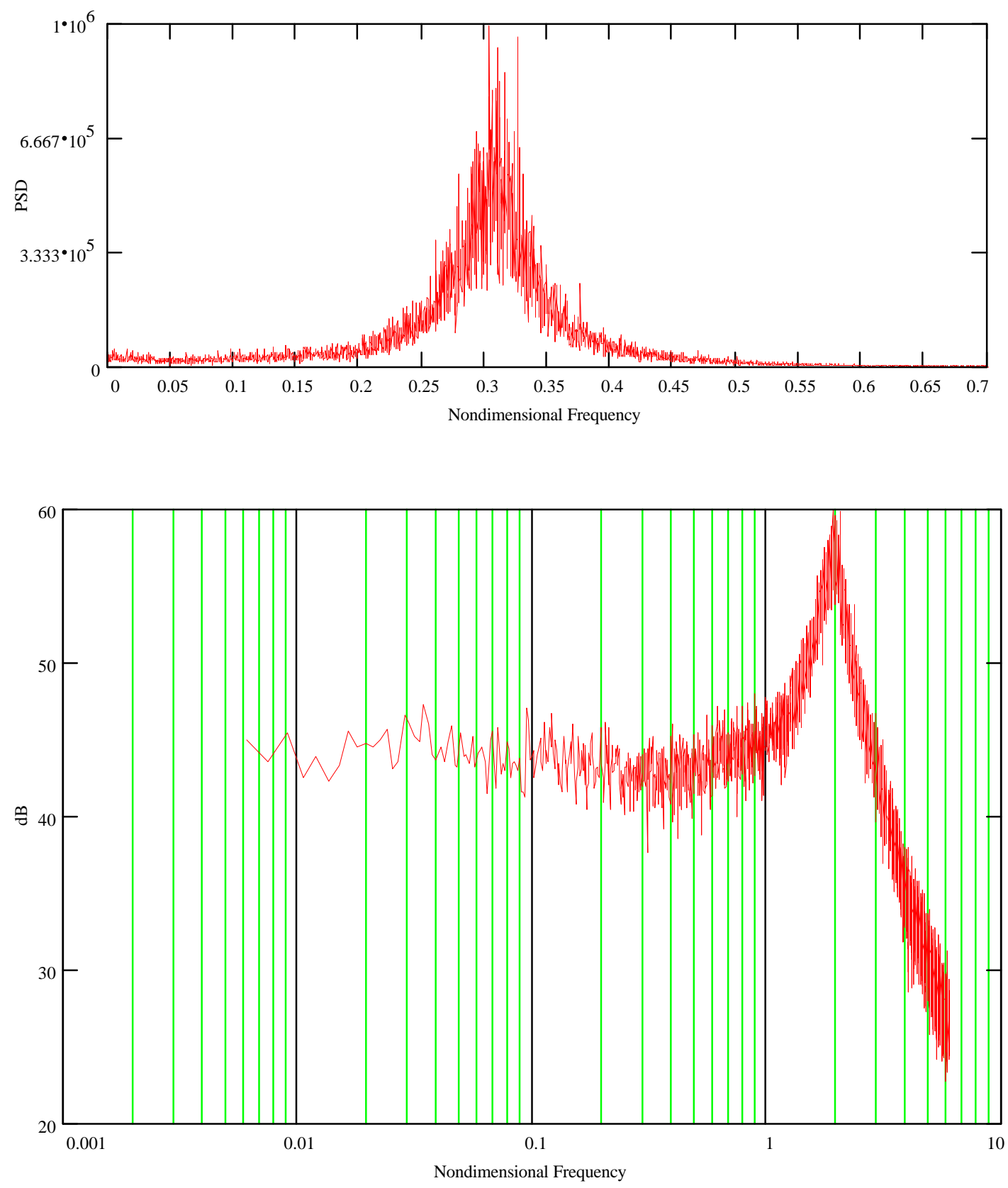

Figure 41: PSD and Bode plot of BFB pressure fluctuations in $10.16 \mathrm{~cm}$ diameter bed D/d relaxation 

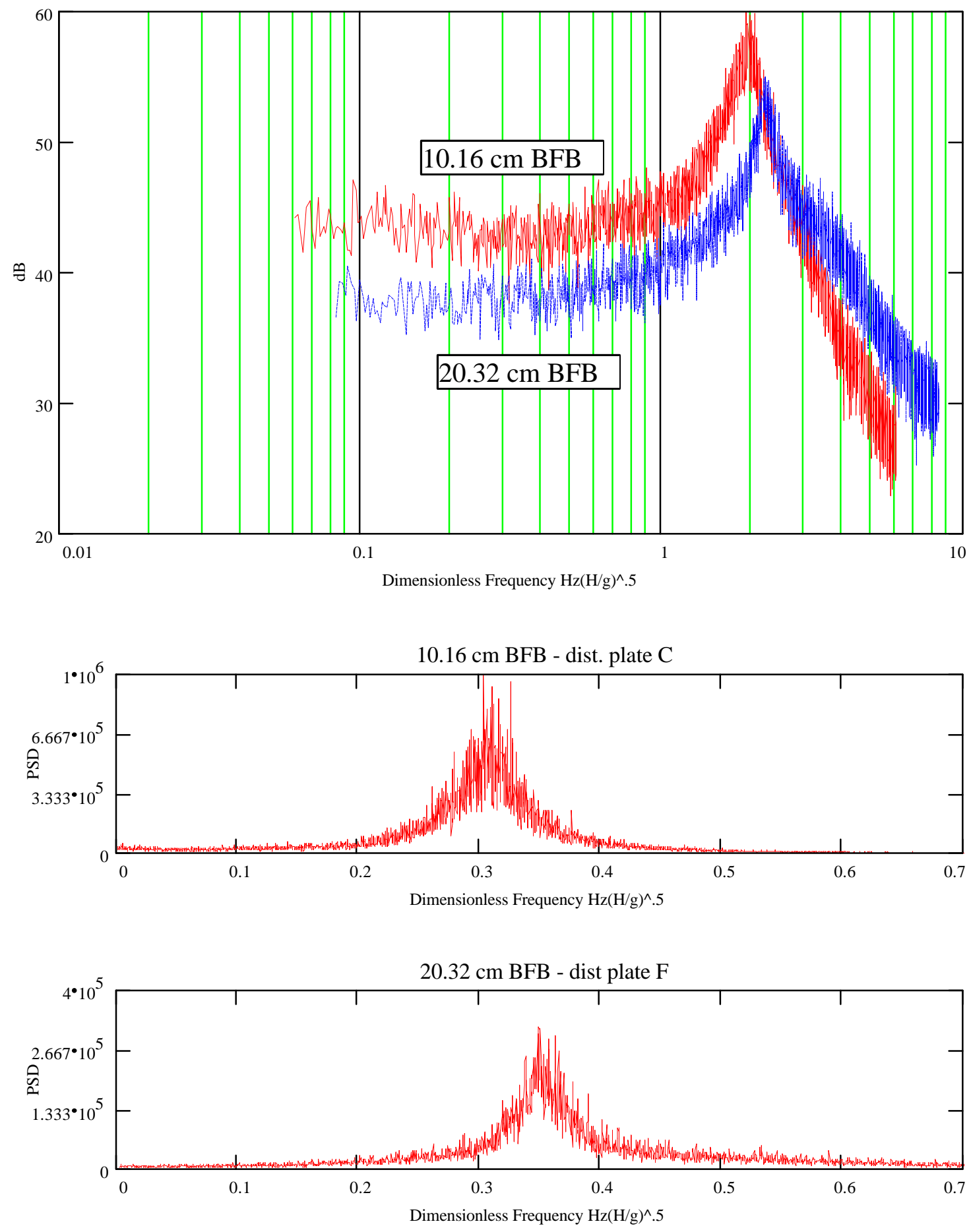

Figure 42: Hot bed similitude with $10.16 \mathrm{~cm}$ diameter bedmethod: $\mathrm{D} / \mathrm{d}_{\mathrm{p}}$ relaxation comparison of Figure 36 and Figure 41 
hydrodynamics quantitatively is difficult to do with spectral analysis, as the frequency peaks are typically made up of a broad band of frequencies. In this study, the location of the center of the of the peak, the height of the peak, and the shape of the peak are considered most important, the height and shape are hence forth referred to as the structure of the Bode plot. In addition, the average bed voidage is measured for each experiment and should be equal under conditions of similitude.

This study attempts to assess the effect particle diameter, bed diameter, particle density, and distributor plate design have on the pressure fluctuations. As shown in Figures 43 and 44, the superficial velocity has an effect on the peak frequency. There is a general upward trend in the peak frequency as the superficial velocity increases in both the 10.16 and $20.32 \mathrm{~cm}$ diameter BFBs. Studies by Brue [20] and de la Cruz Baez [21] examined this effect and drew different conclusions. For instance, de la Cruz Baez reports that the peak frequency decreases as superficial velocity increases, whereas Brue reports that peak frequency remains essentially constant with an increase in superficial velocity above $\mathrm{U} / \mathrm{Umf}=1.5$ as illustrated in Figure 43.

Comparing Figures 45 and 46, very little change in peak frequency is seen with a doubling of the particle size. A very small change in the peak frequency may occur, but it is too small to resolve accurately. Brue [20] addresses the issue of particle diameter and shows that changes in particle diameter do not significantly affect the peak frequency. Further review of Figure 45, 200 micron steel, reveals a second frequency peak at approximately $5 \mathrm{~Hz}$ that does not exist in the 100 micron steel under the same conditions. In addition, the PSD power level at low frequencies is much higher fluidizing with 100 micron steel than with 200 micron steel.

Another important physical parameter of a fluidized bed is the distributor plate. Knowing that it is important to scale a fluidized bed distributor plate, distributor plates with different hole spacing and hole diameter were used under identical conditions with 300 micron glass beads in two cold bubbling fluidized beds. In these tests, two plates of differing hole geometry were used in the $5.08 \mathrm{~cm} \mathrm{BFB}$ and again in the $10.16 \mathrm{~cm}$ BFB. The details of the hole geometry is provided in Table 1. The dimensional results for the 10.16 bed are listed in Figures 47 and 48 . A nondimensional comparison for the $10.16 \mathrm{BFB}$ is listed as Figure 49 and for the $5.08 \mathrm{~cm} \mathrm{BFB}$ as Figure 50. Note that in the $10.16 \mathrm{~cm}$ bed, a shift in peak frequency and magnitude is seen, but the 


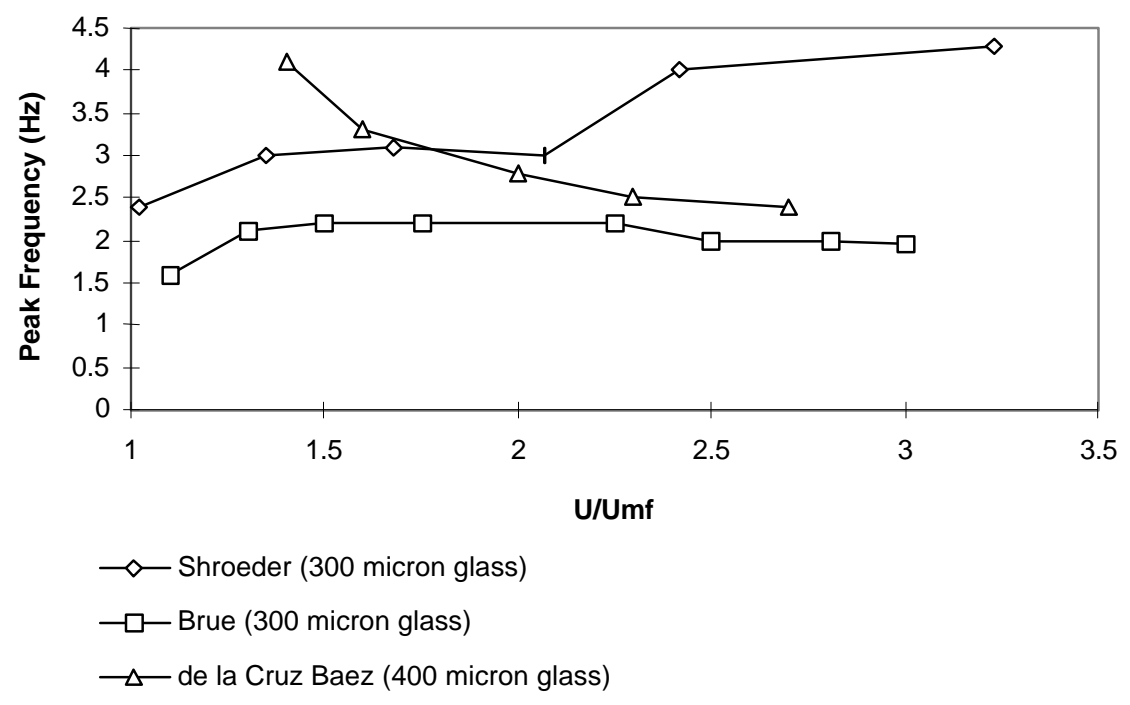

Figure 43: Effect of Velocity on Peak Frequency

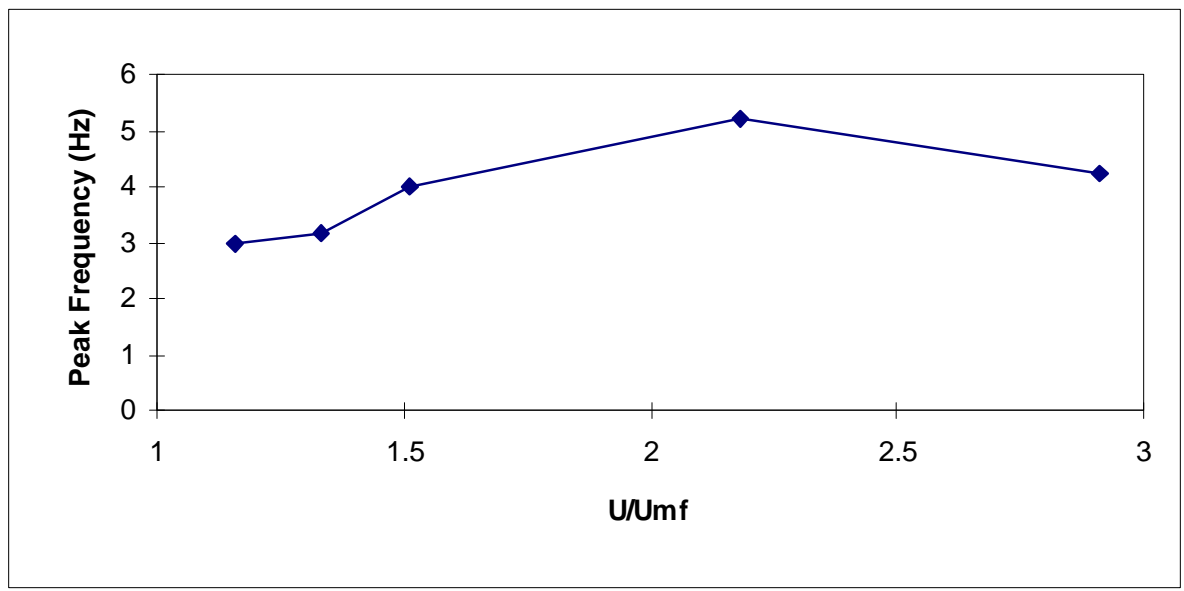

Figure 44: Effect of velocity on peak frequency $20.32 \mathrm{~cm} \mathrm{BFB,} 300$ micron glass beads, $13.6 \mathrm{~cm}$ bed height 
68

\begin{tabular}{|l|l|l|l|}
\hline Experimental operating conditions \\
\hline Bed diameter & $5.08 \pm 0.01 \mathrm{~cm}$ & Bed height & $9.0 \pm 0.2 \mathrm{~cm}$ \\
\hline Particle diameter & $0.20 \pm 0.01 \mathrm{~cm}$ & Pressure measurement & differential \\
\hline Particle density (steel) & $7600 \pm 100 \mathrm{~kg} / \mathrm{m}^{3}$ & Pressure tap position & $3.8 \mathrm{~cm} \& 6.4 \mathrm{~cm}$ \\
\hline Gas density (air) & $1.20 \pm 0.04 \mathrm{~kg} / \mathrm{m}^{3}$ & Avg. voidage btw. taps & $0.50 \pm 0.06$ \\
\hline Superficial velocity & $15.1 \pm 0.6 \mathrm{~cm} / \mathrm{s}$ & Experiment run \# & 63 \\
\hline
\end{tabular}
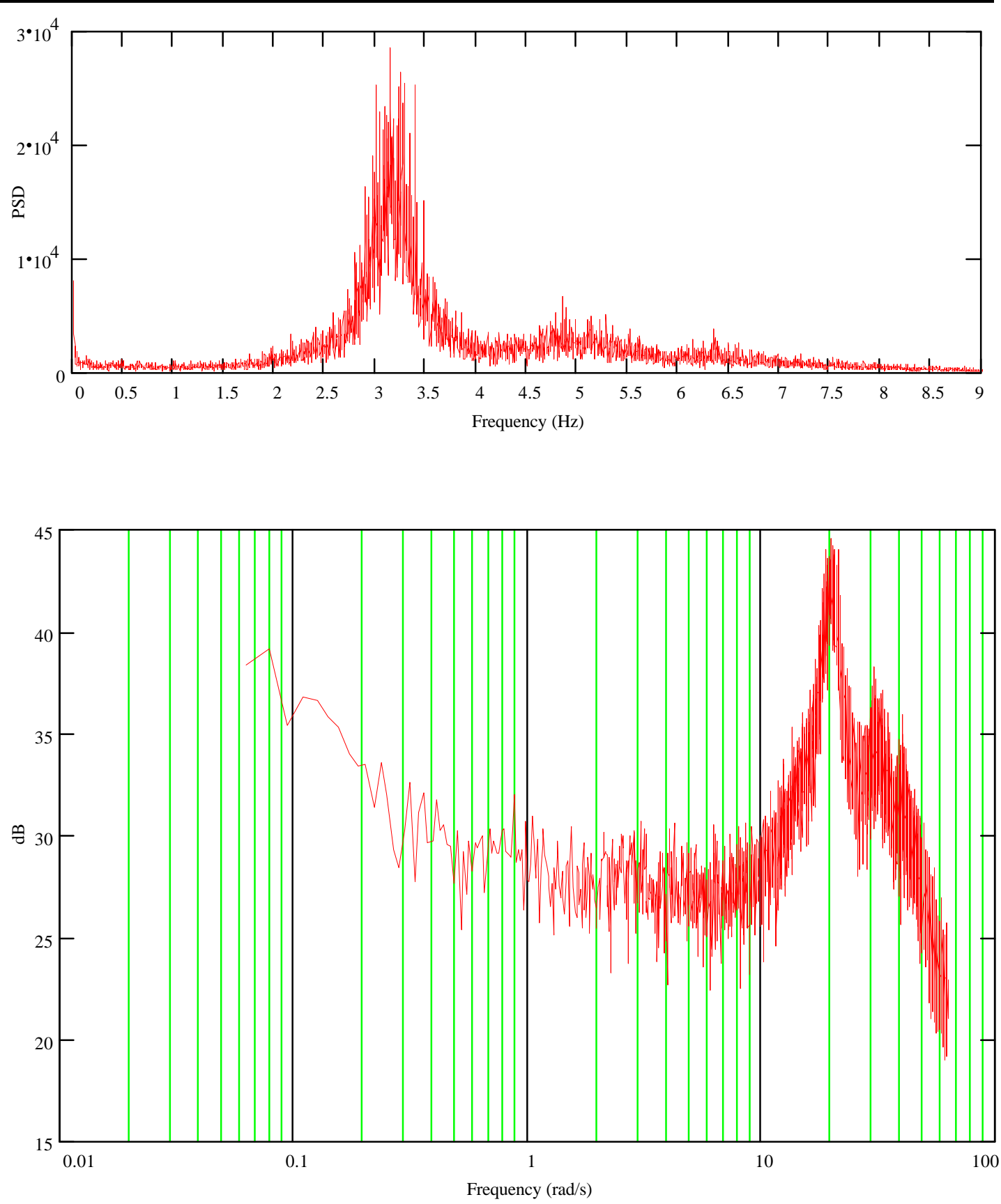

Figure 45: PSD and Bode plot of BFB pressure fluctuations in $5.08 \mathrm{~cm}$ diameter bed of 200 micron steel 


\begin{tabular}{|l|l|l|l|}
\hline \multicolumn{4}{|l|}{ Experimental operating conditions } \\
\hline Bed diameter & $5.08 \pm 0.01 \mathrm{~cm}$ & Bed height & $9.0 \pm 0.2 \mathrm{~cm}$ \\
\hline Particle diameter & $0.10 \pm 0.01 \mathrm{~cm}$ & Pressure measurement & differential \\
\hline Particle density (steel) & $7600 \pm 100 \mathrm{~kg} / \mathrm{m}^{3}$ & Pressure tap position & $3.8 \mathrm{~cm} \mathrm{\&} 6.4 \mathrm{~cm}$ \\
\hline Gas density (air) & $1.20 \pm 0.04 \mathrm{~kg} / \mathrm{m}^{3}$ & Avg. voidage btw. taps & $0.65 \pm 0.06$ \\
\hline Superficial velocity & $15.1 \pm 0.6 \mathrm{~cm} / \mathrm{s}$ & Experiment run \# & 70 \\
\hline Distributor Plate & B & & \\
\hline
\end{tabular}
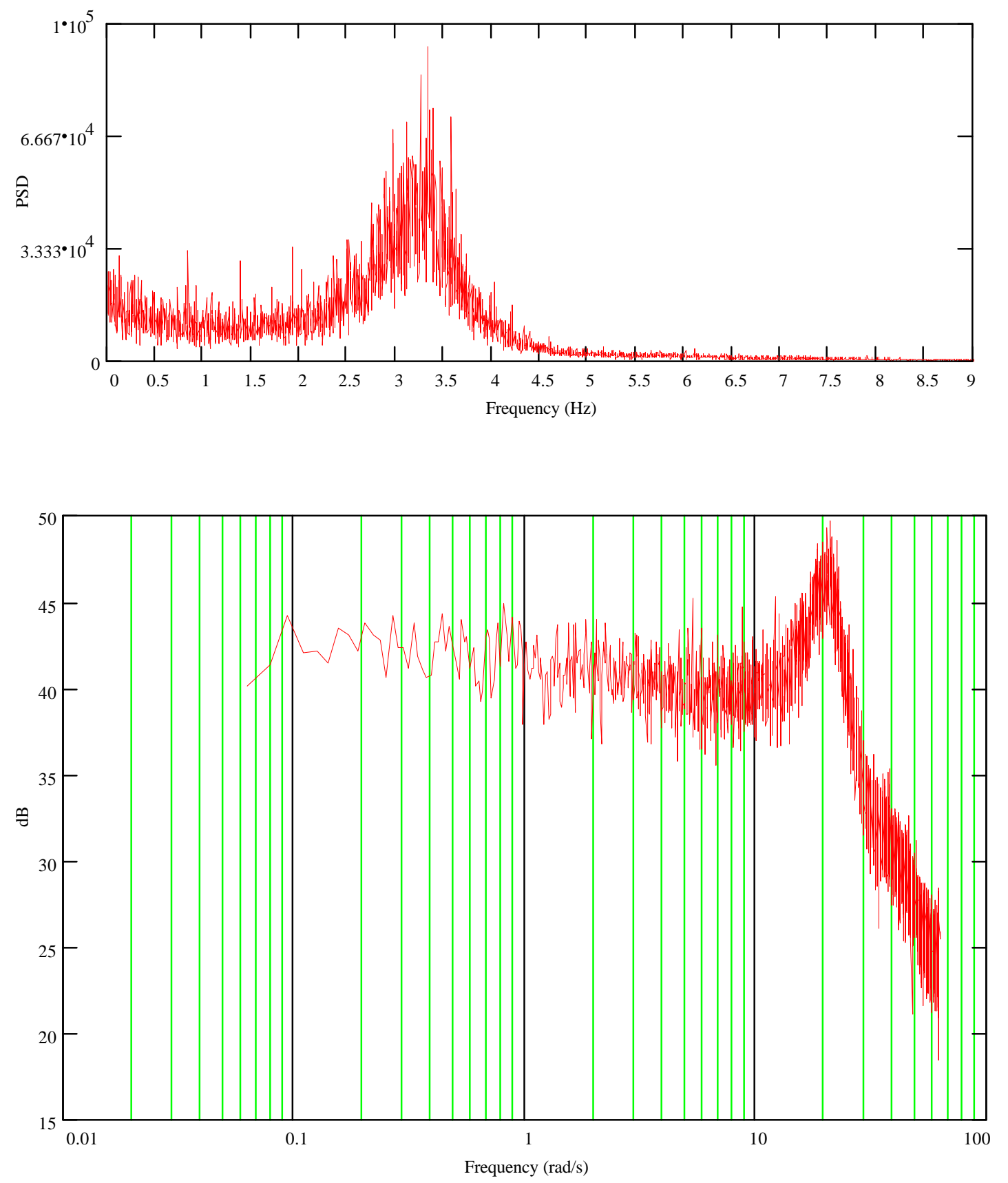

Figure 46: PSD and Bode plot of BFB pressure fluctuations in $5.08 \mathrm{~cm}$ diameter bed of 100 micron steel 


\begin{tabular}{|l|l|l|l|}
\hline \multicolumn{4}{|l|}{ Experimental operating conditions } \\
\hline Bed diameter & $10.16 \pm 0.01 \mathrm{~cm}$ & Bed height & $9.0 \pm 0.2 \mathrm{~cm}$ \\
\hline Particle diameter & $0.30 \pm 0.01 \mathrm{~cm}$ & Pressure measurement & differential \\
\hline Particle density (glass) & $2600 \pm 100 \mathrm{~kg} / \mathrm{m}^{3}$ & Pressure tap position & $3.8 \mathrm{~cm} \mathrm{\&} 6.4 \mathrm{~cm}$ \\
\hline Gas density (air) & $1.20 \pm 0.04 \mathrm{~kg} / \mathrm{m}^{3}$ & Avg. voidage btw. taps & $0.47 \pm 0.06$ \\
\hline Superficial velocity & $15.1 \pm 0.6 \mathrm{~cm} / \mathrm{s}$ & Experiment run \# & 82 \\
\hline Distributor Plate & C & & \\
\hline
\end{tabular}
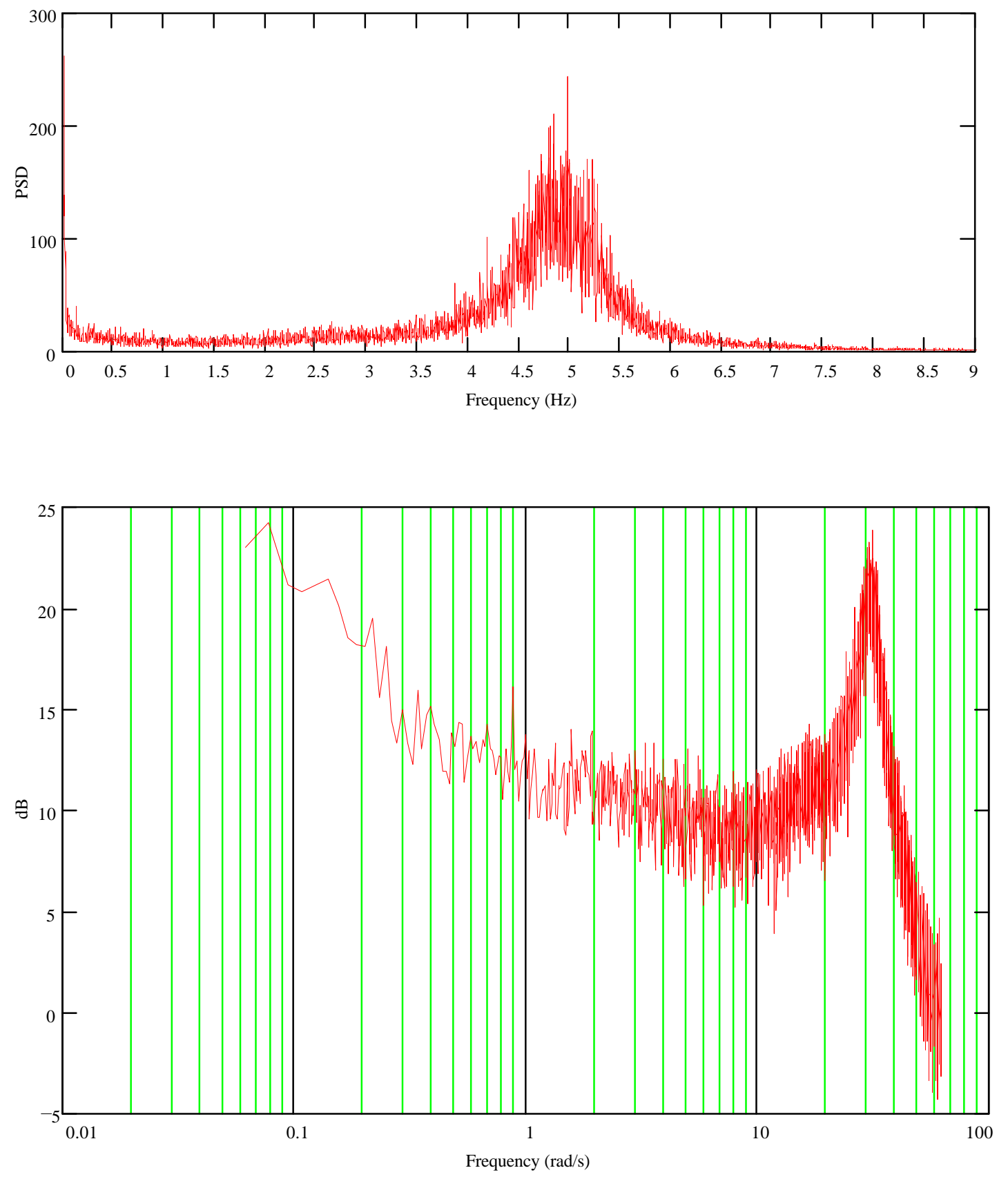

Figure 47: PSD and Bode plot of BFB pressure fluctuations in $10.16 \mathrm{~cm}$ diameter bed distributor plate $\mathrm{C}$ 


\begin{tabular}{|l|l|l|l|}
\hline \multicolumn{4}{|l|}{ Experimental operating conditions } \\
\hline Bed diameter & $10.16 \pm 0.01 \mathrm{~cm}$ & Bed height & $9.0 \pm 0.2 \mathrm{~cm}$ \\
\hline Particle diameter & $0.30 \pm 0.01 \mathrm{~cm}$ & Pressure measurement & differential \\
\hline Particle density (glass) & $2600 \pm 100 \mathrm{~kg} / \mathrm{m}^{3}$ & Pressure tap position & $3.8 \mathrm{~cm} \mathrm{\&} 6.4 \mathrm{~cm}$ \\
\hline Gas density (air) & $1.20 \pm 0.04 \mathrm{~kg} / \mathrm{m}^{3}$ & Avg. voidage btw. taps & $0.51 \pm 0.06$ \\
\hline Superficial velocity & $15.1 \pm 0.6 \mathrm{~cm} / \mathrm{s}$ & Experiment run \# & 84 \\
\hline Distributor Plate & D & & \\
\hline
\end{tabular}
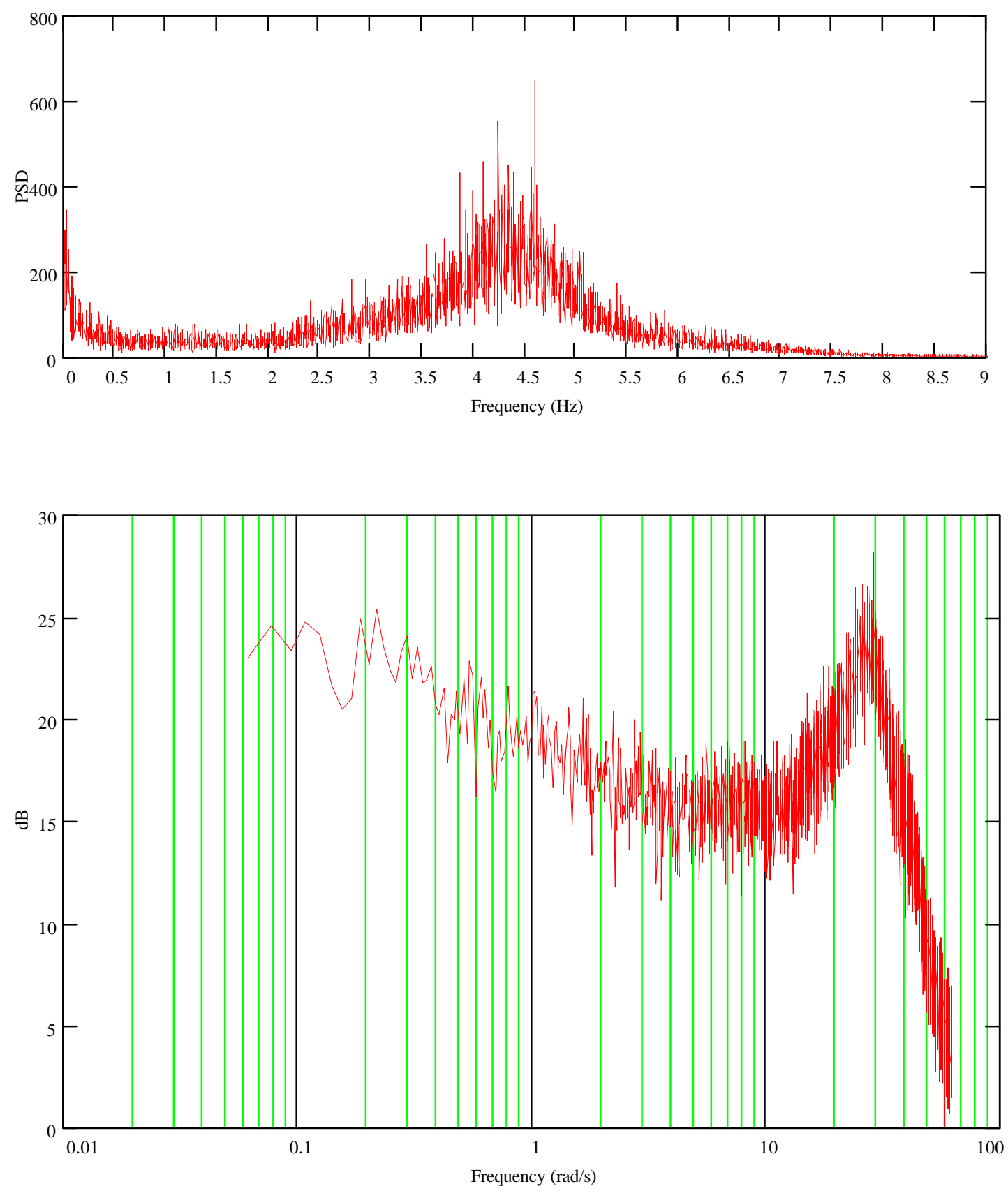

Figure 48: PSD and Bode plot of BFB pressure fluctuations in $10.16 \mathrm{~cm}$ diameter bed distributor plate D 


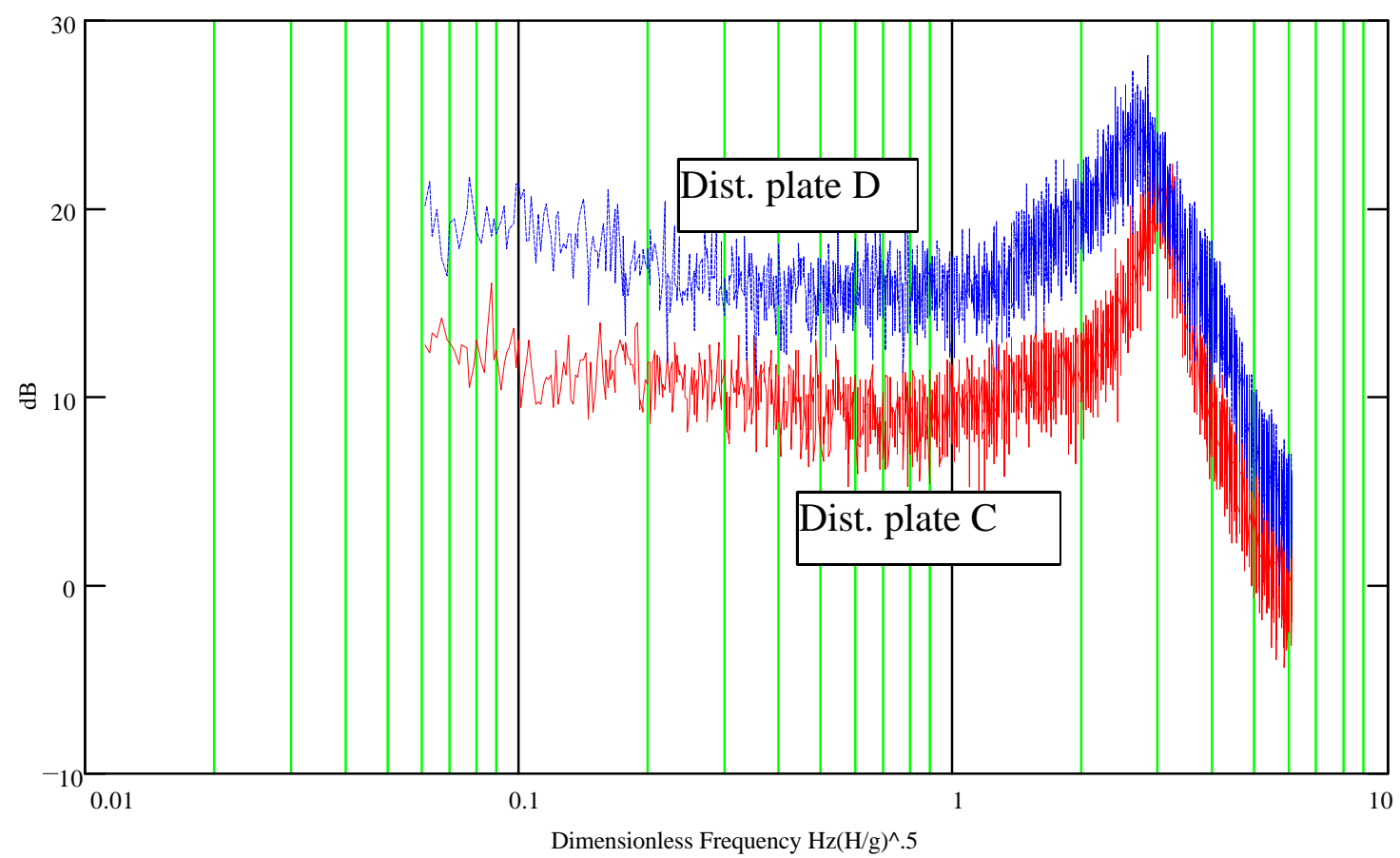

$10.16 \mathrm{~cm}$ cold $\mathrm{BFB}$ with dist. plate $\mathrm{C}$

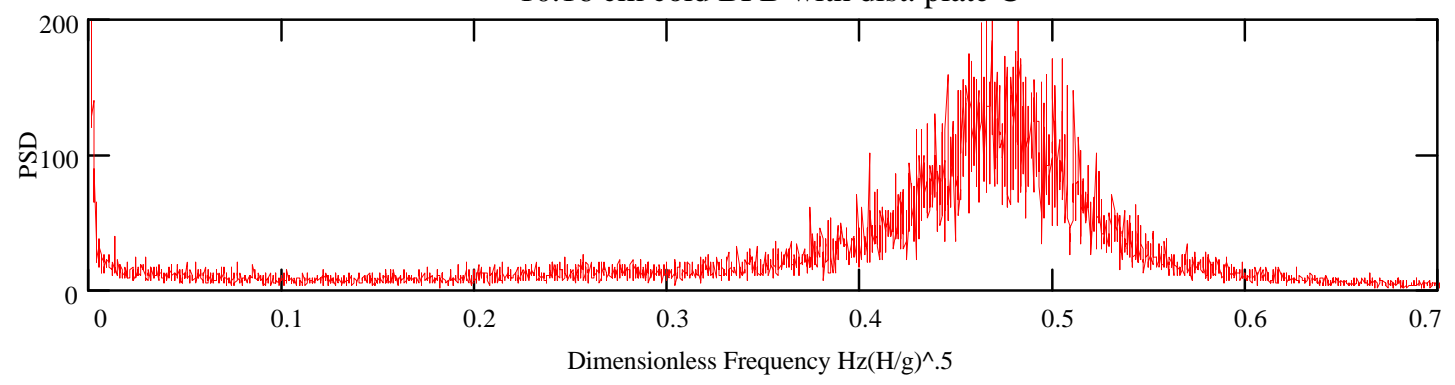

$10.16 \mathrm{~cm}$ BFB with dist. plate D

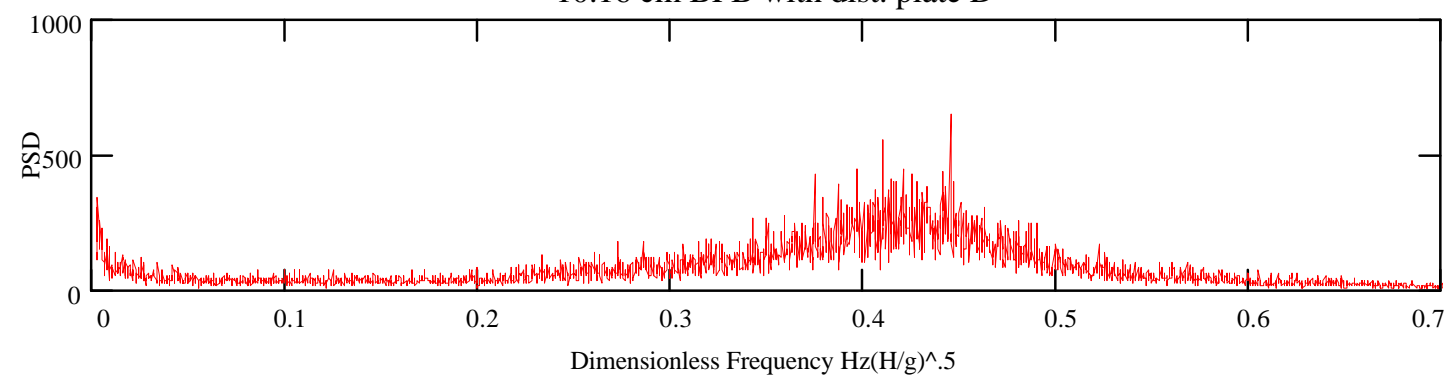

Figure 49: Effect of distributor plate geometry in $10.16 \mathrm{~cm}$ BFB combination of Fig. 47 and Fig. 46 on non-dimensional basis 


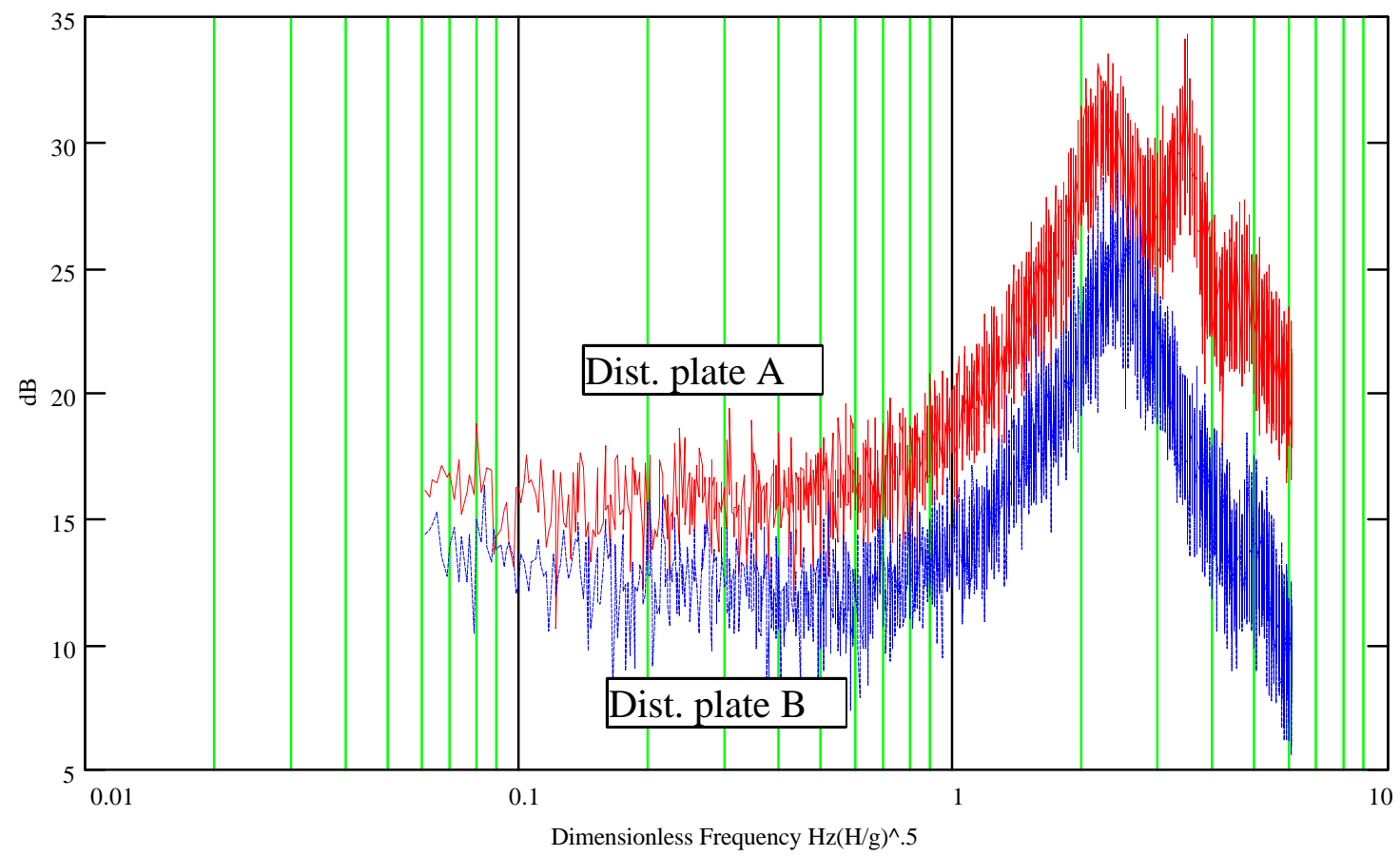

$5.08 \mathrm{~cm}$ BFB with dist. plate A

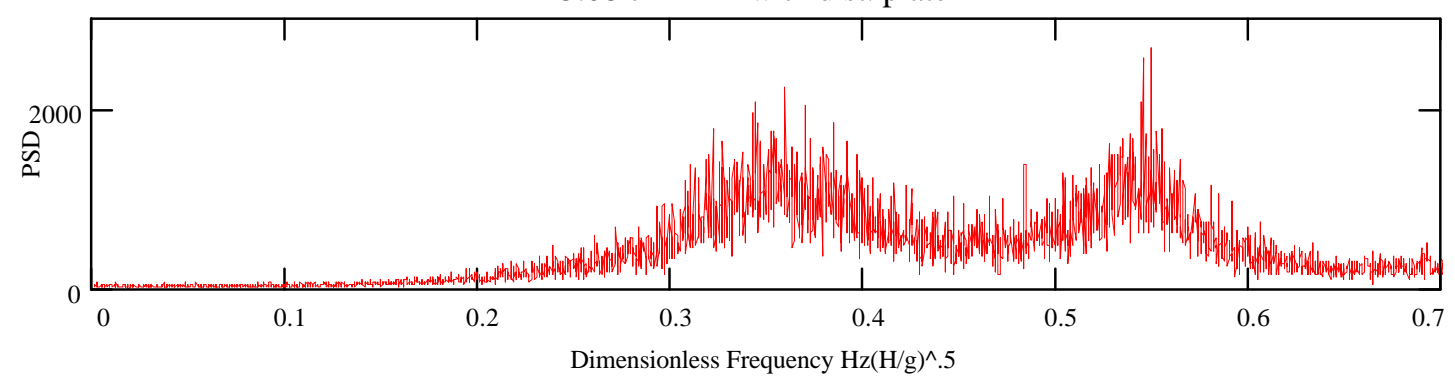

$5.08 \mathrm{~cm} \mathrm{BFB}$ with dist. plate B

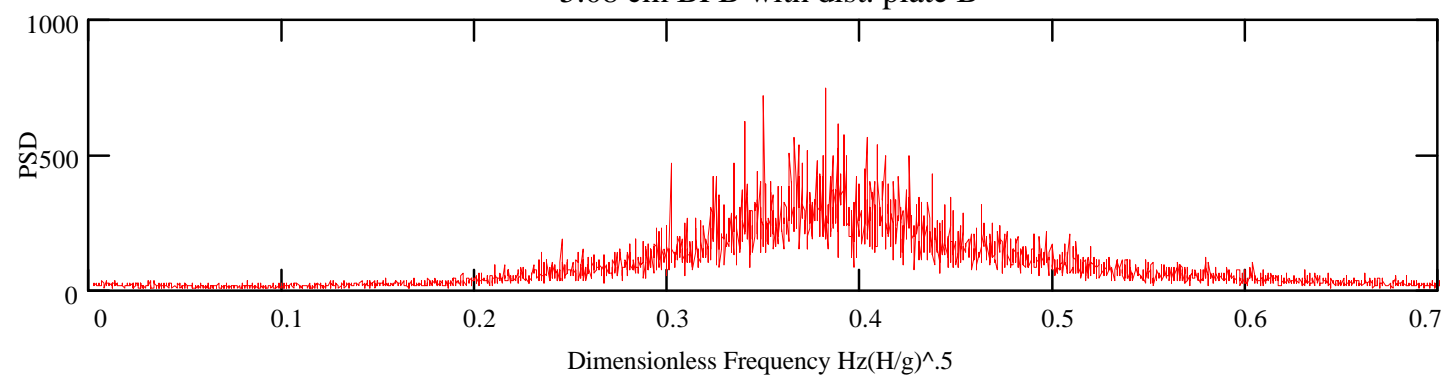

Figure 50: Effect of distributor plate geometry in $5.08 \mathrm{~cm}$ BFB of 300 micron glass beads, 9.0 $\mathrm{cm}$ bed height, $\mathrm{U}=0.151 \mathrm{~m} / \mathrm{s}$ 
general Bode plot structure is very similar with this change in distributor plate geometry. Once again, a second peak frequency appears in the $5.08 \mathrm{~cm}$ BFB as illustrated in Figure 50 in the case using plate A with $0.6 \mathrm{~mm}$ holes in the distributor plate. It seems that the small diameter of the $5.08 \mathrm{~cm}$ bed causes changes in the fluidization hydrodynamics that result in a second frequency peak. De la Cruz Baez [21], investigated the effect of different distributor plates comparing two plates with different number of $1 \mathrm{~mm}$ holes and a filter paper distributor plate. He compared three distributor plates under identical operating conditions and always saw differing peak frequencies in the pressure fluctuations regardless of superficial velocity when comparing distributor plate geometries. Based on this study's results and those of de la Cruz Baez, it can be concluded that the distributor has an effect on BFB hydrodynamics and must be a consideration in all similitude studies.

Important for simplifying the scaling parameters, it must be verified that the $D / d_{p}$ ratio can be relaxed. Experimental runs in both the $20.32 \mathrm{~cm}$ and $10.16 \mathrm{~cm}$ BFBs were completed under identical conditions to verify that the diameter ratio term may be relaxed. To avoid results being changed by the distributor plates, tests were run in the $10.16 \mathrm{~cm}$ BFB using a $1 / 2$ scale distributor plate (plate $\mathrm{C}$ ): hole size and spacing are reduced by $1 / 2$. Another distributor was fabricated for the $1 / 2$ scale model that had identical geometry as the $20.32 \mathrm{~cm}$ bed (plate E): in this case hole size and spacing are identical. The $1 / 2$ scale plate is referred to as the "scaled plate" while the plates with identical hole size and spacing is referred to as the "identical distributor plate" in this study.

Using 300 micron glass beads, tests were run at superficial velocities of $15.1 \mathrm{~cm} / \mathrm{s}, \mathrm{U} / \mathrm{U}_{\mathrm{mf}}$ $=1.7$, and $29.1 \mathrm{~cm} / \mathrm{s}, \mathrm{U} / \mathrm{U}_{\mathrm{mf}}=3.2$. The results of these runs are listed in Figures $51-54$. Notice that the peak frequencies do not coincide with one another in any case. In the $15.1 \mathrm{~cm} / \mathrm{s}$ comparison, Figure 51, the peaks are neither similar in frequency or magnitude when the scaled distributor plate is used. Switching to the identical distributor plate in Figure 52, the peak frequency is increased some and the magnitude of the peak is lowered to the level of the $20.32 \mathrm{~cm}$ bed. Inspecting the $29.1 \mathrm{~cm} / \mathrm{s}$ superficial velocity case, Figures 53 and 54, it is apparent that the PSD and Bode plots are very similar, almost identical, except for a definite shift in peak frequency in both the identical and scaled distributor plate cases.

With this evidence, it is not possible to conclude that the $D / d_{p}$ can be ignored as a scaling parameter in these small beds. Many times the Bode and PSD plots would be similar and suggest 

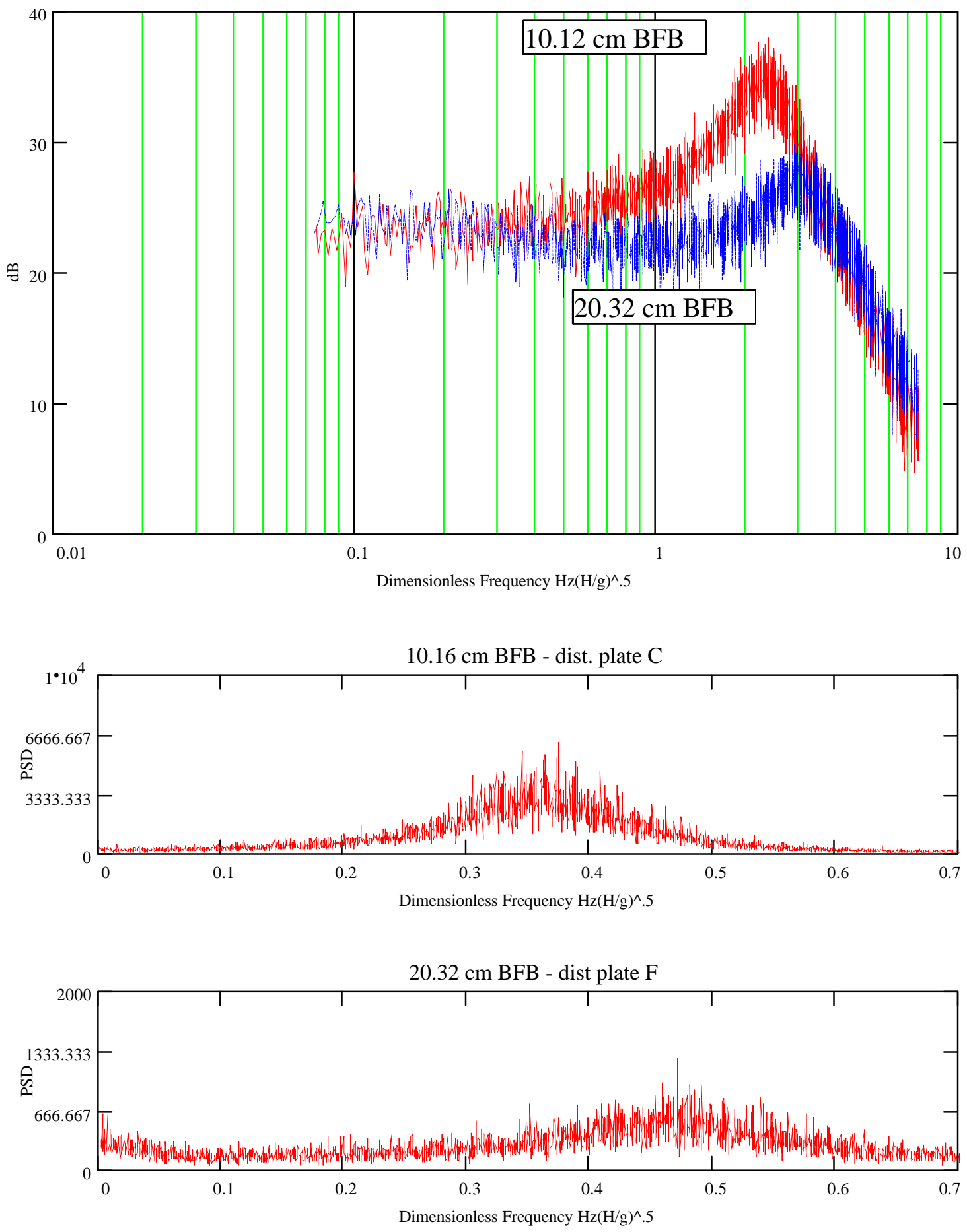

Figure 51: Bed diameter comparison of 20.32 BFB and 10.16 BFB at ambient 300 micron glass beads, $13.7 \mathrm{~cm}$ bed height, $\mathrm{U}=0.151 \mathrm{~m} / \mathrm{s}$ scaled distributor plate geometry 


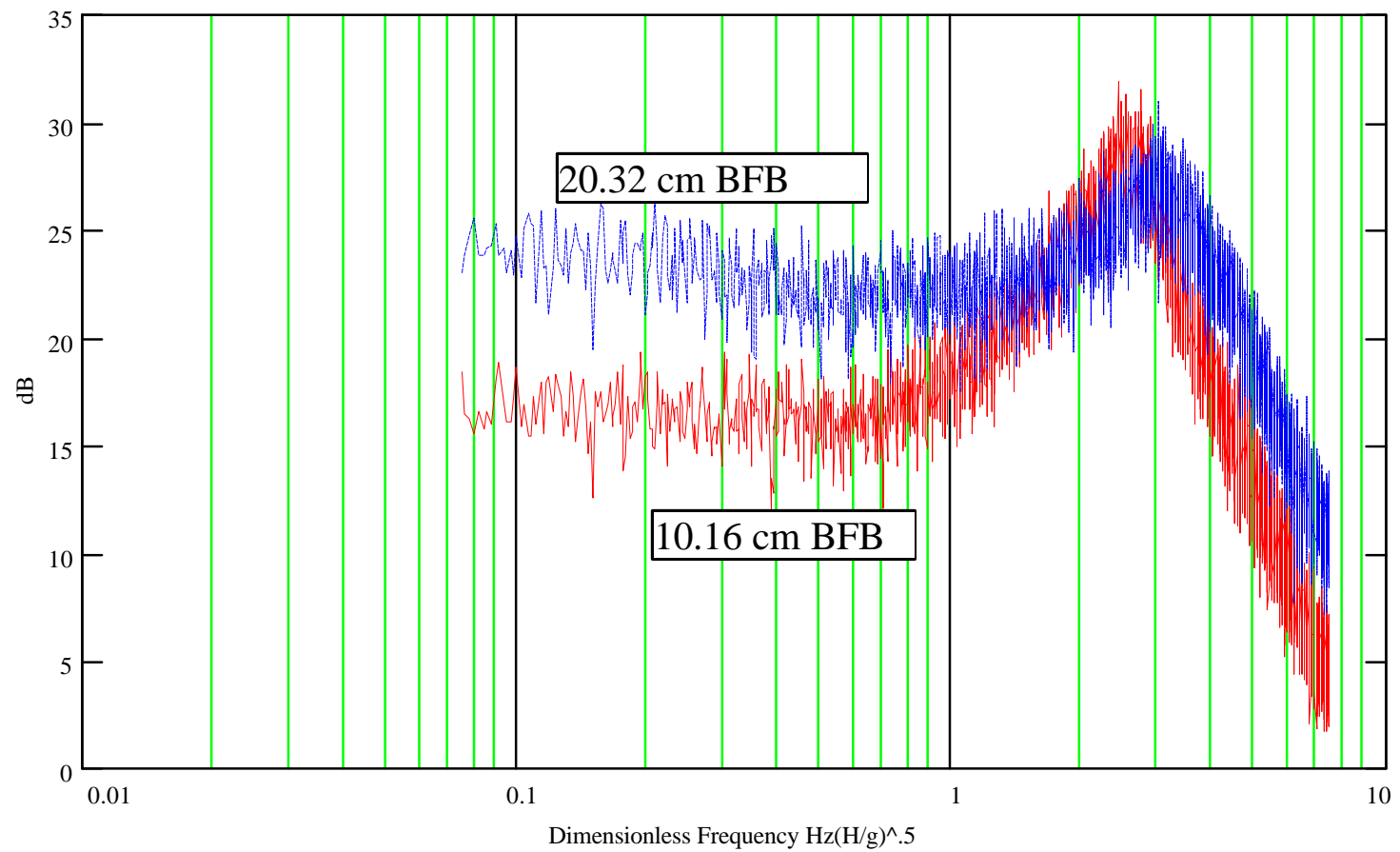

$10.16 \mathrm{~cm}$ BFB - dist. plate E

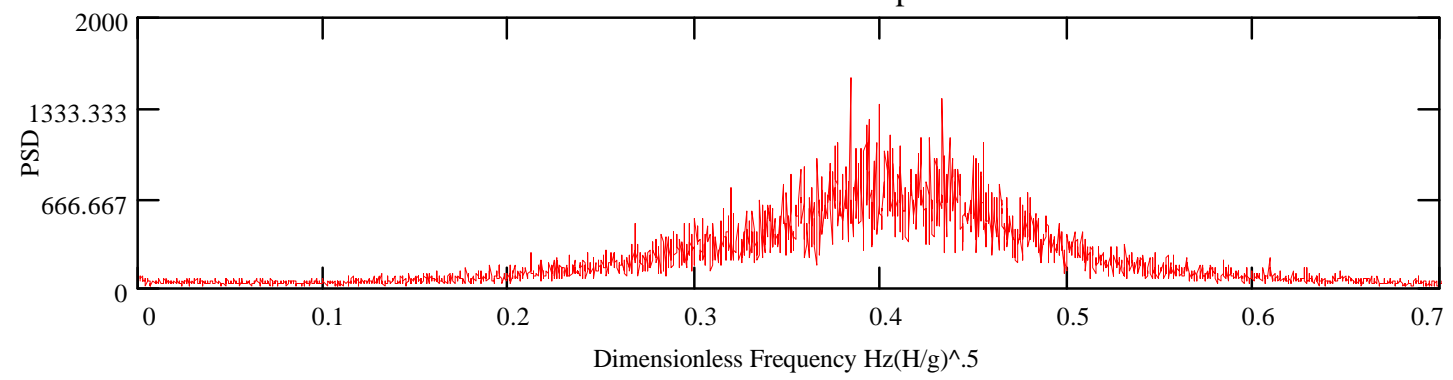

$20.32 \mathrm{~cm}$ BFB - dist plate F

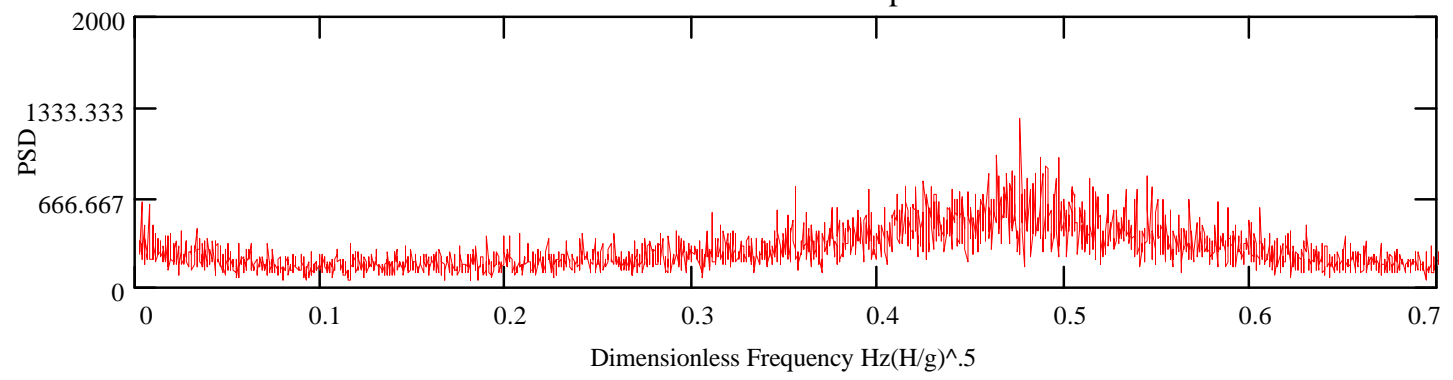

Figure 52: Bed diameter comparison of $20.32 \mathrm{~cm} \mathrm{BFB}$ and $10.16 \mathrm{BFB}$ at ambient 300 micron glass beads, $13.7 \mathrm{~cm}$ bed height, $\mathrm{U}=0.151 \mathrm{~m} / \mathrm{s}$ identical distributor plate geometry 

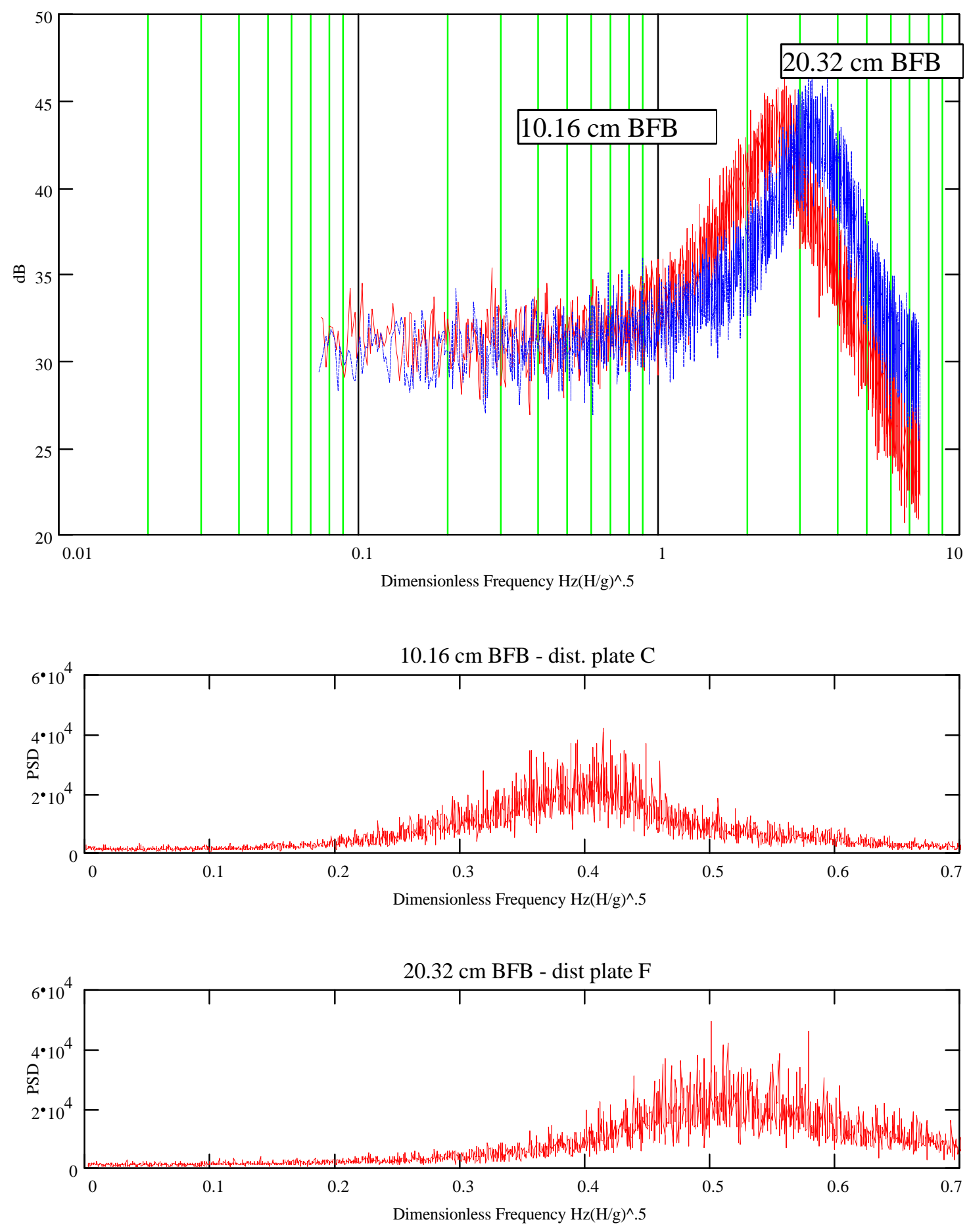

Figure 53: Bed diameter comparison of 20.32 BFB and 10.16 BFB at ambient 300 micron glass beads, $13.7 \mathrm{~cm}$ bed height, $\mathrm{U}=0.291 \mathrm{~m} / \mathrm{s}$ scaled distributor plate geometry 

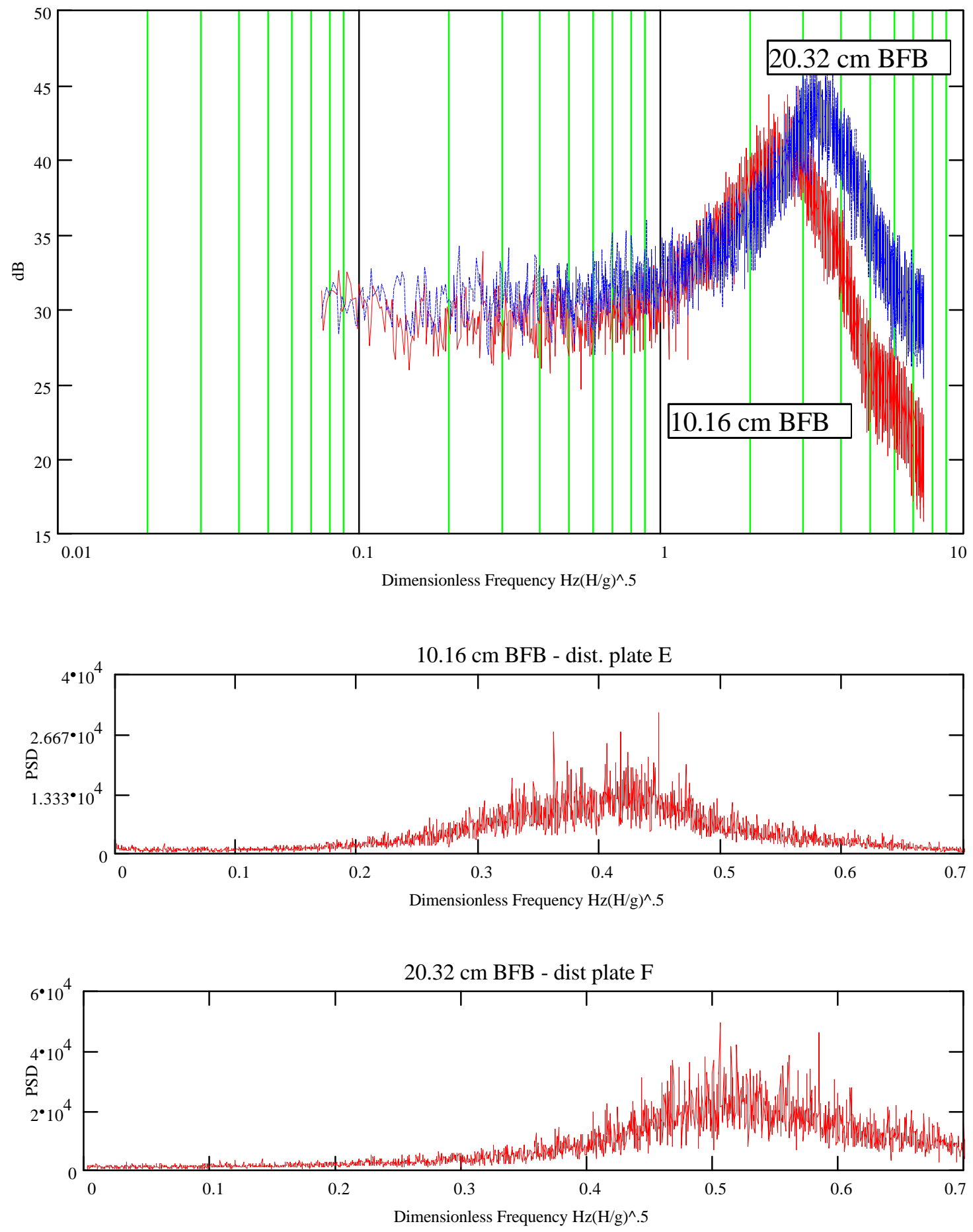

Figure 54: Bed diameter comparison of $20.32 \mathrm{~cm} \mathrm{BFB}$ and $10.16 \mathrm{BFB}$ at ambient 300 micron glass beads, $13.7 \mathrm{~cm}$ bed height, $\mathrm{U}=0.291 \mathrm{~m} / \mathrm{s}$ identical distributor plate geometry 
similitude if a shift in frequency did not exist. It may just be a matter of the beds being too small so that the wall is affecting the pressure fluctuations or that the distributor plates need to be scaled differently. In all cases the larger bed had a higher peak frequency than a smaller bed under identical conditions. If the bed diameter does affect the frequency of pressure fluctuations, it may explain the frequency change in the combustor similitude trials. The dimensionless frequency of the smaller cold BFB was always less than that of the combustor.

Finally, particle density was investigated as a factor affecting the peak frequency. The influence of particle density becomes important in scaling fluidized beds because many times an inexpensive and readily available material cannot be found in the correct density for a given application. If a material of similar density to the desired density can be substituted, fluidized bed scaling may be easier to achieve in practice. In this study, glass, steel, and copper of 200 micron diameter were tested. The result is graphed as Figure 55. Note that the peak frequency does decease with increasing particle density, but the effect is small enough that similarly dense particles $( \pm 15 \%)$ may be substituted in cases where the correct density material can not be found.

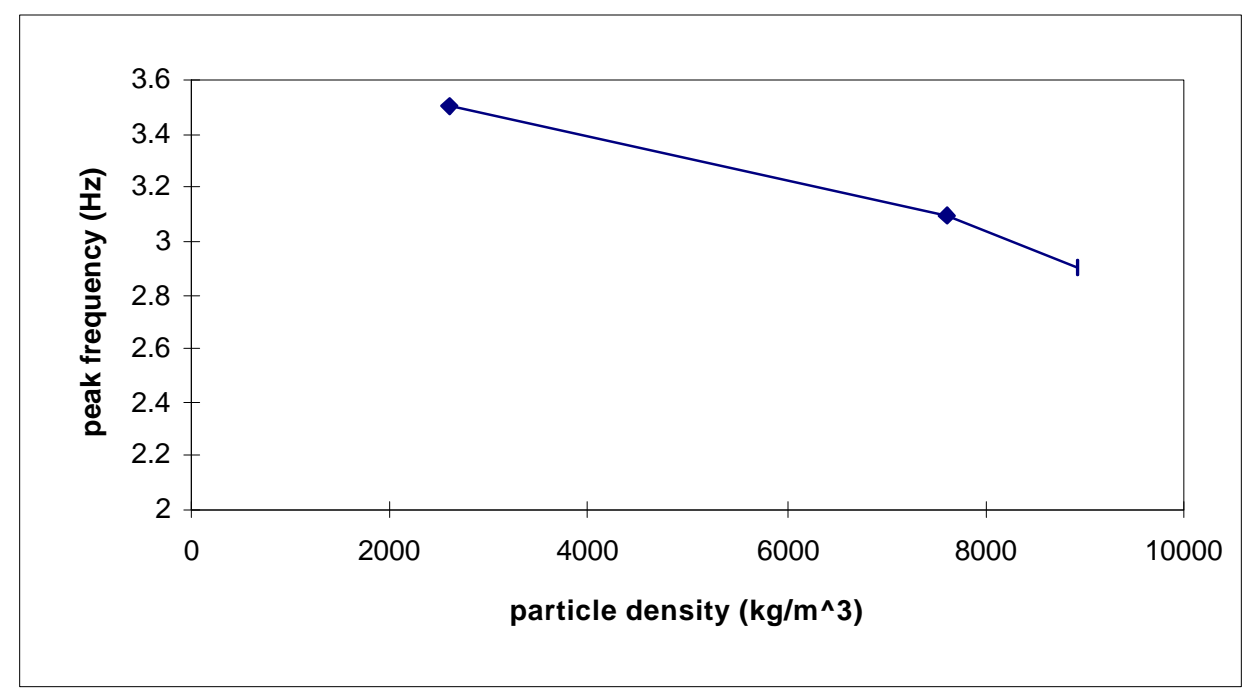

Figure 55: Particle density vs. peak frequency 
80

\section{Experimental Apparatus and Procedures: Circulating Fluidized Bed}

\section{Circulating Fluidized Bed}

This study was performed in two geometrically similar cold-flow CFBs, illustrated in Figure 56. The riser of the larger unit (prototype) is $10.2 \mathrm{~cm}$ in diameter and $3.00 \mathrm{~m}$ tall. This unit is fluidized with $0.2,0.3$, and $0.4 \mathrm{~mm}$ diameter glass beads. Pressure taps are located at 25.4 $\mathrm{cm}$ intervals along the riser, with two additional pressure taps spaced evenly between the first $25.4 \mathrm{~cm}$ interval. Each pressure tap is threaded into the CFB so that the tap is flush with the inner wall. The riser, cyclone, and L-valve of both circulating fluidized beds are constructed of aluminum to reduce electrostatic effects. The downcomer and solids flux meter are constructed of Plexiglas to allow visual observation of bed operation. The $10.2 \mathrm{~cm}$ diameter CFB has two small Plexiglas sections in the riser to observe solids circulation. This large CFB is designed to be operated only at atmospheric pressure, using air as the fluidizing gas. The smaller unit is a onehalf scale model of the larger unit with an inside diameter of $5.08 \mathrm{~cm}$ and a height of $1.50 \mathrm{~m}$. The smaller CFB (model) is fluidized with 0.1, 0.15, and $0.2 \mathrm{~mm}$ diameter steel shot, for the purpose of conducting hydrodynamic similitude studies between the two beds. Since the fluidizing gas density must be greater in the small bed in order to achieve similitude, it is fluidized with pressurized air (0-200 kPa gage).

\section{Solids Flux Measurement}

Since the accurate measurement of solids flux is very important for similitude studies, a meter was constructed that, when activated, would capture particles as they exited the cyclone. A schematic of this solids flux meter is shown in Figure 57. The time it takes for this meter to fill is recorded and converted to a solids flux in $\mathrm{kg} / \mathrm{m}^{2} \mathrm{~s}$. The design of this meter involved a trade-off. If the meter was constructed too small, the time at which it filled would be to short for high accuracy measurements. If it was built too large, the particles removed by the meter would significantly reduce the height of the particles in the L-valve. This change in downcomer bed height reduces the solids circulation rate of the system during measurement. Designing a valve to release the particles from the meter after measurement proved to be difficult. In the end, a simple rubber plug suspended by a nylon cord that extended down through the top of the cyclone was used to control filling and emptying of the flux meter. The meter measured the solids flux with an 


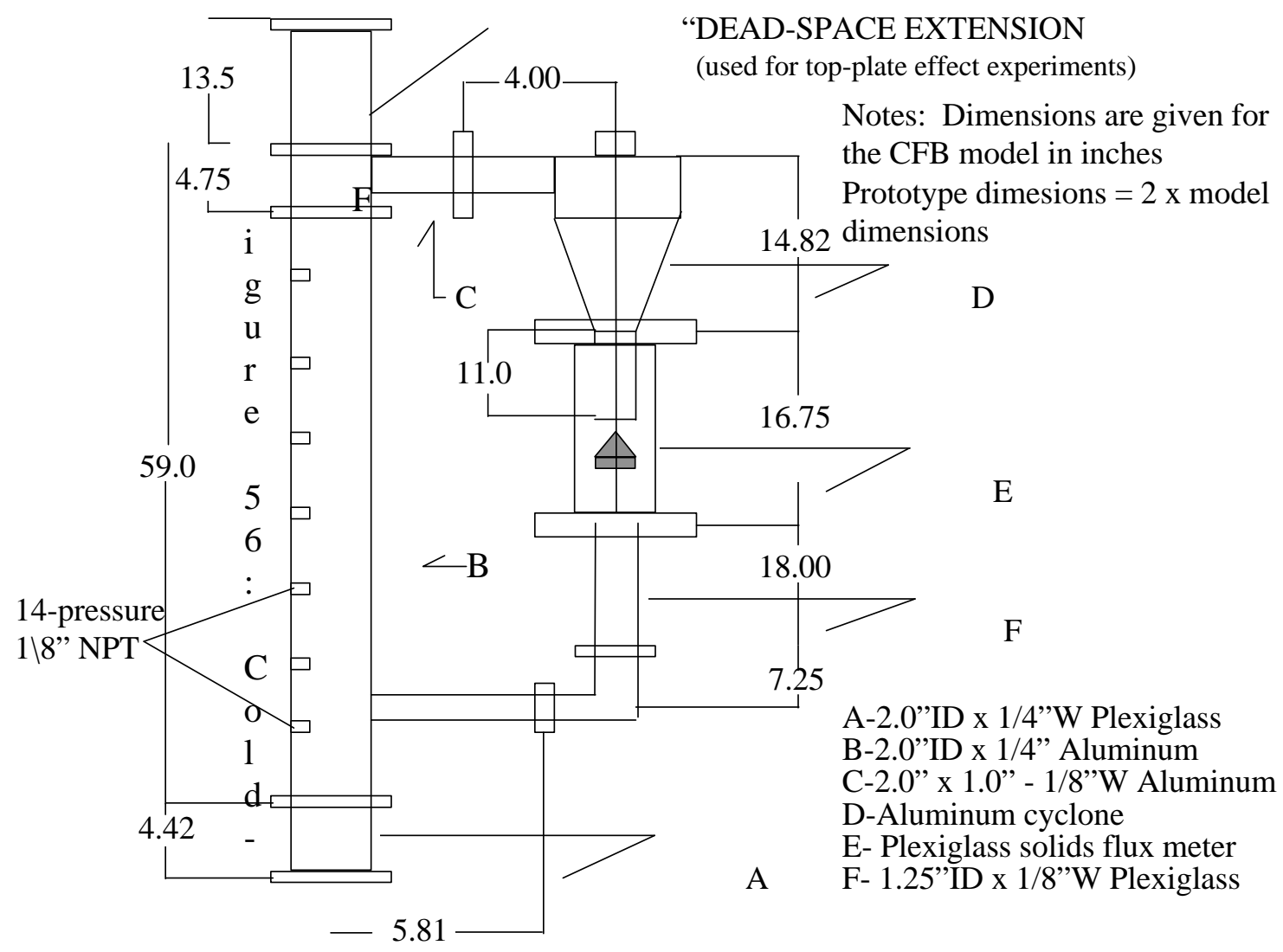

Figure 56: Circulating fluidized bed apparatus (dimensions shown for model) 


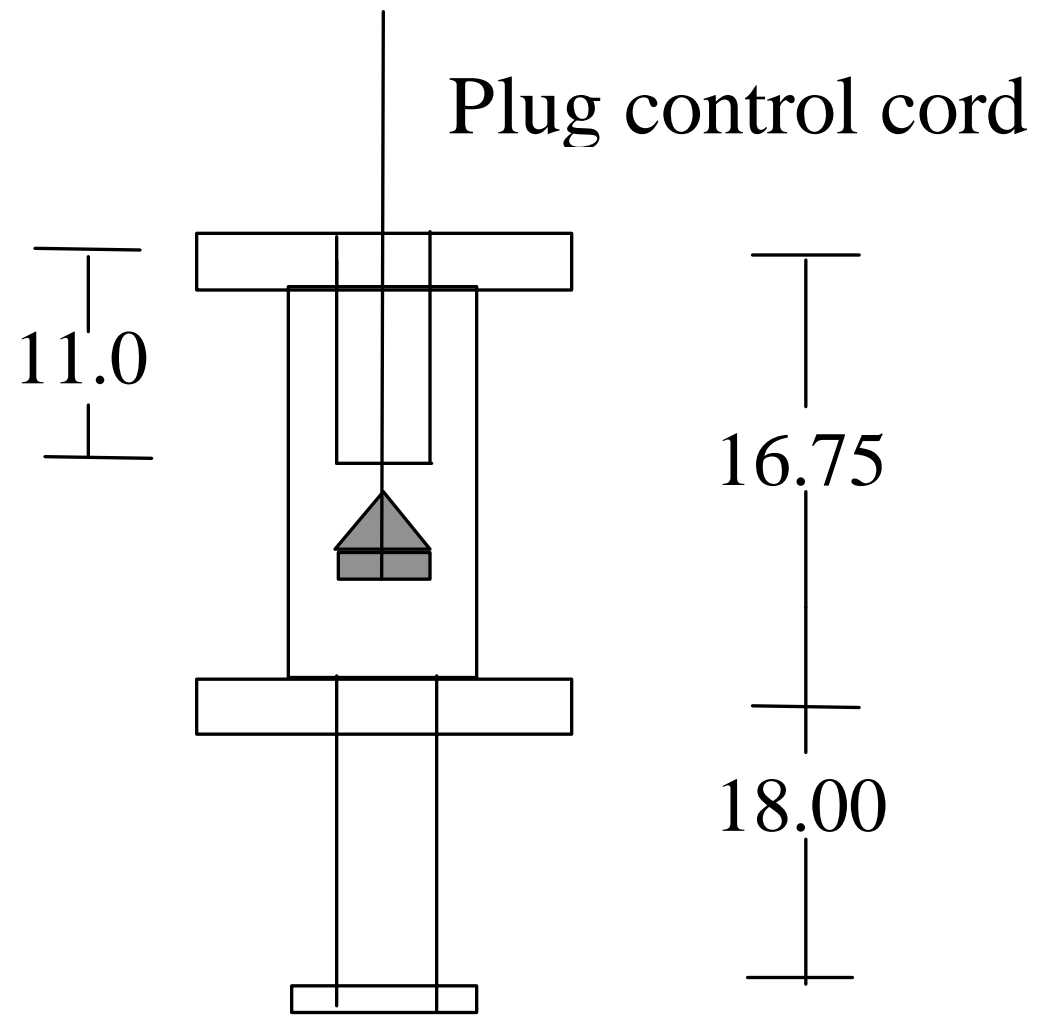

Figure 57: Solids flux meter detail 
overall accuracy of around $\pm 10 \%$, which is good considering the variation in the solids flux inherent in bed operation.

\section{Results and Discussion: Circulating Fluidized Bed}

\section{Global Theory of Pressure Fluctuations}

The first series of tests completed was the experiments using the static pressure probe. A 3/8" tube, 3' long was mounted in the center large CFB top-plate, extending down the center of the riser cross-section. Two feet down from the riser top-plate a hole was drilled in the tube wall. A fine screen was secured across this hole to keep particles out. This allowed for the measurement of the static pressure fluctuations in the center of the bed cross-section. Simultaneously, the static pressure fluctuations at the wall were recorded at this same vertical position. The Bode plots of the pressure fluctuations at the wall and in the center of the bed two feet down from the top plate of the riser are shown in figures $58 \& 59$. The frequency response profiles are identical in each case suggesting that pressure fluctuations are a global phenomena, and not simply the result of local changes in the solids concentration along the wall.

The final two series of tests focused on observing the character of the dominant frequency in CFB pressure fluctuations. The first test involve using a resistance wire heat transfer probe within the CFB to monitor fluctuations in the heat transfer coefficient. Any periodic changes in the local solids density in the bed should manifest themselves in heat transfer coefficient fluctuations. The probe consisted of $35 \mathrm{~cm}$ of pure Nickel 40 gage wire wrapped around a 2" $\mathrm{x}$ 1/4" diameter nylon probe. Using a constant current power supply, the resistance (temperature) fluctuations were monitored by recording the voltage fluctuations across the probe. Theoretical estimates of the probes response times were calculated to be on the order of 0.1 seconds. Comparing the power spectral densities in figures $60 \& 61$ it is evident that the resulting heat transfer fluctuations do not exhibit the dominant frequency as observed in the pressure fluctuation record. This may suggest that pressure fluctuations result from a phenomena not associated with the local solids density (e.g. buoyancy waves). It should be noted that these results may also suggest that the designed probe did not respond as fast as was theoretically predicted during 


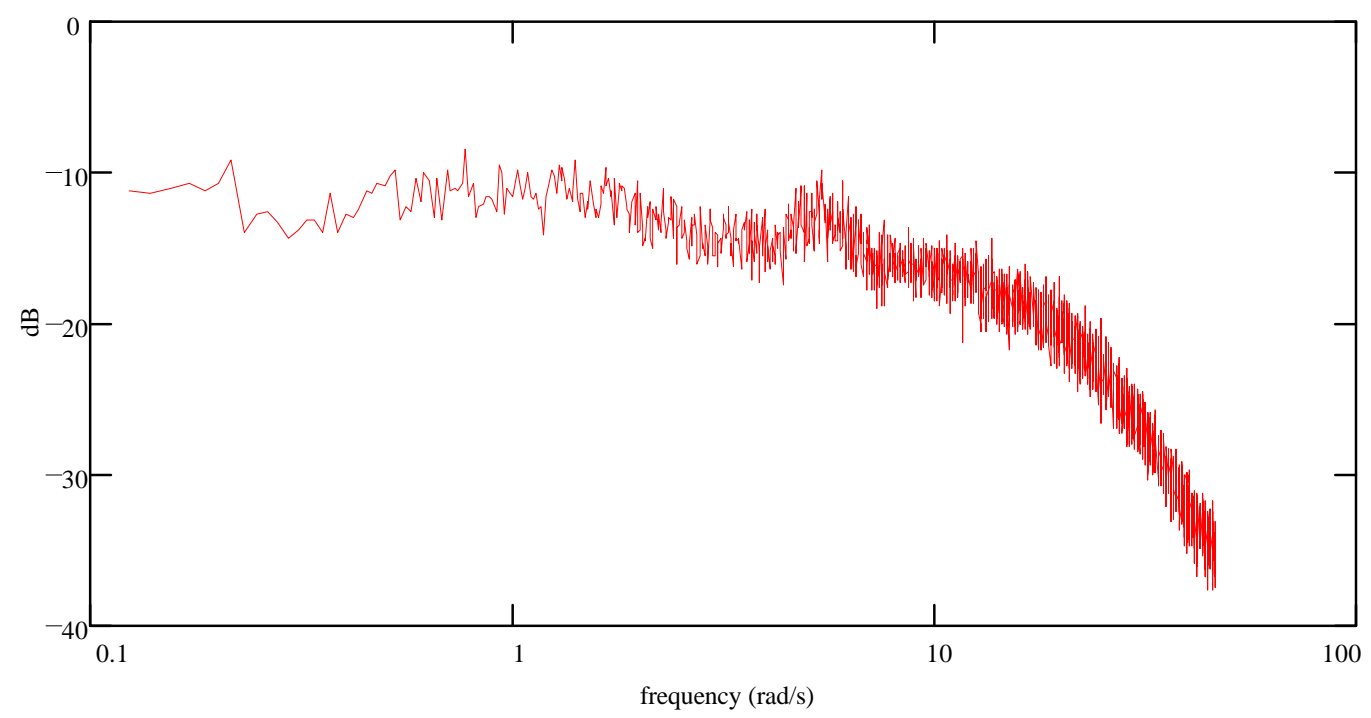

Figure 58: Bode Plot of CFB pressure fluctuations (center probe configuration)

$80 \%$ bed height

Large model w/ $0.2 \mathrm{~mm}$ glass beads solids flux: $19 \pm 3 \mathrm{~kg} / \mathrm{m} \mathrm{s} 2$

superficial velocity: $3.0 \pm 0.3 \mathrm{~m} / \mathrm{s}$

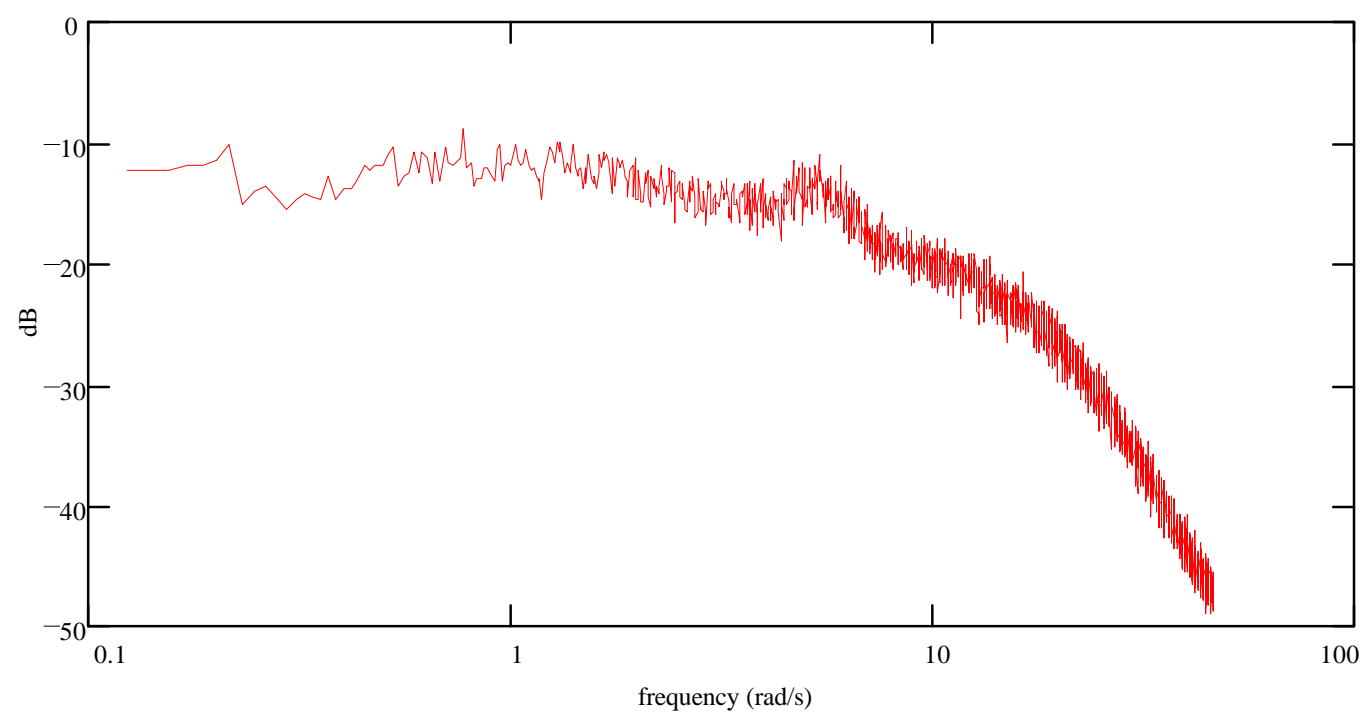

Figure 59: Bode Plot of CFB pressure fluctuations at riser wall

$80 \%$ bed height

Large model w/ $0.2 \mathrm{~mm}$ glass beads solids flux: $19 \pm 3 \mathrm{~kg} / \mathrm{m} \mathrm{s} 2$

superficial velocity: $3.0 \pm 0.3 \mathrm{~m} / \mathrm{s}$ 


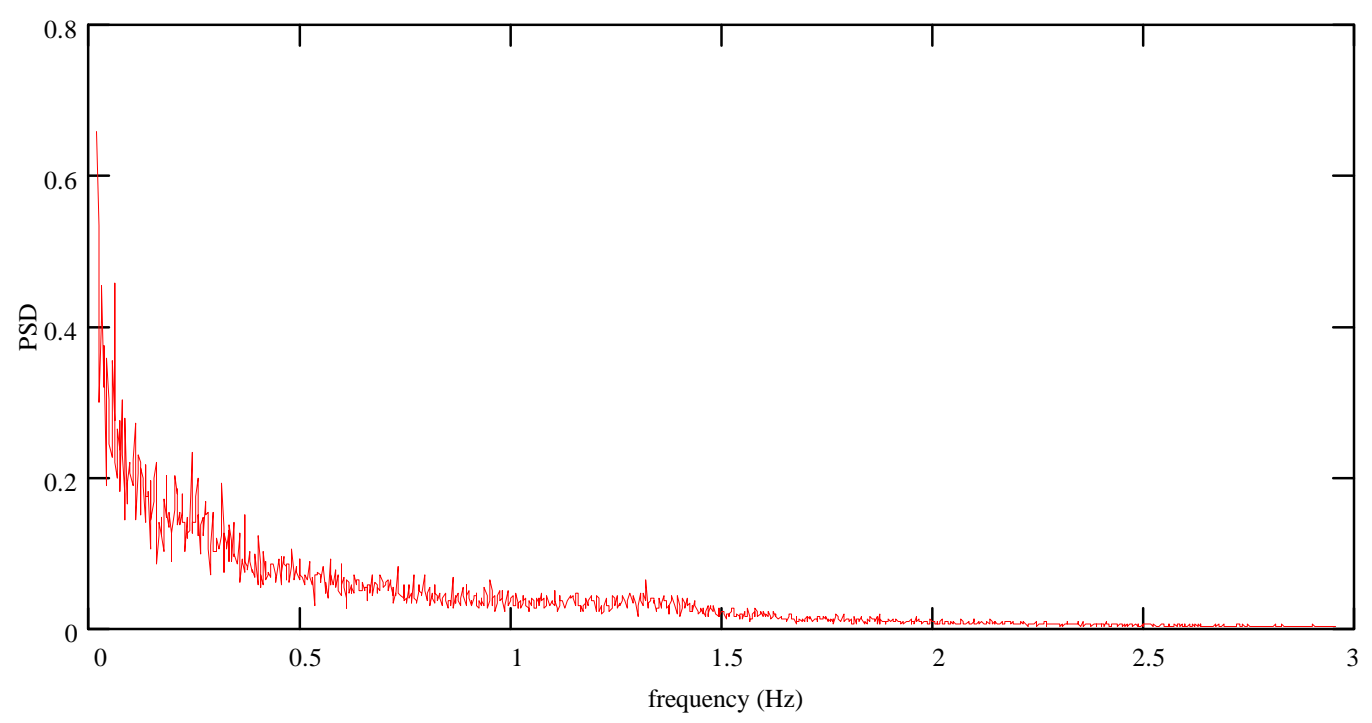

Figure 60: PSD of CFB heat transfer fluctuations

$40 \%$ bed height

Large model w/ $0.2 \mathrm{~mm}$ glass beads solids flux: $12.5 \pm 0.9 \mathrm{~kg} / \mathrm{m} \mathrm{s} 2$

superficial velocity: $3.6 \pm 0.7 \mathrm{~m} / \mathrm{s}$

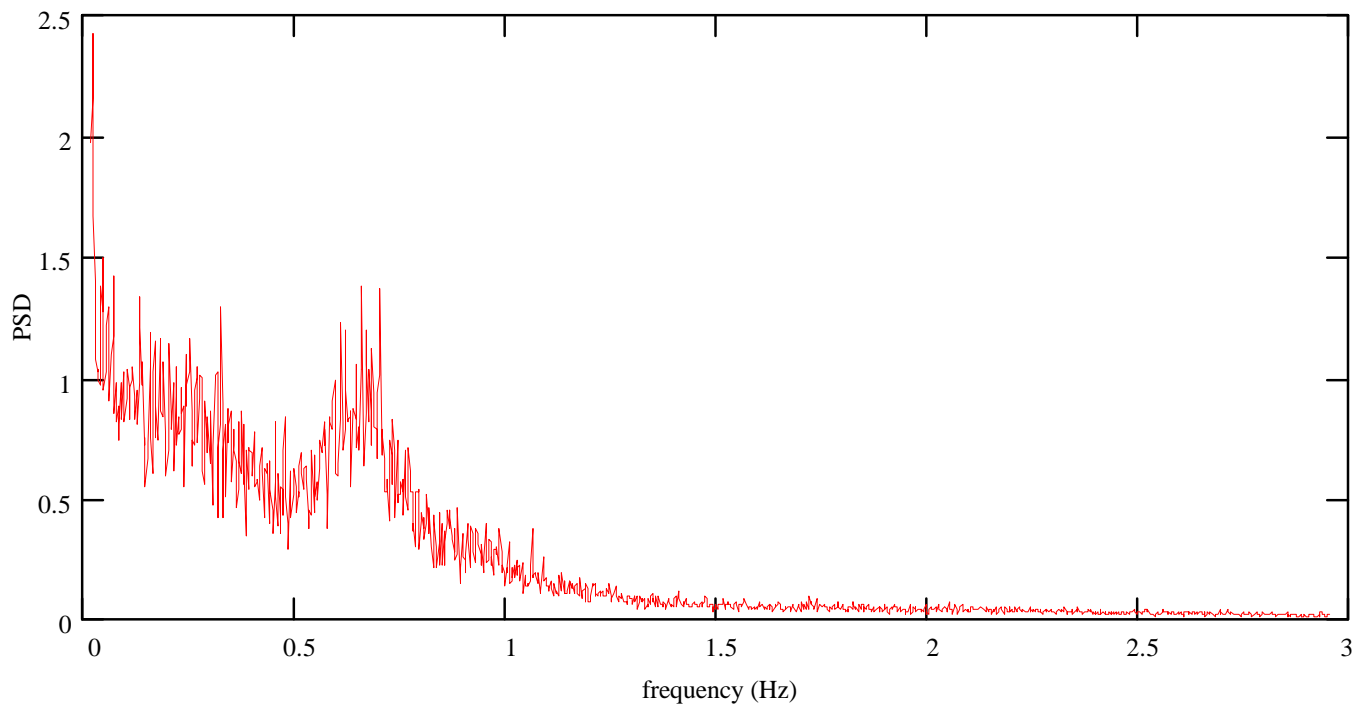

Figure 61: PSD of CFB pressure fluctuations at wall

$40 \%$ bed height

Large model $\mathrm{w} / 0.2 \mathrm{~mm}$ glass beads solids flux: $12.5 \pm 0.9 \mathrm{~kg} / \mathrm{m} \mathrm{s} 2$ superficial velocity: $3.6 \pm 0.7 \mathrm{~m} / \mathrm{s}$ 
probe design. It was difficult to estimate the probe response time accurately under these fluidized conditions. Consequently, at this time, these results are not fully conclusive.

Finally it was hypothesized that the dominant frequency observed in the fluctuation spectrum was inversely proportional to either the bed height or the square root of the bed height as was observed previously in bubbling bed experiments. Two extensions were used to modify the small CFB such that it could be operated at 1.5 and 2 times the original bed height. The bed was fluidized with air at atmospheric pressure and $0.2 \mathrm{~mm}$ steel shot as the bed material. The PSDs presented in figures 62, 63, and 64 show that the dominant frequency observed in CFB pressure fluctuations does not change significantly with changes in the bed height.

\section{CFB Similitude Background}

For CFB hydrodynamics, Glicksman [5] adds an additional independent variable, Gs $\left[\mathrm{kg} / \mathrm{m}^{2} \mathrm{~s}\right]$, to the list previously described for bubbling fluidized bed systems. Using the Buckingham Pi theorem, the full set of independent dimensionless parameters for circulating fluidized beds is summarized as follows:

$$
F r=\frac{U^{2}}{g \cdot d_{p}} \quad \frac{H}{d_{p}} \quad \frac{D}{d_{p}} \quad \frac{\rho_{g}}{\rho_{s}} \quad \operatorname{Re}_{p}=\frac{\rho_{g} \cdot U \cdot d_{p}}{\mu} \quad \frac{G s}{\rho_{s} \cdot U}
$$

As discussed in previous reports, the reactor loading or total mass of particles in the entire CFB system is another independent variable that must be considered in CFB systems that use Lvalves. Under identical conditions, changing the reactor loading will significantly change the resulting axial voidage profile. This additional non-dimensional reactor loading variable was matched in this similitude study. The full set of CFB dimensionless parameters used in this study is:

$$
F r=\frac{U^{2}}{g \cdot d_{p}} \quad \frac{H}{d_{p}} \quad \frac{D}{d_{p}} \quad \frac{\rho_{g}}{\rho_{s}} \quad \operatorname{Re}_{p}=\frac{\rho_{g} \cdot U \cdot d_{p}}{\mu} \quad \frac{G s}{\rho_{s} \cdot U} \quad \frac{M}{\rho_{s} \cdot D^{3}}
$$

where $\mathrm{M}$ is the total mass of particles within the CFB system. 
Fast Fluidization Fluctuations - General characteristics

Two predominant phenomena are observed in the frequency spectrum of fast fluidization systems. Figures 65-67 show typical CFB Bode plots under different operating conditions. Under relatively dilute conditions (and in the upper regions of the bed) the surface wave phenomenon appears along with its first harmonic in the spectrum (see Figure 60). In the transition from dilute to dense conditions, the Bode plot of fluctuations appears highly damped as shown in Figure 66 (i.e. no distinct peaks are observed in the pressure dynamics). Under the dense conditions shown in Figure 67, the voidage wave frequency is evident in the Bode plot. This voidage wave phenomenon is most dominant when fluctuations are measured at low elevations in the bed (5-10\% bed height). The CFB Bode plots under all conditions exhibit a final asymptotic slope of $-40 \mathrm{~dB} /$ decade.

\section{Discussion of Voidage Wave Phenomenon in CFBs}

By observing pressure fluctuations throughout the transition from bubbling to turbulent to fast fluidization, it is evident that the voidage wave phenomenon is present in all three regimes. This phenomenon originates from the lower dense regions of the CFB. It appears only when a lower dense bed has been established (i.e. the axial voidage profile shows decreasing voidage at low bed heights). It is also most dominantly sensed at the lower elevations of the CFB. Figure 68 shows how voidage waves are manifest in the CFB Bode plots of fluctuations measured at different elevations. Secondly, in addition to the observation of this phenomena throughout bubbling, turbulent, and fast fluidization regimes, the frequency of this phenomena can be predicted from the modified-Hiby model proposed for bubbling fluidized beds. The height of the lower dense bed can be estimated from the axial voidage profiles to be between 10-20 $\mathrm{cm}$ (in the $10.2 \mathrm{~cm}$ diameter CFB model). The theory for voidage oscillations under turbulent conditions predicts that this frequency should appear between 2-3 Hz. All Bode plots of lower dense bed pressure fluctuations confirm this.

As expected, this voidage wave also exhibits an inverse square root dependence on dense bed height. When the two CFB models are operated such that similar axial voidage profiles are 


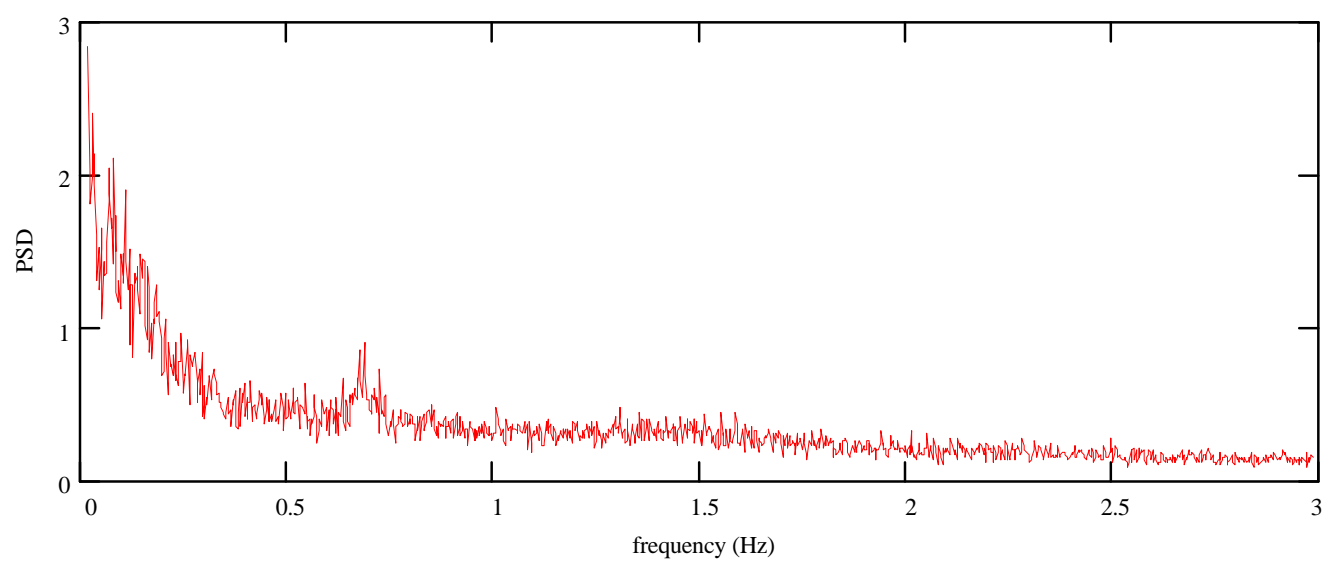

Figure 62: Bode Plot of CFB static pressure fluctuations

$2 \mathrm{x}$ standard bed height (48" extension)

Large model $\mathrm{w} / 0.2 \mathrm{~mm}$ glass beads solids flux: $34 \pm 4 \mathrm{~kg} / \mathrm{m} \mathrm{s} 2$ superficial velocity: $5.5 \pm 0.4 \mathrm{~m} / \mathrm{s}$

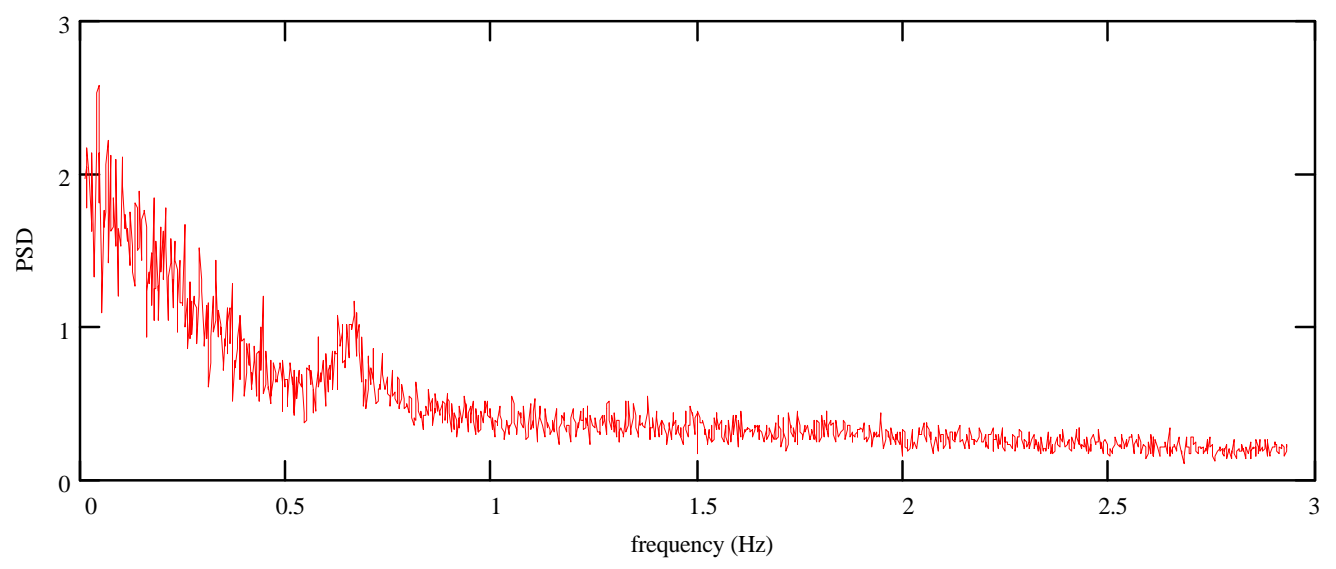

Figure 63: Bode Plot of CFB static pressure fluctuations

1.5 x standard bed height (24" extension) Large model w/ $0.2 \mathrm{~mm}$ glass beads solids flux: $49 \pm 5 \mathrm{~kg} / \mathrm{m} \mathrm{s} 2$ superficial velocity: $6.2 \pm 0.4 \mathrm{~m} / \mathrm{s}$ 
89

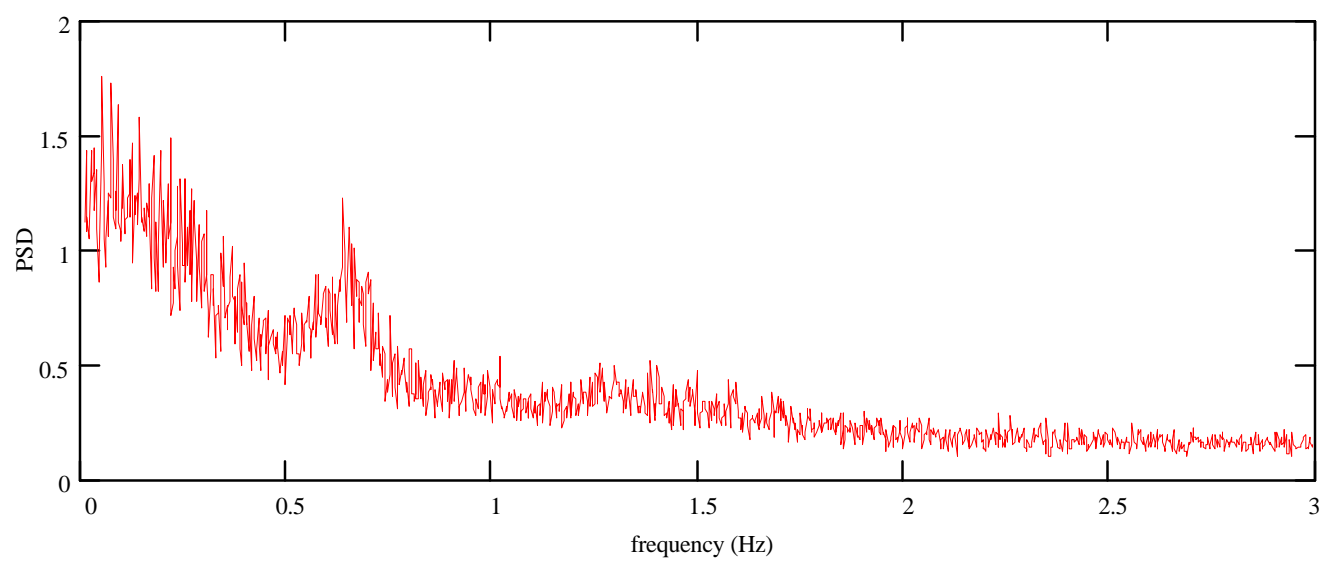

Figure 64: Bode Plot of CFB static pressure fluctuations

standard bed height (no extension)

Large model w/ $0.2 \mathrm{~mm}$ glass beads solids flux: $38 \pm 7 \mathrm{~kg} / \mathrm{m} \mathrm{s} 2$

superficial velocity: $5.6 \pm 0.4 \mathrm{~m} / \mathrm{s}$ 
90

CFB Operating Conditions

$\mathrm{G}_{\mathrm{s}}=13 \mathrm{~kg} / \mathrm{m}^{2} \mathrm{~s}$

$\mathrm{U}=4.7 \mathrm{~m} / \mathrm{s}$ (air @ $1.0 \mathrm{~atm})$

$\mathrm{D}=10.2 \mathrm{~cm}$

$\mathrm{d}_{\mathrm{p}}=0.4 \mathrm{~mm}$ (glass beads)

Differential pressure measurement

(a) $13 \%$ bed height $-25.4 \mathrm{~cm}$ tap spacing

(b) Power Spectral Density

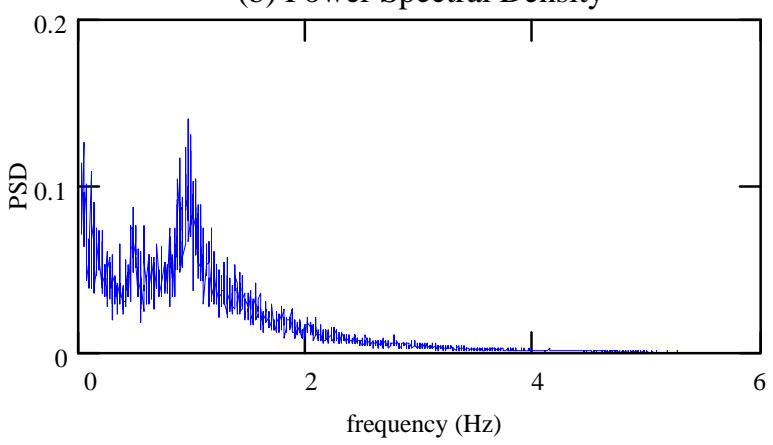

(a) Axial Voidage Profile

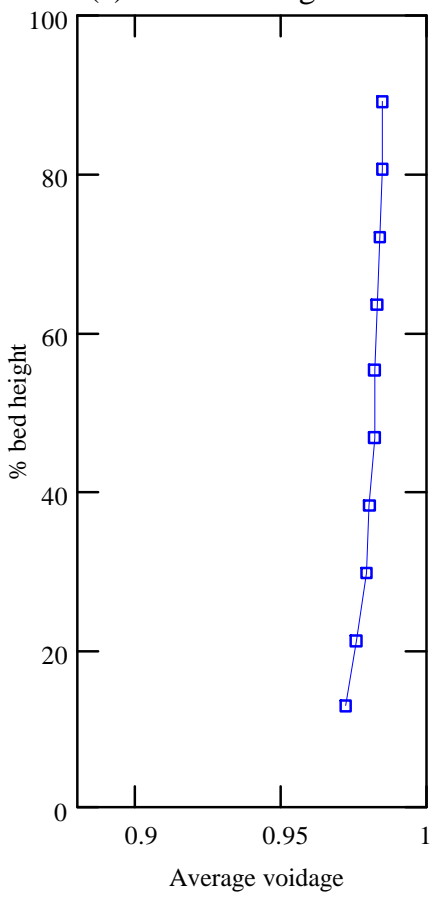

(c) Bode Plot

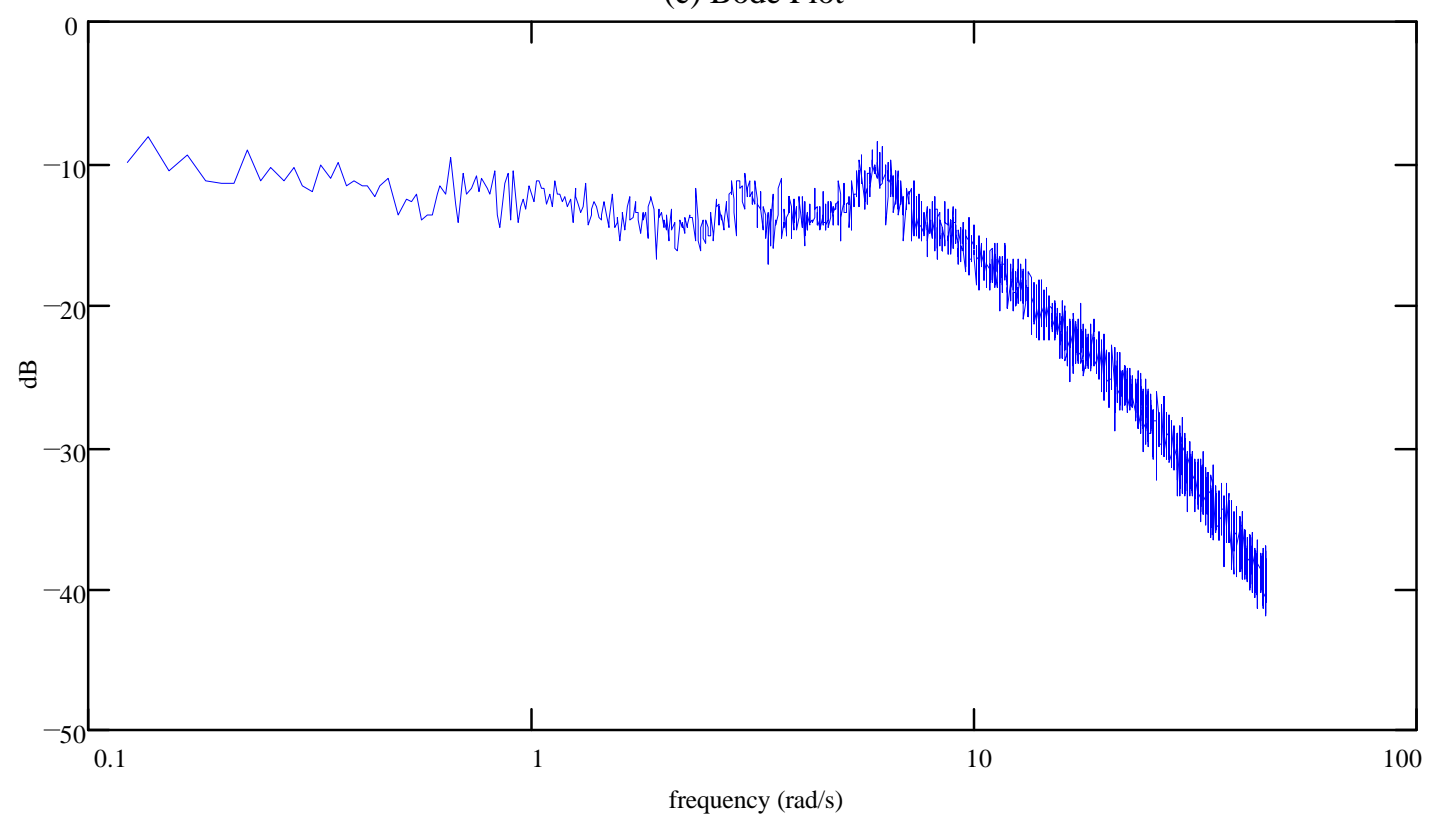

Figure 65: Dilute CFB operating conditions - a) axial voidage, b) PSD, c) Bode plot 
91

CFB Operating Conditions

$\mathrm{G}_{\mathrm{s}}=17 \mathrm{~kg} / \mathrm{m}^{2} \mathrm{~s}$

$\mathrm{U}=4.7 \mathrm{~m} / \mathrm{s}$ (air @ $1.0 \mathrm{~atm}$ )

$\mathrm{D}=10.2 \mathrm{~cm}$

$\mathrm{d}_{\mathrm{p}}=0.4 \mathrm{~mm}$ (glass beads)

Differential pressure measurement

@ $13 \%$ bed height $-25.4 \mathrm{~cm}$ tap spacing

(b) Power Spectral Density

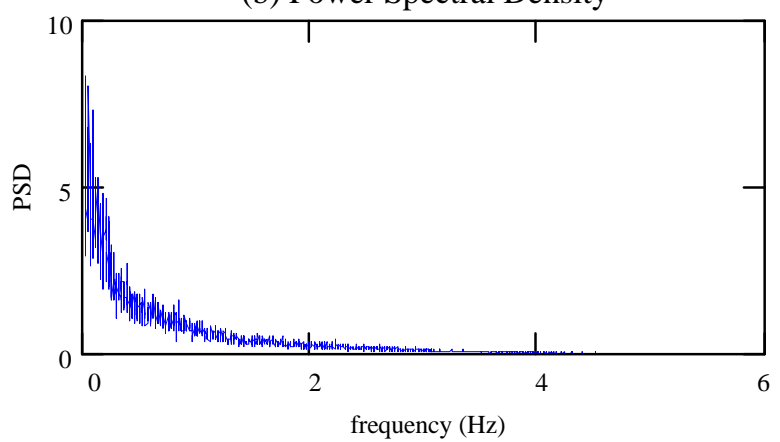

(a) Axial Voidage Profile

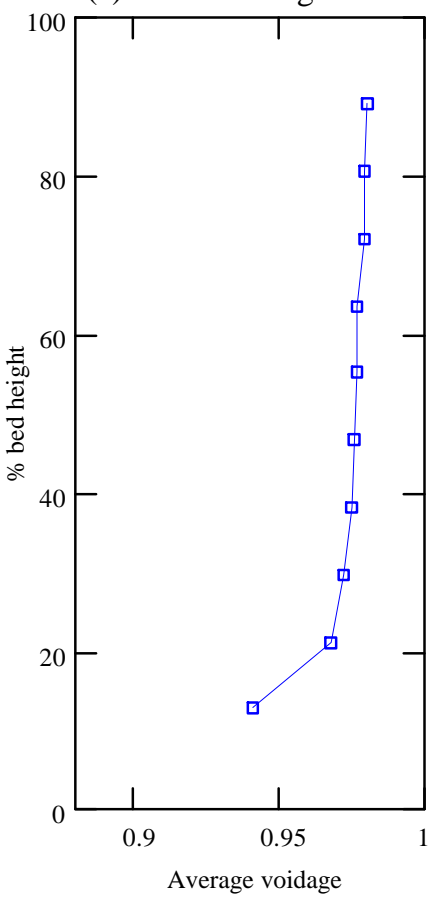

(c) Bode Plot

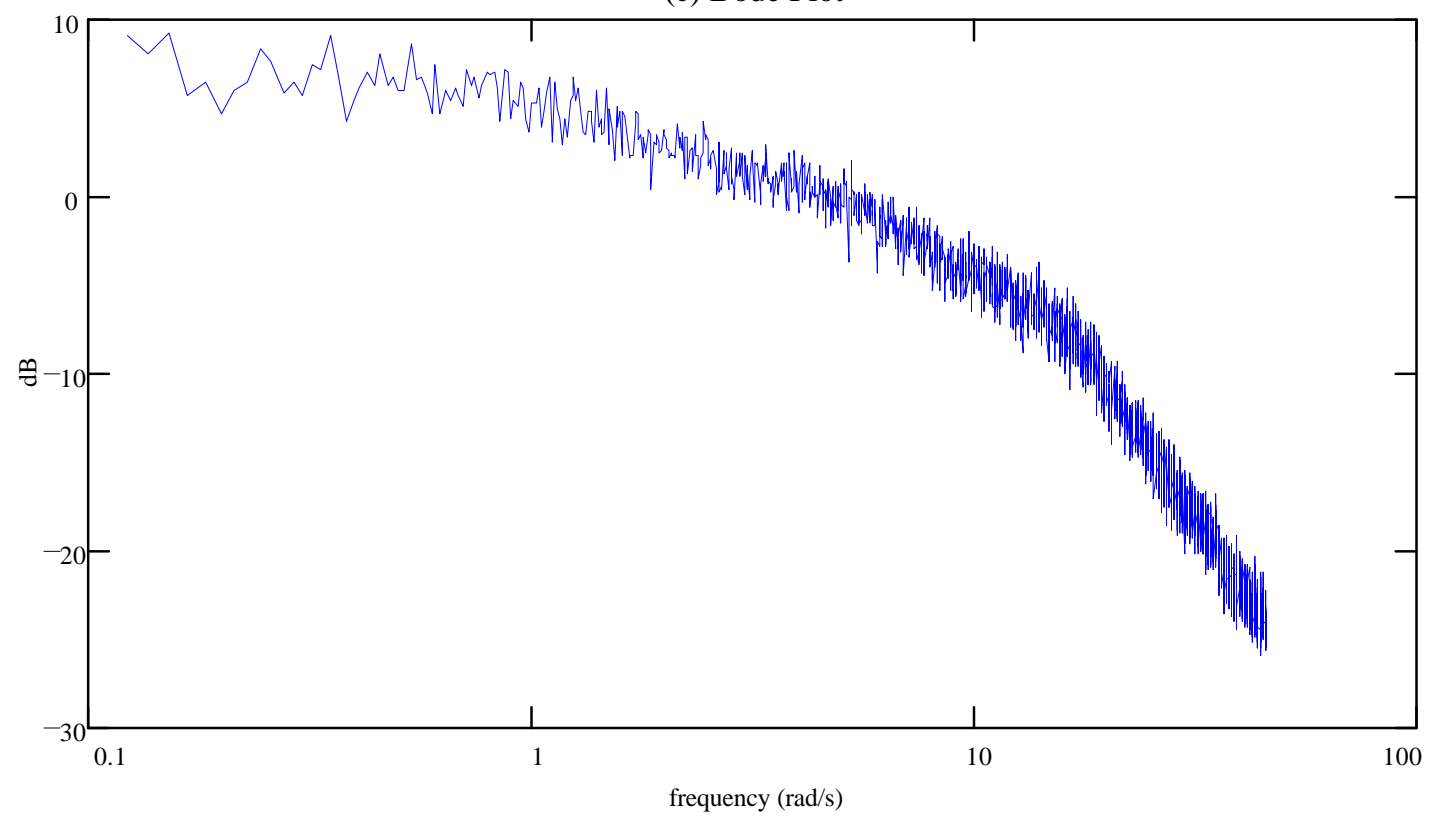

Figure 66: Damped CFB operating conditions - a) axial voidage, b) PSD, c) Bode plot 
CFB Operating Conditions

$\mathrm{G}_{\mathrm{s}}=23 \mathrm{~kg} / \mathrm{m}^{2} \mathrm{~s}$

$\mathrm{U}=4.7 \mathrm{~m} / \mathrm{s}$ (air@1.0 atm)

$\mathrm{D}=10.2 \mathrm{~cm}$

$\mathrm{d}_{\mathrm{p}}=0.4 \mathrm{~mm}$ (glass beads)

Differential pressure measurement

@ $13 \%$ bed height $-25.4 \mathrm{~cm}$ tap spacing

(b) Power Spectral Density

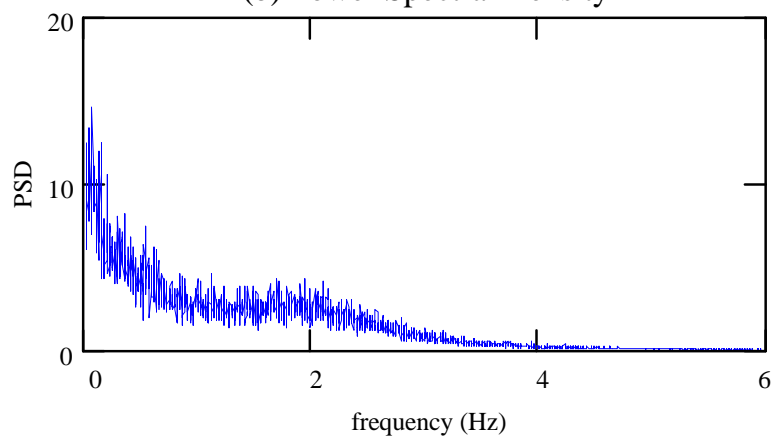

(a) Axial Voidage Profile

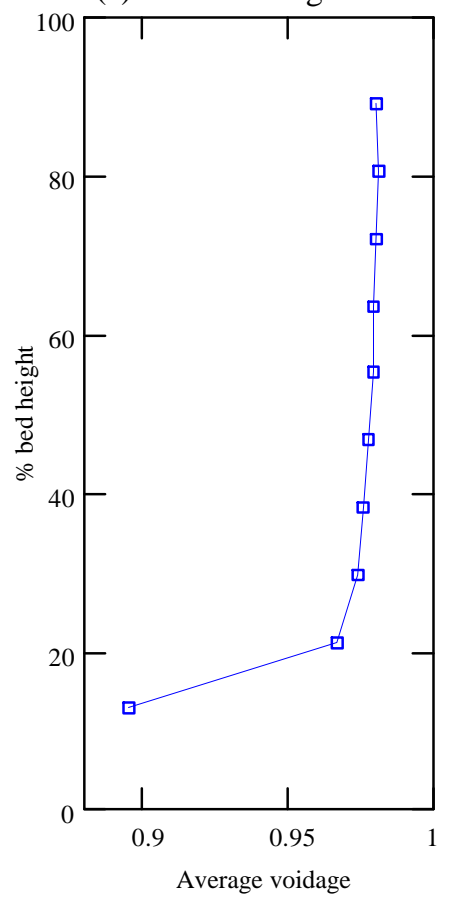

(c) Bode Plot

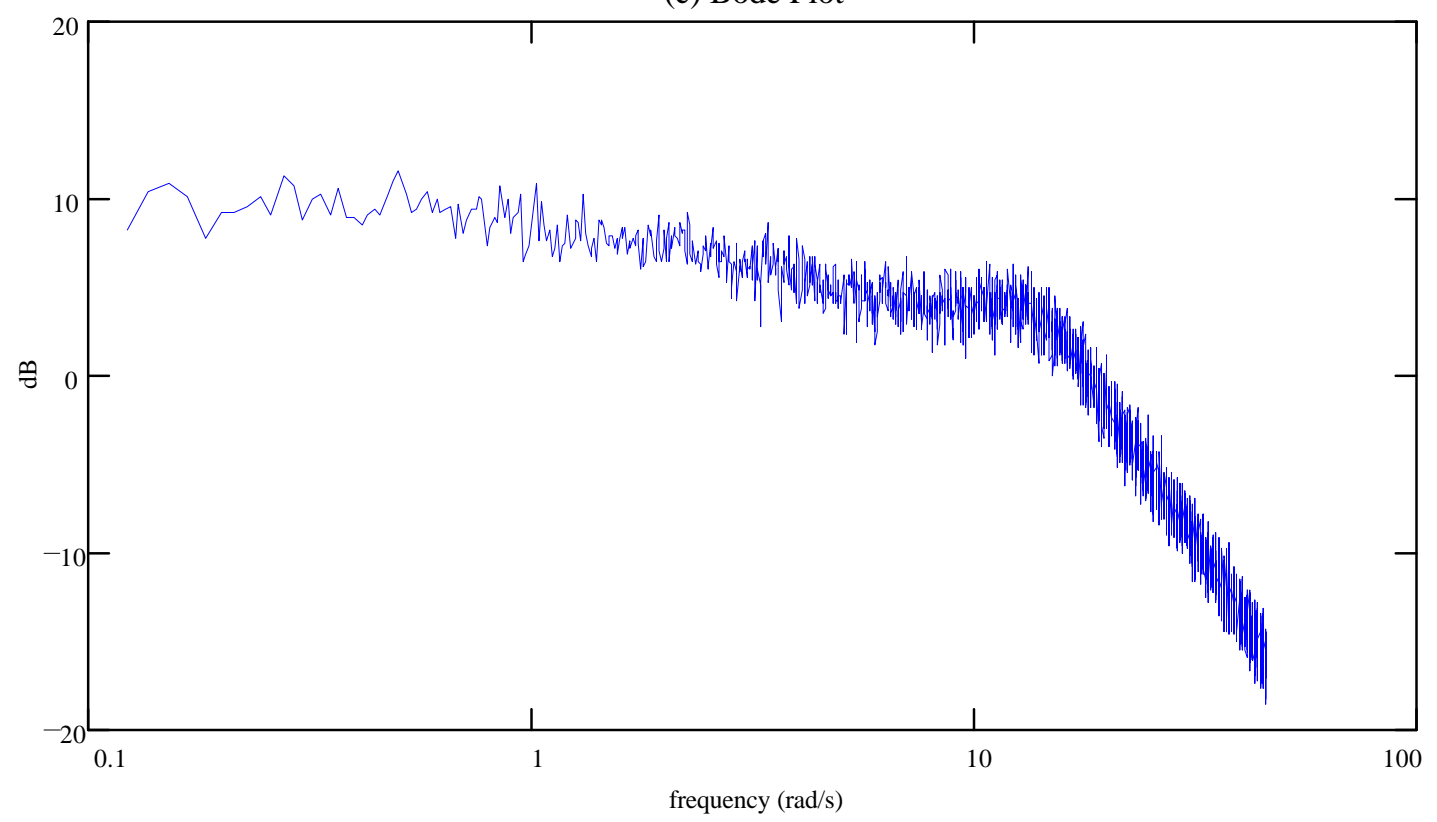

Figure 67: Dense CFB operating conditions - a) axial voidage, b) PSD, c) Bode plot 


\section{CFB Operating conditions:}

$$
\begin{aligned}
& \mathrm{U}=4.1 \pm 0.2 \mathrm{~m} / \mathrm{s} \text { (air @ } 1.0 \mathrm{~atm}) \\
& \mathrm{G}_{\mathrm{s}}=18 \pm 4 \mathrm{~kg} / \mathrm{m}^{2} \mathrm{~s} \\
& \mathrm{D}=10.2 \mathrm{~cm} \\
& \mathrm{~d}_{\mathrm{p}}=0.3 \mathrm{~mm} \text { (glass beads) }
\end{aligned}
$$

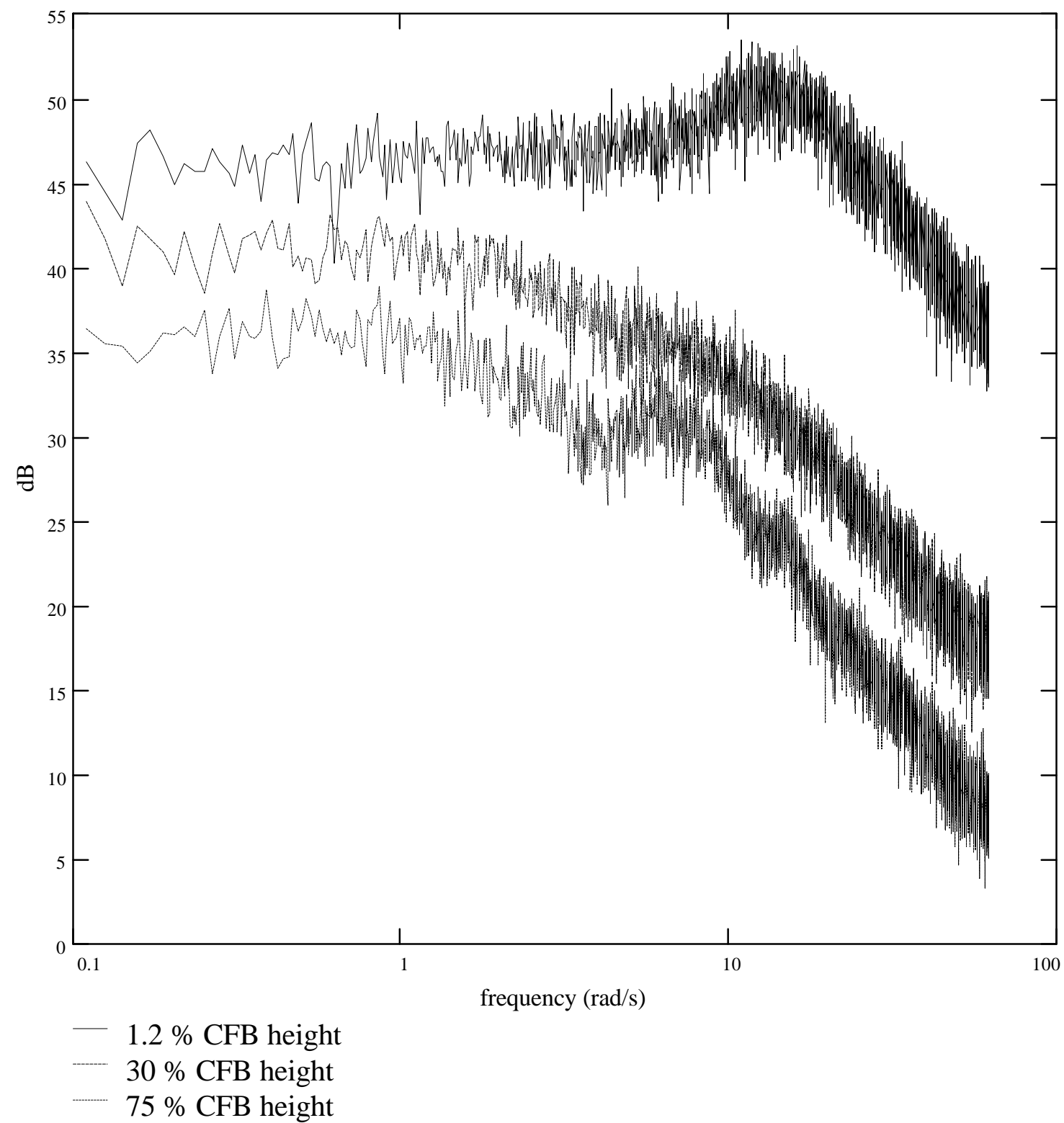

Figure 68: Appearance of dense phase phenomena at various bed elevations 
attained, the lower dense bed height in the large CFB will be twice the height of the small CFB dense bed. Consequently, the lower dense bed frequency in the model CFB appears at a frequency that is 1.4 ( or $2^{1 / 2}$ ) times the frequency that is observed in the prototype CFB. This is shown conclusively in the results of the similitude study that follow. This result suggests that pressure fluctuation measurements at one location could be used as an indicator of the height of the lower dense region in a CFB

\section{Discussion of surface wave frequency phenomena in CFBs}

As seen in the transition regime, surface waves begin to appear in the high velocity turbulent regime prior to fast fluidization. This suggests that this phenomena is associated with the behavior of particles leaving and returning to the dense bed surface, rather than a phenomena associated with the structural CFB height.

Visual observations in circulating fluidized beds and turbulent beds (as they approach fast fluidization) show clusters of solids leaving the dense bed surface at approximately $1 \mathrm{~Hz}$, which corresponds to the frequency peaks observed in the Bode plots. Similar to the transition regime, this frequency of sloshing/cluster propagation originating at the lower dense region of the CFB is hypothesized to be governed by surface wave phenomena. It appears that this frequency is inversely proportional to the square root of the bed diameter, which further supports the hypothesis of pressure fluctuations governed by deep wave phenomena. This result suggests that pressure fluctuation measurements at one location could be used as an indicator of the height of the lower dense region in a CFB.

\section{$\underline{\text { Summary of CFB pressure fluctuations }}$}

CFB pressure fluctuations are indicative of CFB hydrodynamics in two ways. First, the frequency phenomenon that is observed in the lower regions of the CFB under conditions of high solids loading is the result of lower dense bed voidage oscillations as observed in bubbling and turbulent beds also. Our results suggest that a surface wave phenomena inversely proportional to the square root of the bed diameter is also be observed in CFB pressure fluctuations under most conditions. Knowing how pressure fluctuations reflect CFB hydrodynamics, it is possible to use the analysis of pressure fluctuations to validate proposed similitude parameters. 
$\underline{\text { Investigation of CFB similitude parameters }}$

The results of the CFB similitude study are summarized in Table 5. In Table 5, the degree of similarity between the hydrodynamics in the model and prototype CFB is presented. Under these proposed conditions of similitude, a number of characteristics can be noted. The Bode plot profiles in the upper bed ( $75 \%$ bed height) match relatively well in the model and prototype CFB under most conditions. This occurs even when the axial voidage profiles do not match well. This is to be expected from the present understanding of the surface wave phenomenon, which dominates in the upper CFB elevations. The surface wave phenomenon is primarily a function of bed diameter and is not expected to vary with changing operating conditions. The surface wave (dimensionless) frequency will match in two CFBs as long as the bed diameters are scaled properly. Consequently, it cannot be assumed in similitude studies that pressure fluctuations in the upper regions can by themselves verify similitude relations. Upper bed fluctuations must be used in conjunction with lower bed fluctuations and axial voidage profiles before any valid conclusions regarding CFB similitude can be made.

In contrast to upper CFB Bode plots, the lower dense bed fluctuations and axial voidage profiles are rarely similar in prototype and model under Glicksman's conditions of similitude. The model shows a significantly higher voidage in the lower bed than the prototype. The voidage wave frequency in the prototype and model CFB rarely exhibit similar dimensionless frequency and damping. Only under dilute operating conditions were approximately similar hydrodynamics occasionally observed.

It is also important to observe that the matching of Glicksman's similitude parameters does not guarantee that choking conditions in one bed will yield choking conditions in the other. There are three experiments in the model (shown in Table 5) that could not be duplicated in the prototype due to conditions of complete choking under the prescribed similitude parameters. 
96

Table 5. Summary of CFB similitude tests using Glicksman's parameters

Dependent parameters compared: $\quad$ AVP - axial voidage profiles

$5 \%$ - Bode plots from $5 \%$ total bed height

$21 \%$ - Bode plots from $21 \%$ total bed height

$75 \%$ - Bode plots from $75 \%$ total bed height

\begin{tabular}{|c|c|c|c|c|c|c|c|c|c|c|c|}
\hline \# & $\begin{array}{c}\mathrm{H} / \mathrm{dp} \\
\left(\mathrm{x} 10^{-4}\right)\end{array}$ & $\begin{array}{l}\mathrm{D} / \mathrm{dp} \\
\left(\mathrm{x} 10^{-2}\right)\end{array}$ & $\begin{array}{c}\rho_{\mathrm{f}} / \rho_{\mathrm{s}} \\
\left(\mathrm{x} 10^{4}\right) \\
\end{array}$ & $\mathrm{Re}_{\mathrm{p}}$ & $\begin{array}{c}\mathrm{Fr} \\
\left(\mathrm{x} 10^{-3}\right)\end{array}$ & $\begin{array}{l}\mathrm{G}_{\mathrm{s}} / \rho_{\mathrm{s}} \mathrm{U} \\
\left(\mathrm{x} 10^{3}\right)\end{array}$ & $\mathrm{M} / \rho_{\mathrm{S}} \mathrm{D}^{3}$ & AVP & $5 \%$ & $21 \%$ & $75 \%$ \\
\hline & & & & & & & & & & & \\
\hline 1 & 1.5 & 5.1 & 4.7 & 40 & 4.6 & 1.3 & 2.1 & $*$ & $\overline{\text { no }}$ & $*$ & $* *$ \\
\hline 2 & 1.5 & 5.1 & 4.7 & 40 & 4.6 & 1.9 & 2.1 & * & no & no & * \\
\hline 3 & 1.5 & 5.1 & 4.7 & 47 & 6.3 & 1.7 & 2.1 & no & no & $*$ & * \\
\hline 4 & 1.5 & 5.1 & 4.7 & 47 & 6.3 & 2.1 & 2.1 & no & no & no & $* *$ \\
\hline 5 & 1.5 & 5.1 & 4.7 & 47 & 6.3 & 2.8 & 2.7 & $*$ & no & $*$ & $* *$ \\
\hline 6 & 1.5 & 5.1 & 4.7 & 54 & 8.2 & 1.9 & 2.1 & no & $*$ & $*$ & * \\
\hline 7 & 1.5 & 5.1 & 4.7 & 54 & 8.2 & 2.4 & 2.7 & $*$ & no & no & * \\
\hline & & & & & & & & & & & \\
\hline 8 & 1.1 & 3.4 & 4.7 & 71 & 4.2 & 1.1 & 2.1 & no & no & no & * \\
\hline 9 & 1.1 & 3. & 4. & 71 & 4.2 & 1.7 & 2.1 & NP & NP & NP & $\mathrm{NP}$ \\
\hline 10 & 1.1 & 3.4 & 4.7 & 81 & 5.4 & 1.4 & 2.1 & no & no & no & $*$ \\
\hline 11 & 1.1 & 3.4 & 4.7 & 81 & 5.4 & 1.9 & 2.7 & no & no & no & * \\
\hline 12 & 1.1 & 3.4 & 4.7 & 81 & 5.4 & 2.4 & 2.1 & NP & NP & NP & $\mathrm{NP}$ \\
\hline 13 & 1.1 & 3.4 & 4.7 & 110 & 11 & 1.4 & 2.1 & no & no & $*$ & ** \\
\hline 14 & 1.1 & 3.4 & 4.7 & 110 & 11 & 1.7 & 2.7 & no & no & $*$ & $* *$ \\
\hline & & & & & & & & & & & \\
\hline 15 & 0.8 & 2.5 & 4.7 & 108 & 4.1 & 1.0 & 2.1 & no & no & no & $* *$ \\
\hline 16 & 0.8 & 2.5 & 4.7 & 108 & 4.1 & 1.4 & 2.1 & NP & NP & NP & $\mathrm{NP}$ \\
\hline 17 & 0.8 & 2.5 & 4.7 & 126 & 5.6 & 1.2 & 2.1 & no & no & ** & ** \\
\hline 18 & 0.8 & 2.5 & 4.7 & 126 & 5.6 & 1.6 & 2.7 & $*$ & no & $*$ & ** \\
\hline 19 & 0.8 & 2.5 & 4.7 & 148 & 7.7 & 1.4 & 2.1 & no & * & $*$ & ** \\
\hline 20 & 0.8 & 2.5 & 4.7 & 148 & 7.7 & 1.7 & 2.7 & no & no & $*$ & $* *$ \\
\hline
\end{tabular}

Rating system:

** $\quad$ Bode plots match well in both models

* $\quad$ Not all Bode plot characteristics are similar in prototype and model

no Bode plots are not similar in prototype and model

NP Experiment not possible since chosen similitude parameters resulted in choking conditions in the protoype 
It is hypothesized from these experiments that solids flux is not an appropriate independent variable for the establishing of similitude. Representing a measure of the rate of particles leaving the riser, it is not fundamentally an indicator of the total amount of solids suspended in the riser, which is more important for similitude studies.

An alternative to dimensionless solids flux is suggested by these results. Dimensionless solids loading in the riser was substituted for dimensionless solids flux in the experiments illustrated in Figures 69-78. This was done by maintaining the appropriate level of solids $\left(\mathrm{L}_{\mathrm{v}}\right)$ in the CFB downcomer. The full set of dimensionless similitude parameters used in this approach is:

$$
F r=\frac{U^{2}}{g \cdot d_{p}} \quad \frac{H}{d_{p}} \quad \frac{D}{d_{p}} \quad \frac{\rho_{g}}{\rho_{s}} \quad \operatorname{Re}_{p}=\frac{\rho_{g} \cdot U \cdot d_{p}}{\mu} \quad \frac{M}{\rho_{s} \cdot D^{3}} \quad \frac{L_{v}}{D}
$$

The pressure fluctuation Bode plots and the axial voidage profiles match very well when this full set of parameters is matched. In spite of these hydrodynamic similarities, there is one obvious difference between the conditions in the two cases. The dimensionless solids flux (now used as a dependent parameter) is over 50\% greater in the model than the prototype. It was hypothesized that this may be the result of differences in the elasticity of the solids in the riser; changing the dynamics of particle/particle or particle/bed collisions.

Since the predominant collisions in the riser occur between particles and the riser topplate, differences between the steel shot/aluminum top-plate (model) collisions and the glass bead/Plexiglas top-plate (prototype) collisions were investigated. By measuring the rebound height of steel and glass beads, the coefficients of restitution were estimated:

$$
e=\sqrt{\frac{h_{r}}{H_{d}}}
$$

where $\mathrm{H}_{\mathrm{d}}$ is the drop height and $\mathrm{h}_{\mathrm{r}}$ is the rebound height. The resulting coefficient of restitution of glass/Plexiglas collision is over $50 \%$ higher than the coefficient of restitution of steel/aluminum collision. This being the case, the glass particles in the large CFB model are more likely to rebound off the top-plate and back down into the riser, rather than exiting the riser to the cyclone. As a result, the internal recycle rate of steel shot will be much higher, yielding a higher solids flux in the model reactor. The axial voidage profiles in Figures 69 and 74 support this hypothesis by showing a slightly denser upper region in the prototype. 
To definitively support this hypothesis that the top-plate collision strongly affects the measured solids flux, 26" and 13" extensions were added to the large and small CFBs respectively. These extensions allowed particles to progress beyond the riser exit, and change direction, without contacting the riser top-plate. The results of this experiment presented in Figures 79-83 confirms that the coefficient of restitution of particle/bed collisions is an important consideration in similitude studies. In this experiment, the dimensionless solids flux matches exactly in both beds, in addition to pressure fluctuations and axial voidage profiles. Complete hydrodynamic similitude was achieved in this test.

A number of conclusions can be drawn from this CFB similitude study. First, spectral analysis of pressure fluctuations, if properly applied, can be used to verify that similitude has been achieved. To do this, not only must the Bode plot characteristics important for hydrodynamics be identified, but the pressure fluctuation structure at all elevations of the CFB must be similar. The set of similitude parameters defined by Glicksman is not sufficient to establish hydrodynamic similitude. The solids flux as typically measured in the downcomer does not contain information on the solids hold-up in the riser, or the amount of solids that progress downwards in the annulus rather than exit the riser. It is better to use the total mass contained in the riser (using a measurement such as $\mathrm{L}_{\mathrm{v}}$ ) as the important "solids" parameter for the establishment of similitude, rather than the solids flux. This measurement of $\mathrm{L}_{\mathrm{v}}$ can be made more accurately, monitored continuously, and is a much simpler measurement to perform in most CFB systems. Even with this new set of dimensionless parameters, the differences in the coefficient of restitution of particle/bed collisions may make a significant difference in the CFB hydrodynamics.

\section{L-valve Flow Characteristics}

With the proposed set of similitude parameters including the L-valve height, the need for understanding the effect L-valve height has on bed hydrodynamics becomes important. With the scale setup to measure the solids mass out of the L-valve, a number of aeration rates and particle diameters were run. A characteristic set of results is given in Figure 84

The data as shown in Figure 84 shows that L-valve flow rate is essentially constant at high heights. As the standpipe height drops, a point is reached at which the flow rate begins to decrease. The height at which the solids flow rate decreases is lowered with increasing aeration 
Table 6. Operating conditions for similitude experiments (Figs. 7-11) Using riser loading as the independent solids parameter

\section{SMALL CFB}

\begin{tabular}{|l|l|}
\hline $\mathrm{L}_{\mathrm{v}}$ & $23 \pm 1$ inches \\
\hline Reactor loading & $750 \pm 25 \mathrm{~mL}$ \\
\hline Superficial velocity & $2.9 \pm 0.1 \mathrm{~m} / \mathrm{s}$ \\
\hline Solids flux & $30 \pm 4 \mathrm{~kg} / \mathrm{m}^{2} \mathrm{~s}$ \\
\hline & \\
\hline Rep & $85 \pm 12$ \\
\hline Fr & $5700 \pm 800$ \\
\hline $\mathrm{G}_{\mathrm{s}} / \rho_{\mathrm{s}} \mathrm{U}$ & $0.0014 \pm 0.0002$ \\
\hline $\mathrm{H} / \mathrm{d}_{\mathrm{p}}$ & $10200 \pm 1400$ \\
\hline $\mathrm{D} / \mathrm{d}_{\mathrm{p}}$ & $340 \pm 50$ \\
\hline$\rho_{\mathrm{g}} / \rho_{\mathrm{s}}$ & $2150 \pm 30$ \\
\hline $\mathrm{M} / \rho_{\mathrm{s}} \mathrm{D}^{3}$ & $3.15 \pm 0.08$ \\
\hline
\end{tabular}

\section{LARGE CFB}

\begin{tabular}{|l|l|}
\hline $\mathrm{L}_{\mathrm{v}}$ & $45 \pm 2$ inches \\
\hline Reactor loading & $6000 \pm 200 \mathrm{~mL}$ \\
\hline Superficial velocity & $4.1 \pm 0.1 \mathrm{~m} / \mathrm{s}$ \\
\hline Solids flux & $10 \pm 2 \mathrm{~kg} / \mathrm{m}^{2} \mathrm{~s}$ \\
\hline & \\
\hline Rep & $84 \pm 5$ \\
\hline Fr & $5800 \pm 500$ \\
\hline $\mathrm{G} / \rho_{\mathrm{s}} \mathrm{U}$ & $0.0009 \pm 0.0002$ \\
\hline $\mathrm{H} / \mathrm{d}_{\mathrm{p}}$ & $10200 \pm 300$ \\
\hline $\mathrm{D} / \mathrm{d}_{\mathrm{p}}$ & $340 \pm 10$ \\
\hline$\rho_{\mathrm{g}} / \rho_{\mathrm{s}}$ & $2150 \pm 70$ \\
\hline $\mathrm{M} / \rho_{\mathrm{s}} \mathrm{D}^{3}$ & $3.15 \pm 0.05$ \\
\hline
\end{tabular}

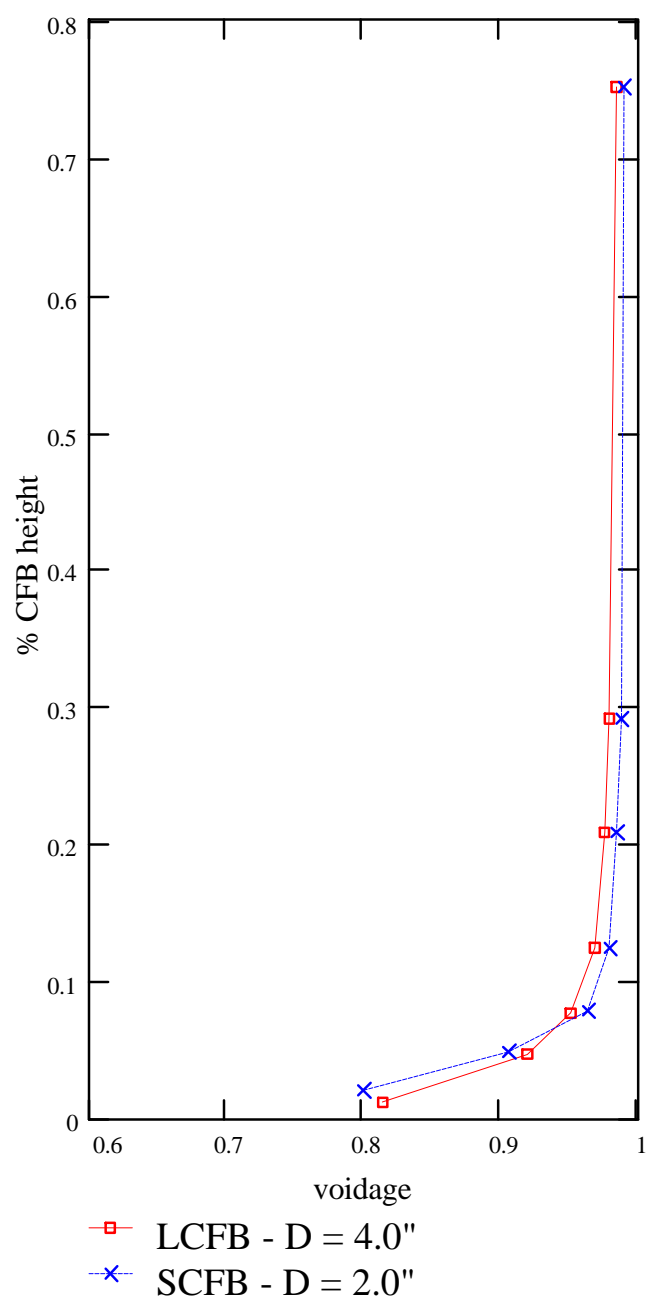

Figure 69: CFB axial voidage profiles (Using revised similitude parameters) 


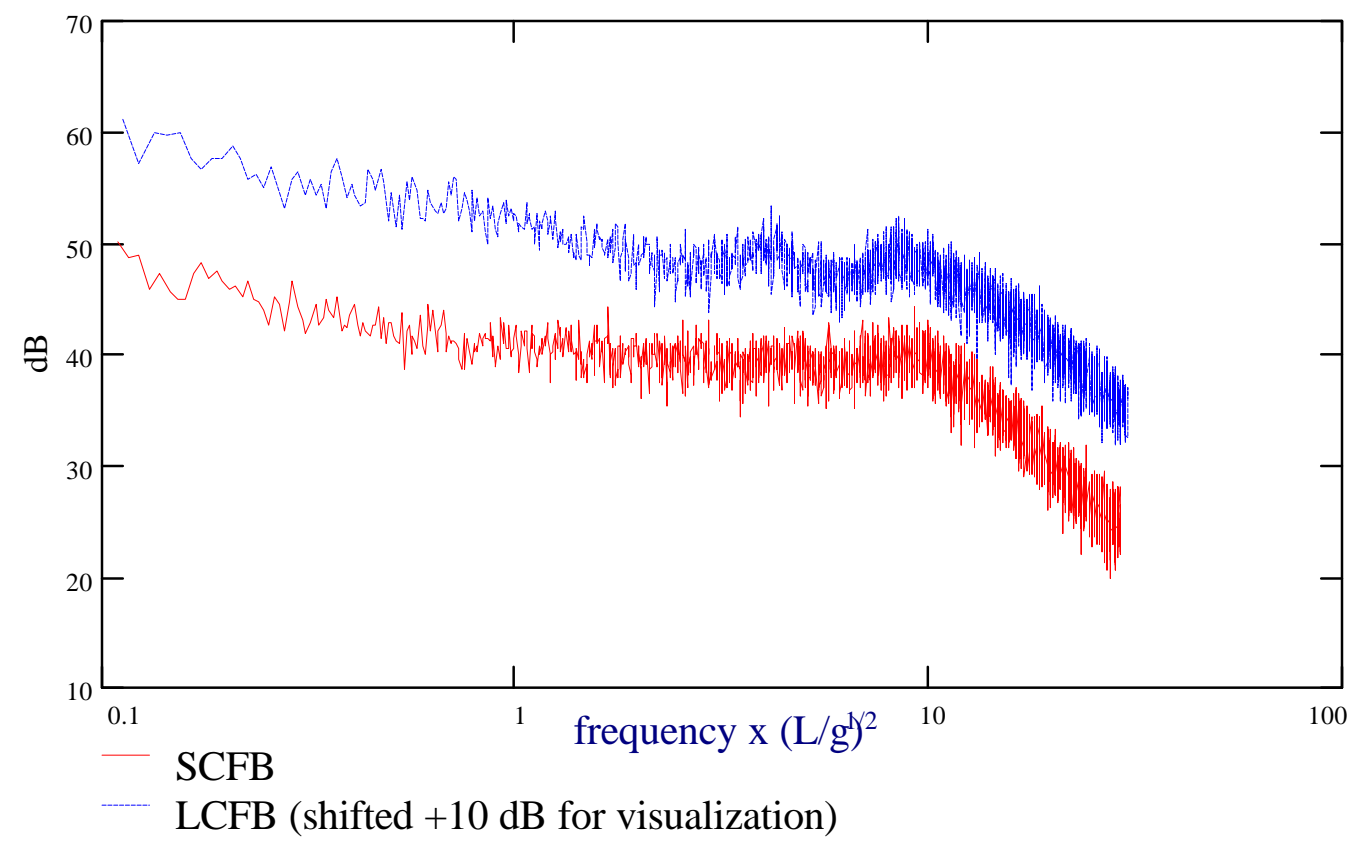

Figure 70: Bode plots of CFB under similitude conditions (1-2 \% bed height) Using revised similitude parameters

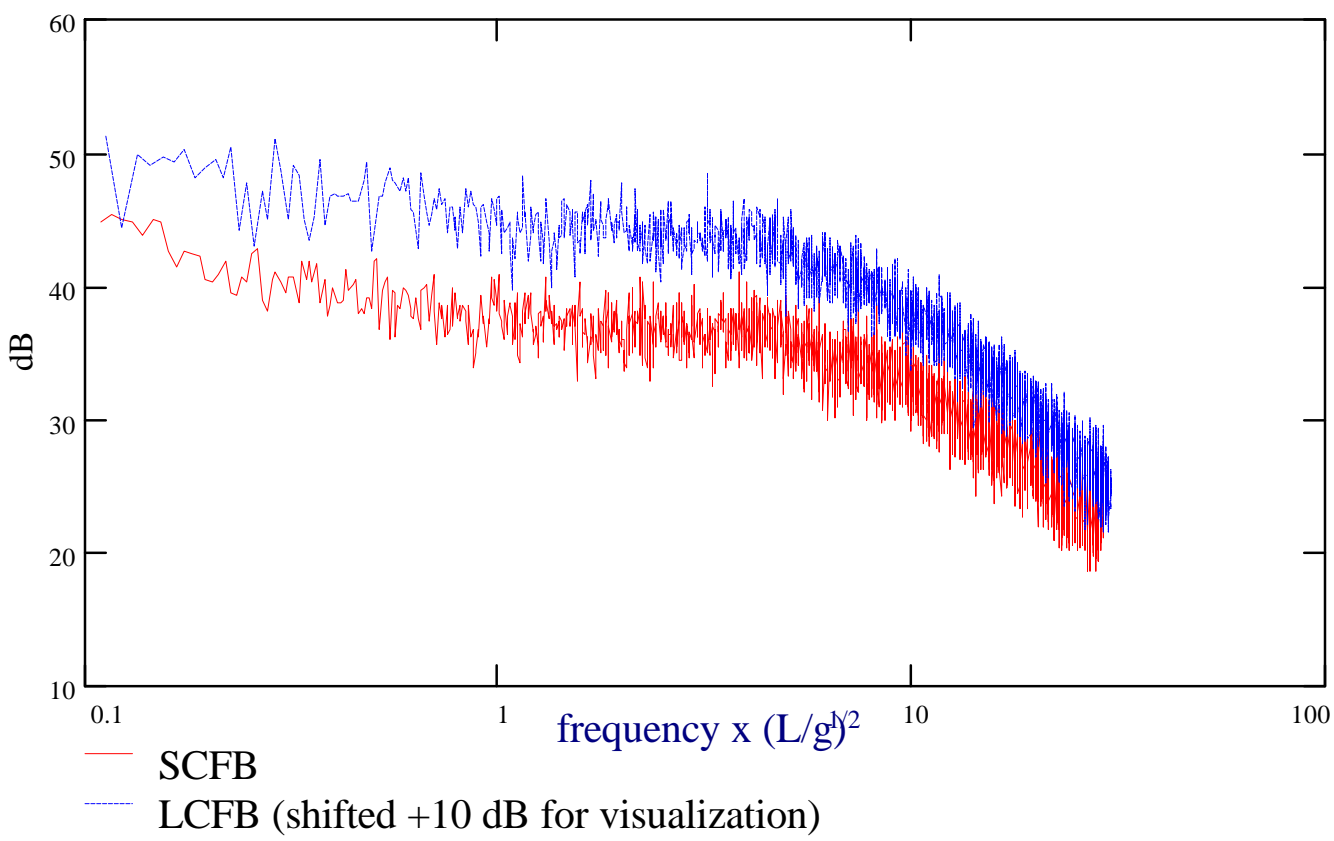

Figure 71: Bode plots of CFB under similitude conditions (5 \% bed height) Using revised similitude parameters 


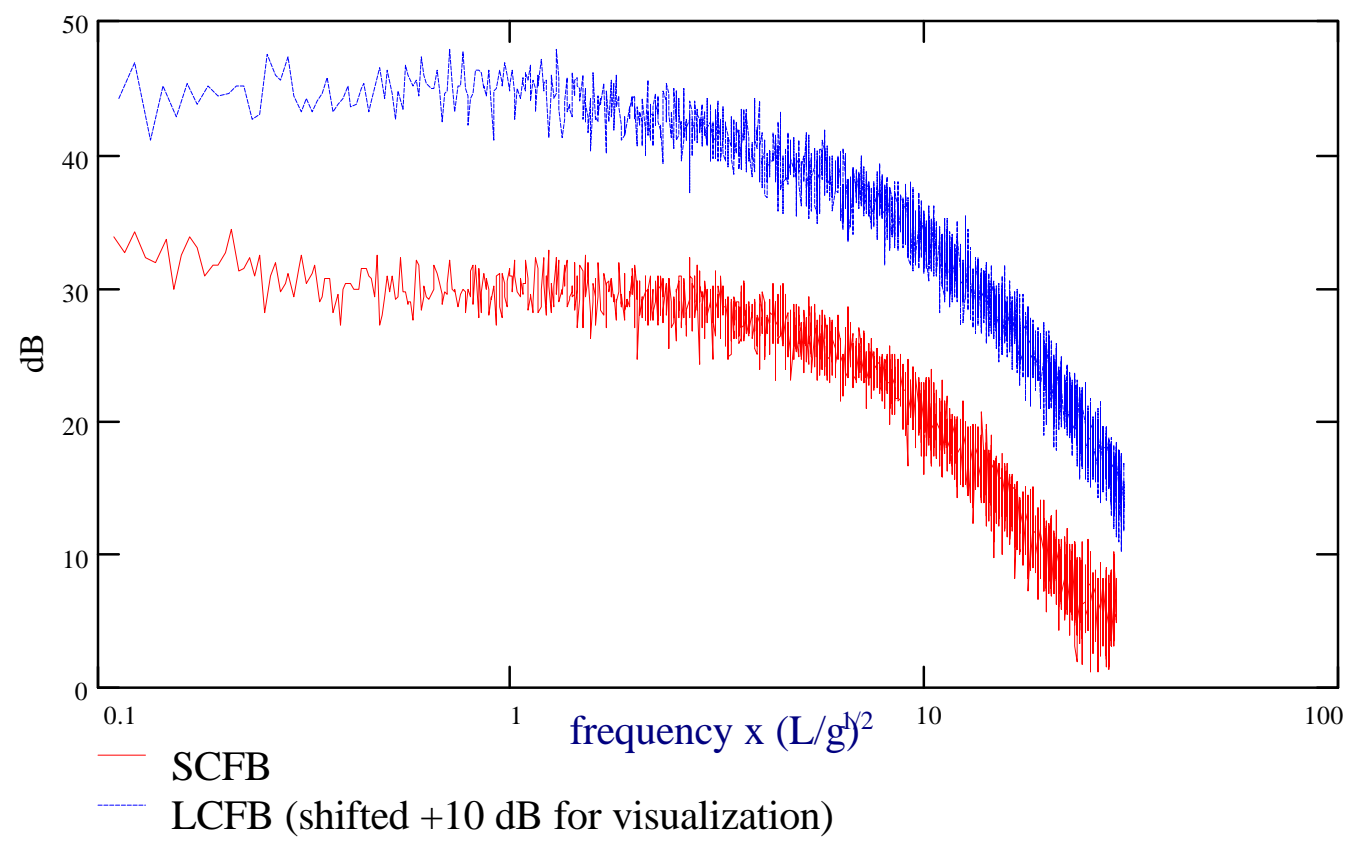

Figure 72: $\quad$ Bode plots of CFB under similitude conditions (13\% bed height) Using revised similitude parameters

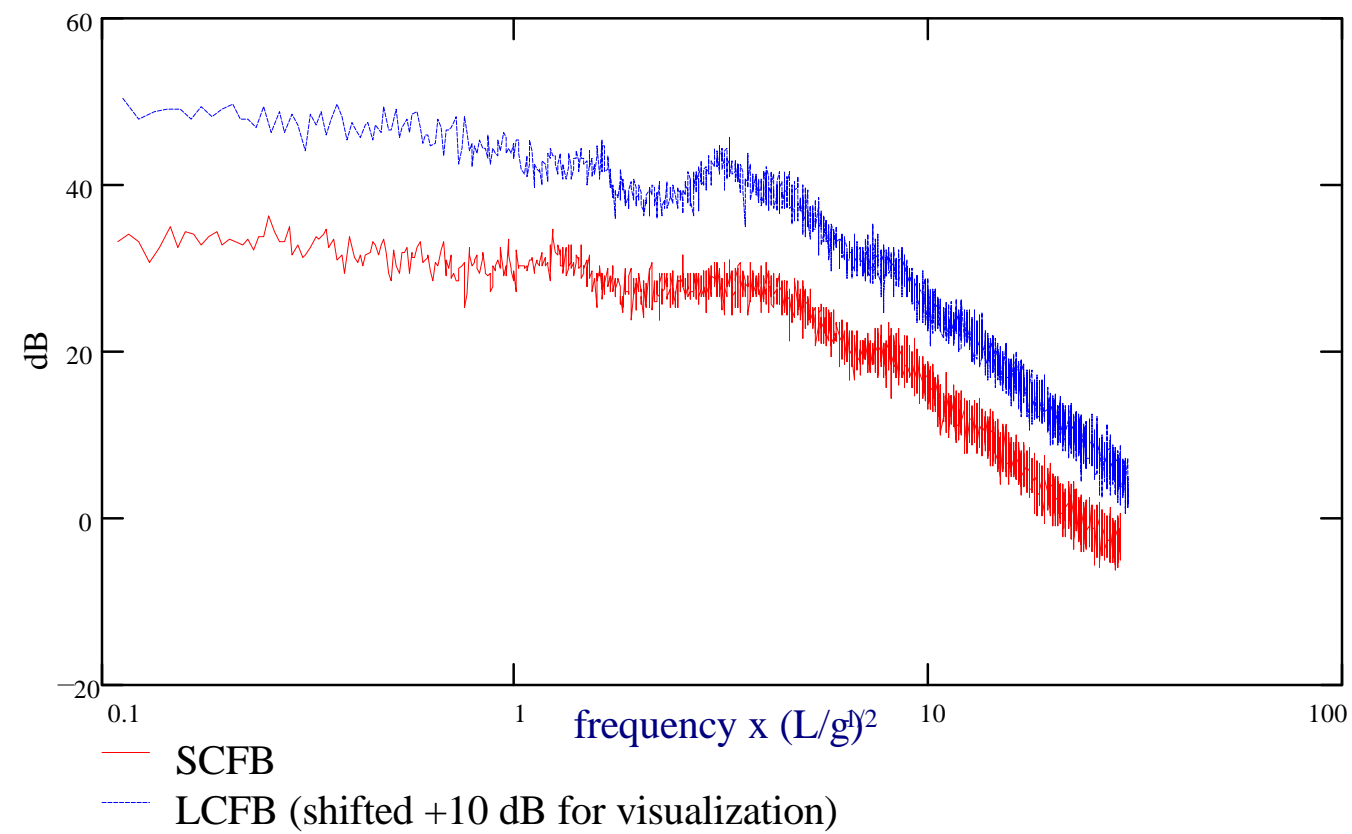

Figure 73: $\quad$ Bode plots of CFB under similitude conditions (75\% bed height) Using revised similitude parameters 
Table 7 Operating conditions for similitude experiments (Figs. 12-16) Using riser loading as the independent solids parameter

\section{SMALL CFB}

\begin{tabular}{|l|l|}
\hline $\mathrm{L}_{\mathrm{v}}$ & $16 \pm 2$ inches \\
\hline Reactor loading & $750 \pm 25 \mathrm{~mL}$ \\
\hline Superficial velocity & $3.2 \pm 0.1 \mathrm{~m} / \mathrm{s}$ \\
\hline Solids flux & $35 \pm 2 \mathrm{~kg} / \mathrm{m}^{2} \mathrm{~s}$ \\
\hline & \\
\hline Rep & $95 \pm 13$ \\
\hline Fr & $7000 \pm 1000$ \\
\hline $\mathrm{G}_{s} / \rho_{\mathrm{s}} \mathrm{U}$ & $0.0014 \pm 0.0002$ \\
\hline $\mathrm{H} / \mathrm{d}_{\mathrm{p}}$ & $10200 \pm 1400$ \\
\hline $\mathrm{D} / \mathrm{d}_{\mathrm{p}}$ & $340 \pm 50$ \\
\hline$\rho_{\mathrm{g}} / \rho_{\mathrm{s}}$ & $2150 \pm 30$ \\
\hline $\mathrm{M} / \rho_{\mathrm{s}} \mathrm{D}^{3}$ & $3.15 \pm 0.08$ \\
\hline
\end{tabular}

\section{LARGE CFB}

\begin{tabular}{|l|l|}
\hline $\mathrm{L}_{\mathrm{v}}$ & $32 \pm 1$ inches \\
\hline Reactor loading & $6000 \pm 200 \mathrm{~mL}$ \\
\hline Superficial velocity & $4.5 \pm 0.1 \mathrm{~m} / \mathrm{s}$ \\
\hline Solids flux & $13 \pm 5 \mathrm{~kg} / \mathrm{m}^{2} \mathrm{~s}$ \\
\hline & \\
\hline Rep & $92 \pm 5$ \\
\hline Fr & $7000 \pm 500$ \\
\hline $\mathrm{G}_{\mathrm{s}} / \rho_{\mathrm{s}} \mathrm{U}$ & $0.0010 \pm 0.0004$ \\
\hline $\mathrm{H} / \mathrm{d}_{\mathrm{p}}$ & $10200 \pm 300$ \\
\hline $\mathrm{D} / \mathrm{d}_{\mathrm{p}}$ & $340 \pm 10$ \\
\hline$\rho_{\mathrm{g}} / \rho_{\mathrm{s}}$ & $2150 \pm 70$ \\
\hline $\mathrm{M} / \rho_{\mathrm{s}} \mathrm{D}^{3}$ & $3.15 \pm 0.05$ \\
\hline
\end{tabular}

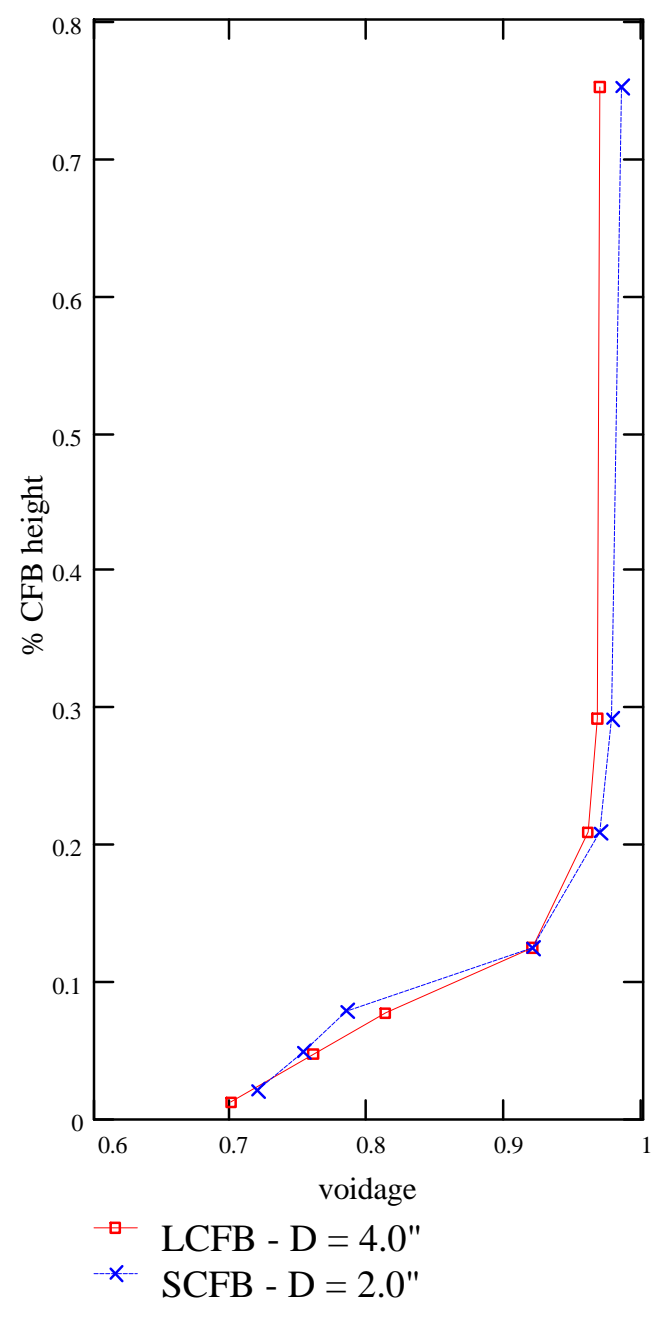

Figure 74: CFB axial voidage profiles (Using revised similitude parameters) 


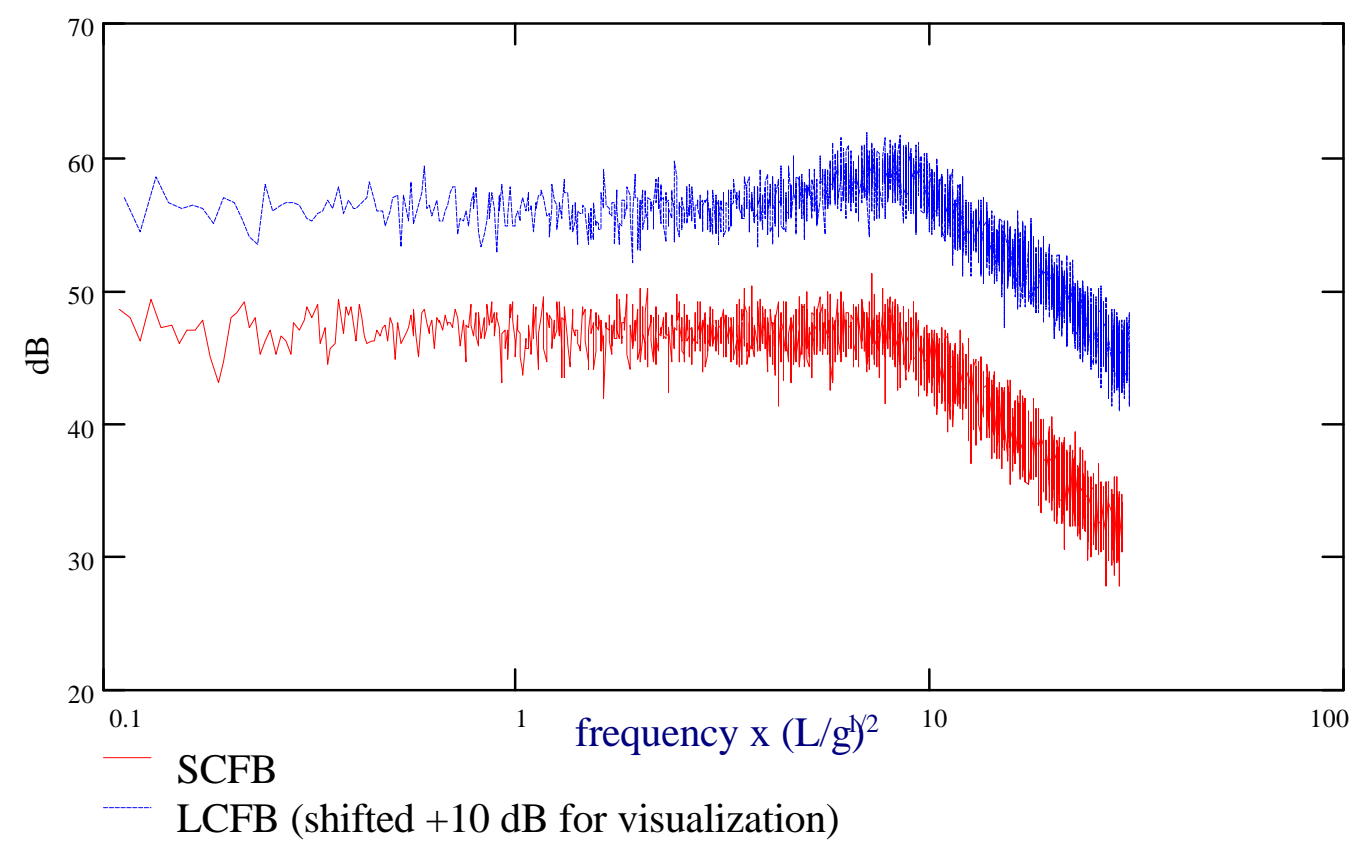

Figure 75: Bode plots of CFB under similitude conditions (1-2\% bed height) Using revised similitude parameters

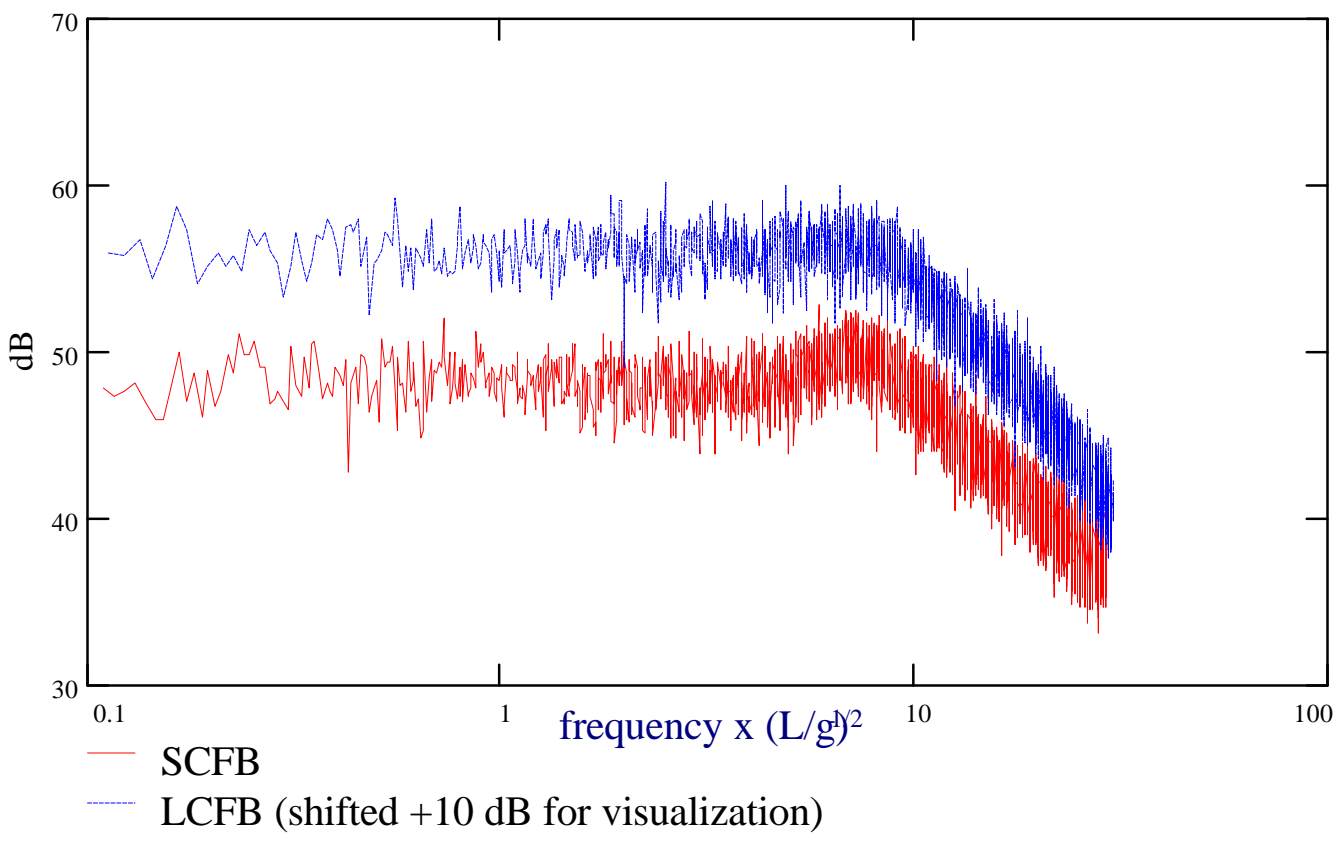

Figure 76: Bode plots of CFB under similitude conditions (5\% bed height) Using revised similitude parameters 


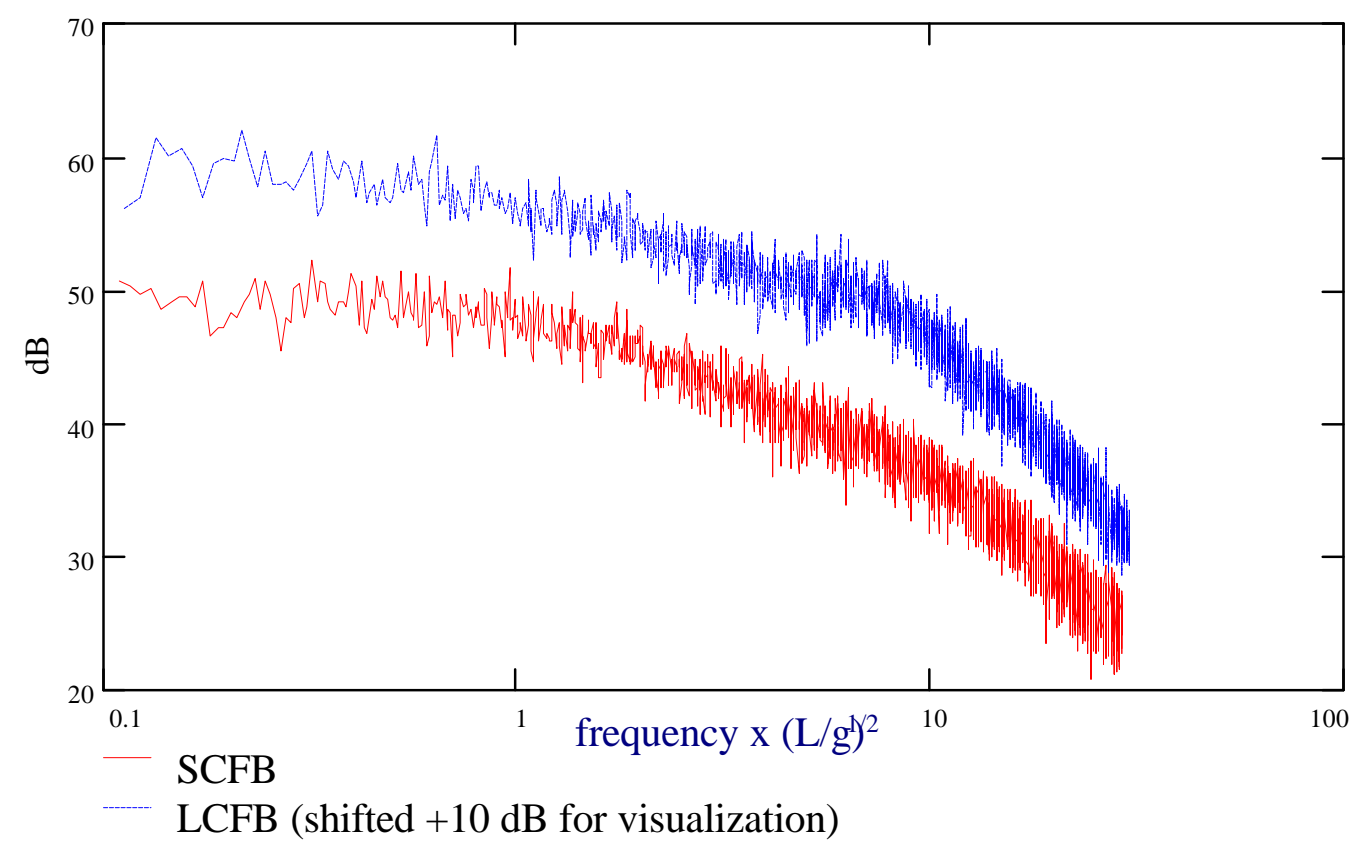

Figure 77: Bode plots of CFB under similitude conditions (13\% bed height) Using revised similitude parameters

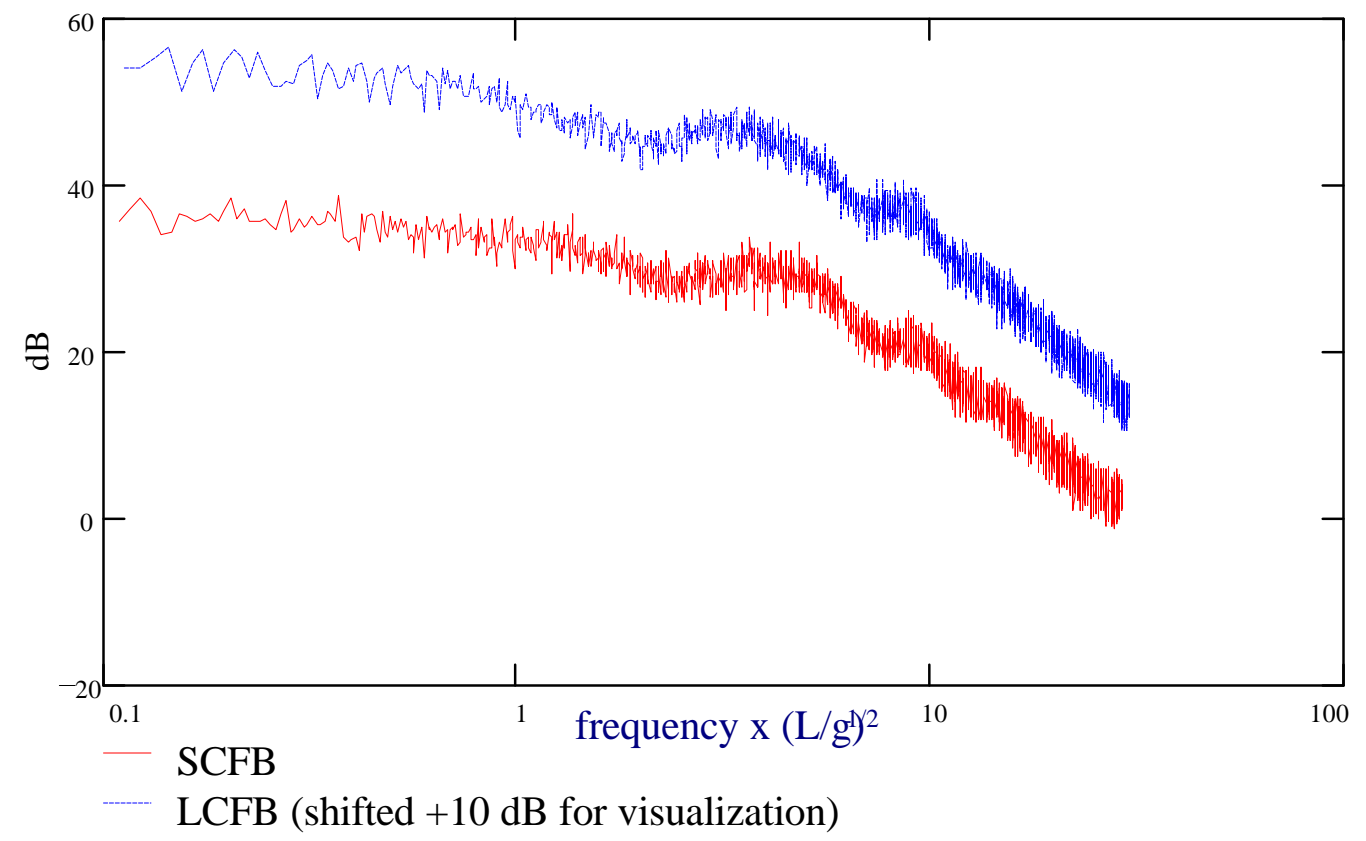

Figure 78: Bode plots of CFB under similitude conditions (75 \% bed height) Using revised similitude parameters 
Table 8. Operating conditions for similitude experiments (Figs. 79-83) Using dead-space extensions

\section{SMALL CFB}

\begin{tabular}{|l|l|}
\hline $\mathrm{L}_{\mathrm{v}}$ & $23 \pm 1$ inches \\
\hline Reactor loading & $750 \pm 25 \mathrm{~mL}$ \\
\hline Superficial velocity & $2.9 \pm 0.1 \mathrm{~m} / \mathrm{s}$ \\
\hline Solids flux & $22 \pm 3 \mathrm{~kg} / \mathrm{m}^{2} \mathrm{~s}$ \\
\hline & \\
\hline Rep & $85 \pm 12$ \\
\hline Fr & $5700 \pm 800$ \\
\hline $\mathrm{G}_{\mathrm{s}} / \rho_{\mathrm{s}} \mathrm{U}$ & $0.0010 \pm 0.0001$ \\
\hline $\mathrm{H} / \mathrm{d}_{\mathrm{p}}$ & $10200 \pm 1400$ \\
\hline $\mathrm{D} / \mathrm{d}_{\mathrm{p}}$ & $340 \pm 50$ \\
\hline$\rho_{\mathrm{g}} / \rho_{\mathrm{s}}$ & $2150 \pm 30$ \\
\hline $\mathrm{M} / \rho_{\mathrm{s}} \mathrm{D}^{3}$ & $3.15 \pm 0.08$ \\
\hline
\end{tabular}

\section{LARGE CFB}

\begin{tabular}{|l|l|}
\hline $\mathrm{L}_{\mathrm{v}}$ & $46 \pm 2$ inches \\
\hline Reactor loading & $6000 \pm 200 \mathrm{~mL}$ \\
\hline Superficial velocity & $4.1 \pm 0.1 \mathrm{~m} / \mathrm{s}$ \\
\hline Solids flux & $11 \pm 2 \mathrm{~kg} / \mathrm{m}^{2} \mathrm{~s}$ \\
\hline & \\
\hline Rep & $84 \pm 5$ \\
\hline $\mathrm{Fr}$ & $5800 \pm 500$ \\
\hline $\mathrm{G} / \rho_{\mathrm{s}} \mathrm{U}$ & $0.0010 \pm 0.0002$ \\
\hline $\mathrm{H} / \mathrm{d}_{\mathrm{p}}$ & $10200 \pm 300$ \\
\hline $\mathrm{D} / \mathrm{d}_{\mathrm{p}}$ & $340 \pm 10$ \\
\hline$\rho_{\mathrm{g}} / \rho_{\mathrm{s}}$ & $2150 \pm 70$ \\
\hline $\mathrm{M} / \rho_{\mathrm{s}} \mathrm{D}^{3}$ & $3.15 \pm 0.05$ \\
\hline
\end{tabular}

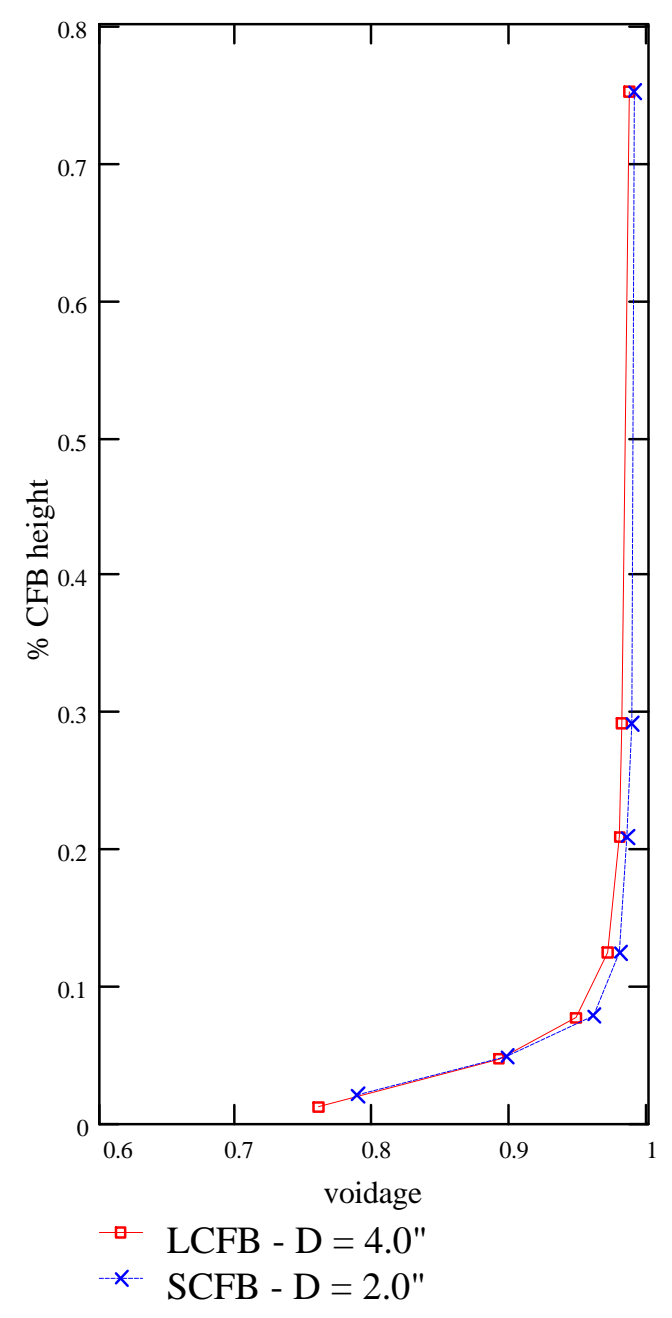

Figure 79: CFB axial voidage profiles (Using dead-space extensions) 


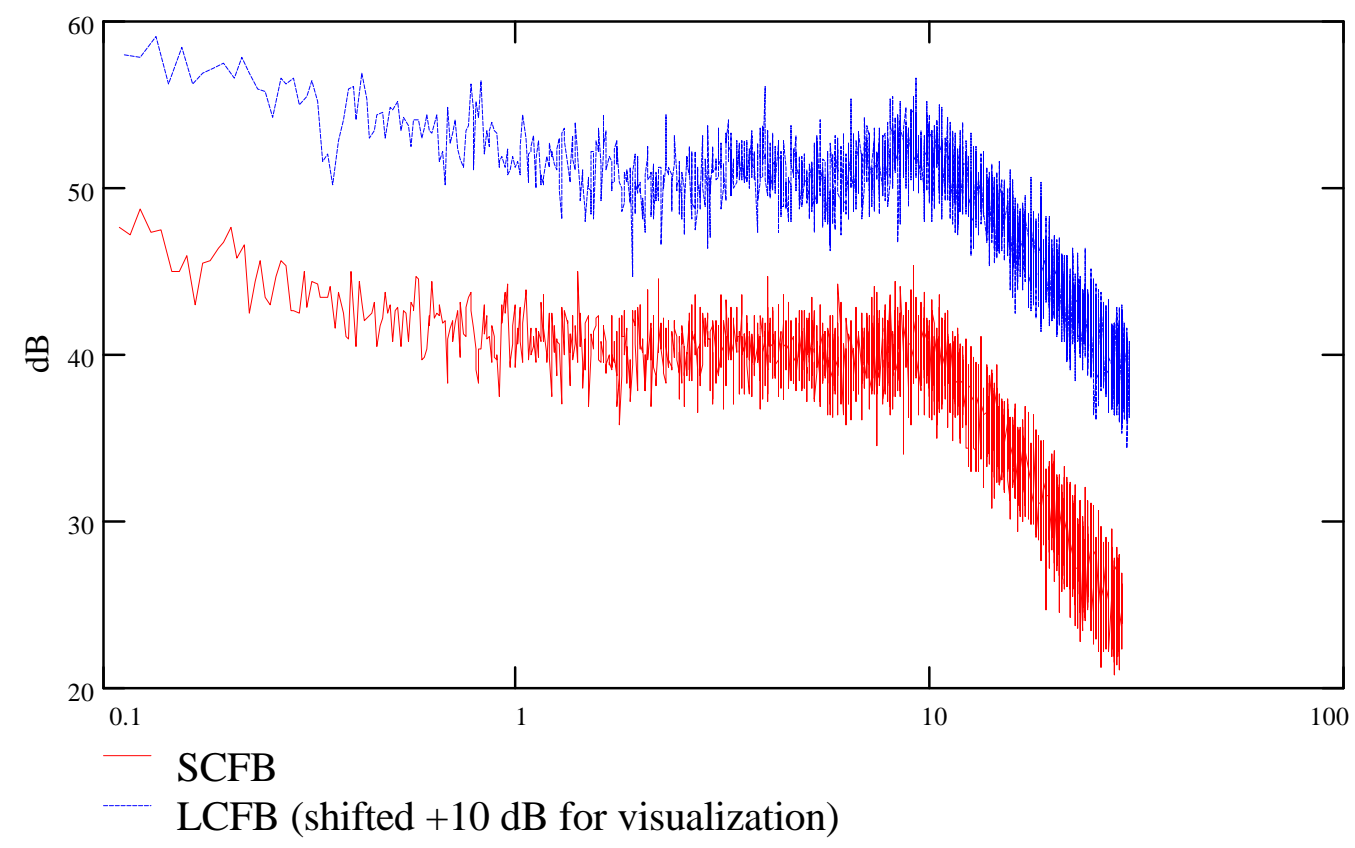

Figure 80: $\quad$ Bode plots of CFB under similitude conditions (1-2 \% bed height) Using dead-space extensions

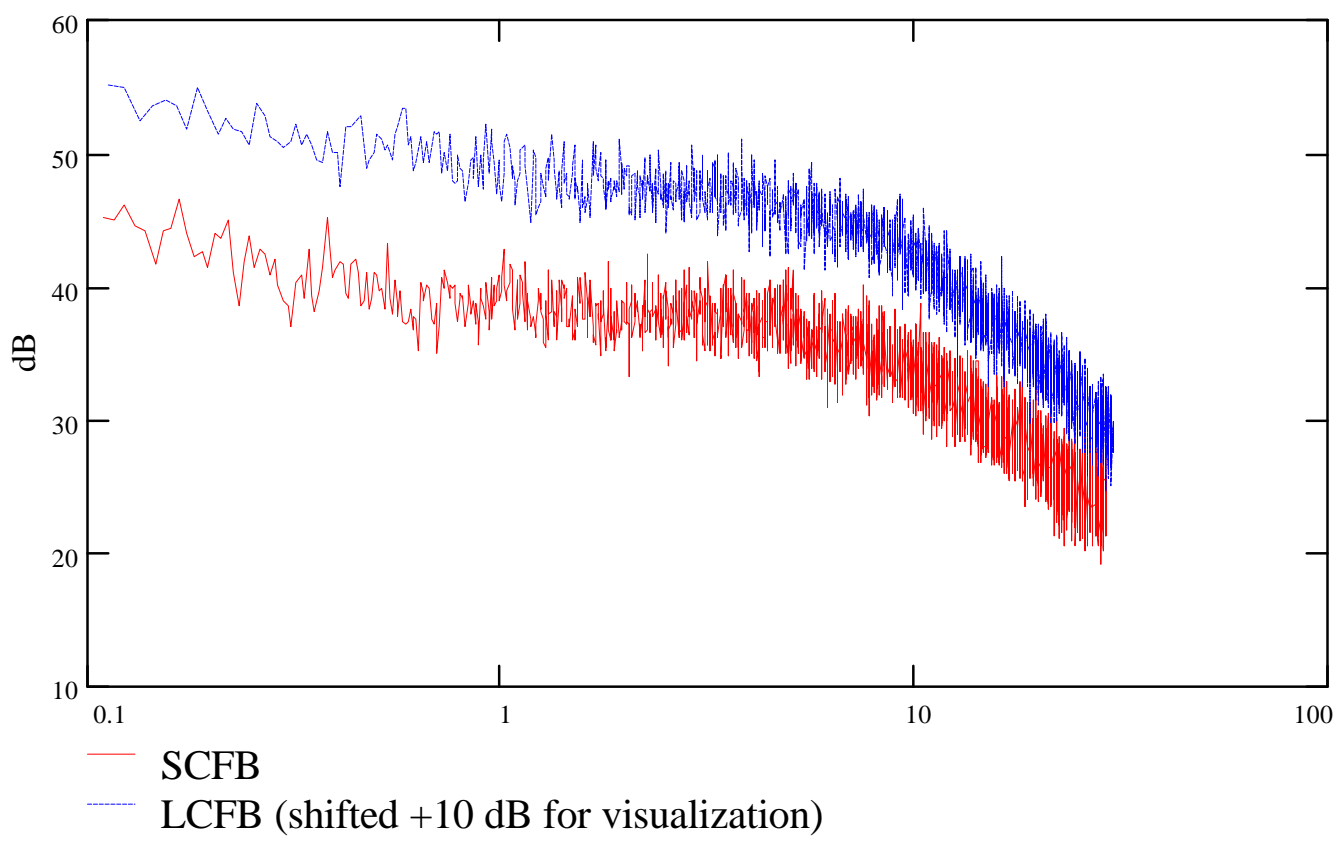

Figure 81: $\quad$ Bode plots of CFB under similitude conditions (5\% bed height) Using dead-space extensions 


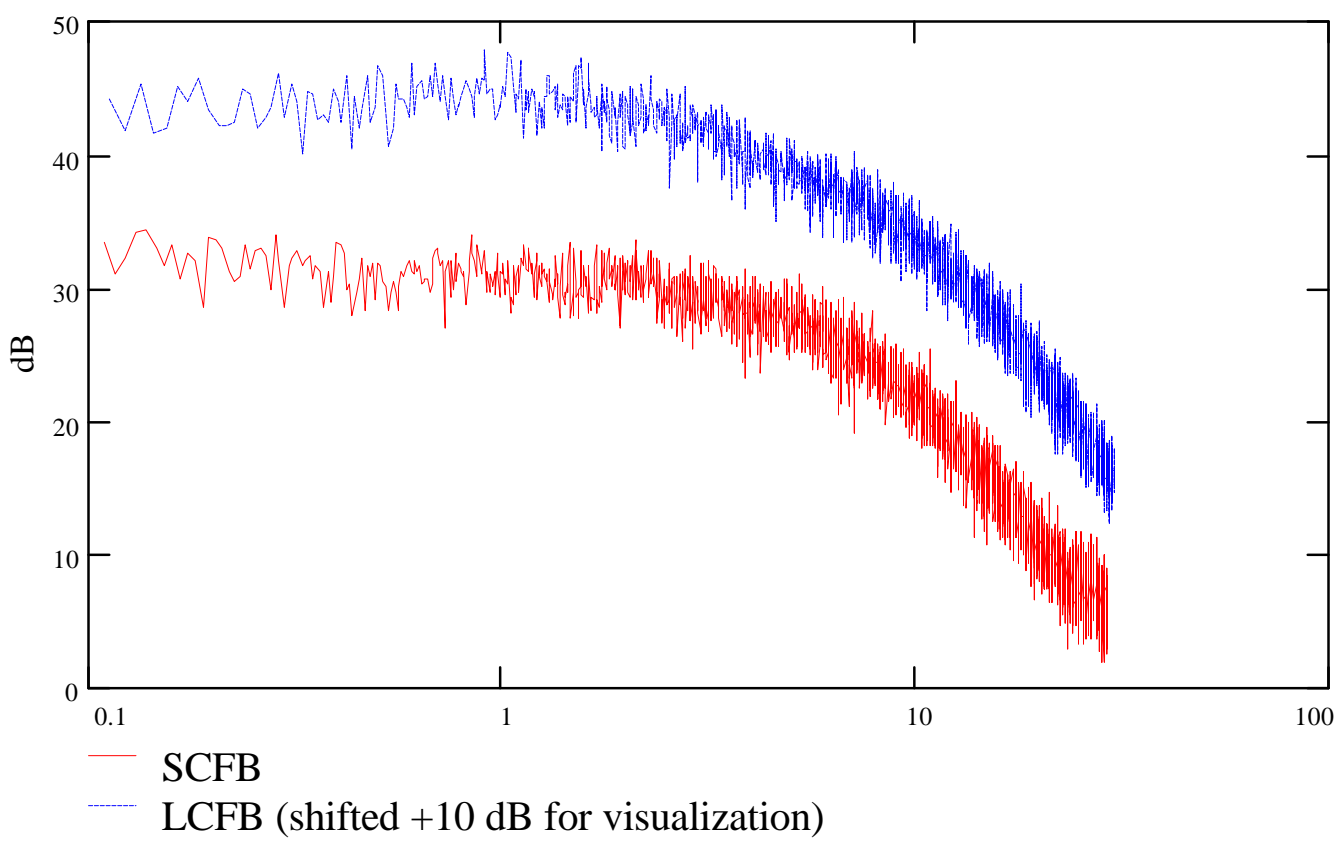

Figure 82: $\quad$ Bode plots of CFB under similitude conditions (13\% bed height) Using dead-space extensions

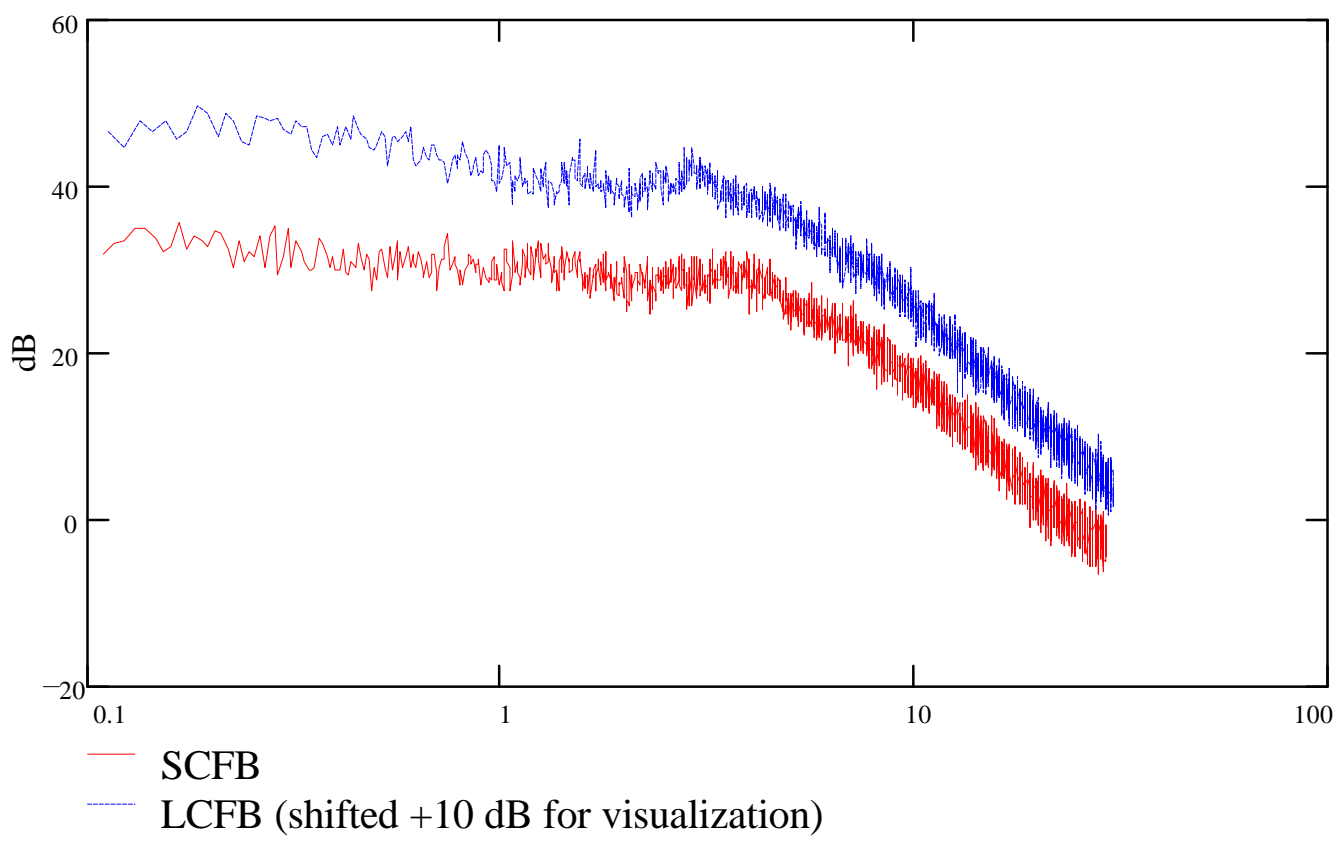

Figure 83: Bode plots of CFB under similitude conditions (75 \% bed height) Using dead-space extensions 
rates. If directly applicable to bed operation, this would demonstrate that there is a height at which L-valves should be operated above in similitude studies to avoid changes in solids flux related to L-valve operation instead of bed hydrodynamics.

These results are similar to what is expected of an L-valve operating in automatic solids flow. With a constant aeration rate, the air flow is split between moving down around the constricting bend and upward through the solids in the standpipe. With a large amount of solids in the standpipe, a large resistance is present to flow through the standpipe so most of the air moves downward through the constricting bend. The air moving downward provides the necessary force to propel the solids out of the L-valve. As the L-valve height is decreased, a larger portion of the aeration air moves upward through the solids in the standpipe. This upward moving air does not provide any propulsion for the solids to move through the constricting bend so the solids flow rate decreases.

This automatic mode of operation is directly observed in circulating fluidized bed operation. The height of solids in an L-valve will adjust to match the mass flux leaving the cyclone. Increasing the L-valve aeration rate will decrease the L-valve height but not necessarily the solids flow rate. The L-valve height will decrease so that the standpipe pressure drop is decreased, with this decreased pressure drop in the standpipe, the increased air flow will flow through the standpipe and not downward through the L-valve constricting bend. Without additional air flow through the constricting bed, the solids flow rate of the L-valve will remain constant. Thus the solids flow rate is determined mostly by the bed operation. The effect of increased solids loading resulting from a lower L-valve height needs to be studied to understand how it affects the mass flux leaving the top of the riser. In addition, the operation of the L-valve in the observed constant flow region needs to be further investigated to see if the L-valve cannot operate in automatic mode above a certain solids level when run in conjunction with bed operation. 


\section{Height in Isolated L-valve vs. Time 300 micron glass}

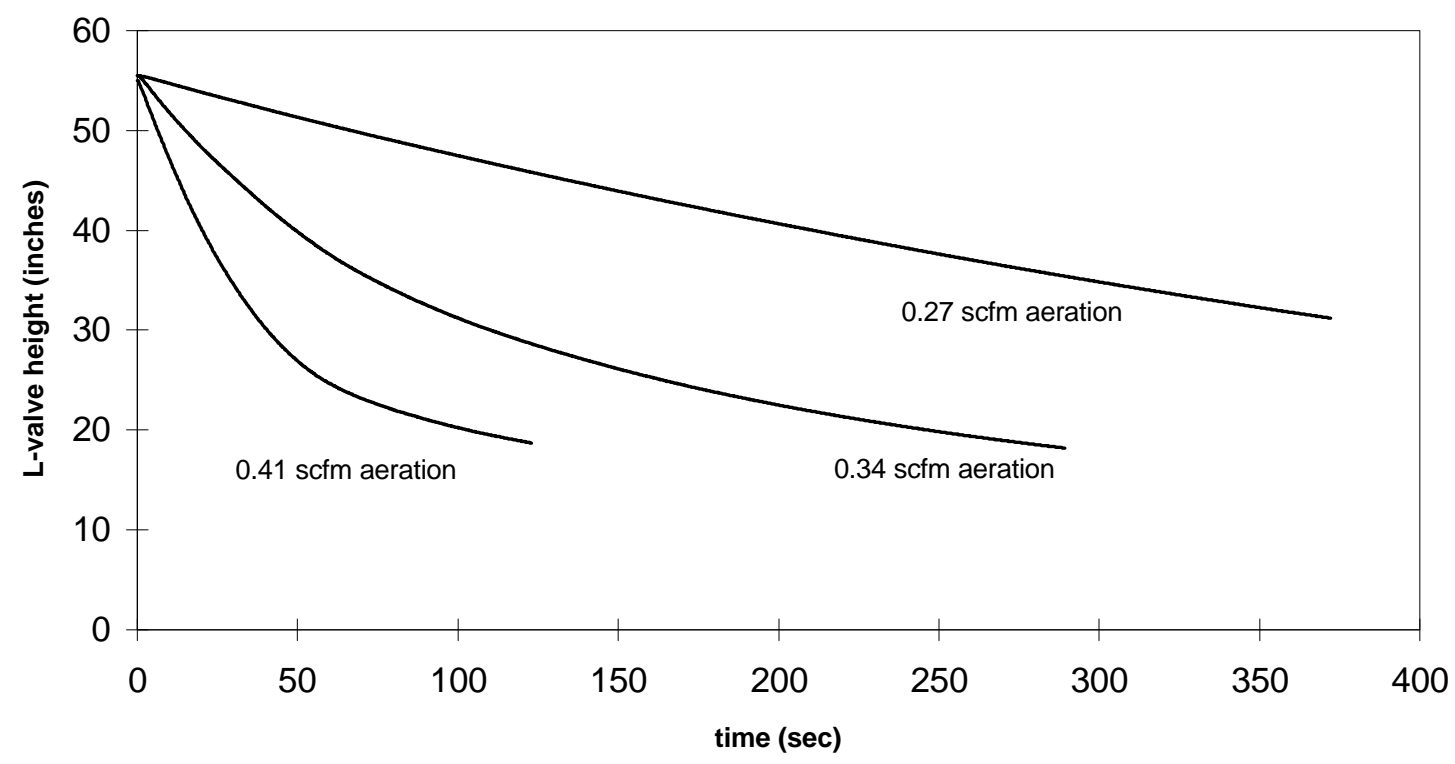

Figure 84: L-valve height vs. Time, 300 micron glass beads 


\section{$\underline{\text { ISU Power Plant CFB Boilers }}$}

A number of experiments were completed to determine the nature of industrial scale CFB Boiler pressure fluctuations. These tests were developed to determine whether CFB pressure fluctuations can be used as diagnostic indicators in industrial scale CFB boilers, and also whether these signals can be related to similar pressure fluctuations observed in small-scale cold-model CFBs. Two 170,000 lb/hr steam Pyropower CFB boilers are located on the campus of Iowa State University. ISU's CFB Boiler \#1 and CFB Boiler \#2 both had two transducers installed along the CFB wall to monitor absolute pressure. All four transducers in the two boilers had an output of 1 to 4 volts. The transducers that measure what was referred to as the bed pressure record static pressure fluctuations immediately above the gas distribution plate. These transducers have a range of 0 to 60 inches of $\mathrm{H}_{2} \mathrm{O}$. The transducers in the combustion chamber measure the static pressure fluctuations at an elevation of 60 feet above the distributor plate. These transducers have a range of -3 to 17 inches of $\mathrm{H}_{2} 0$. The boilers have a square cross-section of $4.3 \times 4.3$ meters (14'x14'), and a height from distributor to top of CFB riser of around 20 meters (65 feet). Under standard operating conditions, the boiler operates with 137,000 lb/hr fluidizing air and $74,000 \mathrm{lb} / \mathrm{hr}$ secondary air. The bed material (ash, limestone, and coal) consists of particles which predominantly range between 100 and 1000 micrometers in diameter. The pressure measured at the bottom of the bed under these conditions approximately ranges from 15-25 inches of $\mathrm{H}_{2} \mathrm{O}$, and the bed temperature is maintained between $1400-1600^{\circ} \mathrm{F}$. The fluctuation data was sampled at $20,50,90,200,400$, and $1000 \mathrm{~Hz}$, with data set sizes ranging from 70,000 to 620,000 data points to insure adequate Bode plot resolution. Using a portable computer with a 12 bit A/D (0$5 \mathrm{~V}$ ) board, the output voltage from the boiler transducers was recorded and stored.

\section{Fluctuations in lower regions of CFB boiler}

Although there is some variation in the structure of the lower bed fluctuations, as seen in time domain plots of Figures 85 and 86, they always exhibit a signal similar to a $0.25-0.3 \mathrm{~Hz}$ square wave. It is evident that the lower bed signal has a dominant period, on the order of a cycle every 3 to 4 seconds. This dominant frequency at $0.25-0.3 \mathrm{~Hz}$ is very pronounced in the power spectral density of these signals shown in Figures 87 and 88. Examining the Bode plot of the bed pressure fluctuations in Figure 87b, the low frequency region of the Bode plot seemingly exhibits 
a system behavior that rolls-off at around $-40 \mathrm{~dB} /$ decade (or greater). This does not lead to the definitive conclusion that the boiler fluctuations are governed by second order phenomena. The Bode plots are difficult to interpret due to the presence of strong harmonics as illustrated in the full spectrum of Bode plots (see Figure 87c).

These strong harmonics can be explained by recognizing that the fluctuations in the time domain exhibit a square wave behavior. Subsequent harmonics observed in the PSD appear at odd multiples of the fundamental frequency (see Figure 88). These harmonics are expected as the Fourier transform estimates a square wave with multiple sinusoids at odd multiples of the fundamental frequency. Before the conclusion can be made that the pressure fluctuations are indicative of CFB boiler hydrodynamics, the nature of the dominant $0.25-0.3 \mathrm{~Hz}$ phenomena must be examined further.

Experiments were conducted to better understand the nature of the $0.25-0.3 \mathrm{~Hz}$ dominant frequency measured at the bottom of the boiler. First, an analog anti-aliasing filter was used while recording data to insure that the dominant frequency observed in the spectrum was not simply the result of a frequency phenomena higher that the sampling frequency (e.g. $60 \mathrm{~Hz}$ line frequency) being manifest in the low frequency spectrum. A 3rd-order Butterworth filter was designed and constructed with a $16 \mathrm{~Hz}(100 \mathrm{rad} / \mathrm{s})$ cut-off frequency. Figure 89 compares the Bode plot of filter data to that of the unfiltered data. Although it is also evident that the filtered data begins to attenuate the signal slightly as the spectrum approaches $100 \mathrm{rad} / \mathrm{s}$, as expected, there is no significant difference in the plots. It can be concluded from this result that the $0.25-0.3 \mathrm{~Hz}$ phenomena is not the result of aliasing. Data recorded at sampling frequencies of up to $1000 \mathrm{~Hz}$ confirms this conclusion, since no dominant frequency phenomena between $0-500 \mathrm{~Hz}$ (other than the $0.25-0.3 \mathrm{~Hz}$ phenomena) is observed in the spectrum.

It was hypothesized that this dominant frequency was not the result of the CFB hydrodynamics but of a standard periodic operation of the CFB Boiler. It was believed that oscillations in the limestone or coal feed systems were the origin of the square wave signal. If this was the case, any dynamics resulting from fluidization fluctuations would be hidden within the dynamics of boiler operation. By analyzing only the part of the signal that resides between subsequent $0.25-0.3 \mathrm{~Hz}$ oscillations, this hypothesis was tested. The Bode plots that resulted from this analysis did not show any dynamic behavior that could be attributed to CFB 
a) 5 minute interval

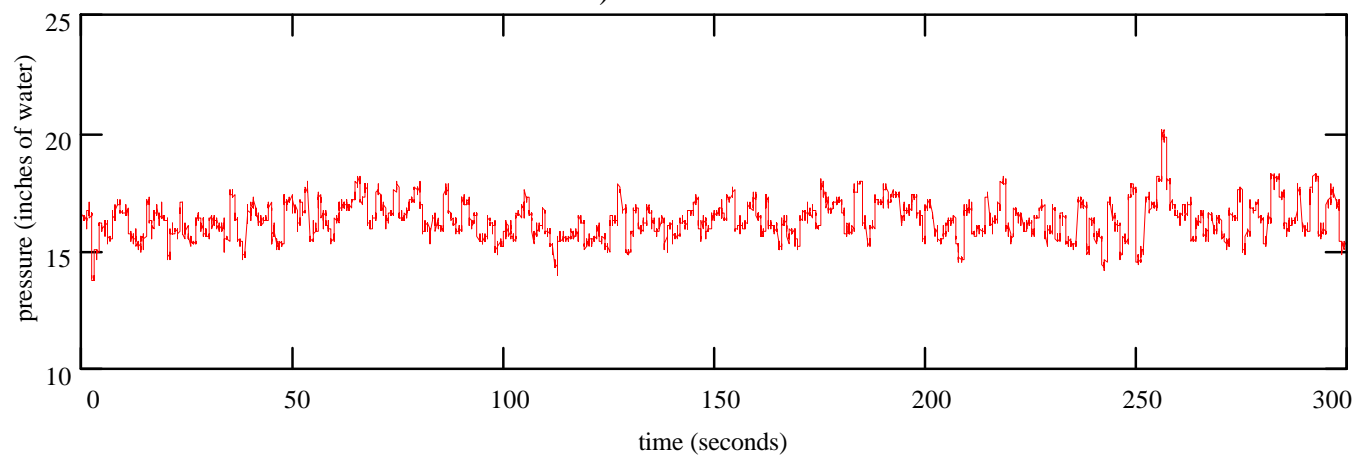

b) 1.5 minute interval

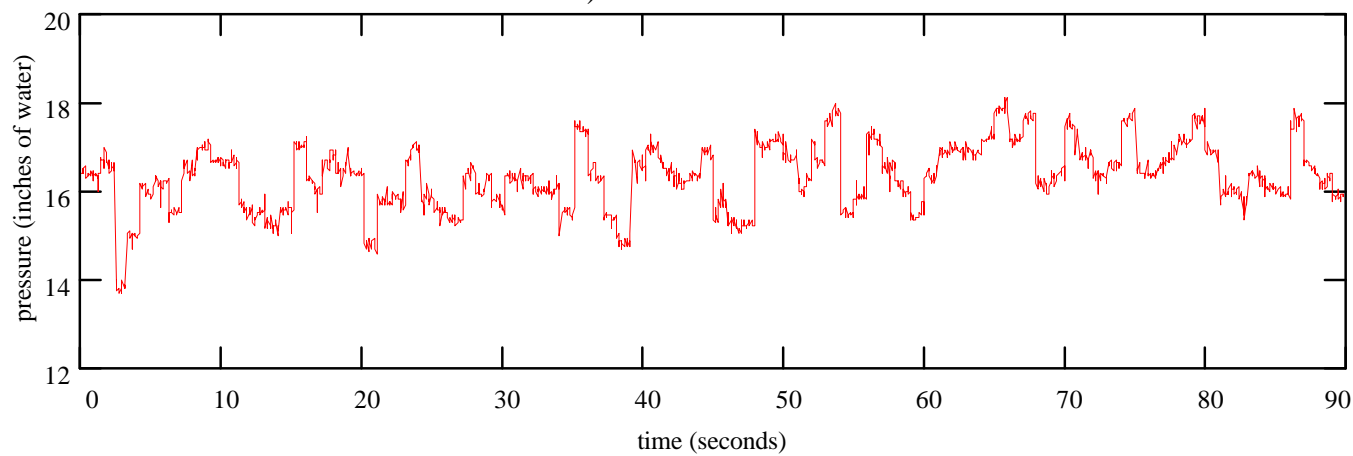

c) 0.5 minute interval

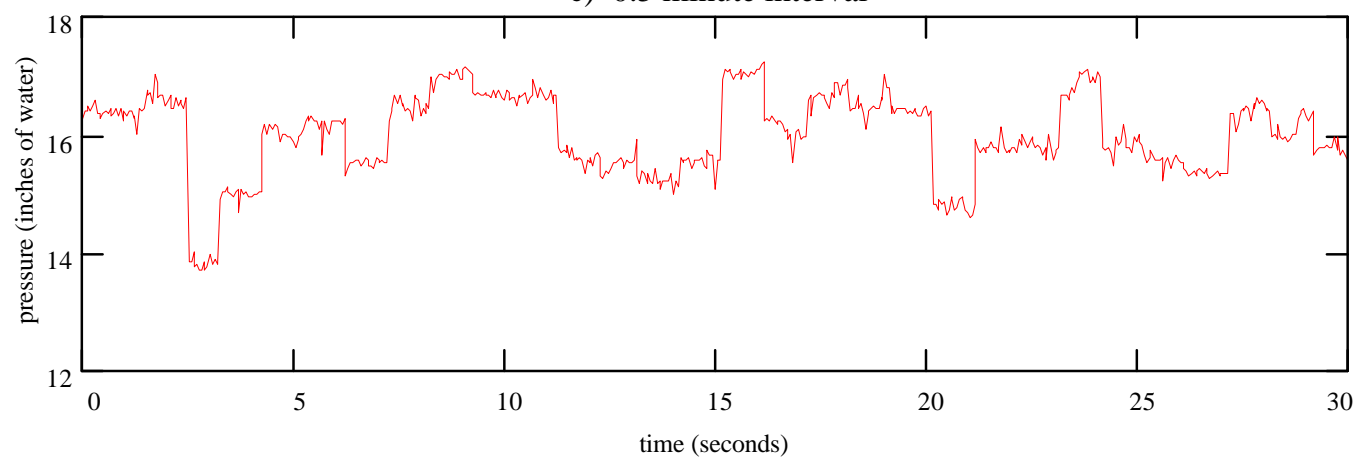

Figure 85: ISU CFB boiler lower bed pressure fluctuations (peak load - morning) 
a) 5 minute interval

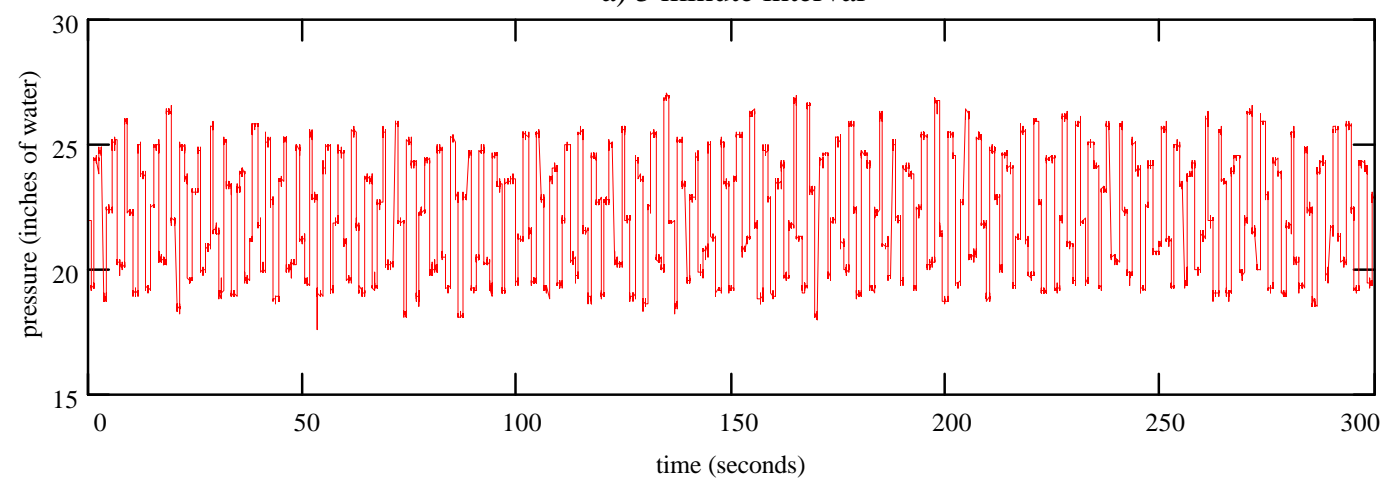

b) 1.5 minute interval

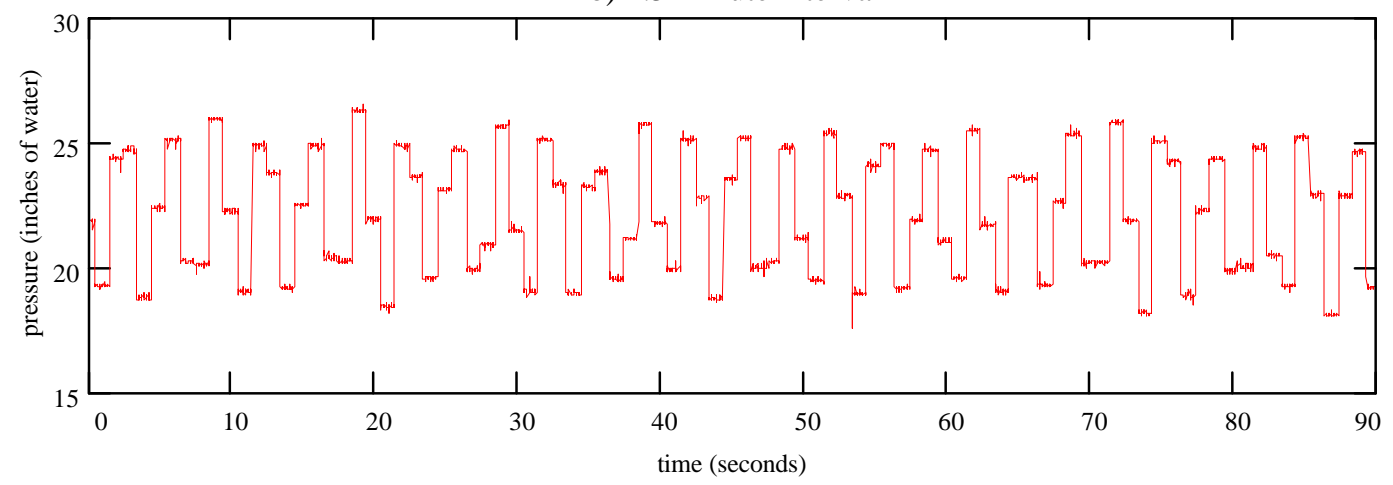

c) 0.5 minute interval

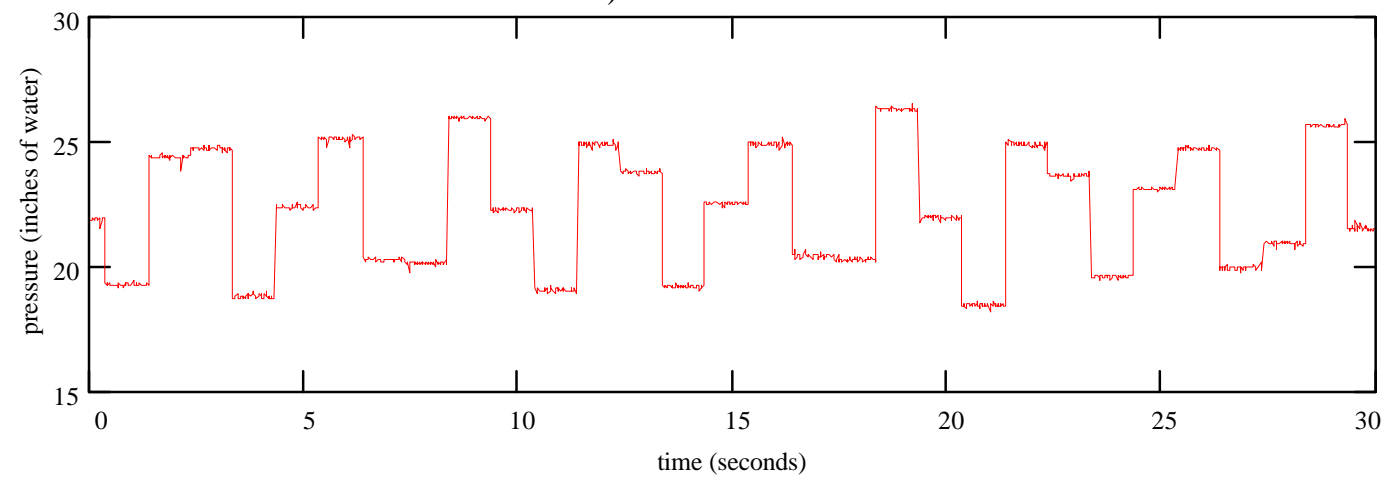

Figure 86: ISU CFB boiler lower bed pressure fluctuations (afternoon load) 
a) Power Spectral Density

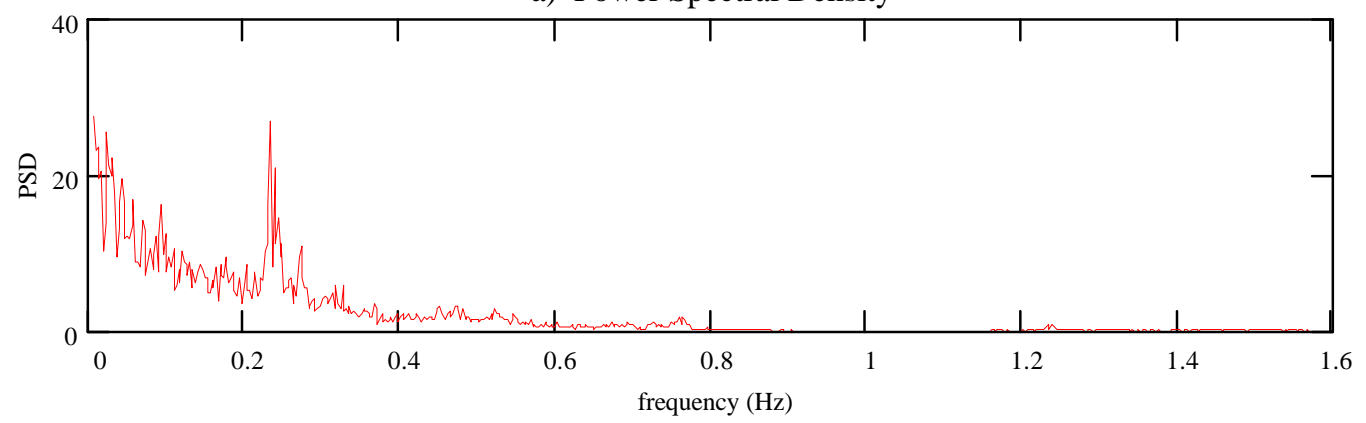

b) Bode plot - partial spectrum

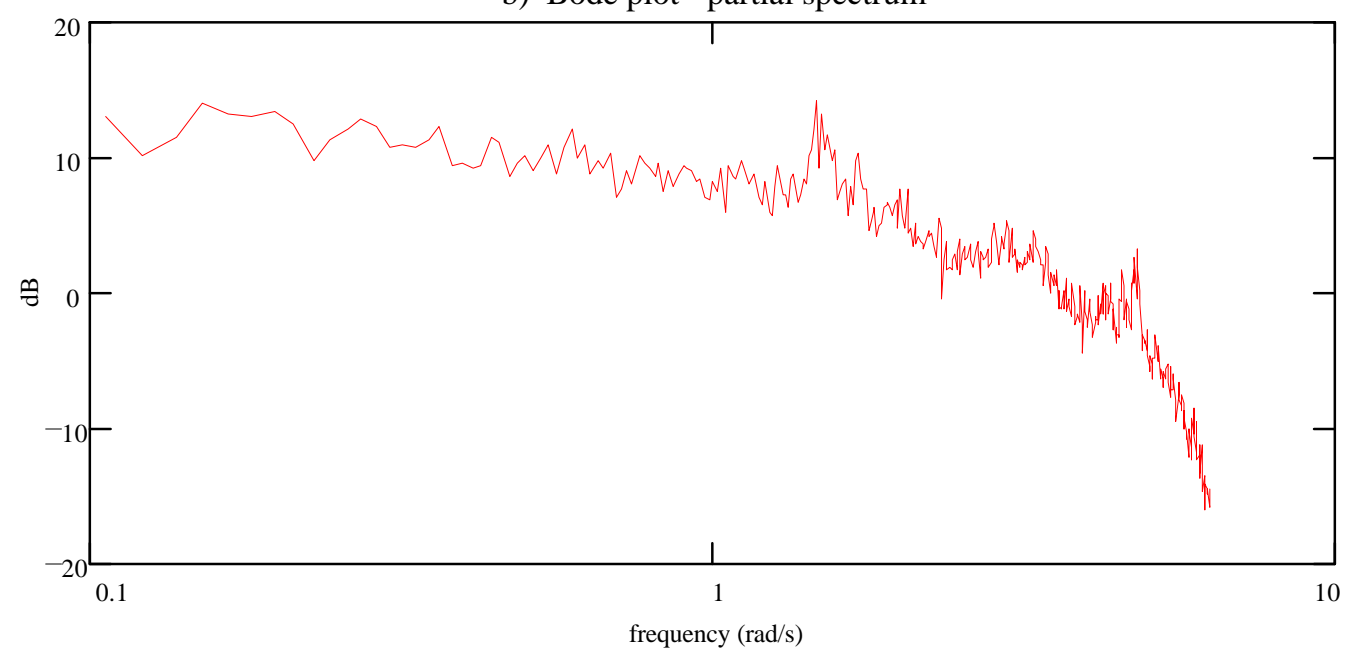

c) Bode plot - full spectrum

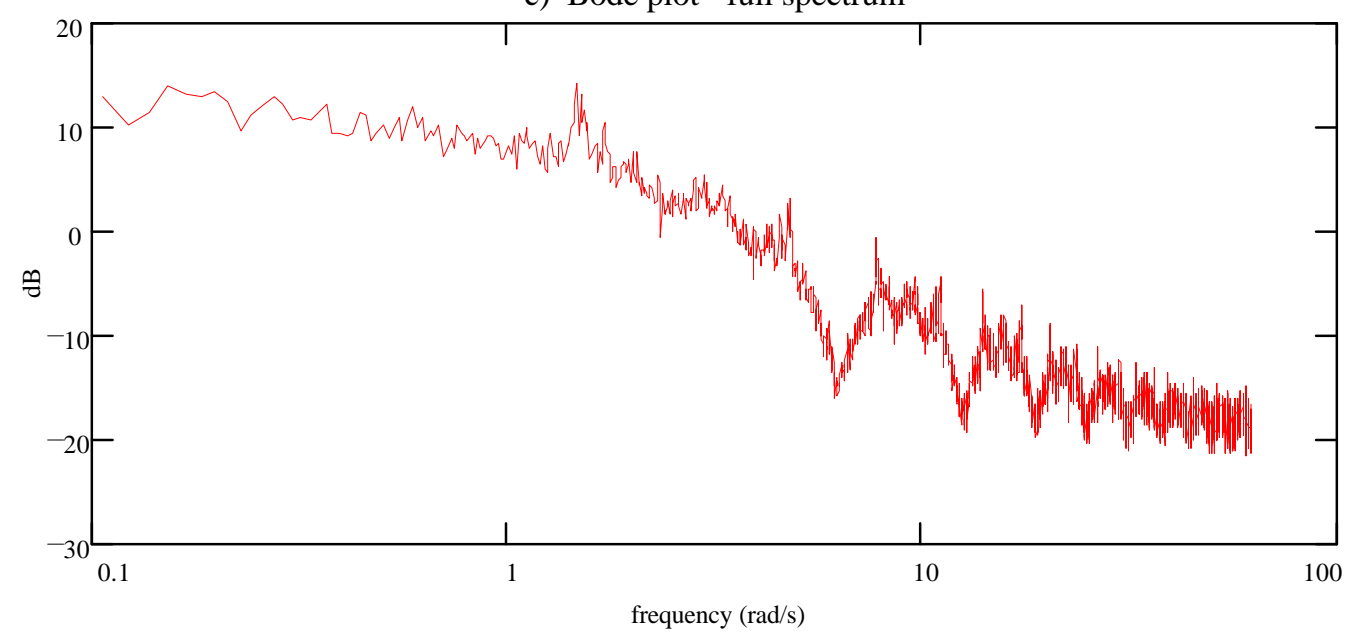

Figure 87: Peak load CFB boiler fluctuations a) PSD b) partial b) full Bode 

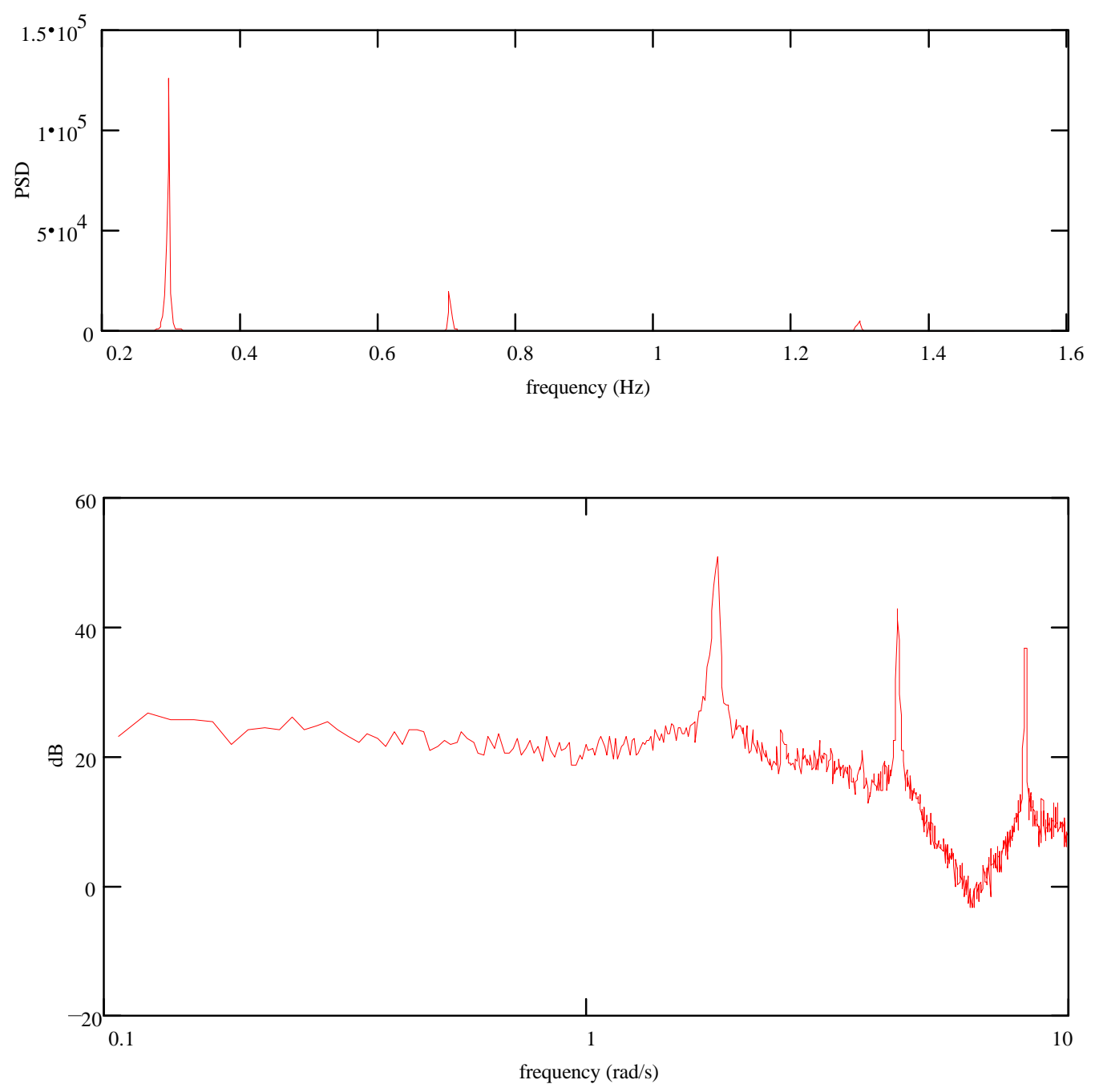

Figure 88: Bode plot \& PSD of CFB boiler lower bed fluctuations (afternoon load) 
hydrodynamics. The resulting plots were typical of the Bode plots of a white noise signal, containing no important dynamic information. It is assumed that all observed dynamics contained in the spectrum are related to the $0.25-0.3 \mathrm{~Hz}$ oscillation.

The most likely explanation for this periodic behavior is the coal feed system. Coal is fed into the boiler at two locations; via the loop seal and directly into the bed on a cleated conveyor belt. Due to the spacing of the cleats and the typical speed of the conveyor, a cleat reaches the entrance of the boiler every 3 to 4 seconds. Assuming that the coal will have a tendency to pile up near the cleat, the rate at which coal enters the boiler will not be continuous. Rather, the feeder will input a batch of coal every 3 to 4 seconds.

By observing boiler fluctuations under high and low loading conditions, this hypothesis is supported. Figure 86 shows bed fluctuations measured mid-afternoon while Figure 85 represents the fluctuations measure during peak operation 8:00-9:00 a.m. During this period of high load, the fluctuations appear less dominated by the "square wave" coal feed fluctuations. This is expected since an increased circulation rate increases the solids suspended in the bed and decreases the observed effect of the coal feed directly into the CFB. The more dilute the operation of the CFB is, the more evident the periodic coal feed will be in the frequency spectrum.

\section{Fluctuations in upper region of CFB boiler}

The combustion chamber pressure fluctuations differ from the lower bed fluctuations because the periodic nature of the coal feed no longer is sensed as strongly at the top of the bed (see Figure 90). At this elevation, the periodic batches of coal entering the combustor have been more evenly dispersed in the upward moving gas flow. The Bode plot of the combustion chamber pressure fluctuations shown in Figure 91 does seem to exhibit an initial roll-off of around -40 $\mathrm{dB} /$ decade. This characteristic frequency occurring at around $0.4-0.5 \mathrm{rad} / \mathrm{s}(0.06-0.08 \mathrm{~Hz}) \mathrm{may}$ be a wave phenomena similar to that previously observed in the CFB models.

The equivalent diameter of the CFB boilers is 4.85 meters. This is 47.5 times greater than the $10.2 \mathrm{~cm}$ diameter CFB model. If a wave phenomena observed in the CFB models was observed in the CFB boiler, it would appear at a frequency inversely proportional to the square 
a) CFB Boiler pressure fluctuation Bode plot (filtered)

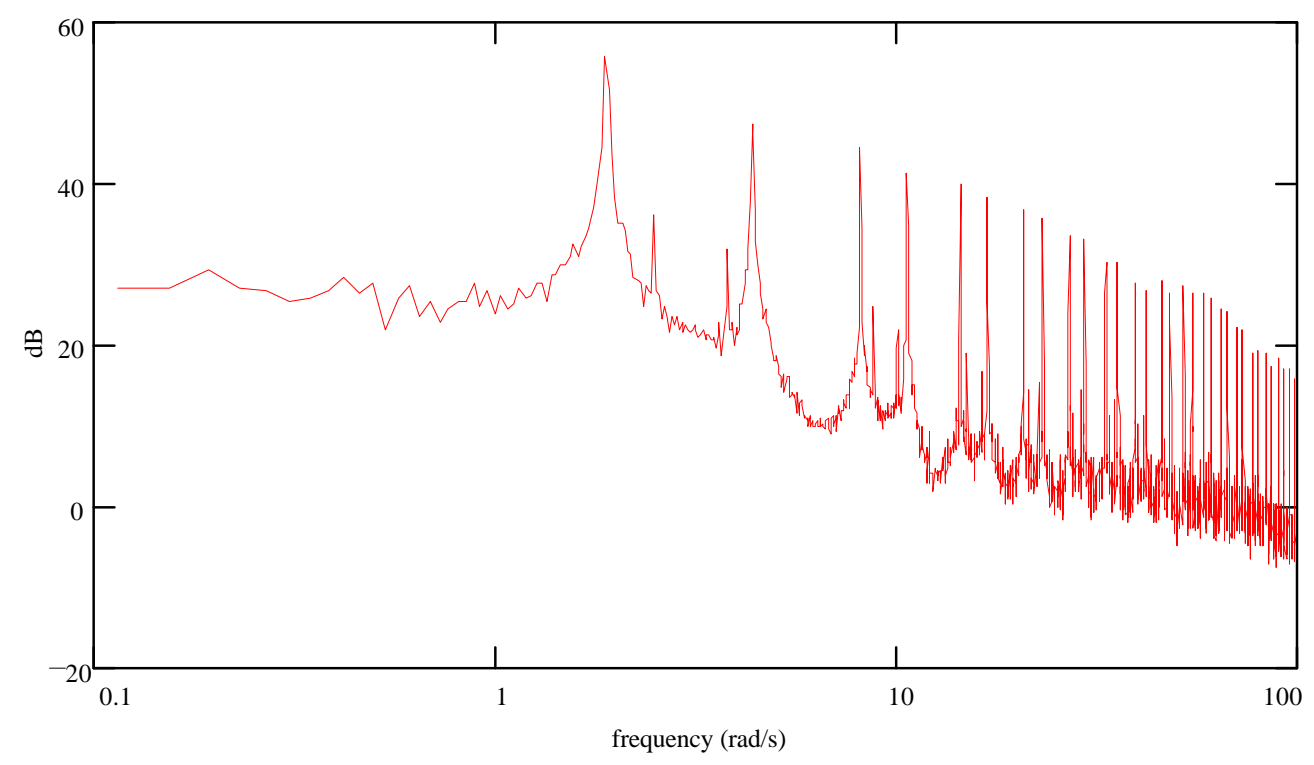

b) CFB Boiler pressure fluctuation Bode plot (unfiltered)

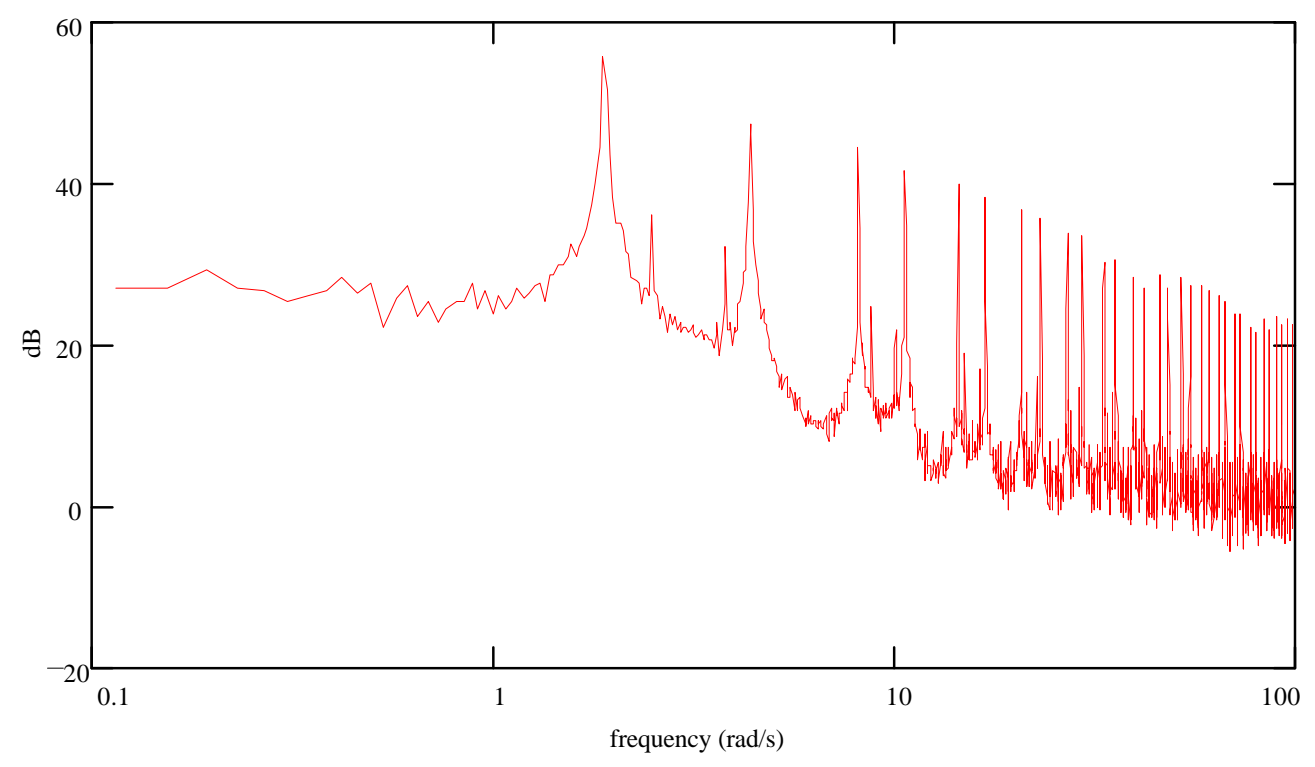

Figure 89: Bode plot of CFB boiler fluctuations a) w/ anti-aliasing filter b) unfiltered 
a) 5 minute interval

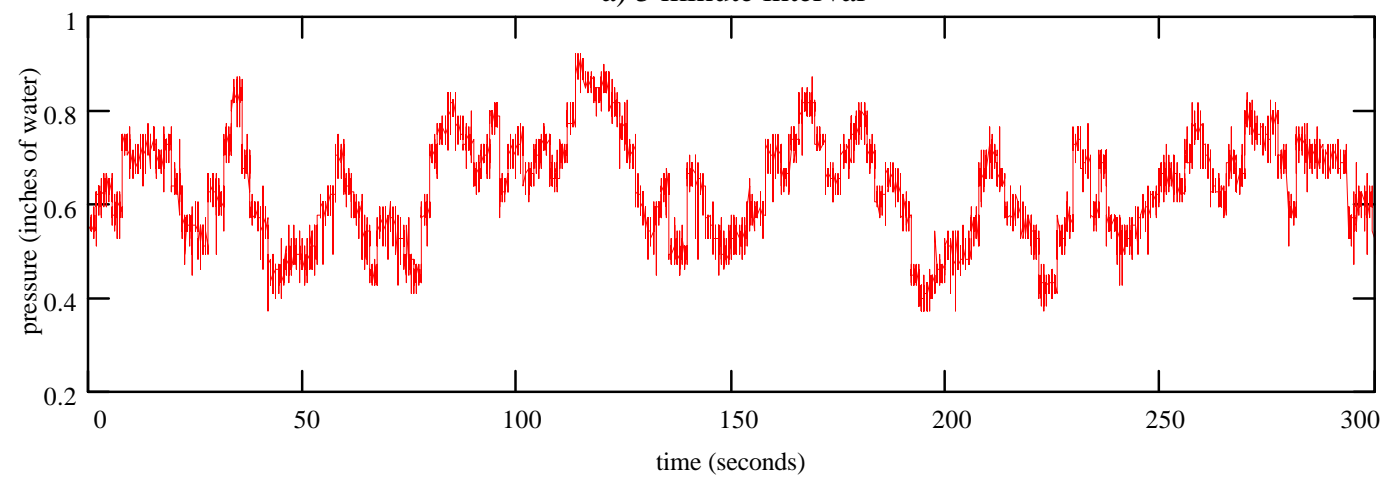

b) 1.5 minute interval

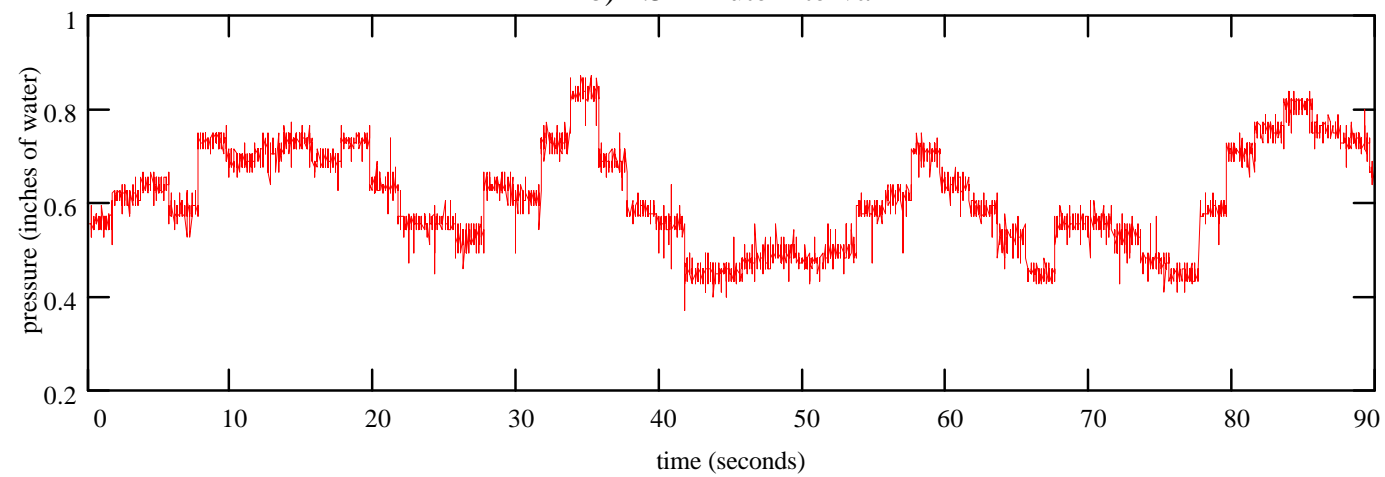

c) 0.5 minute interval

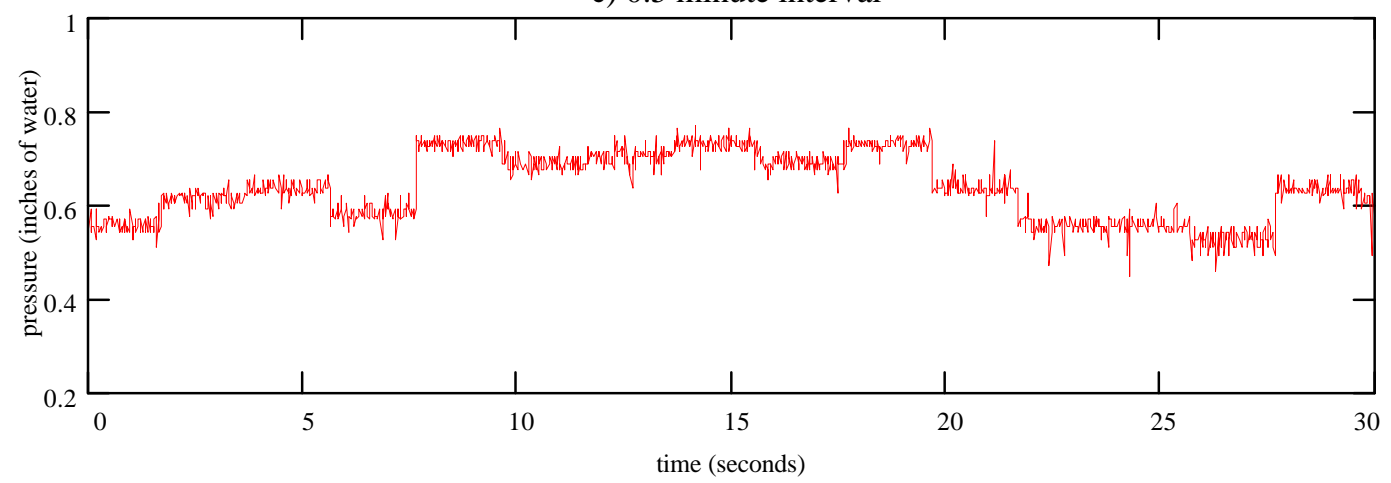

Figure 90: ISU CFB boiler combustion chamber pressure fluctuations 

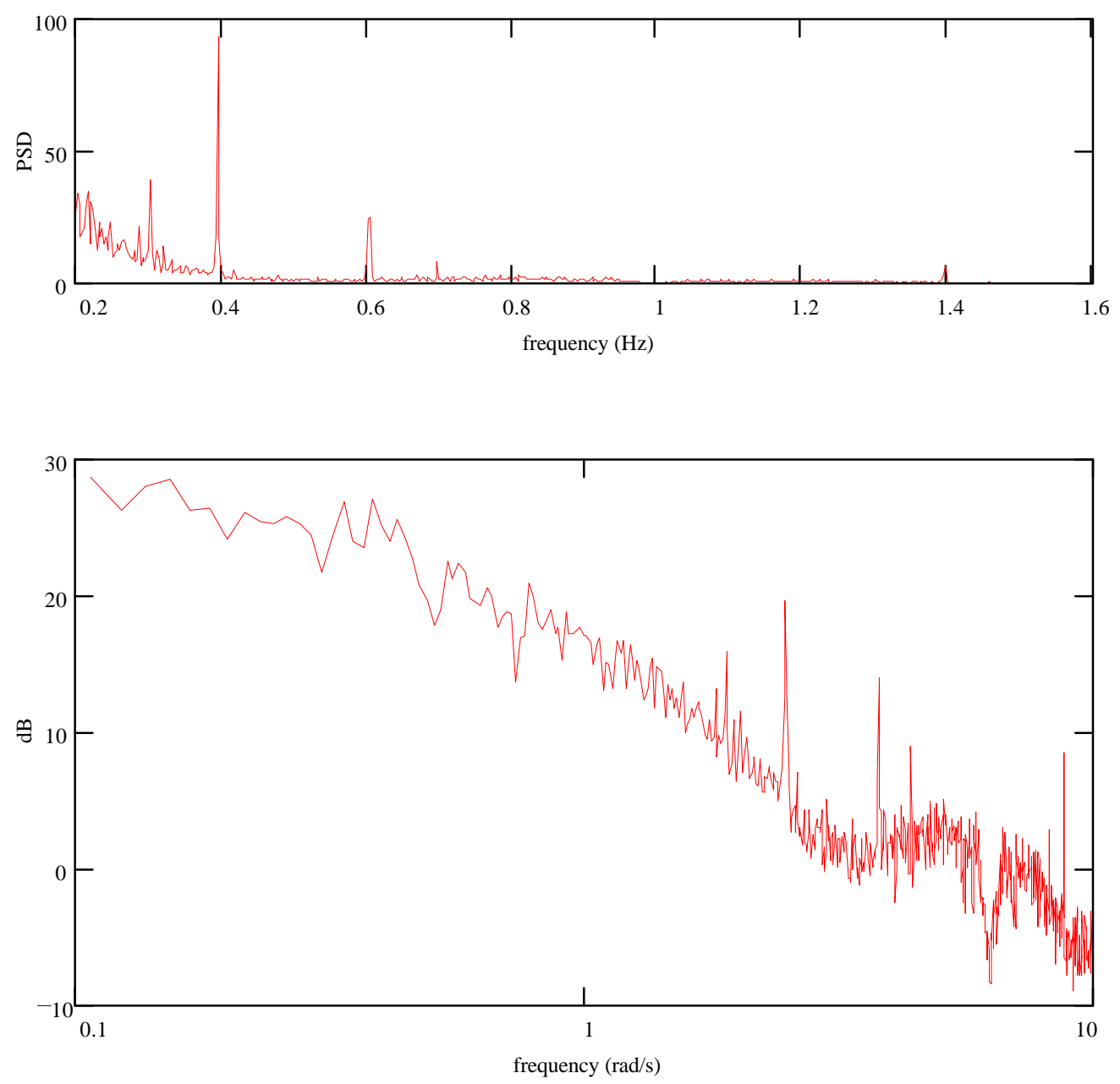

Figure 91: Bode plot \& PSD of CFB boiler combustion chamber pressure fluctuations 
root of the diameter. Observing a frequency at around $0.5 \mathrm{~Hz}$ in the $10.2 \mathrm{~cm}$ CFB model (absolute pressure fluctuations), the predicted wave frequency for the boiler would be $0.07 \mathrm{~Hz}$, as is observed. It is difficult to asses how much of an effect the periodic coal feed has on the combustion chamber fluctuations, therefore this hypothesis that a dilute phase phenomena similar to that observed in the models is acting in the CFB boilers cannot be definitively supported. Additionally, this combustion chamber pressure is a controlled pressure. Exhaust fans are used to keep this pressure at acceptable levels. More must be known regarding the control system dynamics before any definitive conclusions can be drawn regarding the relation of pressure fluctuations to fluidization hydrodynamics in industrial scale CFB boilers.

\section{Conclusions}

The study revealed the importance of collecting sufficiently long data sets to capture low frequency (on the order of $1 \mathrm{~Hz}$ ) pressure phenomena in fluidized beds. Past research has tended toward truncated data sets collected with high frequency response transducers, which miss much of the spectral structure of fluidized bed hydrodynamics. As a result, many previous studies have drawn conclusions concerning hydrodynamic similitude between model and prototype fluidized beds that is insupportable from the low resolution data presented.

Using appropriate data collection and analysis, this study was able to verify that a set of dimensionless parameters derived by other researchers can be used to achieve hydrodynamic similitude between cold -flow model and prototype bubbling fluidized beds. On the other hand, a related set of dimensionless parameters developed by other researchers for circulating fluidized beds were not able to accurately predict similitude between model and prototype. The present study was successful in slightly modifying this set of dimensionless parameters to correctly predict similitude between cold-flow models. Similitude tests between a cold-flow bubbling fluidized bed model and a high temperature bubbling fluidized bed combustor were less successful. Although qualitative agreement in spectral plots of pressure fluctuations was obtained, the data was not sufficiently quantitative to permit its use in predicting the existence of similitude between cold model and hot prototype. Similitude tests between a cold-flow circulating fluidized bed and a hot-flow circulating fluidized bed combustor were also unsuccessful, but for different reasons. 
The circulating fluidized bed combustor, an industrial-scale boiler, presented unique data filtering problems that were never overcome. Modulated air dampers produced pressure fluctuations that propagated into the fluidized bed where they overwhelmed pressure fluctuations associated with the hydrodynamics of the particulate-gas mixture.

The study developed models of pressure fluctations in the circulating fluidized beds in an attempt to understand the nature of the fluctuations. As dynamical systems, circulating fluidized beds proved to be surprisingly complicated. Linear models were constructed from spectral plots of pressure fluctuations, but they proved of limited use in deriving physical insight into hydrodynamic behavior. A variety of acoustical and wave phenomena were used as the basis for explaining pressure fluctuations in the fluidized bed but with little success. 


\section{References Cited}

[1] Glicksman, L.R. "Scaling relationships for fluidized beds." Chem. Eng. Science 1984, $\underline{30}(9), 1373-1379$.

[2] Glicksman, L.R., D. Westphalen, K. Woloshun, T. Ebert, K. Roth, and M. Lints. "Experimental scale models of circulating fluidized bed combustors." Fluidized Bed Combustion, ASME 1991; 1169-1174.

[3] Louge M, and H. Chang. "Fluid dynamic similarity of circulating fluidized beds" Powder Technology 1992, 70, 259-270.

[4] Glicksman L.R., and M.T. Nicastro. "Experimental verification of scaling relationships for fluidized bed." Chem. Eng. Science 1984, 39(9), 1381-1391.

[5] Glicksman, L.R., D. Westphalen, C. Bereton, and J. Grace. "Verification of the scaling laws for circulating fluidized beds." In Circulating Fluidized Bed Technology III. P. Basu, M. Hasatan, and M. Horio, Eds.; Pergamon Press: Oxford, 1991; 199-124.

[6] Glicksman, L. R., M. R. Hyre, and K. Woloshun. "Scale models of circulating fluidized bed combustors.” Report \# DOE/MC/25049-3372, USDOE, Washington, D. C.

[7] Davidson, J. F. "The two-phase theory of fluidization: successes and opportunities." AIChE Symposium Series 1991, 87(281), 1-12.

[8] Roy, R., J.F. Davidson, and V.G. Tuponogov. "The velocity of sound in fluidized beds." Chem. Eng. Sci. 1990, 45(11), 3233-3245.

[9] Hiby, J.W. "Periodic phenomena connected with gas-solid fluidization." In Proceedings of the International Symposium on Fluidization, Eindhoven; Netherlands University Press: Amsterdam, 1967; 99.

[10] Verloop, J. and P.M. Heertjes. "Periodic pressure fluctuations in fluidized beds." Chem. Eng. Science 1974, 29, 1035-1042.

[11] Baskakov, A.P., V.G. Tuponogov, and N.F. Filippovsky. "A study of pressure fluctuations in a bubbling fluidised bed." Powder Technology 1986, 45, 113-117.

[12] Sun, J., M.M. Chen, and B.T. Chao. "On the fluctuation motions due to surface waves in gas fluidized beds." In Proceedings of the First World Conference on Experimental Heat Transfer, Fluid Mechanics and Thermodynamics, Dubrovnik. R.K. Shah, E.N. Ganic, and K.T. Yang, Eds.;Elsevier: New York, 1988; 1310. 
[13] Rahman, M.. Water Waves: Relating Modern Theory to Advanced Engineering Applications; Claredon Press: Oxford, 1995.

[14] Glicksman, L.R. "Scaling relationships for fluidized beds." Chem. Eng. Science 1984, 30(9), 1373-1379.

[15] Glicksman L.R., M.R. Hyre, and P.A. Farrell. "Dynamic similarity in fluidization." Int. J. Multiphase Flow 1994, 20, 331-386.

[16] Glicksman, L.R., M. Hyre, and K. Woloshun. "Simplified scaling relationships for fluidized beds." Powder Technology, 1993, 77, 177-199.

[17] Moody, L.F., "Friction factors for pipe flow." Transactions of the ASME, Vol. 66, 1944.

[18] Schnitzlein, M.G. and H. Weinstein. "Flow characterization in high-velocity fluidized beds using pressure fluctuations." Chem. Eng. Science 1988, 43(10), 2605-2614.

[19] Fitzgerald, T., D. Bushnell, S. Crane, and Yeong-Cheng Shieh. "Testing of cold scaled bed modeling for fluidized bed combustors." Powder Technology 1984, $\underline{38}$, 107-120.

[20] Brue, E. "Pressure fluctuations as a diagnostic tool for fluidized beds." PhD. Dissertation, Iowa State University, Ames, 1996.

[21] de la Cruz Baez, R. G. "Frequency analysis of pressure fluctuations in bubbling fluidized beds and its application to similitude stuudies." Master's Thesis, Iowa State University, Ames, 1994. 